\title{
ANALYSING DOCUMENTS AND INTERPRETING TEXTBOOKS: \\ STUDENTS' HISTORICAL THINKING SKILLS IN LEARNING ABOUT \\ THE BATTLE OF SURABAYA
}

BY

\section{ADITYA NUGROHO WIDIADI}

\author{
A thesis \\ submitted to the Victoria University of Wellington \\ in fulfilment of the requirements for the degree of \\ Doctor of Philosophy
}

VICTORIA UNIVERSITY OF WELLINGTON

2021 
This page is intentionally left blank. 


\begin{abstract}
This thesis examines how secondary students in Indonesia develop historical thinking skills through analysing documents and interpreting textbooks on a key historical event in Indonesia's independence: the battle of Surabaya. Developing historical thinking skills poses a particular challenge in an Indonesian setting. Although history education has been largely aimed at fostering a spirit of nationalism and patriotism among younger people, the recent history curriculum (2013) requires teachers to foster historical thinking skills with their students. This poses a significant challenge for teachers who typically rely on lectures and textbooks with an official government perspective. Even those teachers who are motivated, have difficulties in accessing primary sources needed to stimulate students' historical thinking.

There is a gap in the literature on historical thinking in Indonesia, and this research project contributes to how these challenges can be addressed. To examine how learning history through analysing documents and interpreting textbooks contribute to students' historical thinking skills, this study was informed by the theoretical perspectives of critical pedagogy, cognitivism, threshold concepts, and connectivism. To collect and analyse the data, this study used a mixed methods intervention design. Participants in this study involved three history teachers from three different schools and $11^{\text {th }}$ grade students $(n=191$, age 16-19) that were divided into control and experimental groups. By using six data collection instruments, both quantitative and qualitative, this study conducted two phases of learning interventions.

Findings of this study show that analysing documents and interpreting textbooks (ADIT learning model) contributes to the development of students' historical thinking skills. This was demonstrated by the experimental group who progressed better than those of the control group. However, both groups of students were challenged, especially when dealing with multiple sources and establishing their interpretative position. The findings of this study also show that the advancement of students' historical thinking skills was closely related to students' complex epistemic beliefs about history. Learning through analysing documents
\end{abstract}


and interpreting textbooks, as well as using web-based historical sources, has proven to foster students' historical thinking skills. 


\section{ACKNOWLEDGEMENTS}

Firstly, I would like to thank Allah the Almighty, the One who always bestows His grace upon me to carry out this journey. Without His countless blessings, it would be impossible to accomplish the study in due time. Indeed, Allah is Subtle and Acquainted.

I would also like to gratefully acknowledge the wisdom, encouragement and continuous supports of my supervisors, Dr Mark Sheehan and Dr Sydney J. Shep, who spent countless hours to shape my research through fruitful discussions, insightful suggestions, and valuable corrections. I have not only gained valuable lessons on conducting research and writing my thesis, but also on how I would supervise my students in Indonesia.

I would also like to thank Victoria University of Wellington that has allowed me to embrace my academic journey. I am very thankful for the financial support of Directorate General of Higher Education of Indonesia (DIKTI) and Islamic Development Bank (IsDB), the sponsors of my PhD study in the Aotearoa. It would have been impossible for me to complete my $\mathrm{PhD}$ journey without their sponsorship.

I would like to express my gratitude to all teachers and students in Malang who participated in my study. My thanks also go to all school principals who allowed me to conduct this study in their schools.

To my parents, Mispono Widiadi and Khanifah, who gave so much love, prayer, and support in my study.

Finally, I am indebted to my super wonderful wife, Dewi Martha Indria, who encouraged and allowed me to study overseas. I realise, your struggle is so hard while I am far away from home. Even though you were struggling with your autoimmune disease, you still helped me develop the website and counsel quantitative analysis. You are my great partner and the best mother of our kids Akhmad Arka Aditavatara Widiadi and Abza Aruna Aditavatara Widiadi. To you, I dedicate this thesis. 
This page is intentionally left blank. 


\section{TABLE OF CONTENTS}

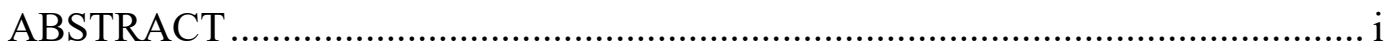

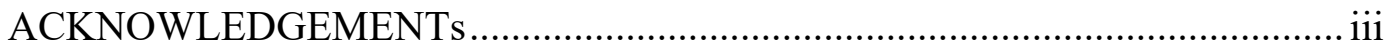

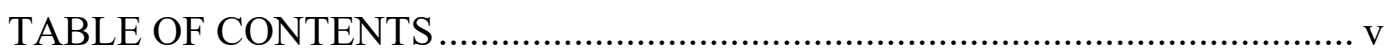

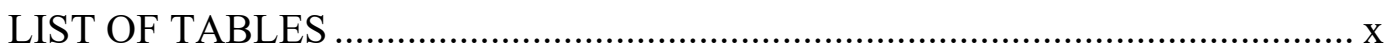

LIST OF FIGURES...........................................................................

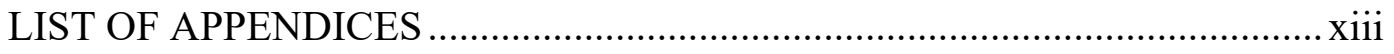

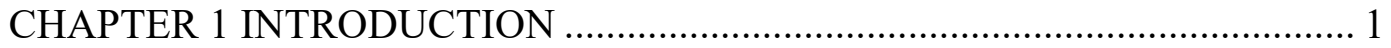

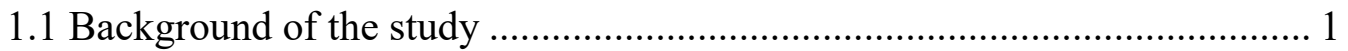

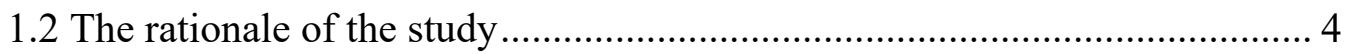

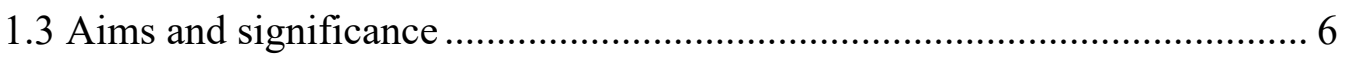

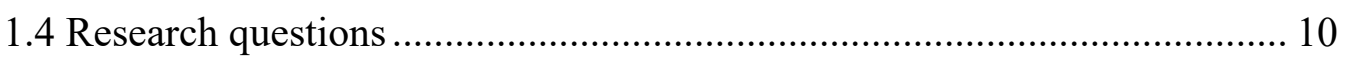

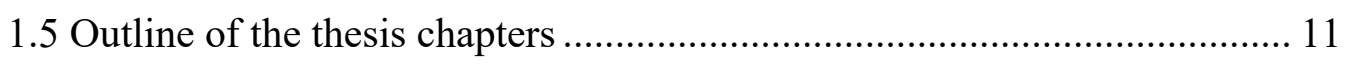

CHAPTER 2 LITERATURE REVIEW …................................................... 13

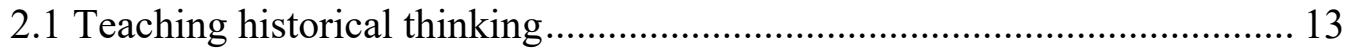

2.1.1 The concepts of historical thinking ............................................. 14

2.1.2 Historical thinking and epistemic cognition ................................. 18

2.1.3 Teaching historical thinking in the global context........................ 22

2.1.4 Teaching historical thinking in the Indonesian context ................. 26

2.2 Historical sources as learning resources................................................. 28

2.3 Web-based historical sources as learning resources ................................ 31

2.4 Analysing documents to improve students' historical thinking skills ........ 34

2.5 Interpreting textbooks to improve students' historical thinking skills........ 38

2.6 Conceptual framework: Analysing documents and interpreting textbooks as an alternative learning model to foster students' historical thinking skills...... 41

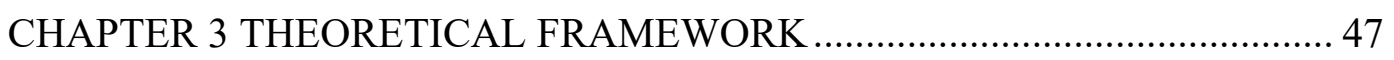

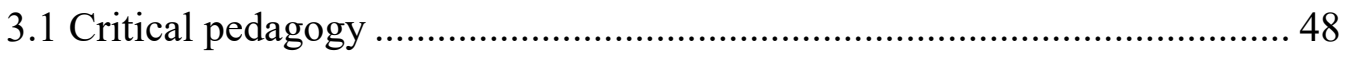

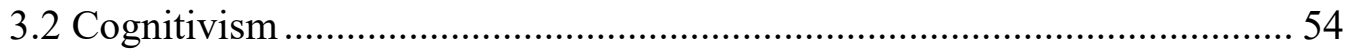

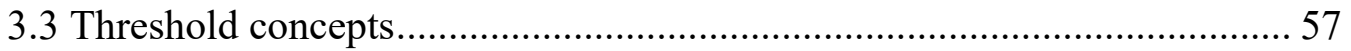

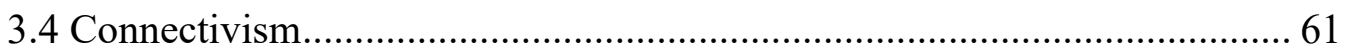

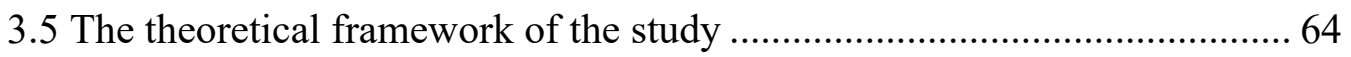


CHAPTER 4 METHODOLOGY

4.1 Research design.

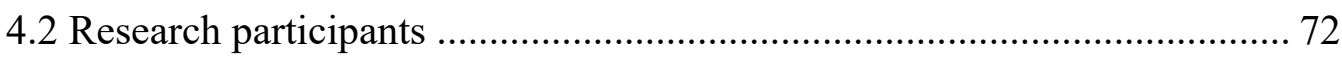

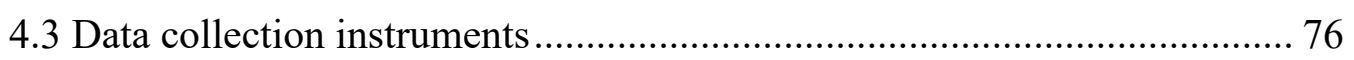

4.3.1 Historical beliefs questionnaire ................................................... 76

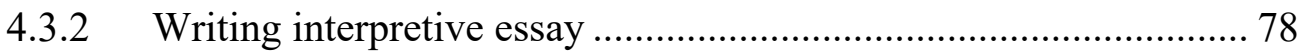

4.3.3 Open-ended questionnaire ........................................................... 79

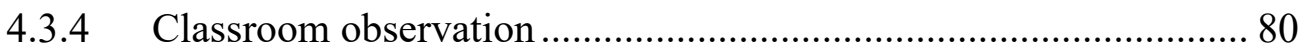

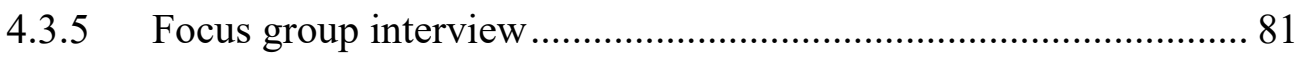

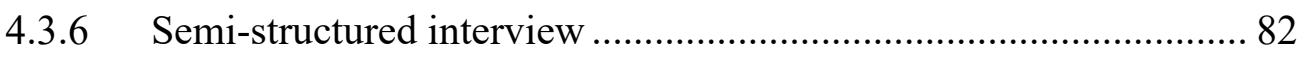

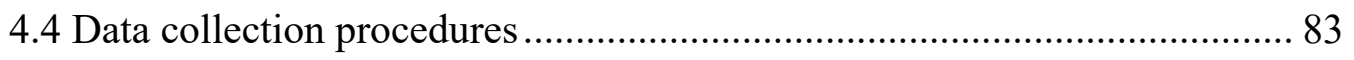

4.4.1 Developing the learning website (www.berpikirsejarah.com)....... 83

4.4.2 Conducting training for teacher participants ................................. 84

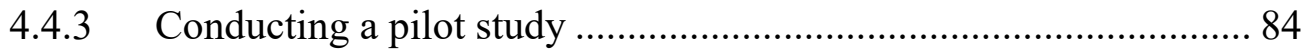

4.4.4 Administering the open-ended questionnaire................................ 86

4.4.5 Administering historical beliefs questionnaires ........................... 86

4.4.6 Conducting teaching and learning intervention, classroom observation, and writing interpretive essay tasks...................................... 86

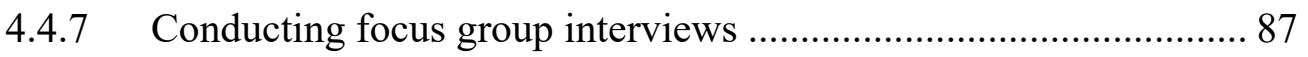

4.4.8 Conducting semi-structured interviews....................................... 88

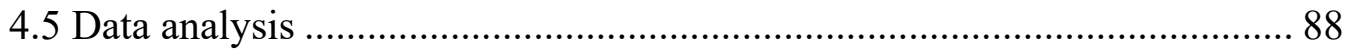

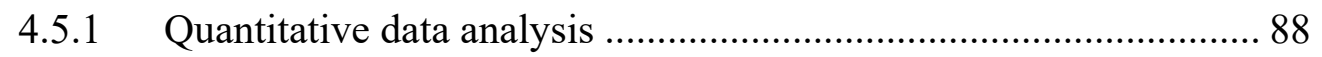

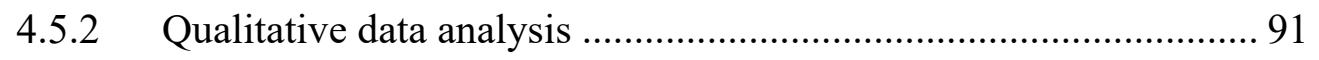

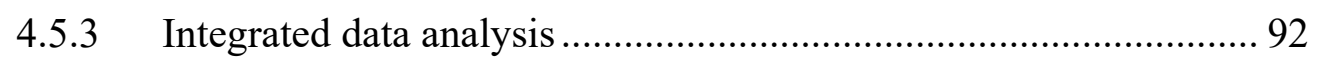

4.5.4 Validity and reliability of the mixed methods design ................... 93

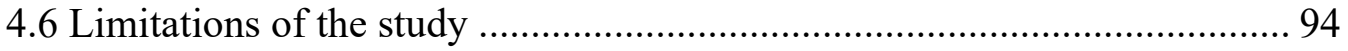

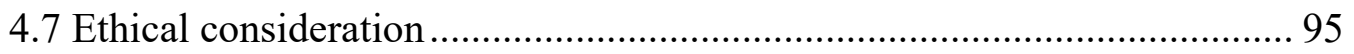

CHAPTER 5 STUDENTS' INITIAL UNDERSTANDING OF THE BATTLE OF

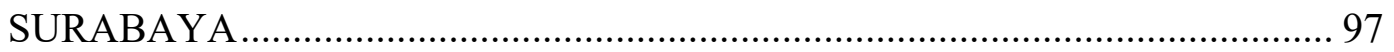

5.1 Students' initial understanding of the Flag Incident ................................. 97

5.1.1 Open-ended question 1: The event............................................. 98

5.1.2 Open-ended question 2: The sources of information ..................... 99 
5.1.3 Open-ended question 3: The chronology of the event ................. 100

5.1.4 Open-ended question 4: The cause of the event........................... 102

5.1.5 Open-ended question 5: The consequence of the event ................ 103

5.1.6 Open-ended question 6: The historical significance of the event 105

5.2 Students' initial understanding of the death of Mallaby .......................... 107

5.2.1 Open-ended question 1: The event............................................. 107

5.2.2 Open-ended question 2: The sources of information ................... 108

5.2.3 Open-ended question 3: The chronology of the event ................. 109

5.2.4 Open-ended question 4: The cause of the event........................... 110

5.2.5 Open-ended question 5: The consequence of the event ................ 111

5.2.6 Open-ended question 6: The historical significance of the event . 113

5.3 The comparison of students' initial understanding between the control and

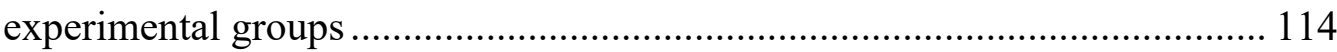

CHAPTER 6 STUDENTS' HISTORICAL THINKING SKILLS IN LEARNING

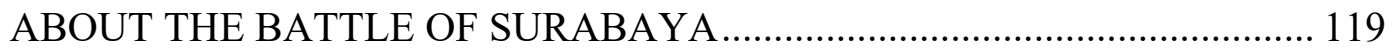

6.1 Students' historical thinking skills based on the writing interpretive essay

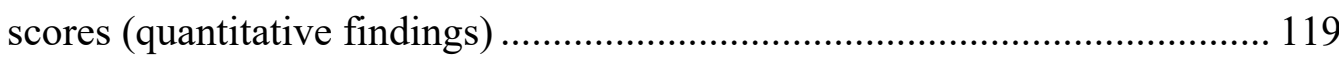

6.2 Students' historical thinking skills based on the teaching and learning

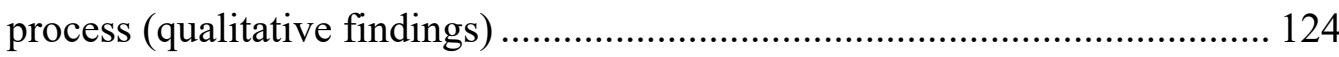

6.2.1 Students' historical thinking skills in the pre-intervention ........... 124

6.2.2 Students' historical thinking skills in the first intervention .......... 131

6.2.3 Students' historical thinking skills in the second intervention...... 149 6.3 The comparison of students' historical thinking skills in learning about the battle of Surabaya between the control group students and the experimental

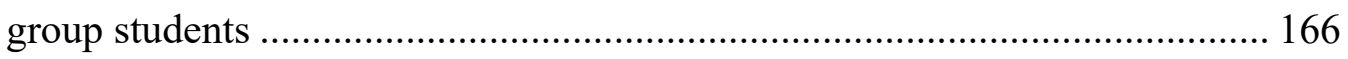

CHAPTER 7 STUDENTS' EPISTEMIC BELIEFS ABOUT HISTORY ......... 171

7.1 Students' epistemic beliefs about history based on the historical beliefs questionnaire.

7.2 Students' epistemic beliefs about history based on the teaching and learning

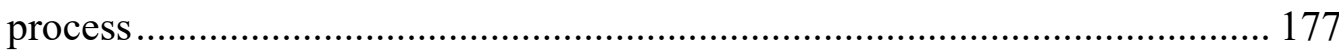

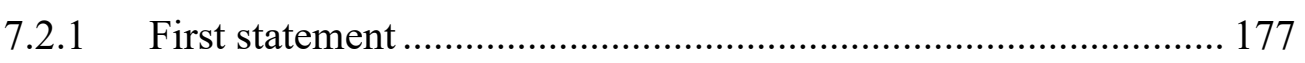

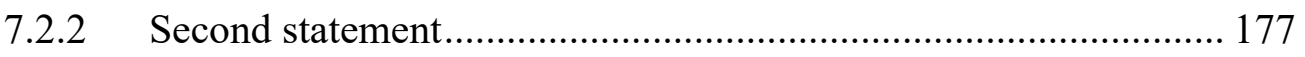




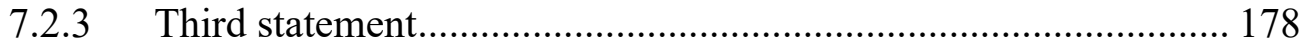

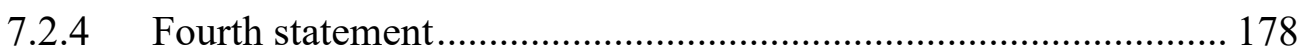

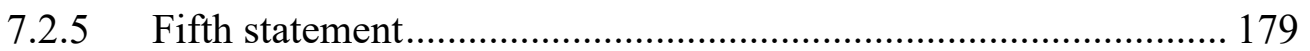

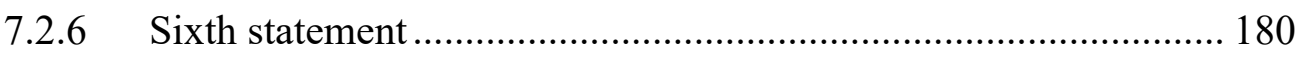

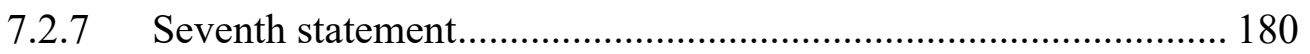

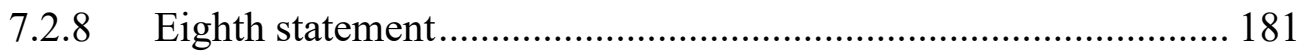

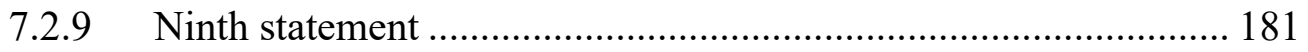

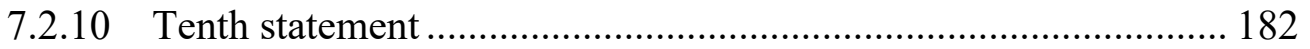

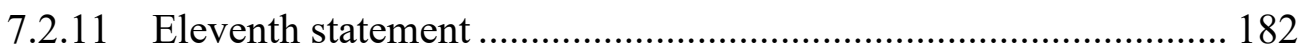

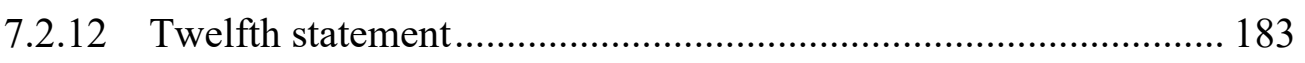

7.3 The comparison of students' epistemic beliefs about history between the control group students and the experimental group students ........................... 187

CHAPTER 8 TEACHING HISTORY THROUGH ANALYSING DOCUMENTS AND INTERPRETING TEXTBOOKS TO FOSTER STUDENTS'

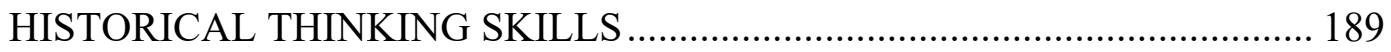

8.1 The challenges of conducting teaching history through analysing documents and interpreting textbooks to foster students' historical thinking skills

8.2 The opportunities for conducting teaching history through analysing documents and interpreting textbooks to foster students' historical thinking skills

CHAPTER 9 TEACHING HISTORY BY USING WEB-BASED HISTORICAL SOURCES AS LEARNING RESOURCES TO FOSTER STUDENTS' HISTORICAL THINKING SKILLS.

9.1 The challenges for conducting teaching history by using web-based historical sources as learning resources to foster students' historical thinking skills 201

9.2 The opportunities for conducting teaching history by using web-based historical sources as learning resources to foster students' historical thinking skills

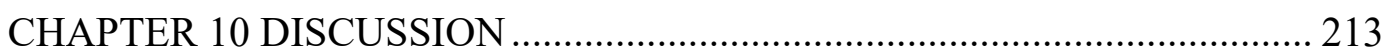

10.1 The pattern of students' historical thinking skills .................................... 213

10.2 The pattern of students' epistemic beliefs about history .......................... 233 
10.3 The potential of analysing documents and interpreting textbooks as a learning model to foster students' historical thinking skills 235

10.4 The potential of teaching history by using web-based historical sources as learning resources to foster students' historical thinking skills 239

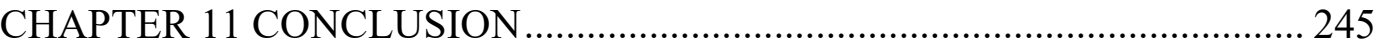

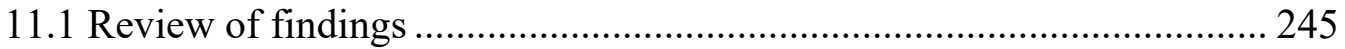

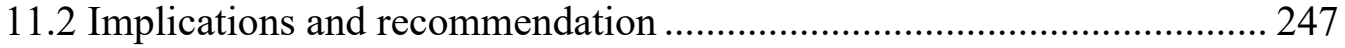

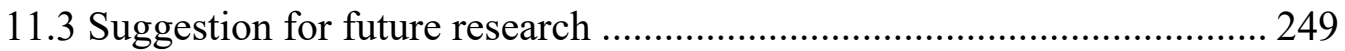

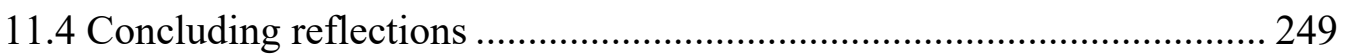

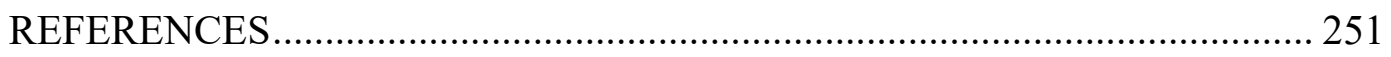

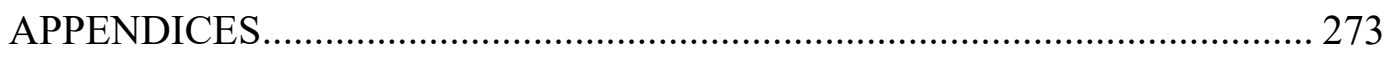




\section{LIST OF TABLES}

Table 4.1 The demographic data of the teacher participants ............................. 73

Table 4.2 The number of student participants.................................................... 74

Table 4.3 The age distribution of student participants ...................................... 75

Table 4.4 The distribution of student participants based on the gender............... 75

Table 4.5 The distribution of student participants based on the ethnicity ............ 76

Table 4.6 The statement items in the historical belief questionnaire (VanSledright,

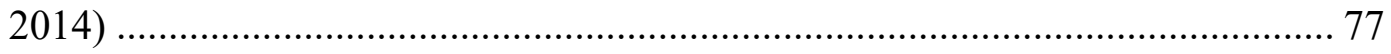

Table 4.7 The schedule of teaching interventions and classroom observations ... 87

Table 4.8 Timetable of focus group interviews ................................................ 88

Table 4.9 The timetable of semi-structured interview ….................................... 88

Table 5.1 Students' responses to the first question (the event of the flag incident)

Table 5.2 Students' responses to the second question (the sources of information on the flag incident)

Table 5.3 Students' responses to the third question (the chronology of the flag incident).

Table 5.4 Students' responses to the fourth question (the cause of the flag incident).

Table 5.5 Students' responses to the fifth question (the consequence of the flag incident).

Table 5.6 Students' responses to the sixth question (the historical significance of the flag incident)

Table 5.7 Students' responses to the first question (the event of the death of Mallaby)

Table 5.8 Students' responses to the second question (the sources of information on the death of Mallaby).....

Table 5.9 Students' responses to the third question (the chronology of the death of Mallaby)

Table 5.10 Students' responses to the fourth question (the cause of the incident that killed Mallaby)

Table 5.11 Students' responses to the fifth question (the consequence of the incident that killed Mallaby)

Table 5.12 Students' responses to the sixth question (the historical significance of the death of Mallaby incident)

Table 6.1 WIE scores of the control group and the experimental group .... 120

Table 6.2 WIE's mean score for each test. 
Table 6.3 Test of normality for WIE scores.

Table 6.4 ANOVA test results of WIE's scores in each group.......................... 122

Table 6.5 The result of the General Linear Model analysis .............................. 123

Table 7.1 HBQ's mean score for each questionnaire distribution ..................... 172

Table 7.2 Test of normality of the HBQ consistency score .............................. 173

Table 7.3 Friedman test results for the HBQ .................................................... 174

Table 7.4 The results of Wilcoxon test in the control and experimental group .. 174

Table 7.5 The results of the Mann-Whitney test to determine the difference between the control and experimental group. 


\section{LIST OF FIGURES}

Figure 2.1: The conceptual framework of this study ........................................ 42

Figure 2.2: Design of the ADIT learning model based on the conceptual

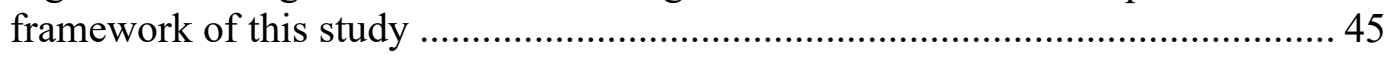

Figure 3.1 The theoretical framework of this study ........................................ 65

Figure 4.1: Diagram of mixed methods intervention design for this study .......... 71

Figure 6.1 Comparison of the WIE mean scores between the control group and the

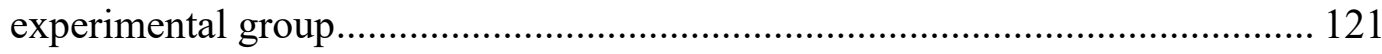

Figure 6.2 Four menus of learning resources for the flag incident material ....... 132

Figure 6.3 Ten documents of perpetrator testimonies from the DHD 45 archives

Figure 6.4 Six menus of learning resources related to the incident of the death of

Mallaby

Figure 6.5 Eight articles from two newspapers in 1945

Figure 7.1 Comparison of the HBQ mean scores between the control group and the experimental group ............................................................................... 173

Figure 10.1 The intersection between the two thresholds .............................. 218

Figure 10.2 The clusters of students' historical thinking skills level................. 219

Figure 10.3 The level of the control group students' historical thinking skills based on the WIE pre-test results.

Figure 10.4 The level of the experimental group students' historical skills based on the WIE pre-test results

Figure 10.5 The level of the control group students' historical thinking skills based on the WIE post-test 1 results.

Figure 10.6 The level of the experimental group students' historical thinking skills based on the WIE post-test 1 results.

Figure 10.7 The level of the control group students' historical thinking skills based on the WIE post-test 2 results. 228

Figure 10.8 The level of the experimental group students' historical thinking skills based on the WIE post-test 2 results. 230

Figure 10.9 The categories of students' epistemic beliefs about history 234 


\section{LIST OF APPENDICES}

Appendix A: Victoria University of Wellington, Human Ethics Committee, Ethics

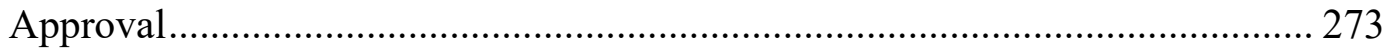

Appendix B: Information sheet for school headmasters .................................. 274

Appendix C: Consent form for school headmasters ........................................ 277

Appendix D: Information sheet for teacher participants.................................. 278

Appendix E: Consent form for teacher participants........................................ 281

Appendix F: Information sheet for student participants ................................. 282

Appendix G: Consent form for student participants ......................................... 285

Appendix H: Historical belief questionnaire (Indonesian version).................... 287

Appendix I: Writing interpretive essay tasks ................................................. 288

Appendix J: Open-ended questionnaire ......................................................... 296

Appendix K: Protocol for classroom observation ............................................ 298

Appendix L: Focus group interview protocol and rules (English translation).... 300

Appendix M: Semi-structured interview protocol (English translation)............. 303

Appendix N: Permission to use instruments ...................................................... 305

Appendix O: HBQ consistency scores of the control group ............................. 306

Appendix P: HBQ consistency scores of the experimental group ..................... 307 
This page is intentionally left blank. 


\section{CHAPTER 1 \\ INTRODUCTION}

\subsection{Background of the study}

History education is a core subject in the Indonesian curriculum and this has long been the case. Before the birth of the Republic in 1945, it was a compulsory subject during the Dutch colonial era, and this continued during the Japanese occupation (Budiarti \& Fahmi, 2013; Hasan, 2011). Throughout these years, the official history curriculum has reflected the interest of the authorities in each era (Darmawan, 2010; Gonggong, 2008).

During the Netherlands colonialism period (1800-1942), history subjects reflected a Neerlandocentric approach which aimed to perpetuate the Dutch rule in Indonesia (Hasan, 2011; Nichterlein, 1974; Purwanto, 2006; Suwignyo, 2012). This changed during the Japanese occupation (1942-45), when the military government tried to eradicate Dutch influences in education in the history curriculum (Darmawan, 2010; Hasan, 2011).

After Indonesia's independence, history education reflected an Indonesiacentric approach which aimed to instil the spirit of nationalism and patriotism of the younger generation (Darmawan, 2010; Mulyana, 2013; Purwanto, 2006; Suwignyo, 2012; Umasih, 2010). Since its independence in 1945, the history education curriculum in Indonesia has undergone a number of changes ${ }^{1}$, and the latest one is 2013 Curriculum (Budiarti \& Fahmi, 2013; Dewi \& Aman, 2019). In the 2013 Curriculum, history is not only required to instil values of nationalism and patriotism but must also be able to equip students with $21^{\text {st }}$-century skills such as curiosity, criticality, and the ability to cooperate and communicate (Hasan, 2019).

The current national education system aims to develop learners' potential so that they are faithful and pious to one and only God; possess morals and noble character; are healthy, knowledgeable, competent, creative, independent, democratic and responsible citizens (Act of The Republic of Indonesia Number 20

\footnotetext{
${ }^{1} 1947$ Curriculum, 1952 Curriculum, 1964 Curriculum, 1968 Curriculum, 1975 Curriculum, 1984 Curriculum, 1994 Curriculum, 2004 Curriculum, 2006 Curriculum, and 2013 Curriculum.
} 
Year 2003, 2003). These educational goals consists of the Core Competencies (Kompetensi Inti) and the Basic Competencies (Kompetensi Dasar) (Hasan, 2013), each of which has four domains: spiritual attitudes, social attitudes, knowledge, and skills (Ministry of Education and Culture, 2013c). However, including all these four domains is challenging for teachers.

In 2013, at the beginning of its implementation, all subject teachersincluding history - had to teach and assess all these four domains through direct teaching but in practice, it was not easy to teach (and assess) students' spiritual and social attitudes across all subjects. In 2016, this was changed so that only two subjects had to teach the spiritual and social attitudes domains through direct teaching (Ministry of Education and Culture, 2016f). These two subjects are Religion and Character Education subjects, and Pancasila and Citizenship subjects. Other subjects teach both domains through indirect teaching (Ministry of Education and Culture, 2016d). Thus, history subjects do not have to teach (and assess) directly the domains of spiritual and social attitudes, but must focus on teaching the domain of knowledge and historical skills.

History is a core feature of the 2013 Curriculum and is taught from elementary to secondary education. In primary school (Sekolah Dasar), Year 1-6, history is an integral part of thematic learning. In this case, history content in Year 1-3 is integrated with the content of other subjects. Meanwhile, in Year 4-6, the content of history is organised within social studies (Hasan, 2013; Ministry of Education and Culture, 2013a). For junior secondary school (Sekolah Menengah Pertama), Year 7-9, history education is also an integrated part of social studies, along with economy, sociology, and geography (Hasan, 2013; Ministry of Education and Culture, 2013b). For senior secondary school (Sekolah Menengah Atas), Year 1012, there are two subjects concerning history, namely, History of Indonesia (Sejarah Indonesia) which is compulsory for every student, and a subject aptly named History (Sejarah) which is compulsory for students majoring in Social Sciences, or as an elective subject for students majoring in Natural Sciences and Language Studies (Hasan, 2013; Ministry of Education and Culture, 2013c).

This thesis focuses on the teaching of history of Indonesia (Sejarah Indonesia) in senior secondary school. The rationale for this focus is that at this 
level, there are opportunities to develop historical thinking skills for students, whereas in primary school, the priority is to develop a holistic personality (Hasan, 2013). In junior secondary school, the 2013 Curriculum encourages students to know and understand the history of their own region, appreciate the contribution of the local historical events, and appreciate the contribution of local people and leaders to the nation (Hasan, 2013). However, it is only in senior secondary school where one of the goals of the history of Indonesia subject is to develop students' historical thinking skills which are the basis for their ability to think logically, creatively, and innovatively (Sardiman \& Lestariningsih, 2017a).

Curriculum development in Indonesia usually causes changes in the structure of the subjects being taught (Slameto, 2015). In the 2013 Curriculum, two history subjects for senior secondary school level were added, and it is expected that history education will dispel the common impression that history is merely memorizing historical facts. Rather history education is expected to no longer merely teach factual knowledge but must also develop historical thinking skills. By shifting from the objectives of having knowledge and understanding about the past to developing students' thinking skills, it is expected to give them "a complete different but better learning experiences in learning history" (Hasan, 2013, p. 172).

However, there are often disparities between the intended (written) curriculum and the implemented (enacted) curriculum (Sheehan, 2008). Some research results show that the implementation of the 2013 Curriculum in history education subjects still faces some obstacles. First, the learning process that should have been student-centred is still centred on the teacher who tends to use the lecture method (Burhanudin \& Sodiq, 2018; Pii, 2016). Secondly, students typically learn by memorisation (Aman, 2019; Irani et al., 2018; Sayono, 2013). Third, due to the limitations of primary historical sources that could be utilised for learning purposes (Irani et al., 2018), teachers tend to only use textbooks as learning resources for their students (Handayani, Basri, \& Ekwandari, 2018; Haniah \& Rokhman, 2017; Mardiana \& Sumiyatun, 2017; Pii, 2016). Fourth, there are limitations in the use of information and communication technology facilities that are still not optimally utilised by teachers for learning purposes (Agustinova, 2018; Aman, 2019; Mardiana \& Sumiyatun, 2017). 
These challenges are the reason why history teaching does not emphasise the cultivation of historical thinking skills for students. It is as if history teaching is still stuck at the time before the 2013 Curriculum. For this reason, efforts need to be made so that the implemented curriculum is in accordance with the intended curriculum.

\subsection{The rationale of the study}

This thesis investigates how senior secondary students in Indonesia develop historical thinking skills through analysing primary sources. Historical thinking skills are a significant shift for teachers in Indonesia. As an educator in a teacher training institution for more than a decade, I have worked closely with many history teachers and their students, especially in Malang, East Java, Indonesia. I have been aware of the challenges teachers face in their subject, including many of their students seeing the subject as having no practical use in their lives because they tend to memorise facts. Teachers have also complained about the difficulties of accessing historical sources so that they have had to rely on textbooks as the main learning resources for students. Finally, they admitted that they have difficulties teaching historical thinking skills because they had not received special training on how to teach historical thinking skills in either pre-service training or as a part of in-service courses on the 2013 Curriculum.

The teaching of historical thinking skills is a significant shift for teachers and students, although in its implementation, Indonesia has lagged behind other countries. In the 1960s, The United States of America (USA) began to introduce students to think historically by investigating open-ended historical questions which included multiple and conflicting primary sources through the Amherst History Project (Reisman, 2012b; Seixas, 2017; VanSledright, 2011). In the 1970s, the Schools Council History Project in England proposed a radical approach by specifically nurturing students' historical skills (Keating \& Sheldon, 2011). In relations with fellow Southeast Asian countries, Indonesia is also lagging behind. Singapore implemented historical thinking skills by promoting historical inquiry to activate students' involvement and provide opportunities for them to cultivate knowledge, skills, and dispositions that are essential to historical thinking and 
understanding (Emerson, 2013). In Malaysia, students are found to have a higher level of historical thinking skills compared to Indonesian students (Awang, Ahmad, Yakub, \& Seman, 2016).

In the context of the difficulties of the teachers in teaching historical thinking skills, there are several key challenges. The first and foremost obstruction in implementing the historical thinking second-order concepts is the difficulty for teachers in keeping up with the demands of the new curriculum. Although the 2013 Curriculum has mandated the teaching of historical thinking skills, the teachers as noted above have had difficulties in applying it (Burhanudin \& Sodiq, 2018; Ruja \& Sukamto, 2015).

The second obstruction to develop students' historical thinking skills in Indonesia is the limitation of the learning resources. Even though teaching historical thinking requires learning resources outside the bounds of history textbooks, history teachers rely only on textbooks, and these typically only present historical knowledge as "fixed claims about the past" (Reisman, 2012a). The utilisation of primary sources as historical evidence is one of the fundamental concepts for teaching and learning how to think historically (Davison, Enright, \& Sheehan, 2014; Lévesque, 2008; Seixas \& Morton, 2013), but the requirement to use primary sources is difficult to meet for teachers in Indonesia. Teachers there do not have the autonomy to choose their own history content and learning materials because they have to follow the national competency standards stipulated in the Regulation of the Ministry of Education and Culture (Ministry of Education and Culture, 2016a, 2016d). They must teach historical events that are set as standard of contents (Ministry of Education and Culture, 2016a), teach them according to predetermined standard of process (Ministry of Education and Culture, 2016b), and then conduct learning evaluations according to settled standard of evaluation (Ministry of Education and Culture, 2016c). If in the learning process students have achieved the expected standard of contents, history teachers will then have some autonomy to teach local history content (Norhidayat, 2018; Romadhoni \& Witir, 2019; Y. Wijayanti, 2017). In this case, the teachers can access local primary sources in the nearest regional archive offices or historical sites, but in the case of finding primary sources for national historical content, this proves to be more difficult. Only a small 
portion of the archival collection of the national archive office in Jakarta has been digitised, while most of the collection must be accessed manually by visiting the office. In the context of struggling to find primary sources, it is unsurprising; teachers prefer a more practical approach by only utilising the official history textbook for their students.

The third challenge in implementing historical thinking skills is that primary sources are not easily accessible for either teachers or students. In developed countries, the success of teaching historical thinking skills in history education is in part due to the ease of access to primary sources. For example, in the case of the USA, millions of documents have been digitised and made readily available to teachers and students in the Library of Congress website (Breakstone \& Smith, 2013; J. K. Lee, 2002; Martin \& Wineburg, 2008; Salinas, Bellows, \& Liaw, 2011). Meanwhile, during the course of my research, only a small collection of the National Archives of the Republic of Indonesia from the period of the Dutch East India Company (VOC) can be accessed online. Since it contains Dutch-written archives from the $17-18^{\text {th }}$ century, it will not be easily and practically utilised in learning history at the school level due to language barrier. Furthermore, in Indonesia there are no available websites containing primary sources that are deliberately developed for the purpose of teaching and learning history. Conversely, many websites like this have been developed and used for teaching history in developed countries. For instance, in the USA there are "Reading Like a Historian" history lesson available in https://sheg.stanford.edu/ (Wineburg, Martin, \& MonteSano, 2011) and "Historical Thinking Matters" available in http://historicalthinkingmatters.org/ (Martin, Wineburg, Rosenzweig, \& Leon, 2008). In Canada, there are also some websites which can be utilised for teaching and learning historical thinking, such as "The Historical Thinking Project" in https://historicalthinking.ca/lessons directed by Seixas and "The Virtual Historian" in http://www.virtualhistorian.ca/en directed by Levesque.

\subsection{Aims and significance}

This research explores alternative efforts to overcome the difficulties faced by history teachers in developing their students' historical thinking skills. In fact, 
international trends in developed countries show the importance of fostering students' historical thinking skills through history education. I believe the same efforts could be applied in developing countries like Indonesia, particularly by using primary sources that are presented through the learning website.

In doing so, I have to consider the position of history education in Indonesia that still focuses on constructing "national identity" (Carretero, Rodriguez-Moneo, \& Asensio, 2012), instilling "collective memory" (Wertsch, 2008), and tends to approach history in a single perspective (McGregor, 2008). These features are in the history teaching 'manual book' — which is often referred to as 'teacher textbook' because of its function to complement 'student textbook' - that guides history teachers in the subject matter of history to construct collective memory, to foster national identity, and to contribute to nation-building both in the present and the future (Sardiman \& Lestariningsih, 2017a). This manual has placed history teachers in an ambivalent position. On one hand, teachers must instil national attitudes that tend to offer history as a single perspective and an official version of the past. On the other, teachers must instil historical thinking skills that require multiple perspectives that sometimes differ from the official version.

I also have to consider that official historical narratives and history curriculum provide justifications of present-day governance by shaping the ways students understand the past and the present (Seng, Baildon, Lim, İnanç, \& Jaffar, 2014) and define the historical events that are considered significant by the state. The official history curriculum tends to promote a historical perspective which offers a single truth of the past and refute other different perspectives. Therefore, this research tries to help teachers teach history by offering their students multiple historical perspectives without the need to contradict the official state version, with the hope that students will have historical thinking skills while obtaining the values demanded by the curriculum.

I also need to consider the reality that history education in Indonesia is still used as a tool to foster nationalism and patriotism (Sardiman \& Lestariningsih, 2017a). This turns out to be a serious obstacle because students seem to have gotten used to being taught that 'my country is right and your country is wrong' (Porter, 2006), reflecting the Indonesiacentric approach. While it may be easier to teach 
history with a single historical interpretation with an absolute truth about the past, this will have an enormous negative impact on the democratic society in the future. Education in Indonesia is aimed at educating young people to become democratic and responsible citizens (Act of The Republic of Indonesia Number 20 Year 2003, 2003), and students need to learn to deal with differences in information and interpretation beyond history textbooks as it will challenge them to think critically. A democratic citizen must be a skilled and responsible decision-maker (VanSledright \& Grant, 1994). In order to achieve this, my aim is to offer a model of teaching history that instils a spirit of nationalism and patriotism, while also fosters students' historical thinking skills so they develop reasoned, evidence-based understandings of the past that equip them to participate in the society as critical citizens who have the ability to think independently and arbitrate competing claims of historical authenticity (Sheehan, 2013, 2014).

Based on the aspects mentioned above and the awareness of the urgent need to foster Indonesian students as critical citizens in a democratic society, this study aims to examine the ideas and efforts to foster students' historical thinking skills in learning history in Indonesian context. These efforts are made by introducing students to processes that teach them to think historically or engage in interpretive processes (VanSledright, 2014). Historical content for senior secondary school students that was deliberately chosen to be used in this study is the history of the battle of Surabaya. This material reflects several aspects that I have explained above, as an example of the historical material used to instil nationalism, patriotism, national identity, and collective memory through Indonesiacentric official narratives. This battle is a significant event in the history of Indonesia and commemorated annually as Hero's Day in Indonesia (Widiadi, 2019). When compared with the significant history of Australia and New Zealand, this battle can be considered as “Indonesia's Gallipoli” (Palmos, 2011). This battle of Surabaya is always taught in Indonesian schools and consistently depicted in the Indonesian school textbooks (Sardiman \& Lestariningsih, 2017b, 2017a; Widiadi, 2019). Unfortunately, these official state-promoted textbooks offer only one interpretation from the authors, without following the international trend by adding primary sources along with other perspectives that may differ from one adopted by the main 
interpretation (Maggioni, 2010). The impact on students in Indonesia is they would consider their mandatory textbooks as the "primary sources" and have "authority" as a fact without any need to critically analyse the information (Nokes, Dole, \& Hacker, 2007; Wineburg, 1991a, 1991b).

Therefore, this research aims at finding out how to use primary sources in learning history in Indonesia, because using multiple sources in history classes may help students better understand the past and how history itself is constructed (Afflerbach \& VanSledright, 2001). Students were given the opportunity to analyse primary historical documents related to the battle of Surabaya and at the same time, they were asked to interpret their textbooks. I then examined how this intervention affected their historical thinking skills.

As the first step in achieving the main aim, I reviewed students' initial understanding related to the battle of Surabaya. I presumed that their initial understanding was influenced by the textbooks which had been their only learning resources. This was also important to do so that I could find out whether there were differences in initial understanding or not between the group of students who received the intervention and the group of students who did not.

The second step I took was examining the progression of students' epistemic beliefs about history during the intervention process. I needed to identify students' epistemic beliefs about history and how they make sense of history since their epistemic beliefs might change by learning historical thinking skills. I suspected that Indonesian students' epistemic beliefs about history were at a low or novicestance prior to the intervention process since they had only received a single interpretation of the past in their education and had little exposure to the process of critically thinking about the past.

The third step was to identify the potential of teaching history through analysing documents and interpreting textbooks to foster students' historical thinking skills. I expected to obtain information based on an empirical finding of the trials in the classroom situation to ascertain whether this learning model can be utilised in Indonesia to develop historical thinking skills. The last step was to identify the potential of teaching history by utilising a website containing digitised historical sources that were deliberately developed to provide alternative learning 
resources besides history textbooks. I hoped to gain valuable empirical data on whether this website can be utilised to teach history in order to foster students' historical thinking skills.

In order to bring and provide primary sources in the classroom, I have developed a website for the purpose of this research. I named this website "berpikir sejarah," which means historical thinking or thinking historically (http://berpikirsejarah.com/). By providing students with primary sources on a website as classroom-ready materials and activities, students were expected to improve their historical thinking skills (Reisman, 2012b; Wiley \& Voss, 1999). For the time being, this website only contains material related to the battle of Surabaya. In the future, I will continue to develop it by adding other contents related to the history of Indonesia so that students there can think historically in analysing the past, and this will illuminate their future as critical citizens in a democratic society, both in local and global contexts.

\subsection{Research questions}

This research seeks to examine the alternative learning model for teaching history in Indonesia through analysing documents and interpreting textbooks to foster students' historical thinking skills. It contributes to the gaps in the literature of teaching and learning historical thinking by using primary sources in developing countries such as Indonesia. So far, the studies that examined students' historical thinking skills have primarily focused on developed countries which already have sufficient facilities to access primary sources (Breakstone \& Smith, 2013; Cowgill \& Waring, 2017; Martin \& Wineburg, 2008; Martin et al., 2008; Reisman, 2012a, 2012b; Wineburg \& Martin, 2009; Wineburg et al., 2011). Meanwhile, history education in Indonesia still has some obstacles in teaching historical thinking skills due to difficulties in accessing primary sources causing both the teachers and students to tend to rely on the textbooks as the only learning resources. My aim in this research is to not only contribute to the academic world in the field of history education, but also provide practical support for history teachers in Indonesia to be able to foster their students' historical thinking skills. 
As will be discussed later in the fourth chapter, that this study used a mixedmethod intervention design, the main thing to be asked in the quantitative part of this study is whether learning history through analysing documents and interpreting textbooks affects students' historical thinking skills or not. Whatever the quantitative test results emerge, in the qualitative section, this study took a more indepth look at the effects of the intervention and why it happened. The main questions in this study are supported by four sub-questions. First, to find out the students' initial understanding before the intervention process. Second, to find out the relationship between historical thinking interventions with students' epistemic beliefs. Third, to find out the challenges and opportunities of learning history through analysing documents and interpreting textbooks. Fourth, to find out the challenges and opportunities of learning history by using historical sources as learning resources that are presented on a website. The following are the research questions in this study:

\section{Main question:}

How does teaching history through analysing documents and interpreting textbooks contribute to students' historical thinking skills?

\section{Sub-questions:}

1. What are Indonesian students' initial understandings of the battle of Surabaya?

2. What are Indonesian students' epistemic beliefs about history and how do these change as a result of historical thinking process intervention?

3. What are the challenges and opportunities for conducting teaching history through analysing documents and interpreting textbooks to foster students' historical thinking skills?

4. What are the challenges and opportunities of using web-based historical sources as learning resources to foster students' historical thinking skills?

\subsection{Outline of the thesis chapters}

This thesis is structured into eleven chapters. Chapter 1 is an introductory chapter which generally describes the background, rationale and aims of the study. It highlights the research questions along with the expected significance of the findings. This chapter also describes history education in Indonesian context and 
explains the significant contributions that this research makes to the body of knowledge and to the practice of teaching history in Indonesia.

In Chapter 2, I review previous literature on teaching historical thinking, specifically those related to the use of primary sources and the use of websites to access historical sources. This chapter also reviews literature that forms the basis for developing a model of teaching history through document analysis and textbooks interpretation. The theoretical framework which I use throughout this thesis is developed in Chapter 3. This chapter covers cognitivism, connectivism, threshold concepts, and critical pedagogy.

Chapter 4 examines the research design, especially the rationale of using mixed methods intervention design. This chapter also addresses the procedure of data collection, instruments, and research participants. In this chapter, I also outline my approach to data analysis and describe the limitations of the study as well as ethical considerations.

In Chapter 5, 6, 7, 8, and 9, I report the findings of my research. The purpose of Chapter 5 is to answer the first sub-question which is to describe students' initial understanding of the battle of Surabaya. The purpose of Chapter 6 is to answer the main research question related to students' historical thinking skills, both in quantitative and qualitative findings. The purpose of Chapter 7 is to answer the second sub-question regarding students' epistemic beliefs about history from both quantitative and qualitative data. In Chapter 8 , I focus on the third sub-question by describing the potential of teaching history through analysing documents and interpreting textbooks to foster students' historical thinking skills. In Chapter 9, I focus on answering the fourth sub-question by exploring the potential of teaching history by using web-based historical sources to foster students' historical thinking skills.

Chapter 10 discusses several patterns of findings that emerge from research data, especially regarding the pattern of students' historical thinking skills after learning history through analysing documents and interpreting textbooks. Finally, I conclude the thesis in Chapter 11 by highlighting the key findings from this research. This chapter also presents the implications and recommendations of the study, as well as suggestions on directions for further research. 


\section{CHAPTER 2 LITERATURE REVIEW}

This chapter presents an overview of the previous literature that is relevant to this study. I start my investigation by examining current trends in teaching historical thinking. Then, I examine the approach of teaching history which currently uses primary historical sources as learning resources. Following this, I explain relevant literature that has provided the opportunities for utilising digitised historical sources presented on a website to be used as media in accessing learning resources. This chapter also examines the opportunities to develop students' historical thinking skills through the process of analysing historical documents. In addition, it examines the chance to foster students' historical thinking skills through interpreting textbooks. This chapter concludes with a conceptual framework that summarizes the ideas found in the literature.

\subsection{Teaching historical thinking}

Teaching students to be able to think historically is essential to equip them with the skills needed in life in the $21^{\text {st }}$ century (Hasan, 2019; Lévesque, 2008; Widja, 2018). These skills will be useful for them in being more critical in dealing with global conditions that are full of uncertain and rapidly changing information. In today's information-rich environment, the main problem is no longer what students know, but whether they know how to process the information they obtained (McGrew, Breakstone, Ortega, Smith, \& Wineburg, 2018). Teaching historical thinking primarily deals with 'how' rather than 'what' students think and learn to think critically about the past (Johnston \& Sheehan, 2016; Sheehan, 2013).

Wineburg (2001) considers historical thinking as an 'unnatural act' that students do not automatically possess, so this skill must be learned and trained. To teach these skills to students means that they must study the past by using a disciplinary "canons of evidence and rules of argument" (Wineburg, 2007, p. 6). Therefore, students should engage in the historical analysis by examining evidence in the form of primary and secondary sources and then corroborate these accounts to form their own interpretation of the past (Cochran, 2010). 
In the next sub-section, I review some concepts of historical thinking from various scholars in this field. Then the following sub-section discusses the relation between historical thinking and epistemic cognition. In the last two sub-sections, I review some of the literature related to the teaching of historical thinking in a global context and in Indonesian context.

\subsubsection{The concepts of historical thinking}

Teaching historical thinking skills not only requires students to master the historical content material but also to analyse that content critically. This is exactly the opposite of the traditional teaching of history which relies only on identifying important dates, individuals, events, or ideas that students must know (Lesh, 2011). This causes students to only learn history through memorising facts that are less beneficial to their life (Hasan, 2010). However, to teach students to think historically, the learning process also requires substantive knowledge. Historical thinking involves complex interactions between these two types of knowledge (Ercikan \& Seixas, 2015).

The first type of knowledge needed to study history is generally referred to as the 'content' aspect (Hasan, 2019; Lazer, 2015). This type of knowledge is also commonly referred to by experts with a variety of different terms, such as 'historical knowledge and perspective' (Seixas \& Ercikan, 2015), or 'substantive knowledge' (VanSledright, 2011, 2014), or 'declarative knowledge' (Ercikan \& Seixas, 2015), and also 'first-order concepts' (P. J. Lee, 2005). The knowledge included in this category, for example, is people or historical actor names, dates or chronological periods, regions, events, capitalism, socialism, economic production, democracy, and many others. Historical content knowledge is the starting point for developing students to a higher level of competence (Hasan, 2019).

Meanwhile, the second type of knowledge needed to study history is referred to as the 'skills' aspect. This type of knowledge is also known as 'historical analysis and interpretation' (Seixas \& Ercikan, 2015), or 'strategic knowledge' (VanSledright, 2011, 2014), or 'procedural knowledge' (Ercikan \& Seixas, 2015), and 'second-order knowledge' (P. J. Lee, 2005). All these terms contain a common meaning which is the knowledge that is used to construct historical arguments and understanding (Cochran, 2010). Unfortunately, this aspect-due to the various 
challenges faced - is often ignored by the teachers in teaching history in Indonesia because they are still too focused on the content aspect and neglect their obligation to encourage the development of students' skills (Anas, 2010).

In order to develop students' historical thinking skills, the history teachers must have a strong understanding of the historical thinking concepts. In the 2013 Curriculum, there are three concepts of historical thinking skills. Meanwhile, the concepts of historical thinking offered by experts are very diverse. The various concepts of historical thinking when juxtaposed sometimes show similarities, often overlapping, and even contradictory (Seixas \& Ercikan, 2015). For this reason, in this sub-section, it is necessary for me to describe some of the concepts of procedural knowledge and why they are needed in historical thinking, which will be described further below.

Historical thinking can be defined as the process of using procedural knowledge to analyse historical content knowledge, in order to understand the past. The fundamental question according to Seixas \& Morton $(2013$, p. 2) is "how do we know what we know about the past?". This question can be answered through an intellectual process that requires critical thinking by using certain concepts. These concepts are used by historians to transform the past into history (Seixas \& Morton, 2013). At the same time, students can also use these concepts as "the rule of the game" to learn history (Lévesque, 2008).

The rule of the game for constructing history has many concepts. In New Zealand, Davison, Enright, \& Sheehan (2014) identify four main concepts of historical thinking: (1) evidence, (2) historical empathy, (3) historical perspective, and (4) historical significance. In Canada, Lévesque (2008) introduces five procedural concepts: (1) historical significance, (2) continuity and change, (3) progress and decline, (4) evidence, and (5) historical empathy. Meanwhile, Seixas \& Morton (2013), also in Canada, extract the essence of historical thinking into the "big six" concepts: (1) historical significance, (2) evidence, (3) continuity and change, (4) cause and consequence, (5) historical perspective, and (6) the ethical dimension. In Germany, Körber \& Meyer-Hamme (2015) define four dimensions of historical thinking competencies: (1) competence in questioning, (2) methodological competence, (3) orientation competence, and (4) subject area 
competence. In the USA, Wineburg (1991a) identifies three ways historians commonly use when reading and assessing historical texts, namely sourcing, contextualisation, and corroboration. These three ways can be taught to students to have historical thinking skills through reading like a historian (Wineburg et al., 2011).

In Indonesia, the 2013 Curriculum has mandated history teachers to teach historical thinking skills to their students. Unfortunately, the 2013 Curriculum document does not provide a detailed explanation of which concepts of historical thinking should be taught. Fortunately, "the teacher textbook", as an official guide to teaching history in Indonesia, provides some insights into these concepts. That is, the students can be taught three historical thinking skills which include: (1) chronology, (2) cause and consequence, and (3) change and continuity (Sardiman \& Lestariningsih, 2017a). However, this manual book does not provide a detailed guidance on how to teach these skills to the students.

From the various concepts of historical thinking that have been mentioned above, some of them will be explained in more detail below. First, one of the most prominent concepts in stimulating students' historical thinking skills is evidence. This concept is the most difficult and challenging part to be introduced in Indonesia because of the limited access to primary sources. Meanwhile, the concept of evidence is the basis of history because writing history becomes possible only when evidence is available (P. J. Lee, 2005). Thus, to develop students' historical thinking skills, they must be engaged in history by actively seeking appropriate sources, analysing these sources, being aware of their context, and constructing their own interpretations (Seixas \& Morton, 2013). Davison (2014a, p. 10) states that "because source material conveys information about the past, using a photograph or the text of a speech can sometimes be a more effective way of putting across information to students than simply telling them".

Historical significance is also a fundamental historical thinking concept. This is how historians determine whether an event in the past is an important phenomenon or not. Historical significance is not a fixed construction. It is contested over time and from group to group (Enright, 2014a; Seixas \& Morton, 2013). Teaching this concept in Indonesia is a challenge because students normally 
are not given the opportunity to determine whether past events are historically significant or not. The selection of important historical events is determined by the state as set out in the curriculum and textbooks, as is also the case in many other countries, including Canada (Lévesque, 2008). Students need to be given the opportunity to determine historical significance independently through a learning process that teaches them the ability to analyse historical documents. Without this opportunity, students would confront history as "an alienated body of facts that appear to have little to do with their own lives" (Seixas, 1997, p. 27).

Thirdly, historical empathy is not less important. This concept requires imaginative thinking as "walking in the shoes of someone from the past" as well as evidence-based cognitive thinking (Davison, 2014b). Meanwhile, Lévesque (2008) sees that this concept requires interrelation between historical imagination, historical contextualisation, and moral judgement. That is why in Seixas \& Morton's (2013) view, historical empathy can also be compared to the concept of "ethical dimension" because it involves moral or ethical judgement. Historical empathy can also be compared as the concept of "historical perspective" in Seixas \& Morton's (2013) view because it has to involve the use of evidence and historical context to infer the thought and feeling of historical actors. These historical thinking concepts indeed overlap with one another.

The historical perspective, the fourth concept reviewed here, is also very important to instil because people can view a historical event in vastly different ways (Seixas \& Morton, 2013). Thus, students need to be taught that there are multiple perspectives on viewing the past and that interpretations of the past are contested (Enright, 2014b).

Fifthly, historians need to determine the relationship between cause and consequence of the event under study (Lévesque, 2008) and a historical event can have multiple causes as well as multiple consequences (Seixas \& Morton, 2013). An idea that is hard for students to understand is they are taught a single causation in history, as is usually the case in the textbook narration. This concept is closely related to the sixth concept, change and continuity. Students also need to able to analyse the sequence of historical events (Lévesque, 2008). The change and continuity concepts are also closely connected to the concepts of progress and 
decline because they are interwoven (Lévesque, 2008; Seixas \& Morton, 2013). All historical thinking concepts mentioned above can be taught to students to give them the main skills in historical thinking, namely chronological thinking skills. This is because chronological thinking is an indispensable tool to structure a historical narrative and to give meaning to a series of events (Lorenc, Mrozowski, Oniszczuk, Staniszewski, \& Starczynowska, 2012). Therefore, chronological thinking is the heart of historical thinking because it provides mental scaffolding for organising historical thought (UCLA History, 2019).

\subsubsection{Historical thinking and epistemic cognition}

In efforts to improve students' historical thinking skills, teachers need to notice and monitor students' epistemic cognition level. Epistemic cognition can be defined as a form of personal views and understanding of the nature of knowledge and the process of knowing (Ferguson, Bråten, \& Strømsø, 2012; Hofer \& Pintrich, 1997). This cognition enables students to consider the criteria, limits, and certainty of knowing certain knowledge, including history (Maggioni, VanSledright, \& Alexander, 2009). There are several other terms related to epistemic cognition, such as epistemic thinking (Johnston, Hipkins, \& Sheehan, 2017; Kuhn \& Weinstock, 2002), epistemic frame (Perkins \& Simmons, 1988), and also epistemic beliefs (VanSledright, 2011, 2014; VanSledright \& Reddy, 2014; Wineburg, 2001).

According to Maggioni (2010, p. 12), "historical thinking requires people to be aware of the nature of history, to generate historical arguments based on the evidence available, and to evaluate the strength of such arguments". For this reason, every effort to develop students' historical thinking skills, students' epistemic beliefs need to be assessed first and then their progress must be monitored afterwards. Counterproductive epistemic beliefs can inhibit and block students' historical understanding and thinking skills. Students need to be immersed in the learning process that teaches them how to think historically so they can move on to a deeper understanding of the past (VanSledright, 2014).

In the case of Indonesia, students are accustomed to learning history by relying on teachers' lectures that refer to the textbooks (Alfian, 2017; Anas, 2010; Andarwati, 2019; Hasan, 2013), and the logical consequence to the students is that they would consider these textbooks as the truth of what happened in the past. In 
addition, students would not understand the nature of history and how history is constructed because they are rarely given the opportunity to analyse historical sources to construct their own interpretation. For this reason, an investigation of students' epistemic beliefs cannot be abandoned if the teacher wishes to cultivate students' historical thinking skills.

There are several studies examining the connection between epistemic beliefs and the ability to think historically, some of which will be reviewed below. Maggioni's (2010) dissertation focused on exploring both students' and teachers' epistemic beliefs in history and their ability to think historically. To measure the level of epistemic beliefs of her research participants, Maggioni (2010) developed a research instrument in the form of "beliefs about history questionnaire", both for students and teachers. The questionnaire data is also integrated with the results of the structured interview. Meanwhile, students' historical thinking skills are assessed through "constructed response tasks" which students worked on after reading six written documents while thinking aloud with the aim of answering certain questions. Maggioni's (2010) research shows that there are several relations between students epistemic beliefs and their capacity to think historically, while for teachers, this is more complex. From Maggioni's study, we can learn that there are some relationships between epistemic beliefs and historical thinking, but these relationships do not always indicate linear progressions due to the complex patterns found in the data as evidence of a complex human-centred process.

While Maggioni (2010) is concerned with the connection between epistemic beliefs and the ability to think historically in teachers and students, VanSledright \& Reddy (2014) examined this connection in prospective history teachers. Their research tries to explore how epistemic beliefs in history might change at college stage, a crucial development point between their status as former students and prospective teachers. Their findings show that the eighteen research participants tend to experience "epistemic wobbling" because they had difficulty understanding the past through its remaining objects and the success to think historically turns out to depend on the level of epistemic beliefs, which requires having reached the “criterialist" stage (VanSledright \& Reddy, 2014). From their study, it can be seen that students' ability to think historically is also influenced by their epistemic 
beliefs. It should also be realised that even university students experience difficulties when dealing with historical sources so that even secondary school students can experience difficulties.

There are other studies that link epistemic beliefs specifically to one of the concepts of historical thinking. Lee \& Shemilt (2003) find progression models in how students dealt with historical evidence, one of the important concepts in historical thinking. Although it is not a rigid and systematic level, this model can map the stages of students' progress in dealing with evidence (P. Lee \& Shemilt, 2003). Still related to the concept of evidence, Nokes' (2014) study also explores the epistemic beliefs and historical thinking of $5^{\text {th }}$-grade elementary school students during the document-based history lesson. The results of his study show that even elementary school students in grade 5 are able to think like historians if given the opportunity to work with documents to solve historical controversies. Meanwhile, related to students' response to the evidence, showing that their epistemic beliefs began to shift to a criterialist epistemic stance, though not as sophisticated and mature as historians. Both studies show the importance of examining students' epistemic beliefs when trying to foster students' historical thinking skills.

In mapping the level of students' epistemic beliefs in learning history, there are several models that can be applied in this study. The first, as has been mentioned previously, is Lee \& Shemilt's (2003) model that can be used to map students' epistemic beliefs progression when dealing with historical evidence. The first level is evidence as "pictures of the past" as if it offers direct access to the past. Students do not question the truth on what they get from the evidence. At the second level, students consider the evidence as information. Students begin to question the truth of the evidence but do not use any methodology to ascertain whether the information offered is correct or incorrect. The third level is evidence as testimony. Students begin to realise that the past is reported by people who lived at that time. They also begin to realise that history has a methodology for questioning the truth about the past. When dealing with contradictory evidence, students will decide with simple dichotomy between good and bad or between truth-telling and lies. The fourth level is "scissors and paste". When faced with lots of diverse and conflicting evidence, students will take several pieces of evidence that they consider to be true 
and then put together into their own versions. The fifth level is "evidence in isolation." Students realise that historians can work out historical facts not only from the testimonies of historical actors and witnesses. There are also many other things that can serve as evidence even though at the time it was prepared not as a report for historians. The sixth level is "evidence in context", where students understand that sources will become evidence if it is understood in its historical context. Students will question what the source means and for whom it was produced.

The second model that can be applied to map students' epistemic beliefs is the theoretical model developed by Bruce VanSledright and his colleagues (Maggioni et al., 2009; VanSledright, 2011, 2014). Based on this model there are three levels of students' epistemic beliefs. The first level is "the copier" stance (Maggioni et al., 2009), or naïve realism (VanSledright, 2011), or naïve objectivist (VanSledright, 2014). This is a novice level which sees no difference between history and the past. When dealing with conflicting versions of the past, they assume that someone had made a mistake and they often experience an intellectual impasse when trying to solve it. Secondary school students who have received history lessons that focus on strong content-knowledge are usually at this level. The second level is "the borrower" stance (Maggioni et al., 2009), or naïve relativism (VanSledright, 2011), or naïve subjectivist (VanSledright, 2014). This is the level for those who can be categorised as competent. It is characterised by the belief that history is all about someone's perspective; conflicting accounts are only a result of the different testimony offered; history is simply a matter of interpretation or opinion and they can believe whatever they want about it. Some college students who have taken historiography and research-methods courses usually fall into this category. The third level is "the criterialist" (Maggioni et al., 2009; VanSledright, 2014) or critical pragmatism (VanSledright, 2011). This level is for those in the expert category. They believe that history is a critical inquiry into the past by comparing sources and understanding the author's perspective. By using ruleguided criteria, reasonable interpretations of the past can be constructed even when confronted with conflicting sources. This level is normally occupied by some history graduate students and most historians. 


\subsubsection{Teaching historical thinking in the global context}

As the literature review in section 2.1.1 above shows that there are various historical thinking concepts put forward by experts, this section focuses on reviewing the literature on ways to teach these concepts that have been practiced in various countries outside Indonesia. In fact, for many years teaching historical thinking has been an important educational goal in many countries. Therefore, considerable studies have examined the ways that can be used to foster students' historical thinking skills. From these various studies, an idea can be taken that there are many different methods that can be applied to teach students to think historically. In addition, there we can also learn that there are different instruments that can be used to measure students' historical thinking skills and abilities.

The most effective means to teach students' historical thinking skills is by utilising historical evidence or primary sources. Analysis of sources for gathering evidence is the centre of historical inquiry, so historians need evidence to make claims and to construct historical narratives (Hover, Hicks, \& Dack, 2016). Thus, teaching historical thinking skills means teachers must teach their students the skills to read and analyse historical sources. Pioneering research on this subject is Wineburg (1991a, 1991b) who examines students' responses when asked to read historical documents and compared with the ability of historians to read the same documents. Wineburg (1991a, 1991b) also identifies three strategies that historians use when reading and evaluating historical texts, namely sourcing, contextualisation, and corroboration. These three strategies can be used by teachers to teach their students' historical thinking skills. In those studies, the methods used to measure students' ability to think historically are think-aloud protocols (Wineburg, 1991a, 1991b). This method is efficient to use in research, but unfortunately, it is not practical if it is used by teachers for teaching history because it has to measure students' responses immediately after reading documents through thinking aloud, whereas historical thinking requires deep thinking which takes a long time.

A more recent and more applicable study in using historical sources in real classroom situations is the work of Wineburg's student, Reisman (2012b, 2012a). By using "the reading like a historian" curriculum and the structure of "document- 
based lesson" activities, as well as through a long-term intervention process, Reisman (2012b, 2012a) discovered significant effects of these treatments on students' historical thinking. The replication of this study in the Philippines also shows the same results, that "the reading like a historian" method with multiple sources has succeeded in developing students' historical thinking skills (CulminasColis, Reyes, \& Garcia, 2016). In measuring the ability to think historically, Reisman (2012b, 2012a) used multiple-choice tests and constructed responses. This method can indeed be applied practically by history teachers. However, the use of multiple-choice test still does not reflect the real ability in "doing history".

Teaching historical thinking can be implemented by focusing on the concept of historical significance. If taught correctly, this concept can teach students why certain events or people are considered important in history when compared with so many other events or people (Rose, 2004). The ability of students to use this concept is important for them to understand how historical discipline works, and it can develop students' historical thinking skills (Harcourt, Fountain, \& Sheehan, 2011). Harcourt, Fountain, \& Sheehan (2011) show that one of the methods that teacher can use to teach the concept of historical significance is by utilising heritages, memorials, and historic sites. As for understanding students' thought on historical significance, history teachers can utilise the methods used by Seixas (1997) in mapping out the students' framework of historical significance by using two types of questionnaires. One questionnaire is based on students' personal perspectives and another to find out what is considered most significant by students from the list of historical events studied at school.

The concept of historical thinking which is most difficult to teach is historical empathy. It is possible for students to imagine how that person lived in the past (Davison, 2017), but this is not easy because they live in such different times (Rantala, Manninen, \& Berg, 2016). Some researchers have identified several methods that can be used by teachers to instil historical empathy, including through lectures, course work, discussions (Brooks, 2011), debates (Jensen, 2008), simulation exercises (Rantala et al., 2016), and writing tasks (Leur, Boxtel, \& Wilschut, 2017). While many methods can be used, various studies show that teaching historical empathy requires historical primary sources to bridge the present 
with the past (Brooks, 2011; Davison, 2017; Endacott, 2010; Endacott \& Brooks, 2018; Endacott \& Sturtz, 2015; S. J. Foster, 2001; Jensen, 2008; Leur et al., 2017; Rantala et al., 2016; Yilmaz, 2007). By using historical sources, students can learn how to understand 'historical contextualisation'-one aspect of historical empathy-besides 'affective connection' and 'perspective taking' (Endacott \& Sturtz, 2015; Leur et al., 2017).

The concept of historical perspective is also essential to be taught in order to foster students' historical thinking skills. This concept is also quite challenging to teach, especially to address the difficult features of the past in the post-colonial nations like New Zealand (Sheehan, 2016) or ex-colonial nations as Indonesia. If the case of New Zealand is still lacking space for indigenous perspectives (Sheehan, 2016), then the case of Indonesia is too dominated by the Indonesia-centric perspective which tends to see European colonisers as evil parties. Therefore, in teaching the concept of historical perspective, students must be given space for a variety of different perspectives so that they can give a critical response to the past (Sheehan, 2016; Sheehan \& Davison, 2017). The recommended method for teaching this concept is by giving students primary sources that contain multipleperspectives (Wansink, Akkerman, Zuiker, \& Wubbels, 2018; Waring \& Torrez, 2010). These primary sources can also be combined with various other secondary sources in different temporal layers (Wansink et al., 2018). The first layer is to use primary sources to represent the perspective of "the past"; the second layer is secondary sources in the form of historian account to represent "between the past and present" perspectives; and the third layer is the perspectives "in the present" from current politicians, journalists, and including the history teacher (Wansink et al., 2018).

The importance of being able to teach the concept of causation cannot be denied by history teachers because it is a core concept in history (Davies \& Marshall, 1991; Ong, 2018). This is because the study of history is essentially a study of causes (Carr, 2001). However, students often find it difficult and confusing in terms of historical causation (Davies \& Marshall, 1991; Ong, 2018; Walsh, 1963). History teachers can teach this concept by providing evidence in the form of primary and secondary sources to students (Davies \& Marshall, 1991; Henríquez \& 
Ruiz, 2014), then asking them to produce written historical explanation essays (Henríquez \& Ruiz, 2014; Ong, 2018) or asking them to make diagrams of causal relationships (Davies \& Marshall, 1991). In this way, students will come up with critical analytical skills that encourage the development of their historical thinking skills.

The concept of historical thinking that is no less difficult to teach is change and continuity. This is because there is uncertainty about what it means to think about historical change, so there is also a lot of uncertainty about what it means to think about continuity (R. Foster, 2013). However, there have been several studies conducted to teach this concept to students. Counsell (2011) has underlined the value of the "enquiry question" as a way to illuminate and direct the challenges of teaching change and continuity. The question will be more effective if students are provided with a set of historical sources and asked to rank the order of the historical development based on those sources (Blow, 2011). The teacher can also teach change and continuity using historical analogy lessons that revolve around one central question and involve students in careful document analyses (Jay \& Reisman, 2019).

From various efforts in teaching historical thinking skills that have been reviewed above, there are two things that can be highlighted. First, primary historical sources are very effective in stimulating students to think historically. All concepts of historical thinking can be stimulated by the existence of historical sources. Second, the most effective and comprehensive method to assess all concepts of historical thinking skills mastered by students is by using writing assignments. In this way students' historical thinking skills can be directly practiced through "doing history". Both of these things can be applied by following the assessment model offered by Bruce VanSledright $(2011,2014)$ in the form of an interpretive essay task. Essays that have been written by students can be assessed using five categories, namely (1) establishing/arguing a position, (2) citing evidence, (3) corroboration, (4) assessing account status, and (5) contextualisation (VanSledright, 2011, 2014). 


\subsubsection{Teaching historical thinking in the Indonesian context}

For many years, teaching history in Indonesia has only focused on teaching historical content that forces students to learn by memorisation. Only after the implementation of the competency-based curriculum in 2004 and especially since the enactment of the 2013 Curriculum, teaching history in Indonesia began to be directed to equip students with historical thinking skills. However, there are still not many studies that discuss the application of historical thinking skills in teaching history in Indonesia. This means that there are still many gaps that must be studied to catch up on the implementation of teaching historical thinking skills, which students need in this $21^{\text {st }}$ century.

There are still not many studies that examine the teaching of historical thinking skills in Indonesia. However, awareness has begun to emerge from history teachers who realise the importance of teaching historical thinking skills. Some of these teachers put their experiences in several articles containing their conceptual ideas. These ideas, for example, suggest the importance for history teachers to teach history with multi-perspectives and multi-interpretation approach to students (Alfian, 2017). This means that teachers are advised to teach the concept of historical perspective. Another idea is a suggestion to give students the opportunity to analyse historical texts and build their own argumentation independently (Alfian, Andarwati, \& Hidayah, 2017). This means that teachers are advised to teach history by using historical sources as evidence. Still related to the concept of primary sources, Alfian (2019) saw an opportunity to use Pararaton, an ancient book from the $16^{\text {th }}$ century, as a learning resource because its translated edition into Indonesian has been widely available on the internet. In addition, he also suggests teaching history by focusing on the aspects of change and continuity so that students could think historically (Alfian, 2018). Unfortunately, all studies mentioned above only contain conceptual ideas without any empirical data regarding its implementation in the classroom or its effect on students' historical thinking skills and abilities.

Several other studies have included empirical data in their research on teaching historical thinking. For example, there are two studies, using classroom action research methods, which aim to improve students' historical thinking skills and abilities (Purnaman, 2015; Tricahyono, 2017). These two studies departed from 
the same research problem where history teachers tend to use historical learning resources that only rely on textbooks and learning by memorisation. Both studies also offer similar alternative solutions to overcome these problems through secondary sources, outside of the textbooks, in order to improve students' historical thinking skills. In this effort, Purnaman (2015) uses biographies of a local figure written by historians, while Tricahyono (2017) uses the resource-based learning model by utilising the collection of books in the school library. Both studies claim to have succeeded in improving students' historical thinking skills and abilities through classroom action research that was conducted. Unfortunately, in the first study, the researcher does not provide a detailed explanation of the task given to the students as a tool to assess students' historical thinking skills (Purnaman, 2015). While for the latter study, the researcher uses conventional multiple-choice questions to assess students' historical thinking (Tricahyono, 2017), which is more appropriate to measure historical understanding than historical thinking. However, both studies have tried to teach historical thinking skills by focusing on the concept of evidence, in this case in the form of secondary sources.

There is one other study that has tried to teach historical thinking in Indonesia through the concept of evidence, in this case utilising historical primary sources. The research, conducted by Daryanti, Hasan, \& Nuraedah (2017), departed from the potential of many historical sites in the form of megalithic relics around Sigi Regency, in Central Sulawesi. Their study examines the effect of the utilisation of prehistoric sites and students' historical thinking abilities toward their learning outcomes on the subject matter of the history of Indonesia; and the results of their research show that there is an interactive effect between the three variables (Daryanti et al., 2017). Unfortunately, the results of their research could not automatically be used by other history teachers in Indonesia, because it requires a field trip to the prehistoric sites in Central Sulawesi. Nonetheless, Indonesian history teachers can imitate it by utilising other historical sites closest to their schools.

The importance of utilising primary sources has also been realised by Utami (2019), which she uses to teach her students' historical thinking skills, specifically to foster historical empathy. She asked her college students, prospective history 
teachers, to look for primary and secondary sources and then made them to write abstractions of their conceptual understanding of the context of Indies society's life in the Dutch East Indies era (Utami, 2019). The results of her research show that in teaching historical empathy students must be able to think reflectively when dealing with sources, both primary and secondary sources. Unfortunately, there are still no similar studies applied to secondary school students.

Thus, it is apparent that there are still many things that can be done to teach historical thinking skills in Indonesia. History teachers and historical education researchers in Indonesia already understand the importance of teaching these skills. They have also realised the importance of historical sources in stimulating students' historical thinking skills. However, it is not easy in Indonesia to access primary sources that can be used as learning resources in the classroom.

\subsection{Historical sources as learning resources}

In the previous section, some of the literature that has been reviewed shows the importance of historical sources for stimulating historical thinking skills, then this section will review some of the literature that has discussed how these historical sources are used as learning resources for students. In this regard, there is a famous phrase saying "no documents, no history" although it is not yet clear who first stated it (Couttenier, 2010; McCullagh, 2017; Voss-Hubbard, 1995). On one hand, this statement is true, because history can be reconstructed using documents from the past. On the other, it is also not quite right, because history can also be reconstructed with various forms of other sources, such as relics, inscriptions, witness testimonies, and others. Whatever it is, historians need historical sources to reconstruct the past. Meanwhile, history teachers need historical sources to teach history to their students, especially in the form of written documentary sources because they are easy to bring to the classroom and can be digitised.

Various history education studies have offered many positive reasons for using historical sources to teach history in the classroom, specifically in fostering students' historical thinking skills (Ashby, 2011; Barton, 1997; Cercadillo, 2006; P. Lee \& Shemilt, 2003; Malkmus, 2010; Pierce, 2008; Reisman, 2012b, 2012a; VanSledright, 2002b; VanSledright \& Afflerbach, 2005; Wineburg, 1991a, 1991b; 
Wineburg \& Martin, 2009; Wineburg et al., 2011). Working with various documentary sources from the past, whatever the form, primary or secondary sources, archives, documents, newspapers, political cartoon, private letter, speech, government memo, etc., would encourage students to critically analyse and contextualise these sources (Staysniak \& Staysniak, 2016). The ability of students to think critically is the conditio sine qua non of the ability to think historically.

As mentioned in the previous section, one of the most central approaches of historical thinking is analysis of primary source evidence. The existence of this concept in teaching history can stimulate other historical thinking concepts to emerge. Historical sources, especially primary sources in this case, can increase and renew students' interest in history because they provide fascinating stories and raise many questions about what happened and why, thus making history relevant and useful to students (Barton \& Levstik, 2008; Veccia, 2004). Primary sources encourage students to be actively involved in constructing their own knowledge and understanding (Kitson, Husbands, \& Stewards, 2011; Malkmus, 2010). In addition, by conducting historical research, primary sources could sharpen students' critical thinking, hone their research skills, and help them think like historians (Sheehan \& Howson, 2012; Veccia, 2004).

However, using historical sources to make learning history come alive for students is great in principle, but complicated in its implementation (Wineburg \& Martin, 2009). If history teachers only provide students with a set of primary sources without an appropriate lesson plan, this can create continuing problems and a dilemma for them (McAleavy, 1998; Reisman \& Wineburg, 2012). This is because students do not approach primary sources in the same manner as historians do (Britt \& Aglinskas, 2002). Teachers must think reflectively about the best use of these materials in order to engage students in exercises that are both historically and educationally sound, so as not to be trapped in the myths of using primary sources in the classroom (Barton, 2005).

Some research results show the effect of utilising historical sources as learning resources for students in real learning situations in their classrooms. Stahl et al. (1996) took the important step by implementing the historian's heuristic strategy_-sourcing, contextualising, corroborating — that Wineburg (1991a, 1991b) 
has claimed could be used by students to read historical sources. They gave eleven historical texts, deliberately chosen to represent a blend of primary to tertiary sources, to 44 participants in two classes of $10^{\text {th }}$-grade students (Stahl et al., 1996). The results of their research show that only a small proportion of the students used three heuristic strategies, but most of them did not (Stahl et al., 1996). For most of the students, simply presenting them with multiple historical texts did not encourage them to think like historians because they only read the first text to get basic facts and information and read the subsequent contradictory texts trying to sort out the information they have obtained (Stahl et al., 1996).

Therefore, certain instructional techniques are needed in order to prompt students to reason historically. Two experimental studies were conducted to try out certain instructional techniques for college students (Rouet, Britt, Mason, \& Perfetti, 1996; Wiley \& Voss, 1999). Rouet, Britt, Mason \& Perfetti (1996) asked groups of college students to use multiple sources of evidence to make reasons about history, written in a short opinion essay. The results of their study show that participants were aware of the characteristics of different types of documents (primary and secondary sources) and were able to make reasoned judgements using available documents and understood the importance of citing primary sources as the most effective way to support arguments (Rouet et al., 1996). Meanwhile, Wiley \& Voss's (1999) research provides multiple sources on a website as a basis for writing arguments. They found that argument writing tasks produced qualitatively different and better essays than narrative essay tasks because it could encourage students to construct arguments from multiple-source texts rather than from textbook-like passages (Wiley \& Voss, 1999).

Utilising historical sources for secondary school students also requires appropriate instructional techniques. Paz's (2005) study also uses the argumentative writing assignments when intervening $708^{\text {th }}$-grade students with four sets of primary and secondary documents. After receiving the intervention process with historical reasoning instruction for 12 days and writing instruction for 10 days, the experimental group students demonstrated more accurate and more persuasive mastery in historical writing. Nokes, Dole, \& Hacker (2007) did a research on 246 students aged 16-17 during the three-weeks intervention, finding that experimental 
groups who received treatment in the form of multiple texts and heuristic instructions, scored higher on history content, sourcing, and corroboration. Meanwhile, groups of students who received treatment in the form of traditional textbooks and content instructions, or those who received traditional textbooks and heuristic instruction, and those who received multiple texts and content instruction, achieved lower scores. The above findings are strengthened by the results of Reisman's (2012a) research which has intervened in $23611^{\text {th }}$-grade students using "The Reading Like a Historian" curriculum for 6 months. The results of her research show that students in treatment classes outperformed counterparts on two measures of historical thinking related to sourcing and close reading (Reisman, 2012a).

From the various literature reviewed above, several conclusions can be drawn. First, historical sources have proven to be very effective in influencing students' historical thinking skills and abilities. Second, appropriate instructional strategies and techniques are needed if historical sources are to have a positive impact on students as their learning resources. For this reason, it is necessary to consider the way of setting up historical sources so that they are easy to use by the students and history teachers, as well as learning models that can be used by utilising the historical sources.

\subsection{Web-based historical sources as learning resources}

After realising the potential of historical sources as learning resources, the next point is to examine the way to offer these historical sources so that they can be easily used as learning resources for students. History teachers may provide students with photocopies of primary sources about certain events. However, this means is ineffective and inefficient because it is economically costly and impractical for teachers.

The most practical and efficient way to bring historical sources to the classroom is in the form of digitised primary sources. Moreover, several studies have shown its benefits in teaching and learning history, specifically in fostering students' historical thinking skills (Fránquiz \& Salinas, 2011; J. K. Lee, 2002; Salinas et al., 2011; Tally \& Goldenberg, 2005). Despite having identical content, the use of digitised historical sources as learning resources certainly has advantages 
over non-digital historical sources. Lee (2002) identified there are seven advantages of the digitised sources. First, digitised historical sources are easier to access, especially if they are uploaded on the internet. Second, digitised primary sources encourage increased archival activities, because non-digital archives, which are usually available in the archive offices, only store official state documents related to major historical events. Third, digital resources have the possibility to build social networks among students, teachers, and historians. Fourth, digital historical resources are easy to "manipulate" so they can be used for learning purposes. Fifth, digitised historical sources make it easy for students to find the required learning resources. Sixth, digital historical sources are more flexible because they provide students with a means to explore alternative representations. Seventh, digitised historical sources are easy to organise, making it easier for students to understand and use them. Therefore, in addition to making history come alive, the use of digitised primary sources also encourages students to have a deeper historical understanding and develop critical thinking skills (Federspiel, 2004).

The most powerful way to deliver digitised primary sources to the students is to upload them to the internet, specifically on a purpose-built website. With a website, digitised primary sources can not only be used by students in a classroom or in one school only, but also all teachers and students in other schools and all interested parties can access these sources from any internet-connected devices at any time and from anywhere (Cohen, 2004). The website can also easily be accessed via students' smartphones. The use of web-based historical sources as learning resources is an inevitable necessity, especially nowadays, as school-age children are those who are categorised as "Gen Z" which are "digital natives" because they grow up with digital technologies (Ahn \& Jung, 2016; Gentina, Tang, \& Dancoine, 2018; McGrew, Ortega, Breakstone, \& Wineburg, 2017; Noonan, 2013; Wohl \& Braiker, 2018). They certainly will be able to learn better if they use digital technology, including in studying history. However, I realised that these terms have the potential to cause polemic, but they are useful for identifying students' preferences or learning styles in the present time.

There have been many studies describing the benefits of using digital historical sources from various websites that are intended for public use 
(Breakstone \& Smith, 2013; Bruton, 2003; Dexter, 1996; Hussey, 2011; Ridgway, 2009; Singleton \& Giese, 1999). Examples of public websites that have often been used for teaching and learning purposes are the Library of Congress (https://www.loc.gov/) and the National Archives (https://www.archives.gov/) in the United States. The collection of the National Archives of the Republic of Indonesia also has the potential to be used for learning purposes. However, there are language barriers and limited access because the collection of these digitised archives that have been published online are still limited to the Verenidge OostIndische Compagnie (VOC) archives from the 17-18 th century (https://sejarahnusantara.anri.go.id/). These types of websites require considerable effort of the part of teachers because they are not specifically developed for the purpose of learning history but also for the benefit of historians and other users. Teachers must closely evaluate the digital historical resources before using them to fit the teaching objectives and curriculum demands (J. K. Lee, 2002).

The task for the teachers will be much easier if there are websites that contain digital historical sources that are intended specifically for the benefits of teaching and learning. In this regard, several websites have been developed in many countries to facilitate history learning. Unfortunately, there is still no website - until the course of my research-specifically developed for the benefits of teaching Indonesian history. Websites specifically developed for teaching history will not only facilitate teachers to teach but also greatly facilitate students in learning history and develop their skills in historical thinking.

The first example is a website that has been developed as a result of a collaboration project between Center for History and New Media, George Mason University and School of Education, Stanford University, which can be accessed at http://historicalthinkingmatters.org/ (Martin \& Wineburg, 2008; Martin et al., 2008). This website has four learning topics that are very useful for teaching American history. Both teachers and students will have no difficulty using this website because the developers have provided instructions on using the website. The available historical sources will also be easily digested by students because they have been modified, so the website only displays the excerpts needed. Although it makes it easier for students to understand the contents of historical 
sources, modified historical sources are also the main weakness of this website, because it causes students not to feel the real sensation of history since the students do not directly see the real documents.

The second example of a website which was also deliberately developed for the benefit of teaching history is https://sheg.stanford.edu/. This website has been developed since 2002 by Wineburg et al. in the Stanford History Education Group at Stanford University. There are several menus that can be accessed, for instance, Reading Like a Historian contains history lessons; and Beyond the Bubble contains history assessment. On this website, there are hundreds of learning topics that already contain the learning materials, the modified historical documents, as well as the lesson plans. Teachers and students from all over the world can take an advantage of this website just by registering online. But unfortunately, this website cannot be used to teach material related to Indonesian history because this topic is still not available.

In Canada, the Historical Thinking Project which was directed by Peter Seixas has developed a website http://historicalthinking.ca/. The advantage of this website is that it provides lesson materials that can be sorted based on the big six historical thinking concepts (Seixas \& Morton, 2013), grade level, and time periods. In Canada, there is also http://www.virtualhistorian.ca/ developed by Lévesque and his team, which is a web-based educational program for teaching and learning Canadian history. Apart from the four websites mentioned above, there are also several other websites that were specifically developed for the benefits of history education. However, history teachers in Indonesia cannot use these websites to teach Indonesian history because there is no material related to the history of Indonesia.

\subsection{Analysing documents to improve students' historical thinking skills}

Primary sources are indeed important for teaching history, and making digitised primary sources available on the internet also makes it easier for teachers and students to access them. However, it must be considered that access does not guarantee success (Reisman \& Wineburg, 2012), especially in the case of Indonesia where teachers and students are not accustomed to using primary sources in history 
teaching and learning. Appropriate teaching and learning strategies are needed so that the digitised primary sources used in the learning process can foster students' historical thinking skills.

To teach students' historical thinking skills, history teachers can train their students to analyse documents from the past. According to Kartodirdjo (2011), historical documents have narrow and broad definitions at the same time. In the narrow sense, the document is a collection of verbal data in written form. In the broad sense, the document is all primary sources' manifestation, such as monuments, artefact, relics, photograph, painting, and many others. Therefore, what I mean by document is all forms of primary sources, especially those in written form. Primary sources are historical fragments, incomplete in themselves, but when assembled and analysed can provide personal insights and deep historical understandings (Cowgill \& Waring, 2017; Veccia, 2004). Students who are familiar and trained to analyse historical documents will not only have deeper historical understandings but also be more skilled in historical thinking.

There are two things that teachers must consider before training their students to analyse documents. First, the documents that will be given to them must be deliberately chosen, with an emphasis on those which can offer conflicting interpretations (Reisman, 2012b). The provision of conflicting documents will provide multiple perspectives as the cornerstone and prerequisite for historical thinking (Wineburg, 1998). Students will have the opportunity to understand distortions in historical texts, such as personal biases, tendency to exaggerate reality, ideology, partisanship, and the like (VanSledright, 2004). Therefore, teachers should choose and carefully sort the documents that will be analysed by students. Teachers can also use websites that have been specifically designed for learning purposes and have provided documents specifically prepared for this purpose.

The second thing that must be considered by the teachers before training their students to analyse documents is the teaching strategy that will be used. Merely giving documents to students who do not yet understand how to analyse them and integrate information obtained into a larger context will not provide educational benefits. Documents analysis is at the heart of giving primary sources to students 
(Veccia, 2004). For this reason, teachers must determine in advance what methods will be taught to their students in analysing documents.

Petri (2004) has offered a three-step document analysis through "observethink-ask" stage. The first step is to ask students to carefully read and observe the documents provided. The second step is to ask students to think about what they have read or seen. Students can connect the information they obtained with the knowledge they already have. The third step is to ask students what additional information students they need to know, specifically to help them understand what they have read or seen. These three steps basically invite students to read the documents in a guided manner under the supervision of the teacher. If students face difficulties, they can ask their teacher so they can understand the contents of the documents correctly. The key to this method is the question, which requires students to be actively involved in the learning process and form questions that guide further investigation.

Another method that can be used by teachers in teaching students to analyse documents is drawing on the views from Bruce VanSledright (2004) in seeing historians assess sources. Analysing documents involves a complex process in assessing the nature and the status of historical sources that contain various perspectives. Historians use at least four interrelated and interconnected cognitive actions in analysing documents, namely identification, attribution, perspective judgement and reliability assessment (VanSledright, 2004; VanSledright \& Afflerbach, 2005). First, identification implicates knowing what a source is. This stage involves a series of questions, such as "what type of source is this? What is its appearance? When was it created? Can it be classified as a primary source or not?". Second, attribution involves recognising that a source is an account constructed by the human for certain purposes. It also requires locating the authors within their historical context because it is important to construct historical interpretations. Third, judging perspective involves careful reading of the sources followed by a series of assessment of the author's social, cultural, and political position. Fourth, reliability assessment involves corroboration between related sources for their relative value as evidence in making claims about what has happened in the past (VanSledright, 2004; VanSledright \& Afflerbach, 2005). 
History teachers can also teach students the skills to analyse documents using the ways of reading historical sources introduced by Wineburg (1991b, 1991a, 2001). This method is called Reading Like a Historian where students are taught how to evaluate sources by asking questions about the author and the context, and by raising questions about other supporting evidence. As previously mentioned, this method consists of three heuristic aspects namely sourcing, contextualization and corroboration. First, sourcing is the act of looking first to the source of the document before reading the body of the text to consider the document's source and purpose (Wineburg, 1991a). This heuristic aspect of this basically has similarities with the "identification" method presented by VanSledright (2004). Second, contextualisation is the act of situating document in a concrete temporal and spatial context (Wineburg, 1991a). This heuristic aspect of this basically has a resemblance with the "attribution" and "judging perspective" proposed by VanSledright (2004). Third, corroboration is the act of comparing documents with one another (Wineburg, 1991a). This heuristic aspect of this has the same goal with "reliability assessment" in VanSledright's (2004) view. These three types of heuristics can be taught to students as sense-making activities to help them resolve contradictions, see patterns, and make a distinction among different types of evidence (Wineburg, 1991a).

Based on the three methods mentioned above, they can all be used to teach students the skills in analysing documents. Teachers only need to determine which ones are easier and more effective to use. The essence of these three methods, in fact, is to teach students not to immediately trust the contents of the documents being read, but rather to always criticise the contents of the documents. To help students focus on analysing documents, teachers can pose a central question that guides students in reading the sources (Reisman \& Wineburg, 2012). Students also need to be given the opportunity to practice multiple times to increase their ability to analyse documents. The ability to analyse documents is needed in teaching students to have critical thinking skills in learning history. These critical thinking skills will be the foundation in their historical thinking skills. 


\subsection{Interpreting textbooks to improve students' historical thinking skills}

In the previous section, I reviewed that the use of primary sources is needed and essential at improving students' historical thinking skills. However, if students only receive a single source — even though it is a primary source-for gaining reliable knowledge (Barton, 2005), it will not be able to foster their historical thinking skills. Basically, this is because primary sources are not automatically more trustworthy than secondary sources (Barton, 2005). Therefore, what is needed is a set of multiple and conflicting sources, both primary and secondary.

As one type of secondary source, history textbooks are still needed and cannot be thrown out of the classroom as suggested by Robertson et al. (2017), especially in the case of Indonesia which officially places textbooks as the main source of learning. This is stated in the Regulation of the Ministry of Education and Culture of the Republic of Indonesia number 8 of 2016 in article 1 paragraph 1, which states that "textbooks are the main source of learning to achieve Basic Competency and Core Competency, and are declared appropriate by the Ministry of Education and Culture for use in education units" (Ministry of Education and Culture, 2016e, p. 2). For this reason, in order to teach Indonesian students' historical thinking skills, the teachers must continue using the official textbooks and then move to introducing the intended primary sources, considering the tendency of official history textbooks in Indonesia which is not to attach or include primary sources in their contents.

Ideally, secondary school history textbooks must present different historical perspectives, causing students not to think that the past can only be seen in one version only. Foster, Morris, \& Davis (1996) consider that history textbooks that could develop students' abilities in historical analysis and interpretation must have four criteria. First, different kind of interpretations must be included in the textbook. Second, the textbook must have features that contain some primary sources, such as documents and eyewitness accounts. Third, the textbook must present pictorial and graphic sources, including photographs, maps, charts, and diagrams. Fourth, every form of questions, exercises, and activities available in the textbook should encourage students' interpretive thinking. Unfortunately, these criteria are not yet 
contained in the official history textbooks for secondary school students in Indonesia. History textbooks in Indonesia still have a tendency to not contain multiperspectives primary sources (Alfian, 2017), have not been able to encourage students to think critically that allow students to have different interpretations (Anas, 2010; Farawita, 2018), and tend to inculcate ideological views (Darmawan, Sjamsuddin, \& Mulyana, 2018; Farawita, 2018). For that reason, there is no other way in Indonesia other than by providing additional learning resources in the form of primary sources, while still using textbooks as the main learning resources.

Although textbooks must still be used in history learning, students who have interacted intensively with primary sources will realise the interpretive nature of history and the existence of multiple perspectives in viewing the past. By combining these two types of learning resources, history teaching should focus on the process of historical interpretation. Students should be able to understand how history is developed, how historical investigation takes place, how to analyse and interpret sources, how the relationship between evidence and the construction of historical accounts is - both as their own construction and those of others (Barton \& Levstik, 2003; Martell, 2013). When students already have the skills in analysing documents, they should be more critical in reading their textbooks. This is because students have come to an understanding that their textbooks are the results of a construction of the authors who interpret the past based on the sources they have. The relationship between students as readers and their textbooks will not only be one-way (Wineburg \& Reisman, 2015), so that students also have the right to give interpretations towards their textbooks by corroborating with historical documents that they have analysed.

Interpreting historical interpretations requires students to engage in a critical thinking about the various ways in which historians interpret the past and students' historical knowledge is developed through this interpreting process (Chapman, 2011; Harada, 2012). Chapman (2011) identifies four benefits students will get if they understand the nature of historical interpretation. Firstly, students will understand that the past has been interpreted in different ways. Then, students will understand how the past has been interpreted in different ways. Furthermore, students will be able to explain why the past has been interpreted in different ways. 
Finally, students will be able to evaluate different interpretations of the past. Meanwhile, the two main objectives of studying history as an interpretation are to develop an understanding that history consists of various competing perspectives, and that history is constantly constructed and debated by people (Martell, 2013).

In teaching the skills to interpret textbooks interpretations, the teacher can ask their students to always evaluate several aspects when reading historical interpretations in their textbooks (Chapman, 2011). First, students must ask whether the interpretations in the textbooks accurately refer to the archives or primary sources used. Second, students must ask how comprehensive the interpretations are in the textbooks in explaining relevant archival traces. Third, students must ask how consistent the interpretations produced are within the contents of the textbooks themselves and with other different claims outside of the textbooks. Fourth, students must also ask how an interpretation can give rise to new possibilities, which raises new questions. In essence, textbooks must be criticised by students and compared with other primary sources that they themselves have analysed (Nokes, 2010).

Harada (2012) gives some instruction on how to teach students the skills in "interpreting interpretations". First, history teachers must give a broad autonomy to their students in making their own interpretations. This is because students' historical interpretation will be disturbed if the teachers provide their own explanations. Teachers should explain that their opinion is only one of the versions from many other historical interpretations. It would be better if the teachers also offer a variety of other interpretations, though they do need to also provide evidence for each interpretation. The second thing that teachers must do is to provide materials, specifically primary sources, to help students think autonomously. Teachers should let their students make their own interpretations based on the materials that have been provided. By using these materials, students must construct arguments to support their interpretations. Finally, teachers must provide opportunities for their students to share their interpretations with each other in class. This can foster a lively debate in the classroom. This debate is very prominent because students will realise that there are various interpretations of history and learn to respect each other's differences in interpretations. 
Therefore, it can be concluded that teaching students to interpret existing interpretations in their textbooks can only be done if students have had the opportunity to analyse documents or primary sources. From there, students will gain an understanding of different perspectives to interpret the past. Thus, students will be able to build their own interpretations by constructing arguments based on the sources they have analysed. The results of their interpretation can be even more useful if shared through classroom discussions.

\subsection{Conceptual framework: Analysing documents and interpreting textbooks as an alternative learning model to foster students' historical thinking skills}

From the various literature reviewed above, I identified several aspects that must be considered in an attempt to foster Indonesian students' historical thinking skills. Those aspects became the conceptual framework and scaffolding in this study. First, teaching historical thinking skills is a necessity because learning history is not sufficient just by gaining historical knowledge. Students must also have skills in historical thinking. Second, in order to develop these aforementioned historical thinking skills, aspects of students' epistemic beliefs must be monitored at the beginning and throughout the learning process because both are interrelated and influence each other. Third, primary sources (evidence) are one of the most important historical thinking approaches in improving students' historical thinking skills because they can stimulate other historical thinking concepts. Fourth, historical sources must be easily accessible by both teachers and students as learning resources; one way this can be done is by digitising primary sources and uploading them in a learning website. Fifth, specific learning models are needed so that the learning resources available on a given website can foster students' historical thinking skills. Sixth, an alternative learning model that can be used is by analysing documents and interpreting textbooks.

From the various concepts that have been described in this chapter, I would like to offer a logical structure of concepts that are interconnected and related to each other in a conceptual framework. This conceptual framework provides visual 
displays of how the ideas in this study are interrelated (Grant \& Osanloo, 2014). The following figure is a visualisation of the conceptual framework in this study:

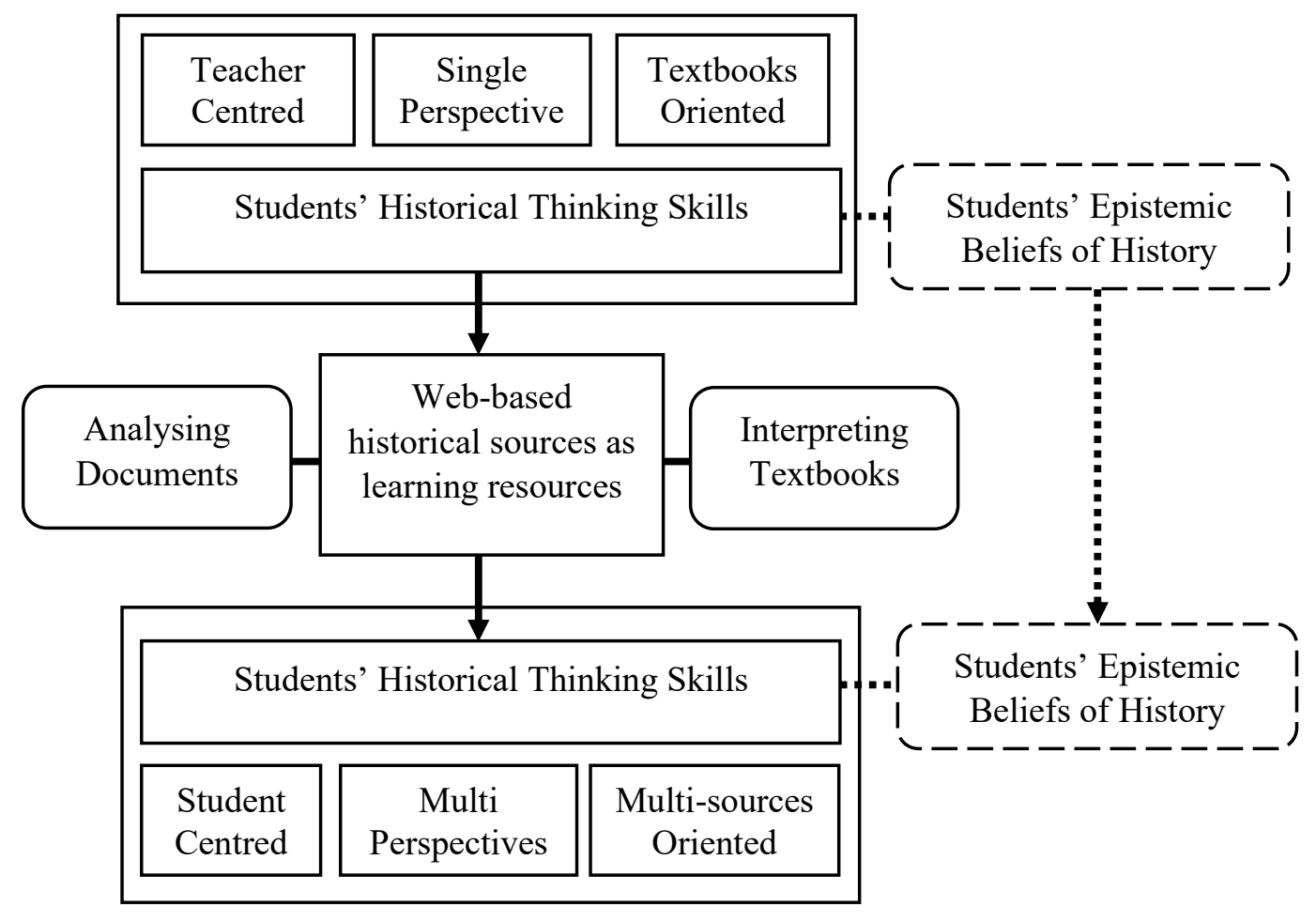

Figure 2.1: The conceptual framework of this study

Based on the conceptual framework above, it can be identified that the historical thinking skills of students in Indonesia have been low. The contextual background of this study shows that history teachers tend to teach using the lecture method so that the learning process is still teacher-centred, and students tend to passively accept the teachers' explanation. Meanwhile, the main learning resource used is history textbooks, which tend to offer a single perspective. Based on the literature review, it is known that to develop students' historical thinking skills, various learning resources are needed and must contain multiple perspectives to stimulate students to think critically. For that reason, students need to be allowed to think independently so that the learning process must be student-centred. Even more, the 2013 Curriculum encourages teachers to use a student-centred learning approach (Ministry of Education and Culture, 2016b). In addition, students' epistemic beliefs in this study should also be examined whether they change when students' historical thinking skills are fostered. 
To foster students' historical thinking skills in this study, I use a learning model "Analysing Documents and Interpreting Textbooks". This learning model can be abbreviated as ADIT learning model (Widiadi, 2009, 2013). The basis for my argument in using this learning model as an alternative way to foster students' historical thinking skills refers to the results of the literature review in this chapter. First, since the use of primary sources has proven to be very important in developing historical thinking skills, students in Indonesia need to be given the opportunity to analyse historical documents as their learning resources. Second, since in Indonesia, the official textbook must be used as a learning resource, students still must use their history textbook but in a critical way, namely by interpreting the historians' interpretations in the textbooks. Based on these two arguments, this study tried to test the effectiveness of this learning model in fostering students' historical thinking skills in Indonesia. This model was tested specifically for learning history and not for other subjects. The results of the effectiveness of this learning model can enrich alternative learning models that can be used to develop historical thinking skills in Indonesia.

The ADIT learning model is heavily influenced by many experts in the field of historical thinking (Reisman, 2012a, 2012b; VanSledright, 2011, 2014; Wineburg, 1991a, 1991b, 2001). However, since their research are based on the conditions outside Indonesia, then in this study, I have had to make several adjustments to match the local conditions. All subjects in Indonesia, including history, are strongly advised to use a 'scientific approach' in their learning process (Ministry of Education and Culture, 2016b). This approach is a five-stages of learning process known by Indonesian teachers as ' $5 \mathrm{M}$ ' namely mengamati (observing: student read/observe specific information), menanya (questioning: students ask questions from what is observed/read), mengumpulkan data/mencoba (collecting data or experimenting: students explore or collect information), menalar (associating: students analyse the information available from exploring activities), and mengkomunikasikan (communicating: students communicate the results of analysis they made) (Hasan, 2013; Ministry of Education and Culture, 2016b). Therefore, the application of the ADIT learning model in this study must adjust the 
learning stages regulated by the Ministry of Education and Culture of the Republic of Indonesia (see Figure 2.2).

In addition, as the results of the literature review, it turns out that there are various ways to assess students' historical thinking skills. However, this thesis believes that the most effective way is through interpretive essay writing assignments. This is because these writing assignments (VanSledright, 2014; Voss \& Wiley, 1997; Wiley \& Voss, 1996) are far more comprehensive in assessing historical thinking skills when compared to other measuring tools such as multiplechoice questions (Reisman, 2012a), think-aloud protocols (Wineburg, 1991a), etc. To focus students' attention in analysing documents and interpreting textbooks in order to produce meaningful essays, the teacher have to give a central historical question (Reisman \& Wineburg, 2012). Thus, the interpretation in the essays written by students should be aimed at answering the central question. Moreover, students are also asked to share the results of their interpretation and proceed with classroom discussions. Through that process, students would be able to understand the different interpretations written by other friends along with the basis of their respective arguments. Therefore, as will be discussed later in the fourth chapter, this study uses writing an interpretive essay task to assess students' historical thinking skills.

Based on the conceptual framework of this study that has been described earlier, the following figure is the design of the ADIT learning model used to develop students' historical thinking skills: 


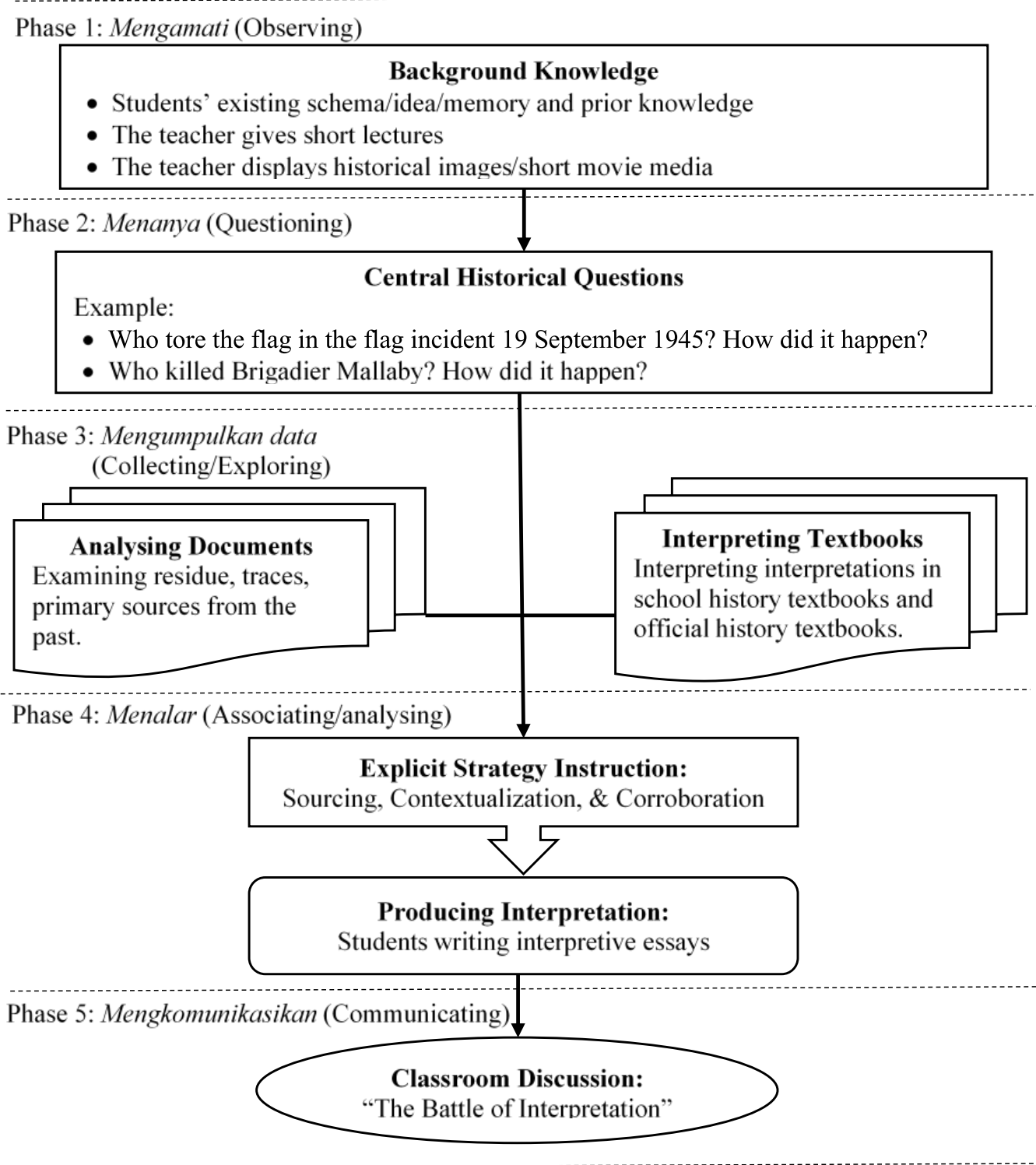

\section{Figure 2.2: Design of the ADIT learning model based on the conceptual framework of this study}

Figure 2.2 above shows the position of the ADIT learning model which adjust to the learning stages of the 'scientific approach' or ' $5 \mathrm{M}$ ' in Indonesia. Since the learning process must be student-centred, at the beginning of the learning activities the teacher only gives short lectures using pictures or video media related to the subject matter, in this case, the battle of Surabaya. After that, the learning process is focused on problem-solving activities guided by central historical questions. The core learning phase is in the form of student activities to find answers through 
analysing documents and interpreting textbooks. The results of students' historical thinking are written in interpretative essays. At the end of the learning phase, students discuss the results of their historical thoughts in a debate activity. 


\section{CHAPTER 3 THEORETICAL FRAMEWORK}

The literature review in previous chapter shows that there are several factors that must be considered in an attempt to foster students' historical thinking skills. In this chapter, I provide the theoretical framework as a strong platform to understand the effect of teaching history through analysing documents and interpreting textbooks on students' historical thinking skills. A theoretical framework in a study is like a "blueprint" (Grant \& Osanloo, 2014) that determines the importance of the study (Lederman \& Lederman, 2015) and guides researchers in formulating research problems (Anfara, 2008; Bloomberg \& Volpe, 2008; Imenda, 2014), designing how to investigate research problems (Anfara, 2008; Grant \& Osanloo, 2014; Imenda, 2014), and giving meaning to the data obtained (Anfara, 2008; Imenda, 2014).

No single theory can provide a perfect explanation of what is being studied (Anfara, 2008; Imenda, 2014), meaning that I needed several theories for exploring a range of phenomena. The application of multiple theories gives a variety of perspectives on the same issue (Grant \& Osanloo, 2014). For that reason, the theoretical framework in this study was not informed by a single theory but utilised a combination of four aligned theoretical perspectives that could be more useful in dealing with complex problems in this study. First, the theoretical perspective that has informed this study was largely framed by the perspective of critical pedagogy because the practice of history education in Indonesia is still dominated by the concept of teacher-centred education and relies on textbook hegemony. Second, I used cognitivism perspectives as lenses through which I can examine and analyse the data related to students' ways of thinking and practise in utilising primary sources in order to think historically. Third, I utilised the perspectives of threshold concepts to illuminate the difficulty students might face in thinking historically, since students could experience troublesome knowledge when presented with conflicting primary sources because previously, they were only accustomed to relying on single-perspective textbooks. Fourth, to frame students' activities in utilising web-based historical sources as learning resources, this study was 
informed by the perspectives of connectivism theory. In the following sections, I provide further details about how these theoretical perspectives provide a theoretical framework to examine students' historical thinking when learning history through analysing documents and interpreting textbooks.

\subsection{Critical pedagogy}

This study was largely framed by critical pedagogy theory because any efforts to foster students' historical thinking skills cannot be separated from aspects of students' critical thinking. The practice of critical thinking is crucial in the historical thinking process which involves high-level cognition (McLaughlin \& McGill, 2017; Philpot, 2017). Unfortunately, this high-level of cognition often does not appear in the learning process because the teaching of history education in Indonesia tends to offer historical content material in a single perspective that is set by the official dominant perspective of the state. Conversely, history should be open to various perspectives because history is multi-interpretive in nature (P. R. Carr, 2008; VanSledright, 2002a; Yogev, 2013). As a result, history education in Indonesia has not reached an optimal learning process because students only build less critical thinking in their daily learning activities. For this reason, I used critical pedagogy as one of the frameworks for formulating research problems, determining the way to investigate, and analysing my research data.

Critical pedagogy is a term used to describe "what emerges when critical theory encounters education" (Kincheloe \& Steinberg, 1997, p. 24). Critical pedagogy is applied using a student-centred educational approach that focuses on problem posing through critical dialogue (Larson, 2014). This approach is a response to systematic oppression and inequality in education (Ford, 2014). Critical pedagogy aims to encourage independent-minded students to question the status quo and engage explicitly with questions of truth (Farrow, 2017), in order to achieve social democracy (de Castro, 2016). Therefore, every application of critical pedagogy must appreciate various perspectives on how knowledge is produced and deployed (Kincheloe, 2008). This is certainly very suitable for history education that cannot escape from a variety of perspectives in interpreting the past. 
As a theoretical perspective, I use several critical pedagogy concepts from Paulo Freire. Undeniably, thoughts on contemporary critical pedagogy are strongly influenced by the ideas of Paulo Freire (Alexander, 2018; Malott, 2011; Rhem, 2013). Freire suggested that education is a praxis of liberation, those who are oppressed must be able to liberate themselves from the oppressors (Freire, 2005a, 2005b; Kaufmann, 2010). In the case of history education in Indonesia, it could be argued that students were oppressed to learn history in a single version. I would suggest that the praxis of education must be aimed at liberating students to have their right to develop their historical perspectives independently. One of the praxes of liberation that was attempted in this study is by teaching students' historical thinking skills.

Although Freire's thoughts about the praxis of liberation were developed based on conditions in Brazil, his ideas can also be applied in Indonesia. Moreover, Freire's educational thoughts have many similarities with Ki Hadjar Dewantara's thoughts (Syaikhudin, 2012). Dewantara is known as the founding father of national education in Indonesia (Towaf, 2016). One of the foundations of education offered by Dewantara is the principle of freedom in education (Dewantara, 1967, 1977). Dewantara (1977, p. 48) stated that "teaching is to educate children to become free human beings in their hearts, minds, and energy". Teachers must implement the "among" system with the educational motto "tut wuri handayani" (Dewantara, 1967, 1977). The system of "among" is a Javanese term of caregiving, where teachers' soul is full of devotion (Towaf, 2016). Meanwhile, "tut wuri handayani" means that the teachers have to grant freedom to their students to develop their talents (Solehan, 2010; Towaf, 2016; D. Wijayanti, 2018), and the teachers only act as advisers and "leaders behind the scenes" (Dewantara, 1967, p. 160). Unfortunately, the praxis of history education in Indonesia has largely ignored Dewantara's advice.

The praxis of liberation through education as stated by Freire (2005b) also has aligned with the goals of education envisaged by Biesta $(2009,2015,2016$ a, 2016b). In Biesta's view, education is a teleological practice; that is, the purpose of education has three dimensions, namely qualification, socialisation, and subjectification (Biesta, 2009, 2015). Freire's praxis of liberation has similarities 
with the educational purpose of subjectification. This is related to emancipation and freedom, and with the responsibility that comes with such freedom (Biesta, 2016b). Thus, students are taught to become more autonomous and independent in their thinking and acting (Biesta, 2009). In addition, in accordance with Freire (2005b) who rejects education as oppression, Biesta (2015) also rejects authoritarian forms of education.

From the many concepts of critical pedagogy offered by Freire, this study was largely framed by his two main concepts, namely problem-posing education and conscientisation. These two concepts are related to one another, in that the praxis of critical pedagogy can be done through problem-posing education which is based on dialogue that helps students to achieve conscientisation (Monchinski, 2008). Conscientisation is an essential ingredient in the development of meaningful education (Freire, 2000) and one of the fundamental concepts in critical pedagogy (Gil-Glazer, 2015). In my study, the concepts of problem-posing education and conscientisation were used to frame the research problems, to design the process of learning interventions, and to analyse research data.

"Problem-posing education" is an instrument for liberation as an alternative offered by Freire to counter the dominance of the "banking-concept of education" which is an instrument of oppression (Freire, 2005b). Freire (2005b, p. 72) explains that "in the banking concept of education, knowledge is a gift bestowed by those who consider themselves knowledgeable upon those whom they consider to know nothing". This problem is unfortunately reflected in the teaching of history in Indonesia, which is usually dominated by the teacher as the most knowledgeable subject, whose role is to regulate this knowledge so that it enters the students who are considered as mere objects. Some other characteristics of the banking concept of education includes denying dialogue, inhibiting creativity, domesticating the intentionality of consciousness, and failing to acknowledge humans as historical beings (Freire, 2005b). Such characteristics will certainly hinder students' historical thinking skills.

Problem-posing education aims at enabling humans to develop their powers critically to understand their existence in the world, and view the world not as a static reality, but as a reality in the process of transformation (Freire, 2005b). The 
learning process in problem-posing education emphasises the importance of dialogue as an indispensable act of cognition which unveils reality (Cruz, 2015; Freire, 2005b). Dialogue belongs to the nature of human beings - as beings of communication; and dialogue is needed in the educational process because dialogue is itself creative and re-creative (Shor \& Freire, 1987). This dialogic process needs to involve some respect between teacher and students, because the teacher must speak with the students and not speak to the students (Cruz, 2015; Freire, 2001). Dialogue is the primary means of giving expression to historical thinking in a classroom setting (Pattiz, 2004), because dialogue requires critical thinking and at the same time generates critical thinking (Freire, 2005b).

In this study, the concept of problem-posing education has provided a useful perspective in my research to design the learning intervention process in order to foster students' historical thinking skills. The learning process was designed to prioritise dialogue between teachers and students. The first thing to do to achieve this relationship was that the teachers must counteract their dominance to overturn the hegemonic culture in the classroom (Yusuf, Taylor, \& Damanhuri, 2017). This relationship was no longer that only teachers were teaching, and only students were taught, but both had to learn together (Freire, 2005a, 2005b). The fundamental role of the teachers in Freirean perspective is to enter a dialogue with their students by simply offering them instruments that can teach themselves to think independently (Freire, 2005a), to build epistemological curiosity (Freire, 2000, 2001), and to challenge them to think critically (Freire \& Macedo, 2005; Horton \& Freire, 1990). In my research, the instruments given to the students were various historical sources, both primary and secondary, which had to be processed to construct their own knowledge.

Through the process of dialogue, both teachers and students can construct knowledge together. To achieve this, teachers must invite their students to be curious, critical, and creative (Shor \& Freire, 1987). Curiosity is what makes students ask, know, act, ask again, and recognise (Freire, 2001). Lively questions are the focal point of successful teaching to stimulate students' critical thinking skills (Karaj, 2017). To awaken the critical nature of the students, teachers must emphasise that all texts are open to alternative interpretations and the teaching of 
interpretation becomes a central focus of critical pedagogy (Kincheloe, 2008). To awaken the creative nature of the students, teachers must give their students concrete action and experience because it is really impossible to teach how to think critically by just giving a speech about critical thinking/thought or by just giving students the opportunity to think (Horton \& Freire, 1990). During the learning intervention process in my research, students' curiosity was stimulated through the delivery of historical questions. This could be in the form of questions that doubt the truth of the textbook contents. Students' critical thinking was stimulated by providing historical sources that contained conflicting perspectives and must be analysed to reconstruct past events. Meanwhile, students' creative thinking was stimulated by giving them the task of writing interpretive essays, which they wrote after evaluating various historical sources, both primary and secondary sources. Through the process of analysing and evaluating historical sources to create interpretive essays, students could experience higher-order cognitive process (L. W. Anderson \& Krathwohl, 2001; Krathwohl, 2002), which is essential in historical thinking.

The second concept that I borrowed from Freire's critical pedagogy was the concept of conscientisation. This concept serves as a lens through which I could examine and analyse the research data related to the history learning process that seeks to foster students' historical thinking skills by posing historical problems that must be solved by analysing documents and interpreting textbooks. According to Freire (2005a, p. 15) conscientisation is "the development of the awakening of critical awareness." Conscientisation is not a panacea for overcoming all obstacles in human life but a critical educational effort to awaken the human position in social, political, cultural, material, ideological, and historical contexts (Freire, 2001, 2005b). Humans are beings who have consciousness, but the conscientisation process requires political reflection and concrete actions (Monchinski, 2008). In education, students' conscientisation can only be achieved through dialogue and critical thinking (Monchinski, 2008). In this process, students are not passive recipients, but are knowing subjects, who actively deepen awareness of the educational reality that shapes their lives and of their capacity to transform that reality (Freire, 1998). 
In the heart of Freire's critical pedagogy, education is the only means to facilitate students' conscientisation to achieve critical consciousness (Freire, 2005a). Freire (1998, 2005b, 2005a) mentions various types of consciousness, such as magical, fanatical, naïve, and critical consciousness. Many experts suggest that there are three to four levels of consciousness (Elias, 1974; Freebersyser, 2015; Monchinski, 2008; Wilson, 1998), whereas Freire (1998, 2005a) himself only emphasises three levels of consciousness. First, the lowest level of consciousness is "semi-intransitivity" which is characterised by humans who only think about fulfilling biological needs (Elias, 1974; Freire, 2005a; Wilson, 1998). They are unable to objectify the conditions of their existence in a critical way because of their near absence of historical consciousness and remain submerged in the historical process (Elias, 1974; Freire, 1998, 2005a; Monchinski, 2008). The second level of consciousness is "naïve transitivity" which is characterised by human consciousness that is still part of the dominant mass and their capacity for dialogue is still fragile (Freire, 1998, 2005a; Monchinski, 2008). The other characteristics of this level are over-simplification of problems, lack of interest in investigation, the fragility of arguments and strongly emotional style, and the practice of polemics rather than dialogue (Freire, 2005a). The third level of consciousness is "critically transitive" which is achieved through the process of conscientisation (Elias, 1974; Freire, 1998, 2005a). This level of consciousness is characterised by depth in the interpretation of the problem, by the soundness of argumentation, and by the practice of dialogue rather than polemics (Freire, 2005a). In my research, I used this conscientisation level to analyse students' consciousness level after going through the process of learning history by analysing documents and interpreting textbooks in order to foster students' historical thinking skills.

In summary, Freire's critical pedagogy theory, specifically the concepts of problem-posing education and conscientisation, provides a broad theoretical framework through which one can explore students' historical thinking skills, starting from being used to identifying research problems, in the form of students' historical thinking skills that have not yet developed due to the learning process that is still dominated by the teachers and textbooks. This theoretical framework was then used to design the process of learning intervention and at the same time was 
also used to analyse the research data that had been obtained. To strengthen this theoretical framework, I also utilised three other theories that I explain in the next three sections.

\subsection{Cognitivism}

Students' historical thinking skills are reliant upon thinking processes in the cognitive structure of each individual student. Thus, the appropriate theoretical perspective to study students' thinking processes is a cognitivism framework. Historically, cognitivism theory is not a new analytical tool in the field of education because it was developed in the second half of the 20 th century (Mayer, 2012; Paciotti, 2013). However, I consider this theory to be very valuable, relevant and useful in my research because I have to analyse how students process new information they obtain from primary sources, which sometimes differs from the old information they obtain from textbooks. This is more apparent for students who are previously accustomed to memorising information conveyed from the teacher or obtained from their textbooks, then experience changes in ways of learning which requires them to construct their own knowledge. The transition from a behaviouristic way of learning to something more focused on how students processed information prompted me to use cognitive theory as one of the theoretical frameworks in this study.

As the theoretical framework, this study has been informed by Piaget's theory of cognitivism, specifically from the concepts of assimilation and accommodation (Piaget, 1928, 1930, 1950, 1952, 1954, 1965, 1971a, 1971b, 2001; Piaget \& Inhelder, 1997). In Piaget's theory of cognitive development, it is claimed that each human subject actively explores his/her environment and actively creates internal structures, which enable him/her to learn about the world in an increasingly objective and differentiated way (Marchand, 2012). Therefore, thinking is an active form of action to learn about one's surrounding environment (Mascolo, 2015). The relationship between organisms and the environment is a fight between the forces of preservation of organisms (by assimilating the environment) and those of changing (by imitating) under the influence of the environment (Valsiner, 2005). 
Piaget argues that intelligence is an organising activity whose function goes beyond the biological organisation by elaborating new structures (de Ribaupierre, 2015). These novel structures are constantly elaborated in a succession of constructions which are called cognitive development (Boom, 2009). This constructive process is naturally possessed by humans as organisms. From birth, humans are active in the creation of their own knowledge (Beilin, 1992). The innate form of functioning to construct humans' knowledge involves general mechanisms of assimilation, accommodation, and equilibration (Barrouillet, 2015).

Assimilation and accommodation are human adaptation strategies in dealing with the environment in order to create an equilibrium (Piaget, 1952). According to Piaget (1950, pp. 6-7) "adaptation must be described as an equilibrium between the action of the organism on the environment and vice versa." Evolving equilibrium between assimilation and accommodation is a process that can lead to human's cognitive development (Montangero, 2015). Equilibration is the core element in the constructive process of human thought (Beilin, 1992). In the process equilibration involves the role of conflict and contradiction so that disequilibrium and reequilibration often occur when adapting to the environment (Stoltz, 2018). In order to create a state of equilibrium, humans can assimilate or accommodate while being involved in the adaptation process. Assimilation and accommodation are two sides of the same coin (Lourenço, 2016), even though opposed to one another (Piaget, 1954).

On one side, assimilation refers to the process by which objects to be known are incorporated into the existing schema (Mascolo, 2015). In its broadest sense, Piaget (1950, p. 7) describes that assimilation is "the action of organism on surrounding objects." Piaget (1954, p. 351) explains further that "assimilation is essentially the utilization of the external environment by the subject to nourish his hereditary or acquired schemata." In the assimilation process, it is the environment which is transformed by being made a part of the subject's schemata (Piaget \& Inhelder, 1997). Schema (plural: schemata or schemas) can be interpreted as patterns of behaviour (Piaget \& Inhelder, 1997) or a network of structures in the human mind which helps to find and understand the surrounding environment (Bormanaki \& Khoshhal, 2017; Müeller, Carpendale, \& Smith, 2009). Therefore, 
in the process of assimilation, there is no change in the schemata because new external elements adjust to the existing schemata.

On the other side, accommodation refers to the simultaneous process of modifying a scheme to include external objects (Mascolo, 2015). The internal structures of knowledge are modified in order to have consistency with external reality, so existing schemata should be changed to accommodate and include incoming new information (Bormanaki \& Khoshhal, 2017; Müeller et al., 2009). Thus, in a broader sense, Piaget (1950, p. 7) describes accommodation as "the environments [which] acts on the organism." However, this accommodation is inseparable from assimilation (Piaget, 1952) because the accommodation of mental structures of reality implies the existence of assimilatory schemata (Piaget, 1954).

Piaget (1954, p. 353) explains the relationship between assimilation and accommodation as follows:

Assimilation and accommodation are therefore the two poles of an interaction between the organism and the environment, which is the condition for all biological and intellectual operation, and such an interaction presupposes from the point of departure an equilibrium between the two tendencies of opposite pole.

Thus, human cognitive development always strives for equilibration, that is "the inherent, self-regulating, compensatory process that motivates the construction of novel patterns of thought over time" (Mascolo, 2015, p. 501). Equilibrium occurs when a human can assimilate an object into a scheme while accommodating the scheme to the object. If assimilation and accommodation fail, disequilibrium occurs because there is a mismatch between the objects and the scheme. Disequilibrium prompts a reorganisation of the scheme in an effort to restore equilibrium (Mascolo, 2015).

Therefore, the concepts of assimilation and accommodation offer potential ways to analyse the findings in my research. I used these concepts to frame my study because I thought that every human thinking process involves assimilation and accommodation in their schemata. Likewise, when students undertake historical thinking processes, they must also involve the process of assimilation and accommodation in their schemata. Since the teaching of history in Indonesia tends to only offer history in a single perspective and in an official version of the past contained in history textbooks, the schemata that have been built are very strong in 
the minds of students. Since the historical narratives contained in history textbooks have similar versions from elementary to secondary school, the schemata in students' mind are built more through the process of assimilation than through the process of accommodation. When students are given the opportunity to learn history by using primary sources, it is necessary to examine how students develop adaptation strategies to deal with different versions of the past, whether through adaptation or accommodation in order to achieve equilibrium. In summary, Piaget's cognitivism theory, specifically the concepts of assimilation and accommodation, provides a theoretical framework through which one could explore how students process historical thinking skills in their cognitive structures.

\subsection{Threshold concepts}

In an attempt to foster students' historical thinking skills, students may face some difficulties in thinking historically. To understand the difficulties experienced by students, this study was framed by threshold concepts. The term "threshold concepts" first appeared as a part of the project of "Enhancing Teaching and Learning Environments" in various higher education institutions across the United Kingdom to improve the quality of the learning environments (Meyer \& Land, 2003). Threshold concepts are a relatively new framework because the first examples of published works appeared as early as 2003 (Tucker, Weedman, Bruce, \& Edwards, 2014; Walker, 2013). Meyer and Land (2003, p. 1) describe the concept as follows:

A threshold concept can be considered as akin to a portal, opening up a new and previously inaccessible way of thinking about something..... a transformed way of understanding, or interpreting, or viewing something without which the learner cannot progress..... There may thus be a transformed internal view of subject matter, subject landscape, or even worldview. This transformation may be sudden or it may be protracted.... with the transition to understanding proving troublesome. Such a transformed view or landscape may represent how people "think" in a particular discipline, or how they perceive, apprehend, or experience particular phenomena.... such transformed understanding leads to a privileged or dominant view and therefore a contestable way of understanding something. 
Therefore, this "learning portal" is considered a threshold concept because its mastery involves learning to look at some aspects of the world in a completely new, transformative and often counter-intuitive manner (Tucker et al., 2014).

As a relatively new idea, threshold concepts are not a totally new construct. There is a great deal of conceptual overlap between the concept of schemata in cognitivism theory and the threshold concepts (Walker, 2013). Walker (2013, p. 251) considers that "whilst threshold concepts can undoubtedly be represented as schema, not all schemas are likely to be threshold concepts." As explained in the previous section, schemata are triggered by the environment. If the learning environment becomes increasingly challenging, students would enter the liminal realm of threshold concepts and have to develop new schemata by linking them together. They will struggle against existing activation patterns which naturally favour more established schemata (Walker, 2013). This is an explanation for the occurrence of "troublesome knowledge" from the cognitivist point of view.

Troublesome knowledge is one of the five main characteristics of the threshold concepts. These five characteristics of the threshold concepts have similarities with the main features of schemata in cognitivism theory (R. C. Anderson, 1977; Walker, 2013). First, "transformative", is an epistemic shift, a previously inaccessible way of thinking about something that has occurred (Baillie, Bowden, \& Meyer, 2013; Land, Cousin, Meyer, \& Davies, 2005; Meyer \& Land, $2003,2005,2006)$. Then, the schema is also transformative, because it must always be reorganised when incoming data reveal a need to reconstruct the concept (Walker, 2013). Second, "irreversible", it cannot be reversed, once the concept is understood it cannot be forgotten or can only be forgotten with considerable effort (Land et al., 2005; Meyer \& Land, 2003, 2005). Schemata also tend to be irreversible, because they are malleable and changeable every moment as information is received from time to time (Walker, 2013). Third, "integrative", because "it exposes the previously hidden interrelatedness of something (Meyer \& Land, 2003, p. 5). Schemata are also integrated, because "schemas are embedded on other schemata, which themselves subsume sub-schema" (Walker, 2013, p. 251). Fourth, "bounded", that "any conceptual space will have terminal frontiers, bordering with thresholds into new conceptual areas" (Meyer \& Land, 2003, p. 5). 
Similarly, schemata are also bounded because schemata enable holistic or gestalt representations which recognise the boundaries between concepts (Walker, 2013). Fifth, as previously mentioned, "troublesome knowledge", because threshold concepts are challenging, difficult to come to terms with, counter-intuitive or requiring a suspension of disbelief (Baillie et al., 2013; Meyer \& Land, 2003). Schemata can also represent "troublesome knowledge" because they often conflict with common sense and have a strong affective component (Walker, 2013).

I used the threshold concepts in this study to identify students' troublesome knowledge when learning history by utilising primary sources. This identification is important because the potential value of the threshold concepts is to aid both teaching and student learning (Barradell, 2013). However, identifying the threshold concepts in history is more difficult than in other subjects such as physics, mathematics, biology, economics and others (Barradell, 2013; Meyer \& Land, 2003, 2006; Tucker et al., 2014). Fortunately, there have been several attempts to identify the threshold concepts in the discipline of history. McGowan (2016) has identified that historical thinking strategies, such as analysing primary sources, are a good representation of the threshold concept experienced by students in learning history. More specifically, Shep et.al (2017) identified that the "big six" concepts of historical thinking according to Seixas and Morton (2013) as the threshold concepts in the subjects of history.

In identifying "troublesome knowledge" experienced by students when they were taught historical thinking skills, I did not specify certain historical thinking concepts based on the opinion of experts - as reviewed in the previous chapter. This refers to the research conducted by Shep and her colleagues (2017) who apparently failed to study the threshold concepts and the historical thinking concepts that had been specifically defined before conducting the survey. Open-ended questions that had been prepared based on the "big six of historical thinking concepts" in their survey turned out could not to be used because the research participants-lectures and professors in New Zealand universities — still did not understand the historical thinking and threshold concepts well enough (Shep et al., 2017). Since my research participants were secondary school teachers and their students, and historical thinking concepts are relatively new in Indonesia, so I only examined the 
"troublesome knowledge" in teaching and learning historical thinking based on the research participants' perspectives.

In searching for threshold concepts that emerged based on students' perspectives, it was necessary to focus on how students thought and not be limited to the content (Timmermans \& Meyer, 2019). Since the essential property of a threshold concept is its transformative character (Baillie et al., 2013), it was necessary to identify the transformation of how students think. I needed to identify students' experiences and understanding in their ways of thinking and practicing since the threshold concepts could be reflected in students' understanding of "how historians think" and their experience to "think like a historian" (Baillie et al., 2013; Land et al., 2005). If the source of these "epistemological barriers" has been identified then efforts can be designed to free up "the blocked spaces" (Land et al., 2005; Meyer \& Land, 2005), so that the cultivation of historical thinking skills in Indonesia can be achieved.

For example, since the teaching of history in Indonesia is generally characterised by the utilisation of learning resources in the form of official textbooks from elementary to secondary schools which offer a single perspective, then basically students only learn and use their "ritual knowledge" (D. Perkins, 1999, 2006). The historical material studied only has "a routine and rather meaningless characters" (D. Perkins, 1999). This ritual knowledge could become troublesome knowledge when students are confronted with learning resources in a variety of primary sources that contain multiple perspectives. The threshold experience felt by students can be identified through classroom observation during the learning process and through interviews to obtain the participants' perspectives. From these two methods, the troublesome knowledge in the efforts to foster students' historical thinking skills in Indonesia could be identified. At the same time, it can also identify the epistemic shift in students' historical beliefs. When the troublesome knowledge has been identified, appropriate responses can be determined to overcome it, whether through active learning, social learning, creative learning, or other responses (D. Perkins, 1999, 2006), especially in today's digital learning environments. 


\subsection{Connectivism}

In this digital age, learning does not only occur in school classrooms but also anywhere, simply because there is so much information that can be accessed easily through the internet (Lang, 2016). Responding to this reality, this study has been informed by connectivism theory. This theory is used to frame the learning process that utilises information and communication technology, because connectivism was offered as a fresh alternative learning theory in the digital age (Boitshwarelo, 2011; Siemens, 2004). Connectivism was developed as criticism of the three main learning theories - behaviourism, cognitivism, and constructivism-and has claimed to provide a lens through which teaching and learning using digital technologies can be better understood and managed (Goldie, 2016; Siemens, 2004). While cognitivism theory views learning as schemata constructions in the minds of individuals, connectivism views learning as a process that not only occurs in the human mind but also by forming connections with other people and through connecting information sets (Barnett, McPherson, \& Sandieson, 2013; Goldie, 2016; Siemens, 2004). Connectivism also views learning as a networked phenomenon that is influenced by socialisation and technology (Goldie, 2016).

Therefore, this study used cognitivism theory to frame historical thinking processes which occur in the students' mind, while connectivism theory was used to frame historical thinking processes which involve the web-based historical sources. It was also used to analyse how students connect the information they have obtained from the website and their textbooks to be discussed with other students when compiling interpretive essays or presenting their essays. Additionally, connectivism was also be used to analyse how students connect the information they got from whatever sources that they can access, especially through digital technology.

Connectivism has received much criticism about its status as a learning theory, as it is considered not to have met the scientific criteria as a theory (Clarà \& Barberà, 2014; Tschofen \& Mackness, 2012) and lacks empirical testing (Goldie, 2016). Nevertheless, I consider that connectivism would be very beneficial to frame my research data because it is a theory that functions to frame the learning process in the online milieu (Barnett et al., 2013; Dunaway, 2011). Moreover, with the rapid 
development in information and communication technology, students cannot be separated from the use of internet in their daily-life activities or for their learning purposes, both in the internal or external realities of traditional classrooms (Dunaway, 2011; Karchmer, 2004; Kop \& Hill, 2008). For this reason, I used connectivism to capture students' learning phenomena which is certainly not only influenced by the learning process in the classroom space but is also exposed to various kinds of information from cyberspace.

The use of connectivism to frame this study was based on the eight principles contained in this theory. The first principle is that learning and knowledge rests in the diversity of opinions (Siemens, 2004). Based on this principle, if during teaching and learning activities there were differences of opinion regarding a historical event, it means there has been a learning process that can encourage students to gain knowledge. The more differences of opinion occurred between students, the more opportunities for knowledge acquisition. This difference of opinion could be stimulated by providing students with primary sources that contain multiple perspectives. Then, I analysed how students connect the conflicting information in the sources and to other students' opinions.

The second principle is that learning is a process of connecting specialised nodes or sources of information (Siemens, 2004). In the connectivism model, a node can be described as a learning community (Kop \& Hill, 2008). The learning community is a group of people who study together through continuous dialogue because of their common interest and this group is always a part of a larger learning network (Boitshwarelo, 2011; Goldie, 2016; Kop \& Hill, 2008). I used this principle to analyse how students connect information within their cohort and with other cohorts in their classroom discussion, given each individual student and each cohort could have different sources of information to connect.

The third principle is that learning may reside in "non-human appliances" (Siemens, 2004) because information is not only in the mind of individual but also available on the internet (Kop \& Hill, 2008). The implied meaning of this principle is that knowledge is distributed through information networks and can be stored in various digital formats (Kop \& Hill, 2008), since knowledge can be stored and manipulated by technology, not only in the brains of individuals (Goldie, 2016). 
The application of this principle in my research enables me to analyse the sources of information utilised by students as materials for writing interpretive essays. Students were exposed to any kind of information that they could easily access, not only depending on the materials provided by the teacher or by primary sources deliberately provided through this research.

The fourth principle is that the capacity to know more, is more important than what is currently known (Siemens, 2004). The point is that the information is always changing so that its validity and accuracy always change as well from time to time depending on the contribution of new information, meaning that the ability to learn must always change over time (Kop \& Hill, 2008). The skills of finding and filtering information through connections that make humans learn more are more important than the current state of knowledge (Kop \& Hill, 2008; Siemens, 2004). Based on this principle, I focused more on analysing students' skills in finding and processing information, not on what students already know.

The fifth principle is that fostering and maintaining connections is necessary to facilitate continuous learning (Siemens, 2004). This means that teaching becomes an activity to facilitate connections in the overall classroom web and teacher must help students to critically examine connections in their courses (Barnett et al., 2013). I used this principle to frame how teacher participants facilitate their students to be able to connect available various information in the learning activities. I used it also to frame how students critically examine all the connecting information available.

The sixth principle is that the ability to see connections between fields, ideas, and concepts is a core skill in connectivism (Siemens, 2004). This is because the navigation of the internet and the means by which information is dispersed on the internet allows students to connect different concepts (Kop \& Hill, 2008). I used this principle in my research to frame how students connect various ideas and concepts in history, or with other disciplines.

The seventh principle is that accurate and up-to-date knowledge is the purpose of all connectivism learning purposes (Siemens, 2004). Since information is constantly changing, students must also have the ability to find and access new information (Goldie, 2016). I used this principle to frame how students try to seek 
new information related to history, which can be different from the information in their textbooks. This can be traced from the references they used to write interpretive essays and from classroom discussions they participated in.

The eighth principle is that decision making is a learning process (Siemens, 2004). Since information is always changing, the validity of information also changes, so students must be able to evaluate the sources and make decisions based on the information obtained (Goldie, 2016). I used this principle to frame how students make decisions for writing interpretive essays because they were dealing with a lot of information from primary and secondary sources that conflicted with each other. In making decisions to produce historical interpretations based on conflicting sources and based on strong arguments, students must be able to think critically.

\subsection{The theoretical framework of the study}

The four theoretical perspectives described above have informed this study, ranging from being used to identify research problems, to designing the process of learning intervention, to analysing the research data obtained. First, Freire's critical pedagogy theory provides a broad theoretical framework for exploring students' historical thinking skills. Specifically, I used Freire's concepts of problem-posing education and conscientisation to frame the process of learning intervention so students were able to think critically, which is needed in order to think historically. Second, Piaget's cognitivism theory has also provided a theoretical framework in this study, specifically the concepts of assimilation and accommodation which became the theoretical lenses through which I analyse students' thinking process in their cognitive structures. Third, threshold concepts provided a theoretical framework in this study to identify students' troublesome knowledge during the learning process to foster their historical thinking skills. Fourth, connectivism theory provided a theoretical framework to illuminate how students utilised and connecting various kinds of information from the web-based historical sources, from their textbooks, from any internet sources they can access, and from their discussions in the classroom space or in the cyberspace in order to develop their historical thinking skills. 
The following figure is a visualisation of the theoretical framework for this study:

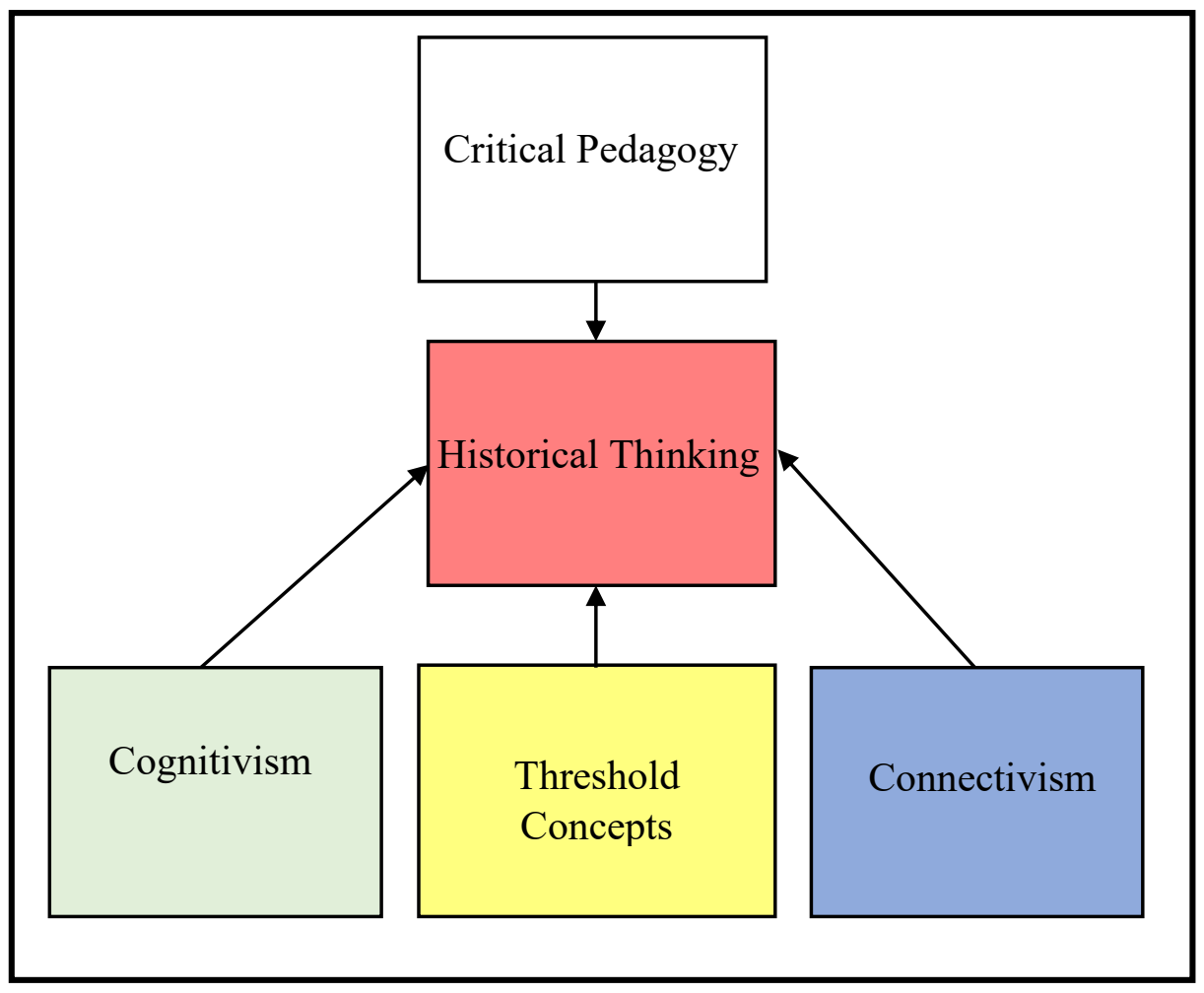

Figure 3.1 The theoretical framework of this study

The theoretical framework in this chapter and the conceptual framework in the previous chapter had significant implications for the methodology I used to answer research questions. In Chapter 4, I outline and explain the methodological design I have employed in this study. 
This page is intentionally left blank. 


\section{CHAPTER 4 METHODOLOGY}

The purpose of my study is to examine an alternative learning model to foster students' historical thinking skills through analysing documents and interpreting textbooks. This chapter describes and explains the research approach of my study. Firstly, I explain the rationale for choosing a mixed methods intervention design used to collect data. Then I describe the research participants involved in this study. Next, this chapter also describes and explains the data collection instruments, procedures and analysis. This chapter ends by addressing the ethical issues and limitations of the study.

\subsection{Research design}

This study used mixed methods intervention design to collect and analyse the data (Creswell, 2015; Creswell \& Clark, 2018). Intervention design aims to "study a problem by conducting an experiment or an intervention trial and adding qualitative data into it" (Creswell, 2015, p. 42). This design was selected to examine whether the intervention process of teaching history through analysing document and interpreting textbooks contributes to students' historical thinking skills. The intervention process was carried out as a learning trial since the students have only been accustomed to relying on textbooks as their learning resources and have never used historical primary sources. This study also quantitatively examined whether the intervention process had any side effects on students' epistemic beliefs about history.

To obtain in-depth explanations about the process and the results of the learning intervention, this study also collected qualitative data before, during, and after the experimental intervention (Creswell \& Clark, 2018). The qualitative data was used to provide in-depth explanations about the challenges and opportunities of teaching history through analysing documents and interpreting textbooks from the teachers' and students' perspectives. The research participants' viewpoints were also used to explain the usefulness of web-based historical sources as learning resources to foster students' historical thinking skills. Therefore, in this study both 
quantitative and qualitative data were combined and complemented each other (Johnson \& Christensen, 2014).

In the application of quantitative interventions, this research applied a quasiexperimental design (Creswell, 2012; Creswell \& Clark, 2018). This design was chosen because it was not possible to provide full control of potential confounding variables (Johnson \& Christensen, 2014), since this study involved human participants who had a variety of preferences which could not be controlled by this study, such as learning style variables. In addition, it was also not possible to artificially and randomly create groups for the experiment, so it had to use the “intact groups" (Creswell, 2012, p. 309). This study involved experimental groups that received treatment and control groups that did not receive treatment interventions. The treatment given to the experimental group was in the form of a teaching and learning process through analysing documents and interpreting textbooks. Additionally, the experimental groups were also given access to a website of learning resources that contained historical documents.

Despite having different learning models and learning resources, both experimental and control groups had the same learning objectives. The process of learning history was aimed at developing students' historical thinking skills and not merely for mastering historical content knowledge. To achieve these goals, the control groups did not access the regular learning process that relies on historical lectures from the teachers, but needed to work from a similar lesson plan to that of the experimental group. First, the teachers had to apply problem-posing education by prioritising dialogue in the learning process. The teachers' main task was to encourage students to think critically in learning history. Second, both groups of students were given the same task to write interpretive essays. The essay assignments contained several central historical questions that students could not easily answer just by reading the information in their textbooks. Instead, they had to look for various sources they had to interpret by themselves. Third, since they would not be able to find answers in the textbooks, both groups were invited to look for whatever learning resources they could access. Fourth, the two groups also studied the same topic regarding the history of the battle of Surabaya. 
The first topic studied was the flag incident on 19 September 1945 before the outbreak of the battle of Surabaya. The second topic was the death of Mallaby on 30 October 1945 at the beginning of the battle of Surabaya. These two topics were chosen because they can stimulate students to think historically by interpreting what really happened in these incidents. At the same time, as I have explained in the first chapter, the battle of Surabaya has a historical significance, being commemorated annually as Hero's Day in Indonesia. Before the learning intervention process, students were given a pre-test in the form of writing an interpretive essay to answer a central historical question about who won the battle of Surabaya. At this stage, students also had to fill out the first questionnaire about historical epistemic belief and had to answer an open-ended questionnaire to find out students' initial understanding of the battle of Surabaya. In the first intervention stage, after studying the topic of the flag incident, students were asked to write an interpretive essay to interpret who tore the Dutch flag in that incident. Then after the first intervention was completed, students answered the epistemic belief questionnaire about history for the second time. In the second intervention stage, after studying the second topic regarding Mallaby's death, students were asked to write an interpretive essay to interpret who killed Mallaby. Then after the second intervention process was completed, students answered the epistemic belief questionnaire for the third time. During the intervention process, both control and experimental groups worked on the same interpretative essay writing tasks and questionnaires. The only difference was that the experimental groups were given access to historical resources available on www.berpikirsejarah.com.- - which I purposely designed for this study-and learned through analysing documents and interpreting textbooks.

In the application of qualitative strands, just before the experimental process was carried out, I applied exploratory sequential core design to develop effective and workable interventions at research sites (Creswell, 2015; Creswell \& Clark, 2018). I used this exploratory phase to understand the context and environment of research sites (Creswell \& Clark, 2018), specifically regarding the availability of computer and internet facilities at schools. I also used this exploratory phase to recruit research participants (Creswell \& Clark, 2018), ranging from schools, teachers, and students involved in the experiments. The main objective of the 
exploratory phase was to obtain qualitative data needed to support the success of the intervention process. At this phase, I also started to develop a rapport with all the research participants (Creswell, 2012). This rapport, primarily with the teacher participants, was very important because the success of the teaching intervention process depends on the teachers' implementation. For this reason, synergic cooperation between me as a researcher and the teacher participants was needed during the research process.

In the qualitative strands during the intervention process, I implemented convergent core design so that quantitative data obtained in the experiment could be combined with qualitative data so they could complement each other (Creswell, 2015; Creswell \& Clark, 2018). In this convergent phase, I conducted classroom observations qualitatively during the teaching and learning intervention process. Qualitative data in this phase was needed to understand how the participants experienced the learning treatment (Creswell \& Clark, 2018). At the same time, I used this stage to identify the potential challenges and opportunities in learning history through analysing documents and interpreting textbooks to foster students' historical thinking skills. This phase was also useful to identify potential prospects and constraints for the utilisation of web-based historical sources as learning resources to foster students' historical thinking skills.

After the intervention process, I implemented an explanatory sequential core design to follow up and help explain the statistical results in more detail (Creswell, 2015; Creswell \& Clark, 2018). In this explanatory phase, I collected qualitative data through focus group interviews with the students' participants and semistructured interviews with the teachers' participants. The main objective of collecting qualitative data in this phase was to understand the outcomes of teaching and learning interventions from the perspectives of the research participants. This stage was also used to obtain feedback from the research participants regarding the learning model and web-based historical sources that have been used.

After all the data had been collected and analysed, findings were integrated. The qualitative data can enhance the interpretation of the quantitative results. This integration was also used to understand the research participants' subjective experiences related to the intervention process based on their perspectives. 
The following figure illustrates the mixed methods intervention design, which was developed from the conceptual framework and informed by the theoretical framework, and then implemented in this study:

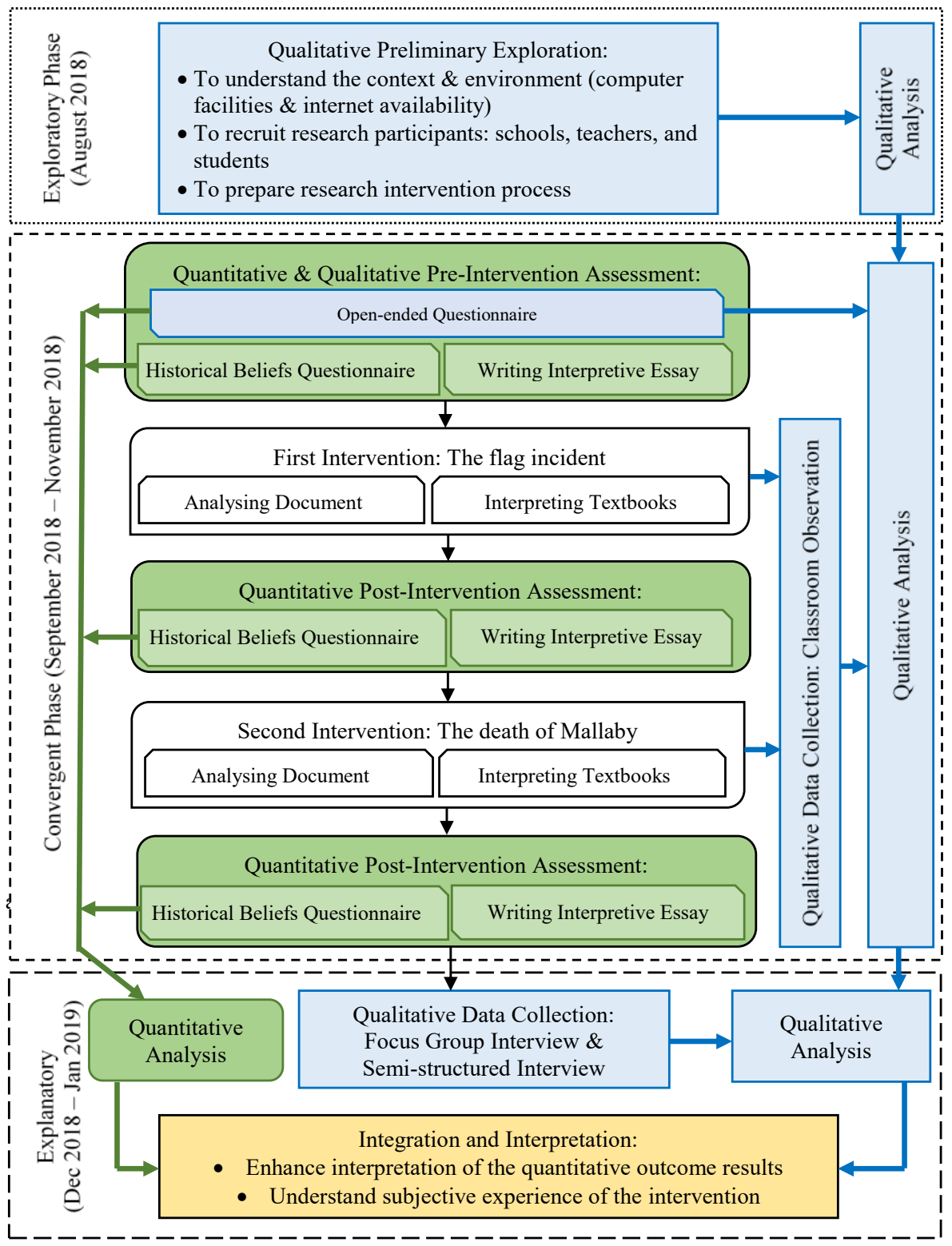

Figure 4.1: Diagram of mixed methods intervention design for this study

Therefore, this research did not use pure quantitative intervention design because it was impossible to control all the factors that influenced students' skills in historical thinking. In fact, various variables and factors beyond my control as a researcher can enrich the research data if captured from a qualitative research perspective. In addition, this study did not use a classroom action research design; 
which a process to improve education by incorporating change and involving educators who work together to achieve improvements in their own practice (Ary, Jacobs, Sorensen, \& Razavieh, 2010). Given the project endeavoured to test the effectiveness of teaching and learning history through analysing documents and interpreting textbooks, there was no certainty that the results could definitely improve the quality of the learning process.

\subsection{Research participants}

This study was conducted from August 2018 to January 2019 in the Malangboth Malang City and Malang Regency, East Java, Indonesia. This region was chosen because it is a service area of Universitas Negeri Malang (State University of Malang) as a teacher training institution. As I explained in the first chapter, my working experience as a lecturer at this institution for more than a decade has given me the opportunity to interact intensively with history teachers in Malang. During this period, I frequently heard various complaints from the history teachers regarding their difficulties in teaching students the skills to think historically: In particular, their impediment in accessing historical primary sources which were important in stimulating students' historical thinking skills.

To determine which schools in Malang could be involved in this study, I used purposive sampling (Creswell \& Clark, 2018). This means that I "intentionally select" the schools that were used as research locations (Creswell \& Clark, 2018, p. 176). The selection criteria were based on the availability of internet connection and computer facilities in these schools. To find schools that met the criteria, I approached the head of the history teachers' association (Musyawarah Guru Mata Pelajaran Sejarah) in Malang and explained the purpose of my research. They offered four state senior secondary schools that met the criteria. Based on this information, I obtained research consent in the local education office and the school headmasters. They all gave their consent and even one of the headmasters strongly supported my research. He felt he had emotional closeness as a short course alumnus at Victoria University of Wellington and because one of his relatives was involved in the battle of Surabaya. The four schools that met the criteria had the same characteristics because they all were state public schools. I set one school as 
the location of the pilot study and the other three schools as the main research locations.

To determine the teacher participants, I used purposive and volunteer sampling (Creswell \& Clark, 2018). The criteria for selecting teacher participants were their digital literacy and their passion to implement learning innovation. In addition, the teacher participants also had to have teaching assignments in grade 11, because the material of the battle of Surabaya is taught to $11^{\text {th }}$-grade students. The first thing that I did was meeting all the history teachers face-to-face at each of the four schools and explained the purpose of my study. On average, each school had three to five history teachers. From these teachers, it turned out that the teacher who volunteered to be involved in my study was the most junior teacher in each school. This was because they were the most digitally literate as well as the most capable and ready to utilise digital learning resources in their classrooms. The teacher participants demographic data is presented in the following table:

Table 4.1 The demographic data of the teacher participants

\begin{tabular}{clclll}
\hline Teachers & Gender & Age range & Ethnicity & Qualification & $\begin{array}{c}\text { Teaching } \\
\text { experience }\end{array}$ \\
\hline Teacher A & Male & $20-30$ & Madurese & Bachelor & 2 years \\
\hline Teacher B & Female & $20-30$ & Javanese & Bachelor & 3 years \\
\hline Teacher C & Female & $20-30$ & Javanese & Bachelor & 5 years \\
\hline Pilot Study & Male & $20-30$ & Madurese & Bachelor & 2 years \\
\hline
\end{tabular}

The table above shows that two out of three teacher participants in the main schools were female and the participant for the pilot study was a male teacher. The age range of all the teacher participants was 20-30 years old and each could be categorised as the most junior teacher in their schools. Based on their ethnic background, two teachers were Javanese and two teachers were Madurese. However, all four teacher participants were fluent in Javanese, so sometimes they mixed Bahasa Indonesia with the Javanese language in their teaching process. Regarding their educational level, all the teacher participants have academic qualification as a bachelor in the field of history education. Except for the teacher participant in School C, during the course of this study, three of the teacher participants were undertaking a master's degree in history education at Universitas Negeri Malang. Their teaching experience was in the range of 2-5 years. 
To determine the student participants who could be involved in this study, I also used purposive and volunteer sampling (Creswell \& Clark, 2018). The first criterion for selecting student participants was those who were already in the $11^{\text {th }}$ grade. This was because the material about the battle of Surabaya is taught to $11^{\text {th }}$ grade students. The second criterion for selecting student participants was based on the determination by the teacher participants. They had to determine two existing classrooms consisting of $11^{\text {th }}$-grade students they taught to become student participants. Students who were in the two classes chosen by the teacher participants could either be involved or not involved in this study voluntarily.

During the pilot study, there were 66 students involved, consisting of two intact classrooms, each totalling 33 students. One classroom was used to pilot material related to the flag incident and another classroom was used to pilot material about the death of Mallaby. All students involved were over 16 years old. Based on gender, there were 24 male students (36\%) and 42 female students (64\%). Meanwhile, based on ethnicity, all students were Javanese.

During the main data collection, the total number of student participants involved in my study was 191 students from three different schools in Malang. For school A, the number of students involved was 52 students. For school B, there were 68 students involved. While for school C, the number of students involved was 71 students. The following table presents the data on the number of students involved in my research:

Table 4.2 The number of student participants

\begin{tabular}{cccc}
\hline School & Control group & Experimental group & Total \\
\hline School A & 25 & 27 & 52 \\
\hline School B & 34 & 34 & 68 \\
\hline School C & 36 & 35 & 71 \\
\hline Total & 95 & 96 & 191 \\
\hline
\end{tabular}

From the number of students mentioned above, all of them were aged 16 years old or above. Thus, related to the ethical issue, they did not need parental consent to be involved in my study. All students were willing to become my research participants and none of the students resigned from their involvement until the data collection process was completed. Most of the student participants, both in the control and experimental group, were 17 years old, while the percentage of students who reached 16 years was around $36.8 \%$ in the control group and $38.9 \%$ in the 
experimental group. As for students who were aged 18 years and over, there were 15 students in the control group and 5 students in the experimental group. The following is a table of the distribution of student participants based on their age:

Table 4.3 The age distribution of student participants

\begin{tabular}{ccccc}
\hline \multirow{2}{*}{ Age group } & \multicolumn{2}{c}{ Control group students } & \multicolumn{2}{c}{ Experimental group students } \\
\cline { 2 - 5 } & Frequency & Percentage & Frequency & Percentage \\
\hline 16 & 35 & 36.8 & 37 & 38.9 \\
\hline 17 & 45 & 47.4 & 54 & 56.8 \\
\hline 18 & 14 & 14.7 & 5 & 5.3 \\
\hline 19 & 1 & 1,1 & - & - \\
\hline Total & 95 & 100 & 96 & 100 \\
\hline
\end{tabular}

In the case of their gender, most of the student participants were female. In the control group, the percentage of female student participants was $55.8 \%$ and the percentage of male student participants was $44.2 \%$. Meanwhile in the experimental group, the percentage of female student participant was $61.5 \%$ and the percentage of male student participant was $38.5 \%$. Detailed data related to the gender of the student participants is presented in the following table:

Table 4.4 The distribution of student participants based on the gender

\begin{tabular}{ccccc}
\hline \multirow{2}{*}{ Gender } & \multicolumn{2}{c}{ Control group students } & \multicolumn{2}{c}{ Experimental group students } \\
\cline { 2 - 5 } & Frequency & Percentage & Frequency & Percentage \\
\hline Female & 53 & 55.8 & 59 & 61.5 \\
\hline Male & 42 & 44.2 & 37 & 38.5 \\
\hline Total & 95 & 100 & 96 & 100 \\
\hline
\end{tabular}

In the case of their ethnicity, the majority of student participants were Javanese. This was reasonable because Malang is located on the island of Java. Only a small number of students were based on other ethnic groups in Indonesia, such as Arab, Madurese, Minangkabau, and Papuan. Nevertheless, student participants who came from ethnic Madurese, Minangkabau, and Arabic were all born and raised in Malang. Two students from Papua had lived in Malang for two years and were able to speak Javanese competently. Since the majority of the students were Javanese and were raised in Malang, in the learning process students often use Bahasa Indonesia mixed with Javanese language, especially when they were discussing in their cohorts. The ethnic composition of the student participants is presented in the following table: 
Table 4.5 The distribution of student participants based on the ethnicity

\begin{tabular}{lccccc}
\hline \multirow{2}{*}{ Ethnicity } & \multicolumn{2}{c}{ Control group students } & \multicolumn{2}{c}{ Experimental group students } \\
\cline { 2 - 5 } & Frequency & Percentage & Frequency & Percentage \\
\hline Javanese $^{\mathrm{a}}$ & 89 & 93.7 & 94 & 97.9 \\
\hline Madurese $^{\mathrm{b}}$ & - & - & 1 & 1.0 \\
\hline Arab $^{\mathrm{c}}$ & 4 & 4.2 & - & - \\
\hline Minangkabau $^{\mathrm{d}}$ & - & - & 1 & 1.0 \\
\hline Damal (Papuan) $^{\mathrm{e}}$ & 1 & 1.1 & - & - \\
\hline Gem (Papuan) $^{\mathrm{e}}$ & 1 & 1.1 & - & 100 \\
\hline Total & 95 & 100 & 96 & \\
\hline
\end{tabular}

${ }^{a}$ Javanese are the largest ethnic group in Indonesia and originally from the island of Java.

${ }^{b}$ Madurese are an ethnic group originally from the island of Madura, East Java.

${ }^{\mathrm{c}}$ Indonesian citizens of Arab descent.

${ }^{d}$ Minangkabau are an ethnic group originally from Minangkabau highlands of West Sumatra.

${ }^{\text {e }}$ Damal and Gem are tribes originally from Papua hinterland.

\subsection{Data collection instruments}

The advantage of using mixed methods research was the large selection of data collection instruments that could be used. As a researcher, I was "able to use all the tools of data collection available rather than being restricted to those types typically associated with quantitative or qualitative research" (Creswell \& Clark, 2018 , p. 13). For the quantitative research, I used data collection instruments in the form of historical beliefs questionnaire, writing interpretive essays, and open-ended questionnaire. For the qualitative research, I used data collection tools in the form of classroom observation, focus group interview, and semi-structured interview. The use of each of these instruments is explained as follows:

\subsubsection{Historical beliefs questionnaire}

Historical beliefs questionnaire was used to answer the second sub-question related to whether students' epistemic beliefs about history had changed as a side effect of historical thinking process intervention. Initially, to measure students' epistemic beliefs about history I adopted VanSledright's (2014) historical beliefs questionnaire which contains 12 statements. This questionnaire has several similarities with the "beliefs about history questionnaire" which has 22 item statements (Maggioni, 2010) and with the "beliefs about learning and teaching in history questionnaire" which has 21 item statements (Maggioni et al., 2009), as I have mentioned in the second chapter. However, I felt that VanSledright's (2014) historical beliefs questionnaire was easier and more practical to be used in Indonesia and because using an existing validated survey was the easiest option in a study 
(Roni, Merga, \& Morris, 2020). In addition, because the statement items in this questionnaire have been used several times, then its validity and reliability have been assured.

The twelve statements in the questionnaire reflected three categories of epistemic beliefs about history. Students were asked to respond by giving a tick mark in the answer column consisting of four alternatives, namely strongly agree, agree, disagree, and strongly disagree. The questionnaire was distributed three times, namely before the intervention process, after the first intervention, and after the second intervention. Both the experimental and the control group answered the same questionnaire. The following table contains the twelve statements in the historical belief questionnaire:

Table 4.6 The statement items in the historical belief questionnaire (VanSledright, 2014)

\begin{tabular}{|c|c|}
\hline $\begin{array}{l}\text { Epistemic beliefs } \\
\text { categories }\end{array}$ & Statement items \\
\hline \multirow[t]{4}{*}{ Naïve objectivist } & There is no difference between the past and history \\
\hline & Historical facts speak for themselves \\
\hline & History is what happened in the past \\
\hline & $\begin{array}{l}\text { It is impossible to know anything about the past because none of us } \\
\text { were there }\end{array}$ \\
\hline \multirow[t]{4}{*}{ Naïve subjectivist } & The past is simply what the investigator makes it to be \\
\hline & Historical investigators know that history is just a matter of opinion \\
\hline & $\begin{array}{l}\text { Since we cannot really know what happened in the past, we can } \\
\text { believe whatever we want to about it }\end{array}$ \\
\hline & $\begin{array}{l}\text { Historical claims cannot be justified since they are simply a matter } \\
\text { of interpretation }\end{array}$ \\
\hline \multirow[t]{4}{*}{ Criterialist } & $\begin{array}{l}\text { Comparing sources and understanding author perspective are } \\
\text { crucial component of the process of investigating the past }\end{array}$ \\
\hline & History is a critical inquiry into the past \\
\hline & $\begin{array}{l}\text { Reasonable interpretation of the past can be constructed even in the } \\
\text { presence of conflicting evidence }\end{array}$ \\
\hline & $\begin{array}{l}\text { History is the reasonable reconstruction of past occurrences based } \\
\text { on the available evidence }\end{array}$ \\
\hline
\end{tabular}

Permission to use this questionnaire was obtained through personal correspondence with Bruce A. VanSledright (see appendix N). As mentioned earlier, I adopted this questionnaire without making any changes to the statement items. However, since it was distributed to senior secondary school students in Indonesia, I added its translation in Bahasa Indonesia, so it became a bilingual questionnaire. Since the questionnaire was presented bilingually, it was pilot tested to ensure its reliability as according to Hammond and Wellington (2013), questions or statements are reliable if it is clear enough to be interpreted in the same way by 
different people. The results of the pilot study — which I will describe in the later section-required me to modify the translation of some of the statements in the questionnaire (see appendix H).

\subsubsection{Writing interpretive essay}

The writing interpretive essay (WIE) instrument was used to answer the main research question related to students' historical thinking skills after learning history through analysing documents and interpreting textbooks. Like the historical belief questionnaire, I also adapted VanSledright's (2014) historical thinking assessment model, which was based on giving assignments in the form of writing interpretive essays to students. The selection of writing interpretive essay assignments as instruments for measuring historical thinking skills was based on the consideration that these tasks could measure students' historical thinking skills effectively and comprehensively - as reviewed in the second chapter.

These writing assignments were given to the students three times, namely as a pre-test before the implementation of learning interventions, as the first post-test after the first intervention process, and as the second post-test after the second intervention. During the pre-test, students were asked to interpret who the winner of the battle of Surabaya was. On the first post-test, students were asked to interpret who tore the Dutch flag during the flag incident. Meanwhile, on the second posttest, students were asked to interpret who killed Brigadier Mallaby. Besides containing one central historical question, each of these three writing interpretive essay tasks also contained three sub-questions related to the chronological, causeconsequences, and change-continuity of the events. These three historical thinking concepts were suggested by "the teacher textbook" to be taught to students (Sardiman \& Lestariningsih, 2017a). All of these types of 'central historical questions' (Reisman, 2012a, 2012b; Reisman \& Wineburg, 2012) were chosen to focus students' attention when analysing documents and interpreting textbooks, although had potential limitations in developing only certain concepts of historical thinking skills. However, both the experimental and control groups worked on the same interpretive writing tasks (see appendix I).

These writing assignments were done by students collaboratively in small cohorts. Each cohort consisted of 4-6 students because the average number of 
students for each classroom was 30 students, so in one classroom there were 6 cohorts. Thus, in total there were 18 cohorts in the experimental group and 18 cohorts in the control group. In writing interpretive essays, all cohorts were able to use any historical sources they could access as references. The only difference was that the experimental group students were given access to web-based digitised primary sources presented on the www.berpikirsejarah.com website.

\subsubsection{Open-ended questionnaire}

This instrument was used to collect open-ended responses to questions on a questionnaire (Creswell, 2012). This questionnaire is intended to answer the first sub-question in this study, which is to find out students' initial understanding and knowledge about the battle of Surabaya. Data regarding students' initial knowledge need to be studied to find out their existing knowledge about this battle, as one of the major events in Indonesian history. This instrument was also used to track the sources of origins of students' historical knowledge. Primarily, the data obtained from this open-ended questionnaire was used to compare the level of students' initial knowledge between the experimental and the control group. It was assumed that both groups of students should have the same level of knowledge before the intervention process.

This open-ended questionnaire contains two pictures related to the battle of Surabaya, each of which is followed by six same questions (see appendix J). The first image is related to the flag incident, and the second image is related to the death of Mallaby. The two images were deliberately chosen because they often appear in student textbooks, from elementary to secondary school levels. Thus, the two images should have been firmly embedded in the students' memory. In addition, these two images are also still present in the history textbook for $11^{\text {th }}$-grade students in senior secondary school level (Sardiman \& Lestariningsih, 2017b).

This open-ended questionnaire was distributed to students before the implementation of the learning intervention process. When completing the questionnaire, students were not allowed to open their textbooks, access the internet, or ask their friends. This was done in order to obtain data regarding their real initial knowledge. Students were asked to answer the questions based on what they knew, and if they did not know the answer, they could answer "don't know" 
or leave it blank. The questions in the questionnaire were presented in Bahasa Indonesia, and the students were also required to answer in this language. The data obtained from the open-ended questionnaire were analysed both qualitatively and quantitatively.

\subsubsection{Classroom observation}

I used classroom observations for gathering open-ended and first-hand information from the research participants at the research sites (Creswell, 2012). The implementation of classroom observations was intended to answer almost all research questions, both the main question and sub-questions. The focus of observations was to collect qualitative data regarding the intervention process of teaching and learning history through analysing documents and interpreting textbooks, about the utilisation of web-based digitised primary sources, and how these intervention processes affected students' historical thinking skills and epistemic beliefs. For the control group, the focus of observation was students' historical thinking skills and epistemic beliefs when learning history through writing interpretive essays, as well as how they used historical sources that they could access to write the essays.

I did this observation four times for each classroom. At the first meeting, I observed students when they studied the flag incident and began writing their first essays. At the second meeting, I observed students as they held a classroom discussion regarding the flag incident. At the third meeting, I observed students when they studied the death of Mallaby and began writing their second essays. At the fourth meeting, I observed students as they held a classroom discussion regarding the death of Mallaby. Since there were three schools involved in this study, each of them had one classroom as an experimental group and one classroom as a control group, and there were six classrooms to be observed. Since each classroom was observed four times, in total I made twenty-four observations.

My role in the observation process was as a nonparticipant observer (Creswell, 2012). I sat in the corner and observed the teaching-learning process while writing fieldnotes (see appendix K). However, when students started writing essays by accessing and reading sources, I walked around the classroom to observe students in their cohorts. Sometimes I interacted with them to ask what sources they 
were reading and discussing within their cohort. I also asked their opinion about the sources they used to write their essays.

To record the observation findings, I wrote a general description of the learning activities in the classroom into a "descriptive fieldnotes" column (Creswell, 2012, p. 217). After the observation process on that day was finished, I continued by writing my personal thoughts in the "reflective fieldnotes" column to comment on the descriptive findings (Creswell, 2012, p. 217). Then, I made temporary conclusions about the results of the observation on that day. To anticipate my limitations in observing all the activities in the classroom, I used three cameras to record the teaching-learning process. The first camera was placed it in front of the classroom to record the entire classroom. The second camera, an action camera, was installed in the teacher's body to record the interaction process between the students and the teacher. I used the third camera to take photos and videos when there were teaching and learning moments that I considered important. Based on the recording of these three cameras, I used them to complete the contents of my fieldnotes.

\subsubsection{Focus group interview}

Focus group interview was used to collect "shared understanding" from several students as well as their views regarding the learning history process through analysing documents and interpreting textbooks they had done (Creswell, 2012 , p. 218). It was also used to answer all research questions qualitatively because it could explain and deepen the quantitative findings that were obtained through historical beliefs questionnaires, writing interpretive essay tasks, and open-ended questionnaire from student participants perspectives. Therefore, through this focus group interview, various confirmations from student participants could be obtained about what they had done in the questionnaires and writing tasks as well as in the learning process they had participated in.

I asked a small number of general questions to elicit responses from all individuals in the group. The questions I asked were semi-structured to enable the emergence of new questions according to students' responses in order to obtain more in-depth data. I prepared 34 questions for the experimental group and 29 questions for the control group (see appendix L). The questions for the experimental 
group were: 3 opening questions, 12 questions to confirm the historical beliefs questionnaires, 1 question to confirm students' answer in the pre-test essay, 6 questions to confirm students' answer in the first post-test essay, 6 question to confirm students' answer in the second post-test essay, 2 questions to ask students' responses to their experiences after learning history through analysing documents and interpreting textbooks, 2 other questions to ask their responses to web-based historical sources, and 2 closing questions that contained suggestions and expectations. The control group also received the same questions, except for the questions related to the learning model and web-based historical sources. The interview process was conducted in Bahasa Indonesia, but sometimes students answered in Javanese. I recorded all focus group interviews using one voice recorder and one video recorder.

In determining the groups of students interviewed in the focus group interviews, I referred to the essay scores of the students. The criterion for selection was the average score of the students' assignments in writing interpretive essays. For each classroom, one cohort of students was chosen because they received the highest average score and one cohort of students was chosen because they received the lowest average score. The determination based on the average score of the three essays writing tasks was intended to obtain perspectives from one group of students who had success in historical thinking and one group that was still challenged by historical thinking.

\subsubsection{Semi-structured interview}

The semi-structured interview was used to gather qualitative information from the teacher participants, so that they could "best voice their experiences unconstrained by any perspectives of the researcher or past research findings" (Creswell, 2012, p. 218). This interview was used to answer all research questions from the teacher participants' point of view. The teacher participants were asked to give their perspectives on the challenges and opportunities of teaching history through analysing documents and interpreting textbooks, as well as the potential of web-based historical sources, to foster students' historical thinking skills.

I conducted individual interviews with the teacher participants and asked 24 questions related to their experiences after teaching history through analysing 
documents and interpreting textbooks (see appendix M). I conducted these semistructured interviews at the end of the research process after the learning intervention activities had been completed. All the interviews were conducted in Bahasa Indonesia and I recorded the interviews using audio and video recorder.

\subsection{Data collection procedures}

This section describes the process of collecting data in this study, starting from the preparation stage to the final stage of data collection chronologically.

\subsubsection{Developing the learning website (www.berpikirsejarah.com)}

The first thing I prepared before data collection in the field was to develop web-based historical sources as learning resources. I developed this website with the help of my partner, Dewi Martha Indria. I was in charge of collecting historical sources that became website content, while my partner was in charge of constructing the website according to the needs of this study and under my direction. For secondary sources, I included excerpts about the flag incident and the death of Mallaby in the battle of Surabaya from two textbooks, namely the official textbook for $11^{\text {th }}$-grade students (Sardiman \& Lestariningsih, 2017b) and the national history of Indonesia which is the official textbook from the Indonesian government (Poesponegoro \& Notosusanto, 2010).

For primary sources I obtained some documents from various sources. From the National Archive of the Republic of Indonesia, I obtained a document related to the background of the flag incident (Djogja Documenten number 1011) and a document related to the Indonesian government's response to Allied Force's accusation regarding the battle of Surabaya (Djogja Documenten number 161). From the archival office of Dewan Harian Daerah (DHD45, a veteran office in East Java), I obtained hundreds of veteran testimonies related to the battle of Surabaya. From the hundreds of testimonies, I deliberately chose ten testimonies related to the flag incident. From the National Library of the Republic of Indonesia, I got two newspapers which contain news of the battle of Surabaya. I also received help from my colleagues, two historians from Universitas Negeri Malang, who lent photocopies of their archival collections, which consist of Ruslan Abdulgani's testimonies and a collection of archives regarding Mallaby's death. 
All the primary and secondary sources posted on the website, were deliberately chosen for their contradictions and multi-perspectives in order to provoke students' historical thinking skills. Besides, the level of complexity of sources also has a gradual level of difficulty, starting from the low level of difficulty on the material about the flag incident and then increasing difficulty on the material about the death of Mallaby. The website was developed using WordPress (www.wordpress.org) because it is easily developed and friendly-designed for novice website developers (Jones \& Farrington, 2013).

\subsubsection{Conducting training for teacher participants}

Before the process of data collection, I also conducted training sessions for the teacher participants. This training was held for two days on 10 and 11 August 2018 at Universitas Negeri Malang. Four teacher participants attended this activity to receive training on how to teach history through analysing documents and interpreting textbooks. The core of the training emphasised that teacher participants should not teach history through lectures or ask students to memorise textbooks. The teachers were trained to teach history through problem-posing education and prioritise the process of dialogue with the students. The teachers were also trained to use historical sources available on the website and how to assess historical thinking skills in students' essays.

\subsubsection{Conducting a pilot study}

To ascertain the potential impact of the interventions and the effectiveness of research instruments before the experiment, I conducted a pilot study as a mini version of my research (Creswell, 2012; Roni et al., 2020). First, I did content and "face validation" (Ary et al., 2010, p. 228; Chan, 2014), to the website and all instruments by asking evaluation from two of my colleagues at Universitas Negeri Malang who are experts in their respective fields. Dr Joko Sayono as an expert in the field of history education and educational technology and Dr Ari Sapto as an expert in the history of the Indonesian revolution. They gave an assessment that all instruments and the website were very good and seemed appropriate for my research. However, Dr Joko Sayono suggested that the sub-questions in essay tasks needed to be slightly modified in order to measure certain historical thinking concepts, and I made changes as suggested. 
Second, after obtaining a suggestion from experts, all instruments were pilot tested to identify potential problems and to revise the instruments as needed before the main data collection (Friedman, 2012). This pilot study was conducted in one of the four schools which were not used as the main research site. The pilot study took over three weeks from 20 August to 6 September 2018. The results of the pilot study showed that the learning website previously prepared could be used effectively by students so that it could be utilised for this study.

As for research instruments, the results of the pilot study showed that some instruments could be used without revisions and some still needed to be revised. The open-ended questionnaire could be used without being revised. The classroom observation guidelines and the format of the fieldnotes also fit the research needs. Related to writing interpretive essay task, students were also able to understand the writing instructions and the questions they had to answer. For the focus group interviews and semi-structured interviews, only a slight revision of the question sentence was needed to make it easier for participants to understand.

As mentioned in the previous section, the historical beliefs questionnaire was prepared as a bilingual instrument. To check whether the instructions and statements were comprehensible and unambiguous, this questionnaire was piloted to ensure its reliability. Hammond and Wellington (2013) have emphasised that questions in the questionnaire are reliable if research participants have similar interpretations on those questions. However, after the historical belief questionnaire distribution, statistical results showed that the reliability of the questionnaire was not reliable $(<0.6)$, because the Cronbach' alpha coefficient scores only 0.351 (Leppink, 2019). Meanwhile, there were two invalid items (Q2 and Q8) and one item (Q3) has low validity. Students also admitted that they had difficulties and could not focus when working on a bilingual questionnaire. They preferred to work on a questionnaire in Bahasa Indonesia. For that reason, I decided to revise the questionnaire into Bahasa Indonesia only and distribute it again at the end of the pilot study. Then, the statistics showed that the instrument was reliable $(>0.6)$, with Cronbach's alpha coefficient score reaching 0.655. Unfortunately, one item statement (Q3) was still invalid because most of the pilot study students gave a response that agreed with the statement that "history is what happened in the past" 
(VanSledright, 2014, p. 98). The same thing happened when I piloted the interview, the students' verbal answers were the same as their responses in this item. Therefore, I did not remove this item because it was not the instrument that was invalid, but because the pilot study students did not fully understand the nature of history, since they did not get historical thinking interventions in depth.

\subsubsection{Administering the open-ended questionnaire}

Accompanied by the teacher participants, I distributed the open-ended questionnaire to the student participants a few days before the implementation of the learning intervention. I distributed this questionnaire on the same day after I explained the information sheet to students and after they gave written consent to be involved in my study. Using a paper and pencil approach, student participants answered questions in this questionnaire in about 15-20 minutes.

\subsubsection{Administering historical beliefs questionnaires}

The historical beliefs questionnaire was distributed three times to the student participants to measure whether there were changes in their epistemic beliefs about history. The first distribution was before the intervention process, just after the distribution of the open-ended questionnaire. The second distribution was after the completion of the first learning intervention concerning the flag incident. The third distribution was after the completion of the second learning intervention concerning the death of Mallaby in the battle of Surabaya. I personally distributed the first historical beliefs questionnaire, while the second and third distribution of the questionnaire was conducted by the teacher participants at the end of the teaching and learning session.

\subsubsection{Conducting teaching and learning intervention, classroom observation, and writing interpretive essay tasks}

The process of teaching and learning intervention was carried out on the History of Indonesia subjects. Based on the 2013 Curriculum, the material of the battle of Surabaya must be taught to $11^{\text {th }}$-grade students. Teacher participants introduced the teaching intervention based on the lesson plan that I prepared, and they learned during the training session. The teacher participants also managed the students' assignment to write interpretive essays, because these tasks were part of 
the learning process. During the teaching and learning intervention process, I acted as an observer in the classroom.

The intervention process took place from September to November 2018. The teacher participants determined the schedule for the intervention process because they were the "owners" of the classrooms. Sometimes, the schedule for the intervention process on a certain day had to be postponed if the teachers were unable to attend or because there were certain activities in the school. For each classroom, the intervention process took place in four meetings with one additional meeting prior to the intervention when students were working on the pre-test essay, openended questionnaire, and the first historical beliefs questionnaire. In total, both the control and experimental groups studied the battle of Surabaya in five meetings. To prevent leakage of learning resources available on the website www.berpikirsejarah.com, the control group students carried out the learning process before the experimental group. During this time, I closed the website access and only displayed "under maintenance" status.

Below is the timetable for the implementation of teaching interventions and classroom observations:

Table 4.7 The schedule of teaching interventions and classroom observations

\begin{tabular}{clcccccc}
\hline \multirow{2}{*}{ No } & \multirow{2}{*}{ Schedule } & \multicolumn{2}{c}{ School A } & \multicolumn{2}{c}{ School B } & \multicolumn{2}{c}{ School C } \\
\cline { 3 - 7 } & & CTR & EXP & CTR & EXP & CTR & EXP \\
\hline 1 & Pre-intervention & Sep 22 & Oct 10 & Sep 12 & Oct 16 & Sep 14 & Oct 18 \\
\hline 2 & The flag incident & Sep 28 & Oct 22 & Sep 26 & Nov 02 & Sep 18 & Oct 25 \\
\hline 3 & The flag incident & Oct 06 & Oct 29 & Oct 03 & Nov 06 & Sep 27 & Nov 01 \\
\hline 4 & The death of Mallaby & Oct 13 & Nov 05 & Oct 15 & Nov 13 & Oct 02 & Nov 08 \\
\hline 5 & The death of Mallaby & Oct 19 & Nov 12 & Oct 17 & Nov 22 & Oct 16 & Nov 22 \\
\hline
\end{tabular}

\subsubsection{Conducting focus group interviews}

The implementation of focus group interviews took place after the teaching and learning intervention process was finished. For each classroom, both in the experimental and control groups, two cohorts of students were selected to be involved in these interviews. As mentioned previously, the criterion for selection was the average score of the students' assignment in writing three interpretive essays. The interviews were conducted in each school in the room provided by the teacher participants. Below is the timetable of the implementation of focus group interviews that have been taken place in both groups: 
Table 4.8 Timetable of focus group interviews

\begin{tabular}{lllccr}
\hline No & \multicolumn{1}{c}{ Schools (groups) } & $\begin{array}{c}\text { Cohorts } \\
\text { (average score) }\end{array}$ & Date & Time & $\begin{array}{c}\text { Member } \\
\text { checking }\end{array}$ \\
\hline 1 & School A (control) & Cohort 4 (lowest) & 26 Oct 2018 & 14.00 & 16 Jan 2019 \\
\hline 2 & School A (control) & Cohort 6 (highest) & 26 Oct 2018 & 13.00 & 16 Jan 2019 \\
\hline 3 & School B (control) & Cohort 1 (lowest) & 31 Oct 2018 & 11.00 & 7 Jan 2019 \\
\hline 4 & School B (control) & Cohort 4 (highest) & 31 Oct 2018 & 12.00 & 7 Jan 2019 \\
\hline 5 & School C (control) & Cohort 2 (lowest) & 23 Oct 2018 & 15.00 & 7 Jan 2019 \\
\hline 6 & School C (control) & Cohort 3 (highest) & 23 Oct 2018 & 14.00 & 7-9 Jan 2019 \\
\hline 7 & School A (experimental) & Cohort 4 (highest) & 19 Nov 2018 & 09.00 & 8-16 Jan 2019 \\
\hline 8 & School A (experimental) & Cohort 5 (lowest) & 21 Nov 2018 & 11.00 & 8 Jan 2019 \\
\hline 9 & School B (experimental) & Cohort 1 (highest) & 27 Nov 2018 & 09.30 & 7-8 Jan 2019 \\
\hline 10 & School B (experimental) & Cohort 2 (lowest) & 27 Nov 2018 & 08.00 & 7 Jan 2019 \\
\hline 11 & School C (experimental) & Cohort 1 (highest) & 22 Nov 2018 & 11.00 & 7 Jan 2019 \\
\hline 12 & School C (experimental) & Cohort 6 (lowest) & 22 Nov 2018 & 12.00 & 7 Jan 2019 \\
\hline
\end{tabular}

\subsubsection{Conducting semi-structured interviews}

After all the teaching intervention processes had been completed, I conducted semi-structured interviews with the teacher participants. The interview process took place at Universitas Negeri Malang because it was located in the middle of the three school participants and also because two of three teacher participants were also pursuing their master's degree at this university. Thus, I arranged the schedule for the interview when they were attending lectures on campus. The following is the timetable of semi-structured interviews with the teacher participants:

Table 4.9 The timetable of semi-structured interview

\begin{tabular}{lrccrr}
\hline No & Schools & Teacher Participants & Date & Time & Member Checking \\
\hline 1 & School A & Teacher A & 30 November 2018 & 15.00 & 8 January 2019 \\
\hline 2 & School B & Teacher B & 30 November 2018 & 14.00 & 7 January 2019 \\
\hline 3 & School C & Teacher C & 30 November 2018 & 13.00 & 7 January 2019 \\
\hline
\end{tabular}

\subsection{Data analysis}

This study has two types of data, both quantitative and qualitative, which were collected from six data collection methods. This enables the data to be analysed quantitatively, qualitatively, and using mixed data analysis. The aspects of validity and reliability in this study must also be considered both from quantitative and qualitative perspectives.

\subsubsection{Quantitative data analysis}

\subsubsection{Data analysis of historical beliefs questionnaires}

To analyse the result of historical beliefs questionnaires, I referred to the creator of the questionnaire that measured the "consistency score" of students' 
answers (VanSledright, 2014, p. 99). From the twelve statements in the questionnaire, there are four choices of answers that students had to choose by giving a tick mark in the column of strongly agree, agree, disagree, or strongly disagree. To measure the consistency score, I had to count the number of answers from students who chose the option of disagrees (disagree or strongly disagree) on the categories of naïve objectivist and naïve subjectivist statements. After that, I had to count the number of answers of students who chose the option of agrees (strongly agree or agree) on the category of criterialist statements. For instance, if a student chose "disagrees" in the naïve objectivist and naïve subjectivist categories with a total of 5 out of 8 statements, and he chose options of "agrees" in the criterialist statements with a total 2 out of 4 statements, it means the ratio of the student's answer is 7 of 12 possibilities. Then it can be interpreted that student consistency score is 58.3. Changes in students' epistemic beliefs can be said to be successful if they reach the criterialist level or achieve a minimum consistency score of 90 or higher, at least a score of 11 of the 12 total (VanSledright, 2014).

After the consistency scores had been calculated, I did a descriptive and inferential statistical analysis. Through descriptive statistical analysis, I obtained various data such as the mean, median, and standard deviation, which showed a comparison of data between control and experimental groups. From the descriptive statistical data, I could also see through histograms or boxplots to indicate whether the data was skewed and not normally distributed. Besides that, I also tested the normality of data statistically using both Kolmogorov-Smirnov because the sample size was more than 50 (Mishra et al., 2019). Then, the inferential statistics were performed through Friedman test because the control and the experimental group were measured on three different occasions and the data were not normally distributed (Mackridge \& Rowe, 2018). To determine which of the medians were different, I proceeded through post-hoc Wilcoxon analysis (Mackridge \& Rowe, 2018). Then, to determine whether there were differences between the two groups, I used Mann-Whitney test (Mackridge \& Rowe, 2018). The historical belief questionnaire data were analysed using data analysis programme SPSS 22. 


\subsubsection{Data analysis of writing interpretive essays}

In assessing students' writing interpretive essay tasks, this study refers to the scoring rubric developed by VanSledright (2014, pp. 91-92). There are five rubric categories: (1) establishes/argues position, (2) citing evidence, (3) corroboration, (4) assessing account status, and (5) contextualisation. Each category has five scoring scales, from 0-4. Referring to the scoring scales, the lowest score that can be obtained was 0 and the highest score was 20 . The teacher participants were tasked with assessing students' essays by referring to the scoring rubric. However, since the students were not accustomed to getting grades of 0-20, I decided along with the teacher participants to modify the total scoring range to $0-100$. This total score was calculated by dividing the students' obtained score by the maximum score that can be obtained, and then multiplying it by 100 . I interpreted this total score as a reflection of students' skills level to think historically.

After the essays scores were obtained, I proceeded with descriptive and inferential statistical analysis. To check the data's normality, I used the ShapiroWilk test because the sample size was 36 groups or less than 50 (Mishra et al., 2019). Since most of the data were normally distributed and only one data which not normally distributed (post-test 2 in the control group), I used the log transformation to make highly skewed distributions less skewed (Mackridge \& Rowe, 2018). Therefore, further analysis had to be done through the parametric methods (repeated measures ANOVA), for comparing the mean score of dependent variables from three different occasions (Mackridge \& Rowe, 2018). I used post hoc analysis using Least Significant Difference (LSD) to find out the difference in the mean score between pre-test, first post-test and second post-test in each control and experimental group and General Linear Model analysis to compare the control group and the experimental group (Sahai \& Ageel, 2000). The interpretive essays data were analysed using the data analysis programme SPSS 22.

\subsubsection{Data analysis of open-ended questionnaire}

To analyse the open-ended questionnaire, I identified various students' responses and then grouped them into themes based on their answers, counting the number of themes that emerged, and the number of times that the participants mention the themes (Creswell, 2012). Therefore, I conducted both qualitative and 
quantitative analysis of the data obtained from the open-ended questionnaire. The qualitative analysis was based on students' responses openly on what they knew and then grouped based on emerging themes. The quantitative analysis was based on descriptive statistics on the frequency of response themes. Then I compared whether there were differences between the experimental group and the control group. Ideally, there should be no difference between the two groups to indicate that the initial understanding of the battle of Surabaya of the two groups was equal. The open-ended questionnaire data were analysed statistically through Microsoft Excel.

\subsubsection{Qualitative data analysis}

\subsubsection{Data analysis of classroom observation}

The process of analysing the data from classroom observations was carried out simultaneously with the implementation of data collection using an interactive model (Miles, Huberman, \& Saldaña, 2014). In this model, data analysis is concurrent flows of activities that include data reduction or condensation, data display, and conclusion drawing. Therefore, when I carried out classroom observations and wrote fieldnotes, I had also analysed the data. During classroom observations, I had made a data reduction or data condensation because I selected certain phenomena that fit the focus of observation and then wrote them down in the descriptive fieldnotes. Based on the data display in the descriptive column, I made another data condensation by giving reflective notes for specific data that was in line with the focus of the study. Based on the results of the reflective note, I made a preliminary and temporary conclusion to the findings of the observation of that day (see fieldnotes column in appendix K). If these temporary conclusions repeat and are found again in the subsequent observation on the next meeting, it means that there has been data saturation and becomes part of my final data as a result of observations.

4.5.2.2 Data analysis of focus group interviews and semi-structured interviews

I transcribed verbatim the qualitative data from the focus group interviews and semi-structured interviews using Word processing software. I did not translate the transcripts into English when I did the analysis to ensure the originality of the data. After the interview transcripts were validated through member checking 
procedure, the qualitative data analysis process was carried out by combining the interview transcripts with the observation fieldnotes. As in the interview transcript, I also wrote the fieldnotes in Bahasa Indonesia because the teaching and learning process in the classroom used this language. Analysing interview transcripts and fieldnotes in the original language is more authentic because it allows me to capture key ideas expressed by the participants in their own words. Meanwhile, the coding process was done in English.

The qualitative analysis involved both manual analysis and by using NVivo 12. Thematic analysis was used to analyse the qualitative data from the classroom observations, focus group interviews, and semi-structured interviews. Thematic analysis refers to "a method for systematically identifying, organizing, and offering an insight into patterns of meaning (themes) across a data set" (Braun \& Clarke, 2012, p. 57). This thematic analysis was carried out in six phases (Braun \& Clarke, 2006, 2012). First, I familiarised myself with the data through transcribing data by myself, and then noted the initial ideas that emerged through the process of reading data repeatedly. Second, I made initial codes from interesting data features systematically. Third, I organised the codes into potential themes. Fourth, I reviewed the themes by checking and re-checking the codes and candidate themes to see if they formed coherent patterns. Fifth, I determined and named the themes after refining the specifics and the essences of each theme. Sixth, I made a report to provide a compelling story based on the results of the analysis. The results of this qualitative analysis were then compared with the results of the quantitative analysis for integrated data analysis.

\subsubsection{Integrated data analysis}

In conducting integrated data analysis, I looked across the quantitative results and the qualitative findings and made an assessment of how the information gathered would address the research questions in my study (Creswell \& Clark, 2018). The steps in the integrated data analysis include: (1) data reduction, (2) data display, (3) data transformation, (4) data correlation, (5) data consolidation, (6) data comparison, and (7) data integration (Ary et al., 2010; Creswell \& Clark, 2018; Onwuegbuzie \& Combs, 2010; Onwuegbuzie \& Teddlie, 2003). 
The first step was data reduction, in which quantitative data were reduced through descriptive and inferential statistical analysis, while qualitative data were reduced during qualitative analysis. The second step was data display. I presented quantitative data in tables and charts, while qualitative data was displayed in lists. The third step was data transformation; that is, transforming quantitative data into qualitative ones or vice versa. For example, I did this step by converting quantitative data from the historical beliefs questionnaire into categories regarding students' epistemic beliefs so that it could be analysed qualitatively. At the same time, the qualitative data from focus group interviews related to aspects of students' epistemic beliefs about history were also categorised based on the levels of epistemic beliefs that were set quantitatively.

The fourth step was data correlation, which involves correlating the data from the different analyses. For example, I correlated quantitative data from the results of historical beliefs questionnaire with quantitised data (quantification of qualitative data) about the level of students' historical beliefs obtained from focus interviews. The fifth step was data consolidation by combining two types of data. The sixth step was data comparison, by comparing data from different sources. The seventh step was data integration, in which the data and the interpretations were integrated into a coherent whole.

\subsubsection{Validity and reliability of the mixed methods design}

Since mixed research involves a combination of strengths and weaknesses of quantitative and qualitative research, assessing the validity and reliability of data is particularly complex (Onwuegbuzie \& Johnson, 2006). Meanwhile, there is still disagreement among scholars on this issue (Creswell \& Clark, 2018). Therefore, in the quantitative aspect, to ensure that the instruments could measure what should be measured, I tested the validity and reliability of the instruments. I explained this aspect in the section about conducting a pilot study above. Additionally, to guarantee the trustworthiness of the qualitative data, I had to consider aspects of credibility, transferability, dependability and confirmability of findings (Ary et al., 2010; Guba, 1981).

Credibility in the qualitative aspect concerns the veracity of data findings (Ary et al., 2010). To address this issue, I used two strategies by employing 
triangulation and member checking with participants (Creswell, 2012). Triangulation was carried out by combining data obtained from various data sources, such as from classroom observation, focus group interviews and semistructured interviews. I also used member checking to give participants the opportunity to review and respond to transcripts of their interviews. The member checking process was done by sending the transcripts of the interviews to the participants. This took place from December 2018 to January 2019 after I completed the interview transcripts. Details of the timeframes of the member checking process can be seen in Tables 4.8 and 4.9.

To guarantee the aspects of transferability, this study provides sufficiently rich, detailed, and thick descriptions of the context so that potential readers can make the necessary comparisons to other situations or contexts with similar characteristics (Ary et al., 2010; Guba, 1981). To ensure dependability, triangulation strategies were also used to establish the reliability of this study. Corroboration of multiple data sources and multiple methods which produced similar findings enhances the dependability of the study (Ary et al., 2010). Triangulation strategies were also used to guarantee aspects of confirmability because the claims of data finding supported by at least two data sources could ensure research objectivity (Ary et al., 2010; Guba, 1981).

\subsection{Limitations of the study}

Mixed methods research offers new insights that go beyond separate quantitative and qualitative results so that deeper knowledge can be obtained (Creswell \& Clark, 2018). However, all studies have limitations. This study also has several limitations that need to be acknowledged. First, one of the challenges of the present study was gathering data from the intervention process conducted by three different teacher participants at three different schools. Although the lesson plan was prepared in detail and teacher participants also received adequate training, accompanied by peer teaching practice during the training, I could not fully control the intervention processes to be done in the same way precisely. During the teaching process, many different contextual factors also influenced the occurrence of differences in the teaching and learning process. Thus, the results of students' 
historical thinking skills in this study did not rule out the possibility of being influenced by a variety of different factors.

Secondly, the interpretive essays scores which were used as the basis for determining students' historical thinking skills, did not automatically reflect the ability of individual students to think historically. This is because the essays were done collaboratively in small cohorts. Any student in a cohort who was able to think historically actually could be tracked during the process of discussion and debate in the classroom. However, the literature reviewed shows that the most appropriate way to measure historical thinking skills is through writing interpretive essays. This study was unable to give the writing assignment individually because it would complicate the teacher participants' role to assess the essays due to the limited time available. Moreover, as a beginner in writing historical interpretive essays, working in cohorts was much more helpful for students to learn history in a better way.

Thirdly, another limitation that was quite complicated was the language barrier. The entire process of data collection was planned to use Bahasa Indonesia. In practice, both teacher and student participants often used mixed languages between Bahasa Indonesia and Javanese. On one hand, it was good because they used the language that best reflected their ideas, but it was also a challenge to translate them in English so that they fit in with their original ideas. Still, another limitation in language was regarding the historical belief questionnaire. I originally planned to give a bilingual questionnaire, so that it could present the original language of the questionnaire and with its translation to make it easier for students to understand. However, during the pilot study students complained that it was difficult to read the bilingual questionnaire, and they preferred the questionnaire to be in Bahasa Indonesia only.

\subsection{Ethical consideration}

This study involves human subjects as informants and participants, so all the instruments in this study had to meet ethical standards. All research instruments were reviewed and approved by the Human Ethics Committee of Victoria University of Wellington in July 2018 prior to my data collection (appendix A). Since this study involves four teacher participants from four different schools as 
well as their students (including pilot study), I had to provide information sheets and consent forms for each participant. First, I provided information about the research to the school headmasters so that they could provide informed consent (appendix B and C). After the headmasters gave their consent, I provided the information sheet for the candidate of teacher participants before engaging in the research (appendix D). After the teacher participants gave their approval (appendix E), I gave them a training session on the details of what they had to do in their teaching and learning process. Lastly, a few days before the learning intervention process began, I provided an information sheet to the students so that they could decide to be involved or not in my study (appendix F and G). All students gave their consent to be involved in my study and no one withdrew during the data collection process. I also prepared the parents/guardians approval column, but it was not necessary because all students were over 16 years old. I also gave students the opportunity to determine their own pseudonyms, but they asked me or the teacher to determine the pseudonym for them. Their decision turned out to make it easier for me in the process of classroom observation and focus group interview because they used their real names naturally during teaching and learning process making it easier for me to identify them when writing the fieldnotes or focus group interview transcriptions.

In this chapter, I presented the research method that I used in this study. The next few chapters present the findings of this study which were obtained through the methods described in this chapter. The findings of the quantitative and qualitative data are presented based on each research question. 


\section{CHAPTER 5 \\ STUDENTS' INITIAL UNDERSTANDING OF THE BATTLE \\ OF SURABAYA}

This chapter presents the results of the open-ended questionnaire. The purpose of this chapter is to answer the first sub-question regarding students' initial understanding of the battle of Surabaya, specifically regarding the flag incident and the death of Mallaby. It is assumed that prior to the intervention process, the experimental and control groups in this study had approximately the same level of understanding. The first section of this chapter presents the comparison of students' initial understanding of the flag incident in the battle of Surabaya. The second section presents the comparison of students' initial understanding of the death of Mallaby in the battle of Surabaya. General comparisons of students' initial understanding are presented in the third section. Preliminary data before the intervention process regarding students' initial understanding of the battle of Surabaya is useful for determining the effectiveness of teaching history through analysing documents and interpreting textbooks in fostering students' historical thinking skills at the end of the intervention process.

\subsection{Students' initial understanding of the Flag Incident}

The flag incident was an event that occurred on 19 September 1945, when the youths of Surabaya tore the blue portion of the Dutch flag and raised back the redand-white part of the Dutch flag as Indonesian flag. This event occurred before the outbreak of battle of Surabaya, but it was "the first open declaration of intent to go to war" (Palmos, 2011, p. 157). As one of the significant events in Indonesia as well as a pivotal moment in the creation of the Indonesian nation-state, many people or parties claim to have been involved in this incident (Widiadi, 2019) and school textbooks also do not mention who tore the Dutch flag in the incident (Poesponegoro \& Notosusanto, 2010; Sardiman \& Lestariningsih, 2017b). The photographs of the flag incident are often displayed in Indonesian history textbooks (Widiadi, 2019) and students are familiar with this image having repeatedly seen the picture. 
Based on the picture of the flag incident presented in the open-ended questionnaire (see appendix J), students were asked to answer six questions. The general result showed that most of the students in the control and experimental group were able to answer in a factually accurate manner because they frequently saw it in the textbooks or during the history lesson in the classroom. However, they did not have a critical and detailed understanding of the chronology, cause, and consequence of the flag incident. The detailed results of the open-ended questionnaire based on the six questions are presented as follows:

\subsubsection{Open-ended question 1: The event}

The number of student participants in this study was 95 for the control group and 96 for the experimental group. However, three students from the control group and seven from the experimental group were absent when the questionnaire was distributed. The first question in the open-ended questionnaire was intended to find out whether students could correctly identify the factual knowledge presented in a picture regarding the flag incident. Students' responses were sorted on to categories of factually accurate and inaccurate answers as the purpose of this exercise was to explore students' existing content knowledge before the implementation of the intervention process. I assumed that the process of teaching history that emphasises lectures by teachers who rely heavily on textbooks that have a single version of history had an impact on students who assimilated the same version continuously. The effect was that they might be able to memorise some factual knowledge about significant events in the past, but they were unable to think critically. In addition, history education in Indonesia, which is still used to instil nationalism, also has an impact on students who see the past in binary, i.e. right or wrong.

Details of the categories and themes of students' answers in the response to the first question can be found in the following table:

Table 5.1 Students' responses to the first question (the event of the flag incident)

\begin{tabular}{|c|c|c|c|c|c|c|c|c|}
\hline \multirow{2}{*}{ No } & \multirow{2}{*}{ Category } & \multirow{2}{*}{ Themes } & \multicolumn{3}{|c|}{ Control group } & \multicolumn{3}{|c|}{ Experimental group } \\
\hline & & & f & $\%$ & $\Sigma$ & f & $\%$ & $\Sigma$ \\
\hline \multirow[t]{2}{*}{1} & Factually & The flag incident & 78 & $85 \%$ & \multirow{2}{*}{$99 \%$} & 74 & $83 \%$ & \multirow{2}{*}{$99 \%$} \\
\hline & accurate & The battle of Surabaya & 13 & $14 \%$ & & 14 & $16 \%$ & \\
\hline 2 & $\begin{array}{l}\text { Factually } \\
\text { inaccurate }\end{array}$ & Forced labour & 1 & $1 \%$ & $1 \%$ & 1 & $1 \%$ & $1 \%$ \\
\hline & & Total & 92 & $100 \%$ & $100 \%$ & 89 & $100 \%$ & $100 \%$ \\
\hline
\end{tabular}


Based on the table above, most of the students' answers in both groups were as factually accurate. There were $85 \%$ of the control group students and $83 \%$ of the experimental group students who specifically answered that the picture asked in the questionnaire was related to the flag incident, while some students said that the picture was related to the battle of Surabaya, which could also be categorised as the factually accurate answer. However, in both groups, there were still factually inaccurate answers from students who responded that the picture was related to forced labour during the Dutch occupation.

\subsubsection{Open-ended question 2: The sources of information}

The second question was intended to find out how students developed their initial understandings in their answers to the first question. Even though there was only one question (how do you know about this event?) some students gave more than one answer that could reflect how they knew the image asked in the questionnaire from various sources of information. These responses were categorised into 10 themes. The column of the percentage of cases in the table shows the number of percentages obtained from the division of the frequencies per theme divided by the total number of students in each group $(n=92$ for the control group and $\mathrm{n}=89$ for the experimental group).

The findings indicate that most of the students from both groups obtained the information about the flag incident from history textbooks. The details of both groups' answers can be seen in the following table:

Table 5.2 Students' responses to the second question (the sources of information on the flag incident)

\begin{tabular}{|c|c|c|c|c|c|c|c|}
\hline \multirow[b]{2}{*}{ No } & \multirow{2}{*}{$\begin{array}{l}\text { Themes of } \\
\text { responses }\end{array}$} & \multicolumn{3}{|c|}{ Control group } & \multicolumn{3}{|c|}{ Experimental group } \\
\hline & & $\mathbf{f}$ & $\begin{array}{c}\text { Percentage of } \\
\text { responses }\end{array}$ & $\begin{array}{c}\text { Percentage } \\
\text { of cases }\end{array}$ & f & $\begin{array}{c}\text { Percentage of } \\
\text { responses }\end{array}$ & $\begin{array}{c}\text { Percentage } \\
\text { of cases }\end{array}$ \\
\hline 1 & $\begin{array}{l}\text { History } \\
\text { textbooks }\end{array}$ & 50 & $36 \%$ & $54 \%$ & 52 & $35 \%$ & $58 \%$ \\
\hline 2 & History teacher & 11 & $8 \%$ & $12 \%$ & 26 & $17 \%$ & $29 \%$ \\
\hline 3 & History lesson & 32 & $23 \%$ & $35 \%$ & 27 & $18 \%$ & $30 \%$ \\
\hline 4 & Internet & 17 & $12 \%$ & $18 \%$ & 27 & $18 \%$ & $30 \%$ \\
\hline 5 & Museum & 0 & $0 \%$ & $0 \%$ & 1 & $1 \%$ & $1 \%$ \\
\hline 6 & $\begin{array}{l}\text { Based on the } \\
\text { image } \\
\text { (guessing) }\end{array}$ & 16 & $12 \%$ & $17 \%$ & 7 & $5 \%$ & $8 \%$ \\
\hline 7 & $\begin{array}{l}\text { Parents and } \\
\text { people's stories }\end{array}$ & 2 & $1 \%$ & $2 \%$ & 5 & $3 \%$ & $6 \%$ \\
\hline 8 & Movies & 6 & $4 \%$ & $7 \%$ & 2 & $1 \%$ & $2 \%$ \\
\hline 9 & TV programs & 4 & $3 \%$ & $4 \%$ & 3 & $2 \%$ & $3 \%$ \\
\hline 10 & "don't know" & 0 & $0 \%$ & $0 \%$ & 0 & $0 \%$ & $0 \%$ \\
\hline
\end{tabular}




\begin{tabular}{llcccccc}
\hline \multirow{2}{*}{ No } & Themes of & \multicolumn{3}{c}{ Control group } & \multicolumn{3}{c}{ Experimental group } \\
\cline { 2 - 7 } & responses & f & $\begin{array}{c}\text { Percentage of } \\
\text { responses }\end{array}$ & $\begin{array}{c}\text { Percentage } \\
\text { of cases }\end{array}$ & f & $\begin{array}{c}\text { Percentage of } \\
\text { responses }\end{array}$ & $\begin{array}{c}\text { Percentage } \\
\text { of cases }\end{array}$ \\
\hline Total & 138 & $100 \%$ & $\mathrm{n}=92$ & 150 & $100 \%$ & $\mathrm{n}=89$ \\
\hline
\end{tabular}

Based on the table above, it is apparent that in the control group, most students claimed that they knew the picture from the textbooks (54\%) while 32 students claimed to know the image from the process of history lessons $(35 \%)$, and 17 students knew the image from the internet (18\%). However, there were also some students $(n=16)$ who answered based solely on the image in the questionnaire $(17 \%)$, that may be deductively guessing based on the image which indicated they had some corresponding background knowledge. In the experimental group students, most students $(n=52)$ also knew the image from the textbooks they had read $(58 \%)$. Then, there were two themes, each of which reached $30 \%$ of cases, namely from the history lesson and from the internet. There were 26 students who claimed to know the image of the flag incident from their history teachers (29\%).

\subsubsection{Open-ended question 3: The chronology of the event}

The third question was intended to find out whether students knew the detailed information about the chronology of the battle of Surabaya, specifically related to the flag incident. Students' answers can be grouped into two categories, namely factually accurate and inaccurate answers. Students' answers were categorised as factually accurate if they could mention the outline of the chronology of the event accurately, while those who could not were categorised as factually inaccurate. From the two sets of answers, each of was further divided again into "detailed chronology" and "undetailed chronology". Themes of "detailed chronology" described the sequence of events accompanied by details of the time of occurrence. On the other hand, if the students' answers were not accompanied by details of the time of occurrence, then they were classified as "undetailed chronology". Those who did not know the answer were categorised as the "don't know", while those who did not answer at all were categorised as "no answer".

The data findings show that most of the students from both groups were able to describe the sequence of the flag incident accurately. However, they did not describe it in detailed chronology and did not even mention when the incident 
occurred. The following table contains complete data on the students' responses to the third question:

Table 5.3 Students' responses to the third question (the chronology of the flag incident)

\begin{tabular}{|c|c|c|c|c|c|c|c|c|}
\hline \multirow{2}{*}{ No } & \multirow{2}{*}{ Category } & \multirow{2}{*}{ Themes } & \multicolumn{3}{|c|}{ Control group } & \multicolumn{3}{|c|}{ Experimental group } \\
\hline & & & $\mathbf{f}$ & $\%$ & $\Sigma$ & $\mathbf{F}$ & $\%$ & $\Sigma$ \\
\hline \multirow[t]{2}{*}{1} & \multirow[t]{2}{*}{$\begin{array}{l}\text { Factually } \\
\text { accurate }\end{array}$} & $\begin{array}{l}\text { Accurate (detailed } \\
\text { chronology) }\end{array}$ & 2 & $2 \%$ & \multirow[t]{2}{*}{$66 \%$} & 0 & $0 \%$ & \multirow[t]{2}{*}{$52 \%$} \\
\hline & & $\begin{array}{l}\text { Accurate (undetailed } \\
\text { chronology) }\end{array}$ & 59 & $64 \%$ & & 46 & $52 \%$ & \\
\hline \multirow[t]{5}{*}{2} & \multirow[t]{5}{*}{$\begin{array}{l}\text { Factually } \\
\text { inaccurate }\end{array}$} & $\begin{array}{l}\text { Inaccurate (detailed } \\
\text { chronology) }\end{array}$ & 2 & $2 \%$ & \multirow[t]{4}{*}{$34 \%$} & 10 & $11 \%$ & \multirow[t]{4}{*}{$48 \%$} \\
\hline & & $\begin{array}{l}\text { Inaccurate (undetailed } \\
\text { chronology) }\end{array}$ & 28 & $30 \%$ & & 30 & $34 \%$ & \\
\hline & & "don't know" & 1 & 1 & & 2 & $2 \%$ & \\
\hline & & "no answer" & 0 & $0 \%$ & & 1 & $1 \%$ & \\
\hline & & Total & 92 & $100 \%$ & $100 \%$ & 89 & $100 \%$ & $100 \%$ \\
\hline
\end{tabular}

When asked to explain the chronology of the flag incident, most of the control group students $(n=61)$ were able to provide answers in factually accurate answers $(66 \%)$. However, only two students gave details of the time of occurrence accurately $(2 \%)$ while others $(n=59)$ did not give details of the time of occurrence $(64 \%)$. As for the category of factually inaccurate, there were 31 students who gave factually inaccurate answers (34\%) and most of them did not give details of the date of the incident $(30 \%)$. There was one student who claimed to not know the answer $(1 \%)$.

Similar to the control group students, more than half of the students $(n=46)$ in the experimental group were also able to answer this question accurately (52\%). Of these numbers, none of the students gave details of the time of the flag incident and was categorised as "undetailed chronology". The answers from the remaining 43 other students can be categorised as factually inaccurate answers in explaining the chronology of the flag incident (48\%). Among the categories of factually inaccurate answers, there were 10 students who tried to give details of the time of the incident, but these were still inaccurate $(11 \%)$. Their mistake was generally due to mentioning that the flag incident occurred on 10 November 1945, when in fact it happened on 19 September 1945. This happened because the Indonesian people, in general, recognise the battle of Surabaya as "the battle of 10 November" and at the same time, it is celebrated as National Heroes Day every November $10^{\text {th }}$. 


\subsubsection{Open-ended question 4: The cause of the event}

The fourth question was intended to find out whether students knew the detailed information about the cause of the battle of Surabaya, specifically related to the flag incident. In analysing the variety of students' answers, two themes emerged and could be categorised as factually accurate answers and the rest could be categorised as factually inaccurate. The data findings indicate that most of the students from both groups were able to answer in factually accurate and each student tended to present only one possible cause of the flag incident in their undetailed answer.

Details of the control and experimental groups' answers to this fourth question can be found in the following table:

Table 5.4 Students' responses to the fourth question (the cause of the flag incident)

\begin{tabular}{|c|c|c|c|c|c|c|c|c|}
\hline \multirow{2}{*}{ No } & \multirow{2}{*}{ Category } & \multirow{2}{*}{ Themes } & \multicolumn{3}{|c|}{ Control group } & \multicolumn{3}{|c|}{ Experimental group } \\
\hline & & & $\mathbf{f}$ & $\%$ & $\Sigma$ & $\mathbf{F}$ & $\%$ & $\Sigma$ \\
\hline \multirow[t]{2}{*}{1} & \multirow[t]{2}{*}{$\begin{array}{l}\text { Factually } \\
\text { accurate }\end{array}$} & $\begin{array}{l}\text { The Dutch raised their } \\
\text { flag }\end{array}$ & 50 & $54 \%$ & \multirow[t]{2}{*}{$67 \%$} & 45 & $51 \%$ & \multirow[t]{2}{*}{$56 \%$} \\
\hline & & $\begin{array}{l}\text { The Dutch still wanted to } \\
\text { control Indonesia }\end{array}$ & 12 & $13 \%$ & & 5 & $6 \%$ & \\
\hline \multirow[t]{9}{*}{2} & \multirow{9}{*}{$\begin{array}{l}\text { Factually } \\
\text { inaccurate }\end{array}$} & The death of Mallaby & 3 & $3 \%$ & \multirow[t]{8}{*}{$33 \%$} & 2 & $2 \%$ & \multirow[t]{8}{*}{$44 \%$} \\
\hline & & $\begin{array}{l}\text { The cruelty of Dutch } \\
\text { colonisers }\end{array}$ & 8 & $9 \%$ & & 10 & $11 \%$ & \\
\hline & & $\begin{array}{l}\text { Allied ultimatum for } \\
\text { Surabaya residents to } \\
\text { surrender weapons }\end{array}$ & 2 & $2 \%$ & & 2 & $2 \%$ & \\
\hline & & $\begin{array}{l}\text { The arrival of the Allies } \\
\text { and the Dutch }\end{array}$ & 3 & $3 \%$ & & 4 & $4 \%$ & \\
\hline & & Seizure of territory & 6 & $7 \%$ & & 3 & $3 \%$ & \\
\hline & & Other answers & 6 & $7 \%$ & & 15 & $17 \%$ & \\
\hline & & "don't know" & 1 & $1 \%$ & & 1 & $1 \%$ & \\
\hline & & "no answers" & 1 & $1 \%$ & & 2 & $2 \%$ & \\
\hline & & Total & 92 & $100 \%$ & $100 \%$ & 89 & $100 \%$ & $100 \%$ \\
\hline
\end{tabular}

For the control group students, most of them were able to answer accurately regarding the cause of the flag incident. There were 50 students who answered that the cause of the flag incident was triggered by the act of the Dutch ex-internees who raised their flag at the Yamato Hotel (54\%). There were also 12 students who answered that the cause of the flag incident was because of the Dutch's desire to regain control of Indonesia after Japan's defeat in World War II (13\%). In total, there were 62 students who could answer accurately (67\%), while the remaining $33 \%$ of the answers fell into the factually inaccurate answers category. For example, 
the most frequent theme was "the cruelty of Dutch colonisers" which reached $9 \%$ and could be categorised as wrong answers because basically, the Dutch colonialism has ended when the Dutch East Indies was occupied by the Japanese military in 1942.

For the experimental group, there were 50 students who answered accurately (56\%) and 39 students whose answers were in the factually inaccurate category (44\%). The experimental group students mostly answered that the cause of the flag incident was because the Dutch raised their flag (51\%). Similar to the control group, many students in the experimental group (11\%) also did not understand that the flag incident did not occur during the Dutch colonial era and saw the Dutch as always acting cruelly. There were also two students who considered Mallaby's death (which occurred on 30 October 1945) as the cause of the flag incident (which occurred on 19 September 1945), and this was included in the category of inaccurate answers.

From both groups, each student only gave one answer regarding the cause of the flag incident. They did not present the possibility of different perspectives on the causes of the flag incident. This indicates that they were accustomed to seeing a historical event caused by only one determining factor

\subsubsection{Open-ended question 5: The consequence of the event}

The fifth question was intended to find out whether students knew the detailed information about the consequence of the battle of Surabaya, in this case, related to the flag incident. Based on the answers of the two groups of students, there were four themes of answers that could be categorised as factually accurate answers, and the rest were put in the category of inaccurate answers. Actually, there were many themes that emerged in the category of the factually inaccurate answers, but what is presented here are themes that appeared in both groups, while themes that only appear in one group were included in the "other answers" theme.

The findings show that most of the students from both groups were able to answer in a factually accurate manner. However, each of these students tended to present only one possible consequence of the flag incident in their undetailed answer. The following table presents data regarding students' responses from both groups: 
Table 5.5 Students' responses to the fifth question (the consequence of the flag incident)

\begin{tabular}{|c|c|c|c|c|c|c|c|c|}
\hline \multirow{2}{*}{ No } & \multirow{2}{*}{ Category } & \multirow{2}{*}{ Themes } & \multicolumn{3}{|c|}{ Control group } & \multicolumn{3}{|c|}{ Experimental group } \\
\hline & & & $\mathbf{F}$ & $\%$ & $\Sigma$ & $\mathbf{F}$ & $\%$ & $\Sigma$ \\
\hline \multirow[t]{4}{*}{1} & \multirow[t]{4}{*}{$\begin{array}{l}\text { Factually } \\
\text { accurate }\end{array}$} & $\begin{array}{l}\text { The Dutch flag was torn, } \\
\text { and the Indonesian flag } \\
\text { was raised }\end{array}$ & 15 & $16 \%$ & $73 \%$ & 14 & $16 \%$ & \multirow[t]{4}{*}{$71 \%$} \\
\hline & & Many casualties & 34 & $37 \%$ & & 39 & $44 \%$ & \\
\hline & & $\begin{array}{l}\text { The emergence of } \\
\text { Indonesian unity and the } \\
\text { spirit of resistance against } \\
\text { the Dutch }\end{array}$ & 3 & $3 \%$ & & 6 & $7 \%$ & \\
\hline & & $\begin{array}{l}\text { The trigger of the battle } \\
\text { of Surabaya }\end{array}$ & 15 & $16 \%$ & & 4 & $4 \%$ & \\
\hline \multirow[t]{7}{*}{2} & \multirow[t]{7}{*}{$\begin{array}{l}\text { Factually } \\
\text { inaccurate }\end{array}$} & $\begin{array}{l}\text { Indonesian won and the } \\
\text { Dutch army were } \\
\text { expelled from Indonesia }\end{array}$ & 5 & $5 \%$ & $27 \%$ & 7 & $8 \%$ & \multirow[t]{6}{*}{$29 \%$} \\
\hline & & $\begin{array}{l}\text { The Dutch won and } \\
\text { Surabaya was controlled } \\
\text { by the Dutch }\end{array}$ & 1 & $1 \%$ & & 3 & $3 \%$ & \\
\hline & & $\begin{array}{l}\text { The Dutch were angry, } \\
\text { and their atrocities were } \\
\text { getting worse }\end{array}$ & 2 & $2 \%$ & & 1 & $1 \%$ & \\
\hline & & Other answers & 16 & $17 \%$ & & 13 & $15 \%$ & \\
\hline & & "don’t know" & 1 & $1 \%$ & & 1 & $1 \%$ & \\
\hline & & "no answer" & 0 & $0 \%$ & & 1 & $1 \%$ & \\
\hline & & Total & 92 & $100 \%$ & $100 \%$ & 89 & $100 \%$ & $100 \%$ \\
\hline
\end{tabular}

By referring to the answers of the control group students, most of their answers could be categorised as factually accurate answers (73\%). The most frequent theme was the emergence of many casualties (37\%) because it was the simplest answer from students when asked about the consequence of a battle. The most appropriate theme in responding to the impact of the flag incident was the tearing of the Dutch flag and the raising of the Indonesian flag; but, only 15 students answered in this theme (16\%). The indirect consequence of the flag incident has triggered the outbreak of the battle of Surabaya and there were 15 students whose answers were included in this theme (16\%). The psychological impact of the flag incident was the emergence of Indonesian unity and the spirit of resistance against the Dutch and there were 3 students whose answers were included in this theme $(3 \%)$. The rest were a variety of factually inaccurate answers theme which reached $27 \%$ of 92 control group respondents.

The similar response also occurred in the experimental group where most students' answers were in the category of factually accurate answers (71\%). The theme of "many casualties" also had the highest frequency of students" answers in 
this group (44\%). At the level below, there were 14 students whose answers could be categorised in the theme of "the Dutch flag was torn, and the Indonesian flag was raised" (16\%). The answer theme of "the emergence of Indonesian unity and the spirit of resistance against the Dutch" was 7\% and the answer theme of "the trigger of the battle of Surabaya" was 4\%. Meanwhile, the remaining answer themes were in the category of factually inaccurate answers $(29 \%)$.

Therefore, all students in both groups responded by giving a single effect of the flag incident, none of which gave alternative answers in the form of multiple consequences. This indicates that they were accustomed to seeing a historical event as having only one single effect.

\subsubsection{Open-ended question 6: The historical significance of the event}

The sixth question in this open-ended questionnaire was intended to ask students' opinion whether the image related to the flag incident was an important event in Indonesian history. Historical events can be categorised significance if they have profound consequences on many people over a long period of time and have a meaningful place in the heart of the next generation (Seixas \& Morton, 2013), especially for students who study history. In this context, students were asked whether the flag incident have a meaningful place in Indonesian history based on their personal opinions. Basically, there were no right or wrong answers to this question because it was asking their opinions and reasons. In reality, the flag incident is always considered a significant event in Indonesia because it is always taught in schools and is prominent in history textbooks as well as being remembered annually as a part of the Hero Day's commemoration.

The data findings indicate that almost all students in the control and experimental groups stated that the flag incident was an important event in Indonesian history. Most of the students considered the flag incident was a significant event because it was useful for understanding the Indonesian' struggle for independence. The following table provides detailed themes of students' answers regarding the historical significance of the flag incident: 
Table 5.6 Students' responses to the sixth question (the historical significance of the flag incident)

\begin{tabular}{|c|c|c|c|c|c|c|c|c|}
\hline \multirow{2}{*}{ No } & \multirow{2}{*}{ Category } & \multirow{2}{*}{ Themes } & \multicolumn{3}{|c|}{ Control group } & \multicolumn{3}{|c|}{ Experimental group } \\
\hline & & & $\mathbf{F}$ & $\%$ & $\Sigma$ & $\mathbf{F}$ & $\%$ & $\Sigma$ \\
\hline \multirow[t]{7}{*}{1} & \multirow[t]{7}{*}{$\begin{array}{l}\text { Historical } \\
\text { significance }\end{array}$} & $\begin{array}{l}\text { To understand the } \\
\text { struggle for } \\
\text { independence }\end{array}$ & 39 & $42 \%$ & \multirow[t]{7}{*}{$99 \%$} & 38 & $43 \%$ & \multirow[t]{7}{*}{$99 \%$} \\
\hline & & $\begin{array}{l}\text { To understand the } \\
\text { struggle against the } \\
\text { colonisers }\end{array}$ & 12 & $13 \%$ & & 14 & $16 \%$ & \\
\hline & & $\begin{array}{l}\text { To understand the } \\
\text { struggle in raising the } \\
\text { Indonesian flag }\end{array}$ & 21 & $23 \%$ & & 7 & $8 \%$ & \\
\hline & & $\begin{array}{l}\text { It has caused many } \\
\text { casualties }\end{array}$ & 1 & $1 \%$ & & 1 & $1 \%$ & \\
\hline & & $\begin{array}{l}\text { To appreciate the } \\
\text { services of Indonesian } \\
\text { heroes }\end{array}$ & 9 & $10 \%$ & & 16 & $18 \%$ & \\
\hline & & $\begin{array}{l}\text { It must be remembered } \\
\text { in history }\end{array}$ & 5 & $5 \%$ & & 7 & $8 \%$ & \\
\hline & & $\begin{array}{l}\text { Lessons learned from } \\
\text { history }\end{array}$ & 4 & $4 \%$ & & 5 & $5 \%$ & \\
\hline \multirow[t]{4}{*}{2} & \multirow[t]{4}{*}{$\begin{array}{l}\text { Historical } \\
\text { insignificance }\end{array}$} & $\begin{array}{l}\text { This event was only a } \\
\text { small example among } \\
\text { other Dutch atrocities }\end{array}$ & 1 & $1 \%$ & \multirow[t]{3}{*}{$1 \%$} & 0 & $0 \%$ & \multirow[t]{3}{*}{$1 \%$} \\
\hline & & $\begin{array}{l}\text { This event has little } \\
\text { effect on the founding } \\
\text { of Indonesia }\end{array}$ & 0 & $0 \%$ & & 1 & $1 \%$ & \\
\hline & & "don't know" & 0 & $0 \%$ & & 0 & $0 \%$ & \\
\hline & & otal & 92 & $100 \%$ & $100 \%$ & 89 & $100 \%$ & $100 \%$ \\
\hline
\end{tabular}

In the control group, there were 91 students who considered the flag incident as shown in the questionnaire picture as a significant event in Indonesian history (99\%). There was only one student who stated that the incident was not important because it was only a small example among the many other atrocities of the colonisers. In the experimental group, there were 88 students who considered the flag incident as shown in the picture as historical significance in Indonesian history (99\%). There was also only one student in this group who argued that the incident was not so important because it had a small impact on the establishment of Indonesia. Therefore, most students in both groups considered that the image related to the flag incident was an important event because it could be used to understand the struggle of the Indonesian people in gaining independence. 


\subsection{Students' initial understanding of the death of Mallaby}

Brigadier Aubertin Walter Sothern Mallaby was a British Indian Army officer who was killed in the early phase of the battle of Surabaya on 30 October 1945. The cause of Mallaby's death has been a matter of debate since it happened, and its historical versions have also been contested. School history textbooks in Indonesia always present this event because it is claimed as evidence of the victory of the Indonesian people in defeating the Allied army (Poesponegoro \& Notosusanto, 2010; Sardiman \& Lestariningsih, 2017b). Pictures related to Mallaby's death are also often included in school history textbooks from time to time (Widiadi, 2019).

Based on a picture related to the death of Mallaby presented in the open-ended questionnaire (see appendix J), students were asked to answer six questions. The general result shows that most of the students in the control and experimental groups were able to answer accurately because they frequently saw it in the textbooks. However, they answered inaccurately about the chronology and cause of Mallaby's death. Although most of them could mention accurately the consequence of the incident, students were generally not critical when describing the chronology, cause, and consequences of Mallaby's death. Most students also considered the death of Mallaby as a significant event in Indonesian history. The detailed results of the open-ended questionnaire based on the six questions are presented as follows:

\subsubsection{Open-ended question 1: The event}

Regarding students' responses to the first question related to the picture of the death of Mallaby, most of the students from both groups answered accurately. Detailed data on the answers of the two groups can be found in the following table:

Table 5.7 Students' responses to the first question (the event of the death of Mallaby)

\begin{tabular}{|c|c|c|c|c|c|c|c|c|}
\hline \multirow{2}{*}{ No } & \multirow{2}{*}{ Category } & \multirow{2}{*}{ Themes } & \multicolumn{3}{|c|}{ Control group } & \multicolumn{3}{|c|}{ Experimental group } \\
\hline & & & $\mathbf{F}$ & $\%$ & $\Sigma$ & $\mathbf{f}$ & $\%$ & $\Sigma$ \\
\hline \multirow[t]{3}{*}{1} & \multirow{3}{*}{$\begin{array}{l}\text { Factually } \\
\text { accurate }\end{array}$} & The death of Mallaby & 39 & $42 \%$ & \multirow[t]{3}{*}{$77 \%$} & 28 & $31 \%$ & \multirow[t]{3}{*}{$55 \%$} \\
\hline & & The battle of Surabaya & 18 & $20 \%$ & & 19 & $21 \%$ & \\
\hline & & $\begin{array}{l}\text { The Red Bridge } \\
\text { incident }\end{array}$ & 14 & $15 \%$ & & 2 & $2 \%$ & \\
\hline \multirow[t]{3}{*}{2} & \multirow[t]{3}{*}{$\begin{array}{l}\text { Factually } \\
\text { inaccurate }\end{array}$} & $\begin{array}{l}\text { The proclamation of } \\
\text { independence }\end{array}$ & 2 & $2 \%$ & \multirow[t]{3}{*}{$23 \%$} & 2 & $2 \%$ & \multirow[t]{3}{*}{$45 \%$} \\
\hline & & $\begin{array}{l}\text { Destruction of a Dutch } \\
\text { car }\end{array}$ & 4 & $4 \%$ & & 5 & $6 \%$ & \\
\hline & & $\begin{array}{l}\text { Other battles in } \\
\text { Indonesia }\end{array}$ & 1 & $1 \%$ & & 14 & $16 \%$ & \\
\hline
\end{tabular}




\begin{tabular}{|c|c|c|c|c|c|c|c|c|}
\hline \multirow[b]{2}{*}{ No } & \multirow[b]{2}{*}{ Category } & \multirow[b]{2}{*}{ Themes } & \multicolumn{3}{|c|}{ Control group } & \multicolumn{3}{|c|}{ Experimental group } \\
\hline & & & $\mathbf{F}$ & $\%$ & $\Sigma$ & f & $\%$ & $\Sigma$ \\
\hline & & $\begin{array}{l}\text { Old buildings in } \\
\text { Indonesia }\end{array}$ & 1 & $1 \%$ & & 5 & $6 \%$ & \\
\hline & & $\begin{array}{l}\text { People's revolt against } \\
\text { the Dutch }\end{array}$ & 1 & $1 \%$ & & 2 & $2 \%$ & \\
\hline & & Other answers & 10 & $11 \%$ & & 8 & $9 \%$ & \\
\hline & & "don’t know" & 2 & $2 \%$ & & 4 & $4 \%$ & \\
\hline & & Total & 92 & $100 \%$ & $100 \%$ & 89 & $100 \%$ & $100 \%$ \\
\hline
\end{tabular}

When compared with students' responses to the flag incident picture, although most students answered accurately, the proportion of factually accurate answers decreased, and the factually inaccurate answers increased. Variations of the factually accurate answers consist of three themes, namely "the death of Mallaby," "the battle of Surabaya," and "the Red Bridge incident." For the latter theme, it was considered a factually accurate answer because the location of the death of Mallaby was near the Jembatan Merah (Red Bridge) in Surabaya, and it is commonly known as the Red Bridge incident. Meanwhile, the variation of the factually inaccurate answers also got more diverse. If the students' responses only appeared once and only appeared in one group only, then I categorised it as "other answers" theme.

For the control group, $77 \%$ of the students answered accurately and the remaining $23 \%$ gave inaccurate answers. In the category of factually inaccurate answers, it seems that students tend to give answers by guessing because they did not know the exact answer. For the experimental group, students who were able to answer accurately had fewer percentages than the control group. There were only 49 students who could answer accurately (55\%) and 40 other students gave factually inaccurate answers $(45 \%)$.

\subsubsection{Open-ended question 2: The sources of information}

As in the second question of the previous section, some students also gave more than one answer regarding the sources of information they used to answer the first question in this section. The data findings indicate that textbooks were also the main source of information for students in answering the first question about Mallaby's picture. The following table is the detailed data on the responses of both groups to the second question regarding the picture related to the death of Mallaby: 
Table 5.8 Students' responses to the second question (the sources of information on the death of Mallaby)

\begin{tabular}{|c|c|c|c|c|c|c|c|}
\hline \multirow[b]{2}{*}{ No } & \multirow{2}{*}{$\begin{array}{l}\text { Themes of } \\
\text { responses }\end{array}$} & \multicolumn{3}{|c|}{ Control group } & \multicolumn{3}{|c|}{ Experimental group } \\
\hline & & $\mathbf{f}$ & $\begin{array}{c}\text { Percentage of } \\
\text { responses }\end{array}$ & $\begin{array}{c}\text { Percentage } \\
\text { of cases }\end{array}$ & $\mathbf{F}$ & $\begin{array}{c}\text { Percentage of } \\
\text { responses }\end{array}$ & $\begin{array}{c}\text { Percentage } \\
\text { of cases }\end{array}$ \\
\hline 1 & $\begin{array}{l}\text { History } \\
\text { textbooks }\end{array}$ & 37 & $28 \%$ & $40 \%$ & 48 & $35 \%$ & $54 \%$ \\
\hline 2 & History teacher & 11 & $8 \%$ & $12 \%$ & 19 & $14 \%$ & $21 \%$ \\
\hline 3 & History lesson & 24 & $18 \%$ & $26 \%$ & 21 & $15 \%$ & $24 \%$ \\
\hline 4 & Internet & 17 & $13 \%$ & $18 \%$ & 29 & $21 \%$ & $33 \%$ \\
\hline 5 & Museum & 0 & $0 \%$ & $0 \%$ & 3 & $2 \%$ & $3 \%$ \\
\hline 6 & $\begin{array}{l}\text { Based on the } \\
\text { image } \\
\text { (guessing) }\end{array}$ & 30 & $23 \%$ & $33 \%$ & 7 & $5 \%$ & $8 \%$ \\
\hline 7 & $\begin{array}{l}\text { Parents and } \\
\text { people's stories }\end{array}$ & 7 & $5 \%$ & $8 \%$ & 2 & $1 \%$ & $2 \%$ \\
\hline 8 & Movies & 3 & $2 \%$ & $3 \%$ & 2 & $1 \%$ & $2 \%$ \\
\hline 9 & TV programs & 2 & $2 \%$ & $2 \%$ & 1 & $1 \%$ & $1 \%$ \\
\hline 10 & "don't know" & 1 & $1 \%$ & $1 \%$ & 5 & $4 \%$ & $6 \%$ \\
\hline & Total & 132 & $100 \%$ & $\mathrm{n}=92$ & 137 & $100 \%$ & $\mathrm{n}=89$ \\
\hline
\end{tabular}

In the control group, there were 37 students who responded to the questionnaire by referring to an image they had seen in their textbooks (40\%). Many students $(n=30)$ also answered just by guessing based on the pictures in the questionnaire (33\%), indicating that they did not know for sure what event was in the picture. The rest of the students claimed that the sources of information used to answer question came from history lessons (26\%), the internet (18\%), and teachers' explanations (12\%) as well as several other sources of information.

The experimental group students $(n=48)$ mostly answered the second questions in the open-ended questionnaire by referring to the textbooks they had read (54\%). Interestingly, there were $33 \%$ of students who claimed to have obtained the information about the image of the death of Mallaby from internet sources $(n=29)$. After that, there were students who got the information from history lessons (24\%) and history teachers (21\%). While the rest of the students' answers can be categorised as other themes, each of them was not frequent enough.

\subsubsection{Open-ended question 3: The chronology of the event}

The third question was intended to find out whether students knew the detailed information about the chronology of the battle of Surabaya, especially regarding the course of the incident that killed Mallaby. The procedure for assigning categories and themes to this third question was the same as the third question on the flag incident section. However, the data findings show the opposite of the 
previous section. Most students, both in the control and experimental groups, gave the factually inaccurate answers in describing the chronology of the incident that killed Mallaby. The following table is the detailed data on the responses of both groups to the third question regarding the chronology of the incident that killed Mallaby:

\section{Table 5.9 Students' responses to the third question (the chronology of the} death of Mallaby)

\begin{tabular}{|c|c|c|c|c|c|c|c|c|}
\hline \multirow{2}{*}{ No } & \multirow{2}{*}{ Category } & \multirow{2}{*}{ Themes } & \multicolumn{3}{|c|}{ Control group } & \multicolumn{3}{|c|}{ Experimental group } \\
\hline & & & $\mathbf{F}$ & $\%$ & $\Sigma$ & f & $\%$ & $\Sigma$ \\
\hline \multirow[t]{2}{*}{1} & \multirow[t]{2}{*}{$\begin{array}{l}\text { Factually } \\
\text { accurate }\end{array}$} & $\begin{array}{l}\text { Accurate (detailed } \\
\text { chronology) }\end{array}$ & 1 & $1 \%$ & \multirow[t]{2}{*}{$30 \%$} & 0 & $0 \%$ & \multirow[t]{2}{*}{$21 \%$} \\
\hline & & $\begin{array}{l}\text { Accurate (undetailed } \\
\text { chronology) }\end{array}$ & 27 & $29 \%$ & & 19 & $21 \%$ & \\
\hline \multirow[t]{5}{*}{2} & \multirow[t]{5}{*}{$\begin{array}{l}\text { Factually } \\
\text { inaccurate }\end{array}$} & $\begin{array}{l}\text { Inaccurate (detailed } \\
\text { chronology) }\end{array}$ & 0 & $0 \%$ & \multirow[t]{4}{*}{$70 \%$} & 0 & $0 \%$ & \multirow[t]{4}{*}{$79 \%$} \\
\hline & & $\begin{array}{l}\text { Inaccurate (undetailed } \\
\text { chronology) }\end{array}$ & 62 & $67 \%$ & & 56 & $63 \%$ & \\
\hline & & "don’t know" & 1 & $1 \%$ & & 12 & $13 \%$ & \\
\hline & & "no answer" & 1 & $1 \%$ & & 2 & $2 \%$ & \\
\hline & & Total & 92 & $100 \%$ & $100 \%$ & 89 & $100 \%$ & $100 \%$ \\
\hline
\end{tabular}

In the control group, only 28 of 92 students were able to answer this question accurately (30\%). Out of the 28 students, only one student gave details of the date of the incident. The rest, 64 students, gave factually inaccurate answers (70\%). Like in the control group students, most of the experimental group students also gave inaccurate answers (79\%). In fact, there were 12 students who answered that they did not know the detailed chronology of the death of Mallaby. There were only 19 students who could explain the broad outline of the chronology without mentioning the exact time of the incident. None of the experimental group students mentioned the date of the incident.

\subsubsection{Open-ended question 4: The cause of the event}

The fourth question was intended to find out whether students knew the detailed information about the cause of the battle of Surabaya, especially related to the death of Mallaby. In analysing the variety of students' answers, four answer themes emerged that could be categorised as factually accurate answers, and the remaining themes were included in the factually inaccurate answer category. The findings show that both in the control and experimental groups, most of the students were unable to answer accurately about the cause of the incident that killed Mallaby. 
The following table is the detailed data on the responses of both groups to the fourth question related to the cause of the incident that killed Mallaby.

Table 5.10 Students' responses to the fourth question (the cause of the incident that killed Mallaby)

\begin{tabular}{|c|c|c|c|c|c|c|c|c|}
\hline \multirow{2}{*}{ No } & \multirow{2}{*}{ Category } & \multirow{2}{*}{ Themes } & \multicolumn{3}{|c|}{ Control group } & \multicolumn{3}{|c|}{ Experimental group } \\
\hline & & & $\mathbf{F}$ & $\%$ & $\Sigma$ & $\mathbf{F}$ & $\%$ & $\Sigma$ \\
\hline \multirow[t]{4}{*}{1} & \multirow[t]{4}{*}{$\begin{array}{l}\text { Factually } \\
\text { accurate }\end{array}$} & $\begin{array}{l}\text { Misunderstanding of the } \\
\text { ceasefire implementation }\end{array}$ & 4 & $4 \%$ & \multirow[t]{4}{*}{$25 \%$} & 2 & $2 \%$ & \multirow[t]{4}{*}{$16 \%$} \\
\hline & & $\begin{array}{l}\text { Allied ultimatum for } \\
\text { Surabaya residents to } \\
\text { surrender weapons }\end{array}$ & 7 & $8 \%$ & & 5 & $6 \%$ & \\
\hline & & $\begin{array}{l}\text { The British army wanted } \\
\text { to control Indonesia }\end{array}$ & 8 & $9 \%$ & & 5 & $6 \%$ & \\
\hline & & $\begin{array}{l}\text { The people of Surabaya } \\
\text { did not want to be } \\
\text { controlled by the British } \\
\text { army }\end{array}$ & 4 & $4 \%$ & & 2 & $2 \%$ & \\
\hline \multirow[t]{7}{*}{2} & \multirow{7}{*}{$\begin{array}{l}\text { Factually } \\
\text { inaccurate }\end{array}$} & The death of Mallaby & 25 & $27 \%$ & \multirow[t]{6}{*}{$75 \%$} & 20 & $22 \%$ & \multirow[t]{6}{*}{$84 \%$} \\
\hline & & $\begin{array}{l}\text { The Dutch still wanted to } \\
\text { control Indonesia }\end{array}$ & 10 & $11 \%$ & & 10 & $11 \%$ & \\
\hline & & $\begin{array}{l}\text { The cruelty of Dutch } \\
\text { colonisers }\end{array}$ & 11 & $12 \%$ & & 8 & $9 \%$ & \\
\hline & & Other answers & 21 & $23 \%$ & & 28 & $31 \%$ & \\
\hline & & "don't know" & 0 & $0 \%$ & & 8 & $9 \%$ & \\
\hline & & "no answers" & 2 & $2 \%$ & & 1 & $1 \%$ & \\
\hline & & Total & 92 & $100 \%$ & $100 \%$ & 89 & $100 \%$ & $100 \%$ \\
\hline
\end{tabular}

In the control group students, there were 23 students who answered accurately $(25 \%)$, while most of the other students $(n=69)$ responses could be categorised as factually inaccurate answers (75\%). In the experimental group students, there were 14 students who could answer accurately (16\%), while 75 other experimental group students' responses could be categorised as factually inaccurate answers (84\%). Similarly, when answering the cause of the flag incident, students from both groups also only gave one possible answer regarding the cause of Mallaby's death.

Students who have historical thinking skills should be aware that a historical event can have multiple causes. However, from the two groups, there were no students who gave answers to more than one possible cause of the Mallaby's death incident. This indicates that students still have weak historical thinking skills because they are accustomed to seeing a historical event having only one causal factor.

\subsubsection{Open-ended question 5: The consequence of the event}

The fifth question was intended to find out whether students knew the detailed information about the consequence of the battle of Surabaya, in this case, related to 
the death of Mallaby. Overall, the results were not as different as their response to the impact of the flag incident. Most students in the two groups were also able to answer in a factually accurate manner. Unfortunately, there were no students who gave more than one possible answer that indicated the multiple effects of an event. The following table presents the students' responses in the control and experimental groups regarding the consequence of the death of Mallaby:

Table 5.11 Students' responses to the fifth question (the consequence of the incident that killed Mallaby)

\begin{tabular}{|c|c|c|c|c|c|c|c|c|}
\hline \multirow{2}{*}{ No } & \multirow{2}{*}{ Category } & \multirow{2}{*}{ Themes } & \multicolumn{3}{|c|}{ Control group } & \multicolumn{3}{|c|}{ Experimental group } \\
\hline & & & $\mathbf{F}$ & $\%$ & $\Sigma$ & $\mathbf{F}$ & $\%$ & $\Sigma$ \\
\hline \multirow[t]{4}{*}{1} & \multirow{4}{*}{$\begin{array}{l}\text { Factually } \\
\text { accurate }\end{array}$} & The death of Mallaby & 16 & $17 \%$ & \multirow[t]{4}{*}{$65 \%$} & 12 & $13 \%$ & \multirow[t]{4}{*}{$62 \%$} \\
\hline & & Many casualties & 21 & $23 \%$ & & 31 & $35 \%$ & \\
\hline & & $\begin{array}{l}\text { Allied ultimatum for } \\
\text { Surabaya residents to } \\
\text { surrender on } 10 \\
\text { November } 1945\end{array}$ & 4 & $4 \%$ & & 1 & $1 \%$ & \\
\hline & & $\begin{array}{l}\text { The outbreak of the battle } \\
\text { of Surabaya }\end{array}$ & 19 & $21 \%$ & & 11 & $12 \%$ & \\
\hline \multirow[t]{7}{*}{2} & \multirow[t]{7}{*}{$\begin{array}{l}\text { Factually } \\
\text { inaccurate }\end{array}$} & $\begin{array}{l}\text { Indonesia won the battle } \\
\text { and the Dutch were } \\
\text { expelled from Indonesia }\end{array}$ & 3 & $3 \%$ & $35 \%$ & 1 & $1 \%$ & \multirow[t]{6}{*}{$38 \%$} \\
\hline & & $\begin{array}{l}\text { Indonesia won the battle } \\
\text { and the British Allied } \\
\text { forces were expelled } \\
\text { from Indonesia }\end{array}$ & 9 & $10 \%$ & & 3 & $3 \%$ & \\
\hline & & $\begin{array}{l}\text { The destruction of the } \\
\text { city of Indonesia }\end{array}$ & 1 & $1 \%$ & & 8 & $9 \%$ & \\
\hline & & Other answers & 17 & $18 \%$ & & 17 & $19 \%$ & \\
\hline & & "don’t know" & 0 & $0 \%$ & & 4 & $4 \%$ & \\
\hline & & "no answer" & 2 & $2 \%$ & & 1 & $1 \%$ & \\
\hline & & Total & 92 & $100 \%$ & $100 \%$ & 89 & $100 \%$ & $100 \%$ \\
\hline
\end{tabular}

In the control group, there were 60 students who could answer accurately $(65 \%)$ and 32 students who answered inaccurately (35\%). From the total of correct answers, there were 21 students who answered that Mallaby's death incident caused many casualties both on the Indonesian side and the Allied army's (23\%) as a logical impact of the battle. The incident also resulted in Mallaby's death according to 16 students (17\%). After Mallaby was killed, this incident resulted in the Allied ultimatum for Surabaya residents to surrender on 10 November 1945, as answered by 4 students (4\%). Finally, there were 19 students who answered that the death of Mallaby triggered the outbreak of the battle of Surabaya (21\%). From the total of factually inaccurate answers, 12 students misjudged the event by assuming that Indonesia was the winner in the battle of Surabaya (13\%). Meanwhile, other 
students' answers were included in other themes grouped in the category of factually inaccurate answers.

In the experimental group, 55 students could answer accurately (62\%) and 34 students gave factually inaccurate answers (38\%). Like in the control group, most of the experimental group students also answered that the impact of this incident resulted in many fatalities (35\%), the death of Mallaby himself $(13 \%)$, Allied force ultimatum (1\%), and the outbreak of the battle of Surabaya (12\%). In the category of factually inaccurate answers, there were many students who answered Mallaby's death causing the destruction of the city of Surabaya $(9 \%)$. This theme was categorised as factually inaccurate answer, since the destruction of Surabaya city was not the direct result of Mallaby's death that occurred on 30 October 1945, but it was more as the direct consequence of the battle of Surabaya after being bombarded since 10 November 1945.

\subsubsection{Open-ended question 6: The historical significance of the event}

The sixth question in this open-ended questionnaire was intended to ask students' opinion whether the image related to the death of Mallaby is an important event in Indonesian history based on their personal opinions. Like in the previous section regarding the flag incident, almost all students in the two groups also tended to answer that Mallaby's death incident-shown in the image on the questionnaire - have a historical significance for Indonesia. The following table is the detailed data containing the responses of the two groups:

Table 5.12 Students' responses to the sixth question (the historical significance of the death of Mallaby incident)

\begin{tabular}{|c|c|c|c|c|c|c|c|c|}
\hline \multirow{2}{*}{ No } & \multirow{2}{*}{ Category } & \multirow{2}{*}{ Themes } & \multicolumn{3}{|c|}{ Control group } & \multicolumn{3}{|c|}{ Experimental group } \\
\hline & & & $\mathbf{F}$ & $\%$ & $\Sigma$ & $\mathbf{F}$ & $\%$ & $\Sigma$ \\
\hline \multirow[t]{6}{*}{1} & \multirow[t]{6}{*}{$\begin{array}{l}\text { Historical } \\
\text { significance }\end{array}$} & $\begin{array}{l}\text { To understand the } \\
\text { struggle for } \\
\text { independence }\end{array}$ & 38 & $41 \%$ & $99 \%$ & 28 & $31 \%$ & $97 \%$ \\
\hline & & $\begin{array}{l}\text { To understand the } \\
\text { struggle against the } \\
\text { colonisers }\end{array}$ & 7 & $8 \%$ & & 9 & $10 \%$ & \\
\hline & & $\begin{array}{l}\text { It has a big impact on } \\
\text { Indonesian history }\end{array}$ & 4 & $4 \%$ & & 7 & $8 \%$ & \\
\hline & & $\begin{array}{l}\text { It has caused many } \\
\text { casualties }\end{array}$ & 5 & $5 \%$ & & 3 & $3 \%$ & \\
\hline & & $\begin{array}{l}\text { To appreciate the } \\
\text { services of Indonesian } \\
\text { heroes }\end{array}$ & 7 & $8 \%$ & & 10 & $11 \%$ & \\
\hline & & $\begin{array}{l}\text { It must be remembered } \\
\text { in history }\end{array}$ & 19 & $21 \%$ & & 14 & $16 \%$ & \\
\hline
\end{tabular}




\begin{tabular}{|c|c|c|c|c|c|c|c|c|}
\hline \multirow{4}{*}{ No } & \multirow{2}{*}{ Category } & \multirow{2}{*}{ Themes } & \multicolumn{3}{|c|}{ Control group } & \multicolumn{3}{|c|}{ Experimental group } \\
\hline & & & $\mathbf{F}$ & $\%$ & $\Sigma$ & $\mathbf{F}$ & $\%$ & $\Sigma$ \\
\hline & & $\begin{array}{l}\text { Lessons learned from } \\
\text { history }\end{array}$ & 6 & $7 \%$ & & 5 & $6 \%$ & \\
\hline & & Other answers & 5 & $5 \%$ & & 10 & $11 \%$ & \\
\hline \multirow[t]{3}{*}{2} & \multirow{2}{*}{$\begin{array}{l}\text { Historical } \\
\text { insignificance }\end{array}$} & "don't know" & 1 & $1 \%$ & \multirow[t]{2}{*}{$1 \%$} & 2 & $2 \%$ & \multirow[t]{2}{*}{$3 \%$} \\
\hline & & "no answers" & 0 & $0 \%$ & & 1 & $1 \%$ & \\
\hline & \multicolumn{2}{|r|}{ Total } & 92 & $100 \%$ & $100 \%$ & 89 & $100 \%$ & $100 \%$ \\
\hline
\end{tabular}

In the control group, there were $99 \%$ of student who stated that the incident was significance and $1 \%$ claimed that she did not know, while for the experimental group students, $97 \%$ stated that the death of Mallaby was an important event in Indonesian history. From 89 students of the experimental group, 2 students said they did not know the answer and 1 student did not give an answer as to whether the Mallaby's death incident has a historical significance for the Indonesian. Most students in both groups considered the image related to the death of Mallaby was an important event because it could be used to understand the struggle of the Indonesian people in gaining independence.

\subsection{The comparison of students' initial understanding between the control and experimental groups}

Based on the findings of the open-ended questionnaire data described above, some comparisons can be drawn. First, most students from both groups could tell or describe the two images presented in the questionnaire factually accurately. For the image related to the flag incident, the number of students from both groups who were able to answer factually accurately reached $99 \%$, while for the image related to the incident which Mallaby was killed, most students were also able to answer factually accurately. The number of factually accurate answers from the control group students reached $77 \%$, and the number of factually accurate answers from the experimental group students reached 55\%. This indicates that the image of the flag incident was better known by students than the image of the Mallaby's death incident. In addition, related to Mallaby's death, students' initial understanding from the control group was slightly better than the experimental group. However, the majority of the two groups were equally able to give descriptions factually accurately regarding the two images presented in the questionnaire, so there were 
no striking differences between the two, presumably due to the two images have been embedded in the students "existing schemata", so that the majority of students could answer factually accurately because they had assimilated the same image repeatedly (see chapter 3.2, page 52).

Second, related to the sources of information that students used to describe the two images asked in the questionnaire, most of them claimed they knew the images from their history textbooks. This indicates that textbooks were the main reference source used by students (Handayani et al., 2018; Haniah \& Rokhman, 2017; Mardiana \& Sumiyatun, 2017; Pii, 2016), presumably due to the limitations of primary sources that could be utilised for learning purposes in Indonesia (Irani et al., 2018). Aside from the textbooks, many students from both groups also claimed that they knew the two images from the history lesson and the history teacher's explanation. These findings indicates that history learning in Indonesia was still teacher-centred based on the lecture method (Burhanudin \& Sodiq, 2018; Pii, 2016). The fourth most frequent answer was that students knew both images from the internet. This indicates that in this digital age students could get any information that can be accessed easily using the internet (Lang, 2016) and connect it with the history lesson in their school (Barnett et al., 2013; Goldie, 2016; Siemens, 2004). The internet has the potential to be used as a means of providing primary sources to students so that they are not overly dependent on textbooks and teachers' explanations, so they can better think historically.

Third, regarding the question about the chronology of the flag incident and Mallaby's death, students in the two groups also shared a common pattern of answers. For the chronology of the flag incident, both the control and the experimental group students were able to answer the general course of the incident factually accurately. However, most of them did not provide details of the time when the incident occurred. For the chronology of the Mallaby's death incident, most students of both groups were unable to explain the details of the event chronologically. This indicates that students from both groups understood the general chronology of the flag incident more than the chronology of Mallaby's death. Unfortunately, very few students understood the details of the time when 
these events occurred, even though this chronological understanding is important as a mental scaffolding to organise historical thinking.

Fourth, regarding the cause of the events, both groups also had the same response pattern. For the flag incident, the majority of the two groups could answer factually accurately about the cause of the incident. Meanwhile, for the Mallaby's death incident, the majority of the two groups could not answer factually accurately about the cause of the event. Interestingly, all students had tendencies to give one possible answer regarding the cause of the event, as if an event is only caused by a single cause. This indicates that both groups of students lack the understanding that a historical event can have multiple causes. The principle of multi-perspectives in history still has the potential to be as "troublesome knowledge" for students (Meyer \& Land, 2003). However, there was no difference between the control and experimental group students regarding their responses to the aspect of cause in history.

Fifth, related to the consequence of the event, the same answer patterns were also found in the two groups. Both in the control group and the experimental group, the majority of students were able to provide factually accurate responses about the consequences of the flag incident and the death of Mallaby. However, most of the students in the two groups simply answered that the two events had the consequence of many casualties. Besides that, students also only gave one possible answer as if a historical event had a single consequence and there was little evidence of them being aware of multiple consequences.

Sixth, regarding the historical significance of the events, the majority of students in both groups also had the same answer pattern. Most of the control and experimental group students considered the flag incident and the death of Mallaby to have historical significance for the Indonesian people, especially, to understand the struggle of the Indonesian people to achieve independence against the colonisers. This implies that students tend to assume that the position of the Indonesian people in these two events was always on the right side and the foreign nation was considered to be on the wrong side, as the "cruel colonisers." This indicates that students did not understand the principle of multi-perspectives in history as history education in Indonesia is still used as a tool to foster nationalism 
and patriotism by using Indonesiacentric approach (Darmawan, 2010; Mulyana, 2013; Purwanto, 2006; Sardiman \& Lestariningsih, 2017a; Umasih, 2010).

Overall, the findings suggest that students' initial understanding of the battle of Surabaya was at the same level and pattern before the teaching and learning intervention process. Both the control group and the experimental group students were mostly able to correctly answer the two events contained in the questionnaire images. The two groups also mostly knew the two events from their textbooks and their teacher's explanation during the history lesson in the classroom. However, most students did not have a detailed understanding of the two events related the chronology, cause, consequence, and historical significance which also indicates the weakness of their ability to think critically and their historical thinking skills.

The next chapter presents the findings of quantitative and qualitative data on whether students' historical thinking skills were affected by teaching history through analysing documents and interpreting textbooks. The presentation of quantitative data findings is based on the results of writing interpretive essay assignments, while the qualitative data finding presented are from classroom observations and semi-structured interviews. 
This page is intentionally left blank. 


\section{CHAPTER 6 \\ STUDENTS' HISTORICAL THINKING SKILLS IN LEARNING ABOUT THE BATTLE OF SURABAYA}

The purpose of this chapter is to answer the main question in this study, namely, how teaching history through analysing documents and interpreting textbooks contributes to students' historical thinking skills in Indonesia. The first section presents the quantitative data on students' historical thinking skills based on the results of writing interpretive essay tests. The second section presents the qualitative findings from classroom observations and interviews that indicate students' historical thinking skills during the learning process in their classroom. A general comparison of students' historical thinking skills between the control and the experimental group is presented in the final section.

\subsection{Students' historical thinking skills based on the writing interpretive essay scores (quantitative findings)}

The writing interpretive essay (WIE) assignments were used to measure students' historical thinking skills. These writing assignments were given to students three times, namely WIE pre-test, WIE post-test 1 , and WIE post-test 2 . Students had to answer the central historical questions in these three tasks interpretatively. In the WIE pre-test, students had to interpret the winner of the battle of Surabaya. In the WIE post-test 1, students had to interpret who tore the Dutch flag during the flag incident at the Yamato Hotel. In the WIE post-test 2, students had to interpret who killed Brigadier Mallaby in the battle of Surabaya.

These assignments were completed in a cohort consisting of 4-6 students for each group. In total there were 36 cohorts, 18 of which were in the control group and 18 others in the experimental group. Each cohort produced three essays (108 in total). These essays were assessed and scored by three teacher participants from the three schools involved in this study. They scored students' essays based on the scoring rubric (see section 4.5.1.2 and appendix I) and I was in charge of checking whether the scores they gave were in accordance with the predetermined criteria. Therefore, before the implementation of the second and fourth learning processes 
(student discussion session), the teacher participants and I always met in advance to discuss the results of their assessment and some interesting findings related to students' historical thinking skills that they found in students' essays. Overall student essay scores are presented in the following table:

Table 6.1 WIE scores of the control group and the experimental group

\begin{tabular}{|c|c|c|c|c|}
\hline \multirow{2}{*}{ Group } & \multirow{2}{*}{ Cohort } & \multicolumn{3}{|c|}{ Score } \\
\hline & & WIE pre-test & WIE post-test 1 & WIE post-test 2 \\
\hline \multirow[t]{18}{*}{ Control } & SCH-A_CG01 & 30 & 45 & 40 \\
\hline & SCH-A CG02 & 45 & 45 & 65 \\
\hline & SCH-A_CG03 & 25 & 45 & 35 \\
\hline & SCH-A_CG04 & 30 & 45 & 35 \\
\hline & SCH-A_CG05 & 30 & 55 & 45 \\
\hline & SCH-A_CG06 & 40 & 65 & 50 \\
\hline & SCH-B_CG01 & 25 & 30 & 35 \\
\hline & SCH-B_CG02 & 35 & 40 & 45 \\
\hline & SCH-B CG03 & 35 & 35 & 35 \\
\hline & SCH-B_CG04 & 35 & 40 & 55 \\
\hline & SCH-B_CG05 & 25 & 45 & 40 \\
\hline & SCH-B_CG06 & 30 & 35 & 50 \\
\hline & SCH-C_CG01 & 35 & 35 & 50 \\
\hline & SCH-C_CG02 & 30 & 40 & 40 \\
\hline & SCH-C_CG03 & 35 & 50 & 50 \\
\hline & SCH-C_CG04 & 40 & 35 & 55 \\
\hline & SCH-C_CG05 & 40 & 45 & 40 \\
\hline & SCH-C_CG06 & 30 & 45 & 35 \\
\hline \multirow[t]{18}{*}{ Experimental } & SCH-A_EG01 & 35 & 55 & 75 \\
\hline & SCH-A_EG02 & 40 & 55 & 85 \\
\hline & SCH-A_EG03 & 35 & 55 & 65 \\
\hline & SCH-A_EG04 & 25 & 70 & 85 \\
\hline & SCH-A_EG05 & 20 & 50 & 55 \\
\hline & SCH-A_EG06 & 35 & 40 & 80 \\
\hline & SCH-B_EG01 & 35 & 90 & 100 \\
\hline & SCH-B EG02 & 25 & 40 & 65 \\
\hline & SCH-B_EG03 & 35 & 40 & 55 \\
\hline & SCH-B_EG04 & 35 & 55 & 90 \\
\hline & SCH-B_EG05 & 30 & 65 & 95 \\
\hline & SCH-B_EG06 & 10 & 65 & 55 \\
\hline & SCH-C_EG01 & 45 & 80 & 100 \\
\hline & SCH-C_EG02 & 35 & 50 & 60 \\
\hline & SCH-C_EG03 & 30 & 50 & 95 \\
\hline & SCH-C EG04 & 30 & 45 & 100 \\
\hline & SCH-C_EG05 & 25 & 40 & 40 \\
\hline & SCH-C_EG06 & 30 & 35 & 40 \\
\hline
\end{tabular}

Based on the results of descriptive analysis, I obtained data related to the mean, median, and standard deviation. Some of the descriptive analysis data are presented in the following table: 
Table 6.2 WIE's mean score for each test

\begin{tabular}{clll}
\hline \multicolumn{1}{c}{ WIE } & \multicolumn{1}{c}{ Group } & Median (minimum-maximum) & \multicolumn{1}{c}{ Mean \pm SD } \\
\hline \multirow{2}{*}{ WIE pre-test } & Control & $32.50(25-45)$ & $33.06 \pm 5.72$ \\
\cline { 2 - 4 } & Experimental & $32.50(10-45)$ & $30.83 \pm 7.91$ \\
\hline \multirow{2}{*}{ WIE post-test 1 } & Control & $45.00(30-65)$ & $43.06 \pm 8.25$ \\
\cline { 2 - 4 } & Experimental & $52.50(35-90)$ & $54.44 \pm 14.84$ \\
\hline \multirow{2}{*}{ WIE post-test 2 } & Control & $42.50(35-65)$ & $44.44 \pm 8.73$ \\
\cline { 2 - 4 } & Experimental & $77.50(40-100)$ & $74.44 \pm 20.57$ \\
\hline
\end{tabular}

Based on table 6.2, we can see the difference in average scores between the two groups. In the WIE pre-test, the mean score of the control group is 33.06 and the experimental group is 30.83 . It could be interpreted that the difference between the two groups only has a small gap, even if the mean score of the control group is higher. In the WIE post-test 1 , the mean score is 43.06 for the control group and 54.44 for the experimental group. It can be interpreted that the mean score of the two groups is slightly different, where the mean score of the experimental group is higher. As for the WIE post-test 2, it can be clearly seen that there is a sharp difference between the two groups because the mean score of the control group is 44.44 and the experimental group is 74.44 . The progress of the mean scores of the two groups can be visualised in the following figure:

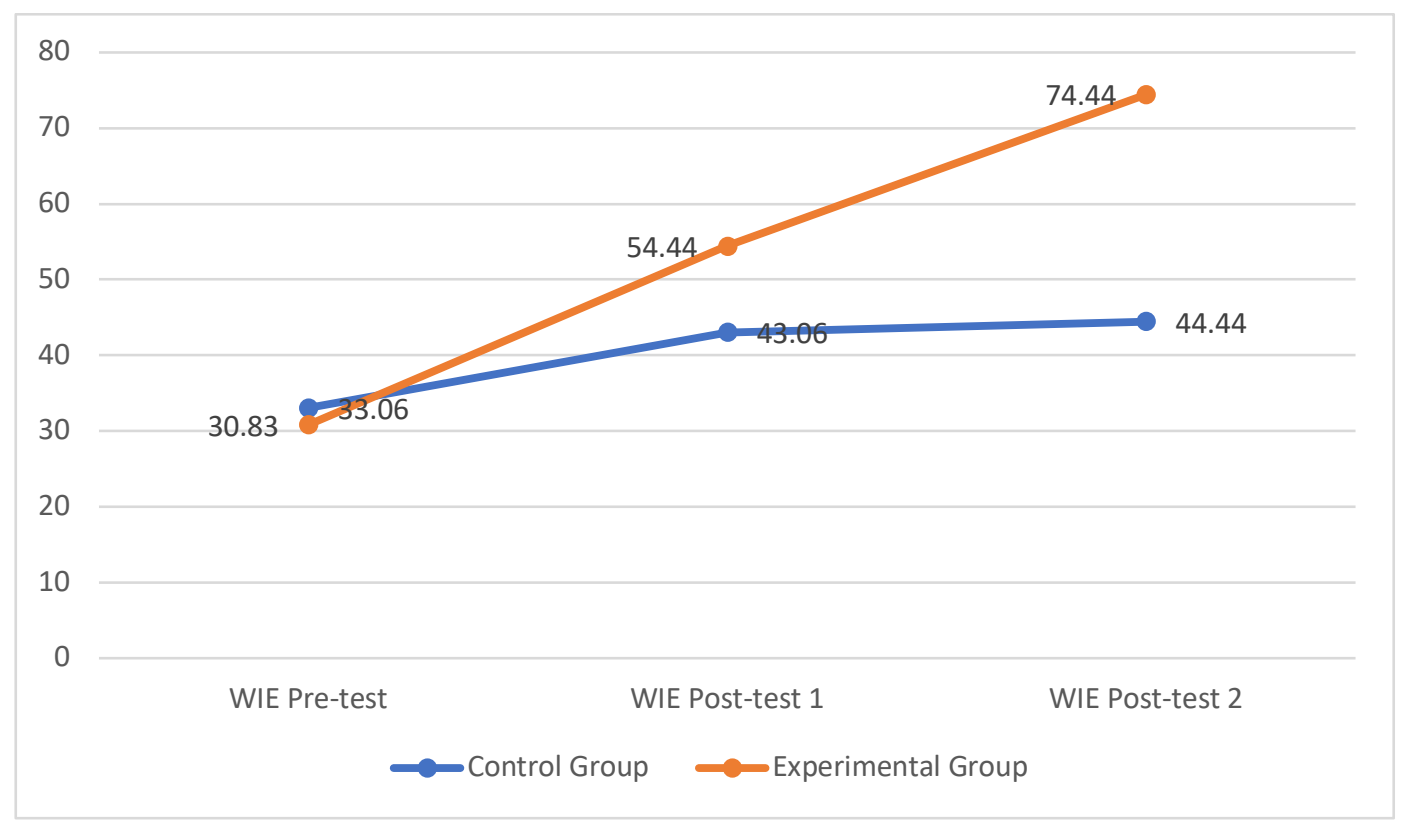

Figure 6.1 Comparison of the WIE mean scores between the control group and the experimental group

Before proceeding to inferential statistical analysis, I had to check the normality of the data first. It was done by using the formal normality test. Since the 
sample size was $36(\mathrm{n}<50)$, I used the Shapiro-Wilk test. This test is more appropriate for small sample sizes ( $<50$ samples) while the Kolmogorov-Smirnov test is used for larger sample sizes (Mishra et al., 2019). The Shapiro-Wilk test shows that almost all data were normally distributed because the p-value obtained was above 0.05 ( $p>0.05)$, except for the control group data in the WIE post-test 2 with p-value under $0.05(\mathrm{p}$-value $=0.048)$. Since most of the data were normally distributed and only one data set was not normally distributed, I used the log transformation to bring it closer to normality. Statistically, when data is not normally distributed, it is still possible to manipulate it to get it closer to normality through data transformation (Mackridge \& Rowe, 2018). The results of the normality test can be seen in the following table:

Table 6.3 Test of normality for WIE scores

\begin{tabular}{clll}
\hline \multicolumn{1}{c}{ WIE } & \multicolumn{1}{c}{ Group } & \multicolumn{1}{c}{ Mean (SD); 95\% CI } & p-value (p>0.05)* \\
\hline \multirow{2}{*}{ WIE pre-test } & Control & $33.06(5.72) ;(30.21-35.90)$ & $0.133^{\mathrm{a}}$ \\
\cline { 2 - 4 } & Experimental & $30.83(7.91) ;(26.90-34.76)$ & $0.092^{\mathrm{a}}$ \\
\hline \multirow{2}{*}{ WIE post-test 1 } & Control & $43.06(8.25) ;(38.95-47.16)$ & $0.064^{\mathrm{a}}$ \\
\cline { 2 - 4 } & Experimental & $54.44(14.84) ;(47.06-61.82)$ & $0.104^{\mathrm{a}}$ \\
\hline \multirow{2}{*}{ WIE post-test 2 } & Control & $44.44(8.73) ;(40.11-48.78)$ & $0.074^{\mathrm{b}}$ \\
\cline { 2 - 4 } & Experimental & $74.44(20.57) ;(64.21-84.67)$ & $0.104^{\mathrm{a}}$ \\
\hline
\end{tabular}

${ }^{*}$ Tests of normality: Shapiro-Wilk

${ }^{a} \mathrm{p}>0.05$, indicates normal distributions

$\mathrm{b}$ indicates normal distributions after transforming the data using the $\log$ transformation $(\mathrm{p}>0.05)$

Since all data are now normally distributed, this suggests that further analysis should be done through parametric methods. The repeated measures ANOVA test was used to compare the mean score of dependent variables from three different occasions (Mackridge \& Rowe, 2018). The following table presents the ANOVA test results:

Table 6.4 ANOVA test results of WIE's scores in each group

\begin{tabular}{|c|c|c|c|c|}
\hline & Test Group & Versus Group & $\begin{array}{c}\text { Mean Difference } \\
(95 \% \mathrm{CI})\end{array}$ & p-value \\
\hline \multirow{6}{*}{$\begin{array}{l}\text { Control } \\
\text { Group } \\
(p=0.000)^{\mathrm{a}}\end{array}$} & \multirow[t]{2}{*}{ WIE pre-test } & WIE post-test 1 & $-10(-14.51 ;-5.49)$ & $0.000^{*}$ \\
\hline & & WIE post-test 2 & $31.41(28.6 ; 34.23)$ & $0.000^{*}$ \\
\hline & \multirow[t]{2}{*}{ WIE post-test 1} & WIE pre-test & $10(5.49 ; 14.51)$ & $0.000^{*}$ \\
\hline & & WIE post-test 2 & $41.41(37.32 ; 45.51)$ & $0.000^{*}$ \\
\hline & \multirow[t]{2}{*}{ WIE post-test 2} & WIE pre-test & $-31.41(-34.23 ;-28.6)$ & $0.000^{*}$ \\
\hline & & WIE post-test 1 & $-41.41(-45.51 ;-37.32)$ & $0.000^{*}$ \\
\hline \multirow{6}{*}{$\begin{array}{l}\text { Experimental } \\
\text { group } \\
(\mathrm{p}=0.000)^{\mathrm{a}}\end{array}$} & \multirow[t]{2}{*}{ WIE pre-test } & WIE post-test 1 & $-23.61(-31.42 ;-15.8)$ & $0.000^{*}$ \\
\hline & & WIE post-test 2 & $-43.61(-52.75 ;-34.47)$ & $0.000^{*}$ \\
\hline & \multirow[t]{2}{*}{ WIE post-test 1} & WIE pre-test & $23.61(15.8 ; 31.42)$ & $0.000^{*}$ \\
\hline & & WIE post-test 2 & $-20(-28.36 ;-11.64)$ & $0.000^{*}$ \\
\hline & \multirow[t]{2}{*}{ WIE post-test 2} & WIE pre-test & $43.61(34.47 ; 52.75)$ & $0.000^{*}$ \\
\hline & & WIE post-test 1 & $20(11.64 ; 28.36)$ & $0.000^{*}$ \\
\hline
\end{tabular}


a The data is significant statistically (multivariate analysis was used repeated measures ANOVA with significance level $\mathrm{p}<0.05$ )

${ }^{*}$ The data is significant statistically (adjustment for multiple comparisons was used LSD (Least Significant Difference) with significance level $\mathrm{p}<0.05$ )

Based on the multivariate analysis using repeated measures ANOVA test in the table above, it can be seen that in general there are significant differences between the mean scores of the whole WIE test. This indicates that at least one group of the WIE test differs from the other WIE test groups. In order to analyse the pattern of difference between the mean scores, I continued with the post hoc analysis using the Least Significant Difference (LSD). The analysis shows that there are significant differences in the mean scores between WIE pre-test, WIE post-test 1, WIE post-test 2, both in the control group and the experimental group $(\mathrm{p}<0.05)$.

To determine the contribution of teaching history through analysing documents and interpreting textbooks on students' historical thinking skills, the difference between the WIE mean scores of the experimental group compared to the results of the control group must be known. To find out the answer, I continued with the General Linear Model (GLM) analysis. The following table is the result of the GLM analysis to compare the WIE mean scores of the control group and the experimental group:

Table 6.5 The result of the General Linear Model analysis

\begin{tabular}{lcccc}
\hline WIE Test & $\begin{array}{c}\text { Control Group } \\
(\mathbf{n = 1 8}) \\
\text { Mean (SD) }\end{array}$ & $\begin{array}{c}\text { Experimental } \\
\text { Group (n=18) } \\
\text { Mean (SD) }\end{array}$ & Difference (95\%CI) & p-value \\
\hline WIE pre-test & $33.06(5.72)$ & $30.83(7.91)$ & $2.22(-2.45 ; 6.9)$ & 0.341 \\
\hline WIE post-test 1 & $43.06(8.25)$ & $54.44(14.84)$ & $-11.39(-19.52 ;-3.25)$ & $0.007^{*}$ \\
\hline WIE post-test 2 & $1.64(0.08)$ & $74.44(20.57)$ & $-72.8(-82.66 ;-62.95)$ & $0.000^{*}$ \\
\hline${ }^{*}$ The data is significant statistically (Multivariate analysis was \\
$\begin{array}{l}\text { significance level } \mathrm{p}<0.05) \\
\end{array}$
\end{tabular}

Based on the results of the GLM analysis in the table above, we can see the comparison between the control and experimental groups on the three WIE tests. First, the difference in the WIE pre-test mean scores between the control and experimental group is not statistically significant because the p-value is above 0.05 $(\mathrm{p}$-value $=0.341)$. This indicates that before the intervention process, both groups had equal levels of historical thinking skills. Second, the difference in the WIE posttest 1 mean scores between the control and experimental group is statistically significant because the $\mathrm{p}$-value is $0.007(\mathrm{p}<0.05)$. This indicates that after the first 
intervention process, both groups had a different level of historical thinking skills. Both experienced an increase in the mean score, but the experimental group got a higher mean score. Third, the difference in the WIE post-test 2 mean scores between the control and experimental group is statistically significant because the p-value is $0.000(\mathrm{p}<0.05)$. This indicates that after the second intervention process, the differences between the two groups got sharper. The experimental group experienced an increase in the WIE post-test 2 mean score, while the mean score of the control group decreased. Based on the above three findings, it can be concluded that the teaching and learning intervention process through analysing documents and interpreting textbooks contributes to students' historical thinking skills. To be able to explain this quantitative data more deeply, it is necessary to compare it with the qualitative data which will be presented in the next section.

\subsection{Students' historical thinking skills based on the teaching and learning process (qualitative findings)}

This section presents some factors that reflect the transformation of students' historical thinking skills during the intervention process in the form of teaching and learning history through analysing documents and interpreting textbooks. The main focus of this section is to describe qualitatively how students use their "procedural knowledge" to analyse historical content knowledge in order to understand the past - as historians do in transforming the past into history (Ercikan \& Seixas, 2015; Seixas \& Morton, 2013). This refers to the results of the essays they had written, presented, and discussed, based on the learning process they had done in the classroom, and based on their perspectives during focus group interviews, as well as based on the teachers' perspectives from the results of semi-structured interviews. To obtain a chronological description of the transformation of students' historical thinking skills, this section is presented through three sub-sections representing the three stages of the intervention process, which are as follows:

\subsubsection{Students' historical thinking skills in the pre-intervention}

This sub-section presents the initial states of students' historical thinking skills prior to the implementation of the learning intervention process. These initial states refer to the results of the WIE pre-test. As presented in the previous section, 
it is apparent that before the intervention processes, the levels of students' historical thinking skills in the two groups were equal. In fact, the mean score of the control group was only slightly higher than the experimental group. In this sub-section, the quantitative data findings from the WIE pre-test are correlated, compared, and integrated with qualitative findings obtained from the focus group interviews. Since the results of the WIE pre-test were not presented and discussed in the classroom, in this sub-section there is no qualitative data based on classroom observations. However, some teacher participants' perspectives from the results of semistructured interviews are also used to explain the initial states of students' historical thinking levels before the implementation of the learning intervention process.

Based on the results of the interpretive essays that have been written by students on the WIE pre-test, I found that students' interpretations of who won the battle of Surabaya can be grouped in three different categories. First, there are several cohorts of students who claimed that Indonesia lost the battle of Surabaya. Included in this first category are 10 cohorts from the control group and 13 cohorts of the experimental group. Second, some cohorts argued that in the battle of Surabaya, Indonesia was defeated militarily but won psychologically. Included in this category are 4 cohorts from the control group and 2 cohorts from the experimental group. Third, there are some cohorts of students who claimed Indonesia won the battle of Surabaya. There are 4 cohorts in the control group and 3 cohorts in the experimental group included in this third category. Interestingly, none of the cohorts based their interpretations on their own arguments because all followed the versions of the sources which they referred to without assessing or evaluating these sources.

Based on the type of sources they used to write the WIE pre-test assignment, most participants used references obtained from the internet. These sources were mainly obtained from Wikipedia, articles from online newspapers or magazines, and from various unverified blogs. Only a few cohorts used references from textbooks as the main reference. All students seemed to consider the sources they got as direct access to the past and any information obtained from those sources was considered as a single truth about the past. They simply followed the version of the sources they got without questioning whether the information offered was 
true or false. This was the main reason for teachers giving low scores on students' WIE pre-test.

By referring to the results of the WIE pre-test, I triangulated it with the results of focus group interviews to get students' confirmation at the end of the intervention process. In the first answer category, as mentioned above, most of the cohorts in both the control and experimental groups correctly interpreted that Indonesia was defeated by British Allied forces in the battle of Surabaya. Apparently, they came to that conclusion because they only followed the majority of sources that have the same version, as can be seen in the control group students' (SCH-B_CG01 cohort) confirmation during the focus group interview, as follows:

Researcher: Why did you think that Indonesia was defeated and the winner of the battle of Surabaya was British?

Buumio: Because we took the answer from [the version presented in] most sources, and it was explained that Indonesia was defeated.

Researcher: Do you agree with Buumio's answer?

Buregino: In my opinion, Indonesia's defeat was due to a lack of weapons. So, at that time, the Allied forces had a large number of modern weapons, and Indonesia lost because of that.

Researcher: What were the sources?

Buregino: The source was Wikipedia, and the majority of other sources were the same as Wikipedia.

A similar reason was given by the experimental group, namely because the sources on the internet gave the same answer. The following are some excerpts from the results of focus group interviews with them (SCH-C_EG06 cohort):

Researcher: Why did you think that the winner of the battle of Surabaya was British, and Indonesia was defeated?

Ciputrie: Because there were already too many casualties, it was stopped, and it was insufficient to fight the Allied forces anymore.

Researcher: Is there any proof? What was the source?

Ciputrie: I forgot.

Researcher: [By checking and reading students' essay] The source was www.aninsulastri.blogspot.com, this is tracked in your essay. Do you believe in the sources obtained from this kind of Blogspot?

Ciputrie: Actually, I was a little doubtful.

Researcher: But why was it used? Indeed, at that time there were no primary sources available, but why did you trust aninsulastri's blog at that time?

Ciputrie: Because the other web contents were the same.

Cinursalmae: Because we are also used to using [internet sources] right? If we have assignments, we always use internet sources, even though we also know that it [the truth] can't be proven yet. 
Interestingly, although most groups answered correctly, many of them just realised while writing their pre-test assignment that in fact, Indonesia lost the battle of Surabaya. Previously they thought that Indonesia was the winner of the battle of Surabaya, as recognised by students in one of the following sample focus group interview excerpts (SCH-A_CG04 cohort):

Researcher: So [your conclusion], we lost the battle?

Abrilliano: Yes

Researcher: All this time, before writing this essay, did you know that we lost the battle?

Araihano: No!

Researcher: What did you think?

Araihano: We won, Sir, because we gained independence.

From the excerpts of the focus group interview described above, students matched available information or counted the number of sources that had a similar version to determine which was correct. They seemed to oversimplify the problem and lacking in interest to investigate further. This strategy was also found in the second and third answer categories.

For the second answer category, students stressed that Indonesia indeed lost militarily but won mentally. They presented this argument by only following the version of the sources they got and at the same time acknowledging that they had previously considered Indonesia as the winner of the battle of Surabaya. This is exemplified by the following focus group interview excerpt (SCH-A_CG06 cohort):

Airbaho: [Indonesia] actually lost, but in the hearts, we won, mentally. So actually, in the battle of Surabaya, we finally lost. But [the effect of] this battle was not just one, two, or three days, right? It was very long, right? There we can see that the people of Surabaya have tried to fight for Indonesian independence. But still lost. But they still lost. But this battle raised a sense of nationalism from the people themselves. So, in my opinion, the victory was in the hearts of the people.

Researcher: Before this, did you know that we actually lost?

Azaedo: Previously, I did not know that [Indonesia] was defeated, because before Indonesia was defeated, Brigadier Mallaby was killed in his car. Brigadier Mallaby was their commander, right? So, the losers should be the British.

Airbaho: The battle of Surabaya is always commemorated every November 10 [as national hero's day]. Strangely, we lost but it is commemorated. Probably, the victory was in the effort to raise a sense of nationalism. 
Apparently, in this second category of answers, students only followed the version of the internet source they got. Namely, from one article in an online newspaper, www.surabaya.tribunnews.com, that discussed the issues regarding the Surabaya battle, "November 10, losing the war, how come it became a hero day?" It seemed that the student cohorts, both from the control and experimental groups, who used this reference, did not try to corroborate it with other sources. Students only followed the one version of the source they got, without critiquing or assessing the status of the source. It seems as though they assumed that the source could offer direct access to the past so there was no need to question whether the information obtained was correct or incorrect.

For the third answer category, some cohorts answered that Indonesia was the winner of the battle of Surabaya. It was very easy to trace that their essay was influenced by their textbooks that tended to cover up Indonesia' defeat and was only glorifying Indonesia's ability to withstand the attacks of British Allied forces and its success in killing Allied army officers. This is reflected in the statement of the control group students (SCH-B_CG04 cohort) as follows:

Researcher: Why did you think that the winner of the battle of Surabaya was Indonesia, and British lost, how can it be like that?

Bafirmano: In my opinion, Britain suffered a crushing defeat, because they send down two of their top generals who had won the Second World War, but instead they died in vain. Though it only attacked one city, Surabaya, they still did not succeed.

Researcher: Any other opinion?

Bafirmano: Sir, may I add [opinion]?

Researcher: Yes, please.

Bafirmano: Because the British ate their own words. As I recall it, the British arrogantly said that Surabaya would be destroyed in a matter of hours. In fact, after so long, the British could not break down the Indonesian defence.

Balinggaro: In my opinion, [as written in the textbook] it can be interpreted as winning, and it can also be interpreted as losing. But, it is more strongly interpreted as winning because the youths managed to survive for 3 weeks from the British which had complete weaponry and a lot of infantry. The fact that we could survive for 3 weeks was great; it is enough to be called a win.

In the same vein, a cohort from the experimental group (SCH-A_EG05 cohort) also made the following statement: 
Amalzae: If I'm not mistaken, it was a battle in Surabaya, between the Surabaya people and the British or the Allies. Well, we were able to withstand the attacks of the British soldiers.

Researcher: Anyone wants to add [something]?

Afredoe: Because most sources, such as the textbooks said that the Indonesian won, so that the Indonesian won.

Similar to the first and second answer categories that have been described above, in the third answer category which considers Indonesia as the winner of the battle of Surabaya, students also only referred to one main source that they thought could provide direct access to the past. In this case, their main reference was their textbook. As epitomised in their utterances, "the textbooks said that the Indonesian won, so that the Indonesian won," which indicates that students assumed the textbook had the authority to determine the truth about the past.

Related to findings in students' essays that they tend to prefer to use references obtained from internet sources, this was confirmed by the three teacher participants in the semi-structured interview session. Apparently, students previously always preferred to use instant sources obtained from the internet. As complained by teacher B who stated, "when students are given problems, they tend to just open the internet. They rarely combine it with other sources. So, yes, they only use 'ready-to-eat' material." Teacher A also said the same thing by stating, “for example, if I asked [students], 'when was Indonesia's independence?' it turns out that they'd just use Google Voice [Hey Google], then they'd found the answer immediately." Teacher C also explained the same situation in her school, "in fact, sometimes students are too lazy to read long descriptions [in textbooks]. If they use the internet to search for what they are looking for, that's what they get instantly.... I admit that my students embrace 'Wikipediaism' because they believe in Wikipedia more than their own teachers." The term "Wikipediaism" that was expressed by teacher $\mathrm{C}$ shows that students prefer to use internet sources because it is more practical.

Therefore, in this sub-section, there are some findings that can be deduced from the results of students' WIE pre-test and interviews with both student and teacher participants. First, there was no difference between the control and experimental group students before the implementation of the learning intervention. This refers to the similar patterns of students' responses from the two groups during 
the interview. This also confirms the findings of the quantitative data from the WIE pre-test results which showed no significant difference between the control and experimental groups. Second, although most cohorts of students were able to correctly answer the central historical question in the WIE pre-test, apparently some students admitted that they had just learned that Indonesia had lost the battle of Surabaya when writing the essay. This indirectly indicates that students' existing schemata have been embedded with prior knowledge that Indonesia was the winner of the battle of Surabaya, particularly because it is always commemorated as Hero's Day in Indonesia every November $10^{\text {th }}$.

Third, in both the control and experimental groups, students were still unable to develop critical thinking skills in assessing sources. They still considered the sources they found as "the picture of the past" which offered direct access to the past and also considered these sources as "information" without the need to assess its status as correct or incorrect (P. Lee \& Shemilt, 2003, p. 21). They only followed the version of the sources they obtained as if those sources certainly tell the truth about the past. So, they basically did not develop their own argument position or interpretation. This indicates that they were habituated to learning a single version of history-which is always considered correct — and did not feel the need to develop their own perspectives independently.

Fourth, the implications of being accustomed to a learning environment that only consumes a single version of history caused students to deal with "troublesome knowledge" when given the opportunity to develop their own perspectives (Meyer \& Land, 2003; Walker, 2013). To solve the problem, they matched available information or counted the number of sources that had a similar version. This was reflected in their expressions, such as "the majority of other sources were the same as Wikipedia" or "because the other web contents were the same". Meanwhile, for other sources that have different versions, they ignored them and did not mention anything else in their essays.

Fifth, students were accustomed to using the internet to do various tasks given by the teacher. Unfortunately, students only relied on internet sources-such as Wikipedia - that were not developed specifically for the purpose of learning history. Students' learning process could be more optimal if there was a web-based 
historical source available which was developed specifically for learning history. It has the potential to be utilised as learning resources to foster students' historical thinking skills.

\subsubsection{Students' historical thinking skills in the first intervention}

This sub-section presents the progression of students' historical thinking skills in the first stage of the intervention process. Based on the results of the WIE post-test 1, it was apparent that both the control and experimental group students experienced an increase in the mean score, but the experimental group got a better mean score. Therefore, there were significant differences in the level of students' historical thinking skills in which the experimental group students were slightly better than the control group. In this sub-section, the quantitative findings from the WIE post-test 1 are correlated, compared, and integrated with qualitative findings obtained from the classroom observations and focus group interviews.

Based on the results of the interpretive essays that were written by students on the WIE post-test 1, it was discovered that the variety of students' answers was increasingly complex because the historical versions contained in the historical sources varied and conflicted with one another. Any historical sources may be used by students to answer the central historical question, namely who tore the Dutch flag in the Flag Incident. For the control group, students could access whatever historical sources they could obtain by themselves. It turns out that they relied on sources accessed through the internet as the findings of the WIE pre-test show. For the experimental group students, they could also use whatever sources they wanted to use, but they were given access to the digital learning resources available on the www.berpikirsejarah.com website (see Chapter 4, section 4.4.1, page 81).

This website provides historical learning resources that can be accessed by experimental group students, which consist of four menus. The first menu contains short excerpts from the student textbooks that describe the chronology of the flag incident (http://berpikirsejarah.com/ib-buku-teks/). In this textbook, there is no explanation on who tore the Dutch flag in the incident (Sardiman \& Lestariningsih, 2017b). The second menu contains short excerpts from the official textbook from the Indonesian government, the national history of Indonesia (http://berpikirsejarah.com/ib-sni/). This book does not explain who the 
perpetrators of the flag's tearing. It only describes a short chronology of the incident (Poesponegoro \& Notosusanto, 2010). The third menu is a collection of 10 testimonies on those claiming to have been involved in the flag incident or witnessed it. Of the ten testimonies, there are testimonies that support each other's testimonies, but some are conflicting with each other (http://berpikirsejarah.com/ibtestimoni/). The fourth menu is an archive containing information about one of the backgrounds of the flag incident, namely President Sukarno's order to raise the Indonesian flag throughout Indonesian territory (http://berpikirsejarah.com/ibanri/). The following figure illustrates the four menus on the website's home page that contains the flag incident materials:

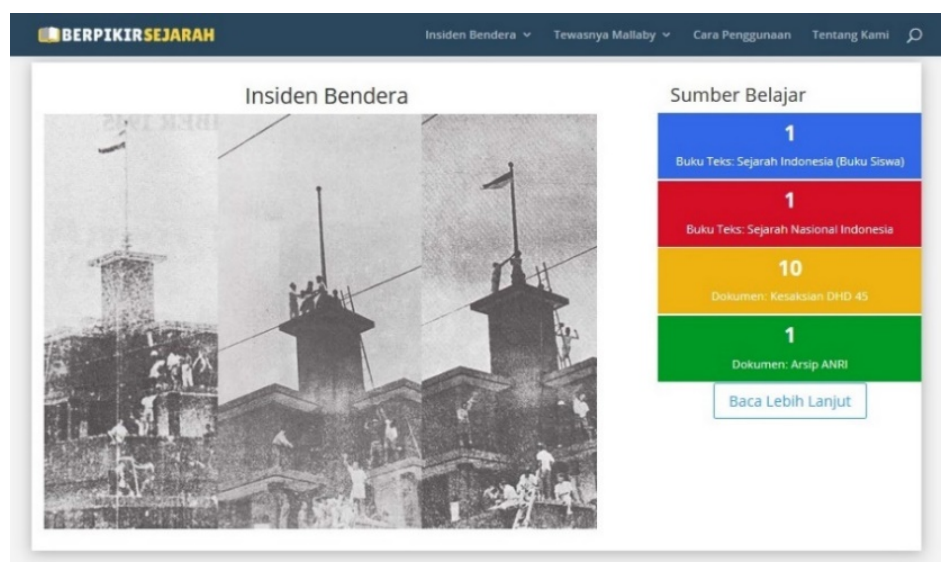

Figure 6.2 Four menus of learning resources for the flag incident material

Students could choose the four learning resources in writing their essays. For instance, if students wanted to read the testimonies of the perpetrators of the flag incident, they can choose archival documents from DHD 45, as shown below:

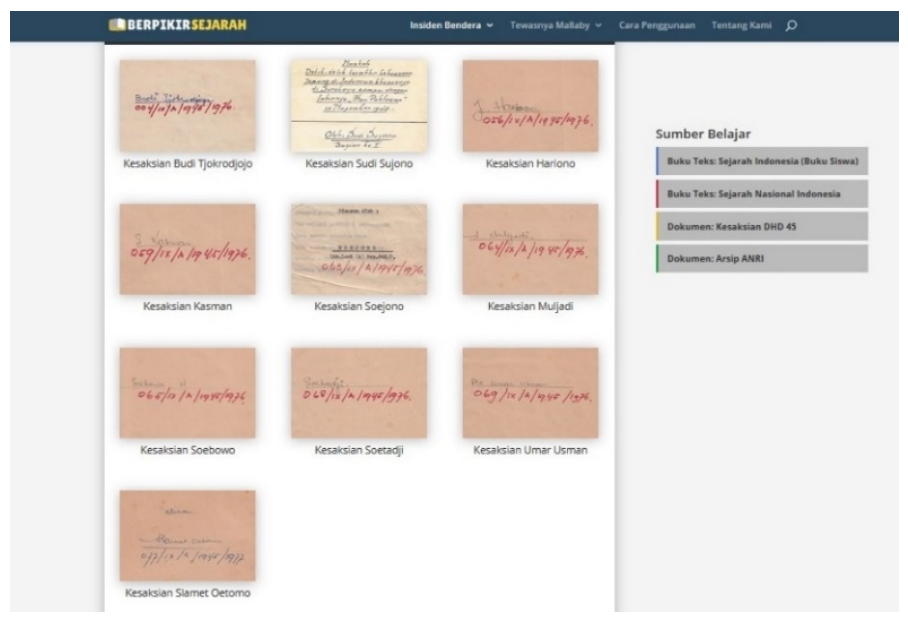

Figure 6.3 Ten documents of perpetrator testimonies from the DHD 45 archives 
Although the control group students did not have access to the digital learning resources available at www.berpikirsejarah.com, both the control and the experimental groups received the same learning process as prepared in the lesson plan. Teacher participants were prepared to teach history through problem-posing education, emphasizing the importance of dialogue between teachers and students. Since the first learning intervention meeting, the teachers only posed problem-based questions to encourage students to think independently. The teachers held dialogues with the students ranging from general questions about Indonesian independence, to more specific questions about the flag incident, such as "What happened in Indonesia after the proclamation of Independence?", "Did Indonesia really gain independence at that time?", "Why at that time were there still Japanese and Allied forces in Indonesia?", "When did the flag incident occur?", "Where was the location of the flag incident", until the central historical question was asked, "who actually tore the Dutch flag in the flag incident at Yamato Hotel on 19 September 1945?". After the central historical question was asked, students were invited to look for historical sources, read and discuss the sources, and then write their interpretation in the interpretive essay.

In order to find the sources, both the control and the experimental groups used their laptops or smartphones as tools to access the internet. Interestingly, for the experimental group who had been given access to primary sources available on the learning website, there were several cohorts who prefer to access non-primary sources from various websites. They appeared to want to search for answers practically by browsing on Google by retyping the central historical question. In the control group, the same thing was found in almost all cohorts. When reading the sources, each group had their respective strategies in reading the sources they had obtained. There were two general strategies found regarding students' techniques when reading sources. First, each student individually searched for the sources and then read the sources by themselves. After that, they discussed it within their cohort. The second strategy was the cohorts coordinated the division of tasks in reading the sources for each of their members and then discussed the results of their reading within their cohorts. The former strategy was mostly apparent in the control group students, while the latter strategy was mostly found in the experimental group 
students. This happened because the experimental group was not too preoccupied with the activity of searching sources because they had been provided with learning resources.

While students were discussing within their cohorts, the teacher monitored the students' discussion process by going around the classroom. At that moment, it was not uncommon for students to complain to the teacher because they were confused when dealing with the different versions of information they found in the sources. When faced with such situations, the teacher participants have been trained not to give direct answers to students but encouraged them to assess the source by comparing it with other sources or by provoking further discussions with their cohort members. For example, this situation was reflected in one of the learning processes in the control group, as follows:

Asekaro: Sir, [how come], according to this [source, the perpetrator was] Kusno? But why [according to] this one, [the perpetrator was] Sidik?

Teacher A: Please note that finding first, and then try to corroborate them with other sources.

Atalithao: I don't understand, Sir. How can I write the essay [while the sources have different versions]?

Teacher A: Well, I will not teach the way I taught before. [I used to determine] that this is correct, and this is wrong. [Now] I want to invite you to think [critically] based on the available sources. Source A states this, source B states this, source C states this.

Asekaro: Does this mean all sources are included?

Teacher A: They may be included, but later you must conclude it based on your own interpretation. In my opinion this..., because of this..., this..., this...., like that.

Similar situation also occurred in the experimental group students as reflected in the following conversation between the teacher and the students:

Teacher B: Are you having any difficulties?

Bunikene: Yes, Ma'am. We have a lot of difficulties, Ma'am.

Bunandae: Do we have to write in detail, Ma'am?

Teacher B: You can compare those [sources]

Balfawwaze: Well, that is precisely our difficulty, Ma'am, if we have to compare one [source] with another [source].

Bunikene: The problem is there are so many sources.

Teacher B: Well, you can start by analysing one source, [then] assessing one [other] source.

Balfawwaze: That's the difficulty. 
At this first learning meeting, students' historical thinking skills were still not clearly visible during the teaching and learning process in the classroom, especially because the students still had not finished writing their essays. Nevertheless, when students discussed this with their respective cohorts, it can be traced back to the initial strategies used by students in analysing and assessing the sources. Two strategies were discovered which were similar to when they analysed sources for writing WIE pre-test essay. First, students only selected sources that they considered to have the authority of truth. For example, a control group student named Cakrahadyano believed in the information he obtained from Wikipedia, "so far we have more confidence in Wikipedia because it is more verified than other free blogs." The second strategy was those who analysed the sources by matching similar information, or by counting the number of sources that had the same version, or by referring to the majority. This is reflected in the conversation in the control group as follows:

Teacher B: Basencio, have you found the answers?

Bufitriao: Not yet, we are still looking for the argument, Ma'am.

Basencio: [We are confused] because there are so many different [versions].

Teacher B: Confused?

Basencio: Yes.

Basusilo: Some said he [Ploegman] was strangled.

Basencio: [But] some said he [Ploegman] was shot.

Bufitriao: We are still looking for the majority [of the version].

Basencio: But we have got this much, Ma'am (showing their sources in the laptop).

Bufitriao: The majority will be used [as the answer].

Researcher: What about the majority?

Bufitriao: The majority will be used [as the answer]

Teacher B: They are still confused, Sir.

Bufasyandao: Because every website has a different version.

Aditya: So, the most will be used [as the answer].

Bufasyandao: Yes, the most [similar] opinions.

This strategy was also found in the experimental group students, as in the following conversation during the learning process:

Teacher C: Have you found [the answer] to who tore the flag?

Cakevinandae: Hariono and Kusno Wibowo.

Teacher C: Who said that?

Cakevinandae: Said Budi Tjokrodjojo's [testimony].

Teacher C: Have you compared it with other testimonies? 
Chapsarie: Most of them [the testimonies] state that [the perpetrators] were Hariono and Kusno Wibowo. Lots of them [have the same version]; one of them is Sudi Sujono's [testimony].

Cakevinandae: [Yes] many; one of them is Budi Tjokrodjojo's [testimony].

It was only until the second learning meeting took place-when students presented their essays and held discussions in their classrooms - that the students' historical thinking strategies were apparently increasing. These strategies can be seen in their essays and in their debates while discussing the matter in front of the classroom. At that time, the differences between the control group and the experimental group began to appear. In the following description, I will first describe the findings in the control group and then continue with the description of the findings from the experimental group.

In the control group, the essays they had written for WIE' post-test 1 basically had similar modes with the essays they had written for the WIE' pre-test, particularly in the strategy of searching for the sources they used to write their essays and the strategies they used to establish their interpretations in the essays. All cohorts relied on the internet to search for sources in writing their essays, especially from Wikipedia (13 cohorts), online magazines or newspapers (7 cohorts), and various unverified blogs (6 cohorts). There were indeed several cohorts that used more than one source, but they only chose sources that had the uniform version regarding the event. Similarly, in the strategy to determine the position of interpretation, they still referred to the majority of versions of the source which had the uniform information. However, out of 18 cohorts in the control group, there was 1 cohort that became an outlier (SCH-C_CG03 cohort). This happened because they accidentally got primary sources in the form of three testimonies from the www.berpikirsejarah.com website.

Actually, during the data collection process for the control group students, I had blocked the access to the www.berpikirsejarah.com website. I activated WordPress maintenance mode to make it unusable and the website only displayed "under maintenance" status. However, it turned out that the attachment files on the website could still be downloaded even though students were not able to enter the website as long as they were able to find the URL (uniform resource locator) 
address of the attachment files. At the end of the learning process, I asked them how they could find the primary sources. One student named Ciatikaho told me that:

At that time, we were looking [for sources], and we typed in the keywords 'books about the flag incident'. So, we were looking for [sources] like books. We kept searching to the very last [page], and kept searching. We downloaded a lot of books. At that moment, we found www.berpikirsejarah.com, then we opened it, then the PDF file was automatically downloaded.

Although some of the sources got leaked, it is interesting to see how the control group students used the leaked sources to answer the central historical question in their essay.

In answering the central historical question, the variety of answers in their essays was centred on four different names as the perpetrators who tore the Dutch flag. There were cohorts who concluded that the perpetrators were "Hariono and Kusno" (11 cohorts), "Kusno and Sudirman" (3 cohorts), "Kusno" only ( 2 cohorts), and "Kusno, Onny, and two unknown persons" (1 cohort). Meanwhile, the remaining one cohort, as the outlier, could not draw any conclusions.

This cohort was unable to draw conclusions because they were dealing with conflicting sources; moreover, they found primary sources that contained confessions of people who claimed to have been involved or witnessed the flag incident. As written in the essay, during the presentation they only described various versions of the perpetrators of the flag incident based on the sources they had. For example, they described the various versions of the perpetrators who tore the Dutch flag; based on Wikipedia they found the name Kusno Wibowo, based on Soejono's testimony they found Praseno Sisworo, and based on Soebowo's testimony they found Soenarjo. So, at the end of their presentation, they stated, "so, at this time our cohort is still unable to conclude as to who exactly tore the flag in the flag incident at the Yamato Hotel on September 19, 1945 because of the testimonies of witnesses turned out to have different versions". Then, during the focus group interview, I tried to reconfirm the reason they could not draw conclusions:

Researcher: When writing the essay, why did you not dare to confirm "this person was the perpetrator"?

Cakrizao: Because in the [sources], there were three different people. So, we had some doubt. 
Researcher: So, you become doubtful when dealing with different sources?

Cakbilalo: Yes (all the students nodded).

Meanwhile, for other cohorts who merely relied on secondary sources from the internet, they had no doubts in establishing their interpretations. This happened because they did not obtain too many conflicting sources. Even if they found a different version, they selected it based on sources that they considered to have the authority or simply chose sources that had similar versions. The strategies they used in assessing sources could be tracked from the interviews. For example, the following is the results of the focus group interview with one cohort (SCHA_CG04) in School A who assumed Wikipedia had the authority to deliver correct information about the past:

Researcher: Based on your essay regarding the flag incident, who tore the Dutch flag?

Abrilliano: Hariono and Kusno.

Researcher: The sources?

Abrilliano: Wikipedia.

Researcher: Why Wikipedia?

Abrilliano: In my opinion, Wikipedia is the most famous [online encyclopaedia]. So, in my opinion, Wikipedia is not made carelessly. It is different compared to blogs made by individuals. In my opinion, Wikipedia is more trustworthy.

Researcher: But anyone can edit Wikipedia.

Abrilliano: In my opinion, if anyone can edit Wikipedia, he might be editing it because he already knows [the correct version].

Araihano: [He edited it] not for fun, Sir.

In the same vein, one of the cohorts (SCH-B_CG01) in School B also stated that Wikipedia can be trusted and because other sources also stated the same thing, as follows:

Researcher: Based on your essay regarding the flag incident, why did you think that the perpetrators of the flag tearing were Hariono and Kusno?

Budiaho: Because, at that time, Hariono and Kusno were those who climbed [the hotel building].

Researcher: Ah, because Hariono and Kusno climbed the building. What was the evidence? What was the source?

Budiaho: Wikipedia.

Researcher: Did you believe in Wikipedia version, that it was Hariono and Kusno who went up [the building] and tore off the flag?

Budiaho: Yes, but several sources also stated the same. 
Researcher: Ah, because of the other sources, the majority [of the sources] stated Hariono and Kusno, then it can be concluded that they were the perpetrators, is that so?

Budiaho: Yes.

In the same perspective, one of the cohorts (SCH-C_CG02) in School C stated that Wikipedia had an international reputation as a reliable source:

Researcher: Based on your essay regarding the flag incident, why did you think that the perpetrators of the flag tearing were Hariono and Kusno?

Cakpradikao: Because, as I recall it, in a source, on the internet, yes, called Wikipedia.

Researcher: Yes, you used a single source, Wikipedia.

Cakpradikao: There, it was written that there were three [people] in action, namely Hariono, Kusno, and one more [name], I forgot, cannot remember who. Then the one who tore [the flag] was only one of the three people, namely Kusno.

Researcher: So, [only] Kusno, huh?

Cakpradikao: Yes.

Researcher: What was the source? Wikipedia, right?

Cakpradikao: Yes, Wikipedia, as I said.

Researcher: Why did you trust Wikipedia?

Cakpradikao: Yes, because it [has] become an international benchmark.

Besides referring to the belief that the past can be ascertained and known by some authorities such as Wikipedia, some other cohorts in the control group students also believed that matching or counting the same information from several sources could also be the solution to find out the truth about the past. This was reflected in various statements of the control group students during the learning process and during the focus group interview sessions. One of the results of the interview is presented below (SCH-B_CG04 cohort):

Researcher: Based on your essay regarding the flag incident, why did you think that the perpetrators of the flag tearing were Hariono and Kusno. [Can you tell me] why? Why not the others? What was the source?

Busherlyo: The source was [taken from an article accessed at] www.okezone.com.

Researcher: Why do you believe in that version?

Balinggaro: Because, in my opinion, when the flag incident happened, the youngsters mentioned in the articles that we have analysed, [the names] we found, only Kusno and Hariono. There were no other youths [in the sources], besides Kusno and Hariono.

Researcher: Do you believe in that source [www.okezene.com]?

Balinggaro: We believe, Insya Allah [God willing], we believe. 
Researcher: Why do you believe [that source]?

Balinggaro: Because from various [other] sources, not only one source but from other sources; they also stated the same [version].

Researcher: So, if the majority [of the sources] have the same [version], then it can be considered as truth?

Balinggaro: Yes.

Bafirmano: Because we cannot find out the information [about the past] that is truly true, so we conclude it based on the majority.

Therefore, almost all cohorts in the control group used the strategy of assessing sources by determining the aspect of authority of the sources and the highest number of the similar version in the sources for determining the truth about the past. While one cohort - the outlier, who obtained several primary sources that were leaked unexpectedly_could not draw conclusions and merely described the versions of each source. They experienced troublesome knowledge because they were unintentionally faced with conflicting testimonies. The other cohorts had no trouble because they neglected the conflicting versions they obtain from secondary sources. In establishing their position of interpretation, all cohorts only follow the version of the argument found in the sources, without critiquing the sources, as well as without constructing their own interpretations. In writing the chronological aspects of the incidents, aspects of cause-consequence, and aspects of changecontinuity, all cohorts also simply followed the version of the sources they used. I supposed all of this happened because control group students had not found extremely contradictory sources since they deliberately chose sources which had a similar version. Even if they had found sources with diverse versions, they ignored it and felt no need to write it in their essay. They thought they had found the correct answer from the "authority" and the "majority" of sources.

In the experimental group students, the situation was different, because they were confronted directly with conflicting sources with diverse versions about the past. They experienced more troublesome knowledge than the control group students, so it is interesting to note their efforts to cross the threshold portal. Based on the essays they had written for WIE's post-test 1, there was a slight shift in the strategy they used in writing the essay, although most cohorts still followed the strategy that they had previously used to write the WIE's pre-test. In terms of the sources they used to write essays, some cohorts still used secondary sources 
accessed through the internet even though they had been provided with primary sources. In terms of establishing the position of interpretation, some cohorts experienced a shift in their strategies to answer the central historical question.

In answering the central historical question, the variety of students' answers in their written essay was centred on four different names as the perpetrators who tore the Dutch flag. The majority of the cohort concluded that the perpetrators were "Hariono and Kusno" (11 cohorts), "Hariono, Sudirman, and Kusno" (1 cohort), "Hariono" only (1 cohort), "Kusno" only (1 cohort), "Soenarjo" (1 cohort) and 3 cohorts could not draw any conclusions. From these various possible answers, there were four categories found in students' efforts to write their interpretive essay. These categories refer to several emerging themes from verbal reasons that were often expressed by students during presentations, discussions, and focus group interviews. The reasons used by students were always related to two main things. The first was related to what sources were used and why. The second was related to reasons about how to establish their interpretations as well as argumentations. The following are descriptions of the four categories that emerged in the experimental group students.

The first category consists of cohorts whose essays did not progress. The cohorts included in this category are the cohorts who worked on their WIE' posttest 1 essays that looked the exact same way as when they wrote the WIE' pre-test essays. In terms of using sources to write essays, they tended to use sources that have a uniform version only. Even though they already knew that the www.berpikirsejarah.com website there were sources that had different versions, they tended to ignore them and only chose sources that had the same version. This can be traced in their essays. There were cohorts that only used one primary source from one witness testimony, or cohorts who chose to use multiple testimonies that have similar version only, or cohorts who chose the similar version of testimonies combined with secondary sources - mainly Wikipedia-which have a similar version. They had not used-or even mentioned-sources that have different versions. In terms of establishing their interpretations, they simply followed the version of the source they had chosen. They did not write down the possibility of other alternative versions in their essays, as if there was only one true version of 
history. Of the 18 cohorts in the experimental group, there were 8 cohorts that fell into this category.

Students' historical thinking in this category, besides being traceable through their essays, was also clearly visible from the results of observations. As found in almost all cohorts in the control group, cohorts in this category also selected the sources and determined their position of interpretations based on the version of the majority of sources. For example, this was illustrated in a conversation between the teacher and students (SCH-B_EG03) when discussing the causes of Ploegman's death, as follows:

Teacher B: OK, any other opinions? [What about you] Bauditorioe? Bauditorioe: According to Budi [Tjokorodjojo's] testimony, he stated [that Ploegman] was strangled.

Bufirlye: In Sudi Sujono's [testimony, it stated] "strangled" as well.

Teacher B: Why did you use Budi's testimony?

Bupramuditae: Because it was the most voted [the most same version].

Teacher B: [Sorry], do not whisper, I cannot hear you, [loudly please!].

Bupramuditae: Because most other sources also [stated that Ploegman] was strangled.

The same case also happened in other schools. For example, in one occasion during the discussion at School A, the teacher asked one of the cohorts (SCH-A_EG01), "why did you use [the testimonies from] the two people [Budi and Sudi]?" and then one of the students named Abdullahe answered firmly "[because it was] almost the same."

In the two cases above, the cohorts used two testimonies from Budi and Sudi, which had a similar version, in determining their interpretations. They did not feel the need to use other sources that had different versions. They assumed the same version contained truth, so they only selected sources based on the similarity of versions. Meanwhile, there were also cohorts that used a primary source from one of the testimonies and combined it with a secondary source from Wikipedia. For instance, one of the students named Araihane (SCH-A_EG06) answered, "here [in our cohort], the source is Slamet's testimony, combined with Wikipedia, thus Slamet-Wikipedia." There were also cohorts who only chose to use one source in their essays. For example, one of the cohorts (SCH-C_EG02) in School C answered that the perpetrator who tore the flag was Soenaryo. This was because they only used one testimony from Soebowo. 
Based on the results of the focus group interview, cohorts in this category clearly seen that they only read sources with the same version of narration and ignored sources that had different versions. In the example of the interview excerpt below, students (SCH-A_EG04 cohort) claimed that they only read three primary sources that had the same versions, namely Budi Tjokrodjojo's, Sudi Sujono's, and Hariono's testimonies, and confessed that they did not read other primary sources with different versions, including Soebowo's testimony.

Researcher: Based on your essay regarding the flag incident, why did you think that Hariono and Kusno were the perpetrators of the flag tearing?

Arifdahe: The reason was that people who climbed up on top [of the building] were Hariono and Kusno. They tore the flag.

Researcher: Based on what evidence?

Arifdahe: The evidence was many testimonies who stated that Hariono was on top [of the building], then he tried to tear [the flag]. Then because he took too long, Kusno joined [him] to tear the flag.

Researcher: I checked your essay; you relied on the testimony of Budi Tjokrodjojo as the main reference, right?

Arifdahe: Yes, Budi's [testimony], but Hariyono's [testimony] as well.

Researcher: Ah, Hariyono's [testimony] as well. Do you believe in the versions in these sources?

Arifdahe: Yes.

Researcher: OK, I see. But then, have you read Soebowo's testimony? He claimed that the perpetrator was Soenarjo. What do you think?

Arifdahe: We did not read it.

Researcher: Ah, you did not read it. So, you read Budi Tjokrodjojo's [testimony] only?

Arifdahe: Budi, and the person who climbed, Hariyono. And then one more source [Sudi], there were three [sources].

Therefore, cohorts that can be categorised in this first pattern are those who only used sources with the same version of narration. They knew there were several sources with different versions but chose to ignore it. In determining the position of interpretation, they also simply followed the version of the sources they had chosen, with the reason that these sources had the same version or the most versions so that it was considered to contain the truth.

The second category consists of cohorts who realised that history has different versions of the past. However, they still had difficulty moving beyond the threshold and still experienced troublesome knowledge in dealing with conflicting sources. In order to escape these difficulties, they wrote the essay by describing various 
versions of the sources they obtained. Unfortunately, they still had difficulties in assessing the sources to establish their own interpretations. The simplest way was that they described all versions but did not specify any interpretation or argumentation. For example, this was confirmed from the results of the focus group interview (SCH-A_EG05) as follows:

Researcher: Based on your essay regarding the flag incident, who were the perpetrators [of the flag incident]?

Asabrinae: many kinds of [answers]

Researcher: Yes, [but] I did not find any conclusion here [in your essay] regarding who the perpetrators were. Then my next question: Is it really not possible to produce a reasonable conclusion when dealing with conflicting sources?

Amalzae: [Yes,] probably, because the sources had different [versions], not interconnected, not related [to one another]. So, we had a little difficulty in drawing conclusions about who tore the flag at the Yamato Hotel. And, there were many sources of testimonies, so there were many answers.

Researcher: Many answers, huh?

Amalzae: Yes.

There were three cohorts that could be included in this second category. They realised that historical sources had many different versions of the past and then wrote these different versions in their essays. Unfortunately, they still had difficulties in establishing their interpretations so that they were unable to draw concrete conclusions.

The third category consists of cohorts who also realised that history has different versions of the past. Then, their strategy to overcome difficulties in determining the answer was by determining the source which was considered the best as well as the correct one or based on several sources that had the same version to tell. For instance, this strategy was acknowledged by one cohort (SCH-C_EG06) during their presentation in front of the classroom, spokesman of the cohort named Cinursalmae stated:

So, regarding the first question about who tore the flag at Yamato Hotel. Well, because in the resources (the website) there are 4 menus, and after that [in one of the menus] there are 10 testimonies from the people involved in the incident, in our opinion, the most complete and truest of these testimonies are Budi Tjokrodojo's [testimony] and Sudi Sujono's [testimony]. 
Finally, they determined their position of interpretations based on information obtained from the two testimonies. This was also proven during their focus group interview session, as follows:

Researcher: In your essay, initially you described various versions which come from Budi's, Sudi Soejono's, Muljadi's, and Soebowo's [testimonies], right?

Ciputrie: Yes

Researcher: Then, you concluded that the perpetrators were Hariyono and Kusno?

Ciputrie: Yes

Researcher: How did you draw the conclusion?

Ciputrie: From the first (Budi's) and the second (Sudi's) testimonies. Only from those testimonies.

Cohorts that chose one version of testimony (which they considered the best version of the past) often received many questions from other cohorts and became a heated debate in the discussion process. As an example, this happened at School B when one cohort (SCH-B_EG04) was repeatedly "attacked" with various questions by other cohorts:

Bhramawatie (SCH-B_EG04): In the discussions in our cohort, we concluded that Kusno and Hariono succeeded in lowering the redwhite-blue flag and then tore off the blue part. Then they raised it again as red and white flag.

Bapriliae (SCH-B_EG06): Thank you [for your presentation]. [Your conclusions were] based on whose testimony?

Bunandae (SCH-B_EG04): We used all sources from the website www.berpikirsejarah.com. That's from Slamet Oetomo' testimony. He was a witness of the battle of Surabaya.

Bapriliae (SCH-B_EG06): On what grounds? There are many testimonies. Why did you choose that testimony?

Bhernandae (SCH-B_EG01): Yes, why did you believe more in Slamet Oetomo's testimony?

Buregise (SCH-B_EG01): Has it been compared with other testimonies? For example, with the testimony of Budi Tjokrodjojo?

Bangelica (SCH-B_EG01): What about the other testimonies [are they ignored]?

When the SCH-B_EG04 cohort received a variety of insistent questions from other cohorts, they were silent and tried to think for a moment. After that, they continued the debate as follows: 
Bunikene (SCH-B_EG04): When we compare it with the other testimonies, such as Budi Tjokrodjojo's, Sudi Sujono's, and others [testimonies], we decided to prefer Slamet's testimony because he followed the incident to the end, as if he knew the incident to the end, while the other testimonies seemed to only know the beginning [of the incident].

Bangelicae (SCH-B_EG01): Then, what about the other testimonies?

Bunandae (SCH-B_EG04): Because according to our cohort, the testimony from Slamet Oetomo is more convincing than the other testimonies.

Buregise (SCH-B_EG01): What is the reason that it's more convincing? Bunandae (SCH-B_EG04): Because he was a witness until the end [of the incident].

Eventually, there were five cohorts from the experimental group that could be included in this category. Cohorts in this category realised that historical sources had many different versions of the past. They accommodated the different versions of the sources in the essays they had written. Unfortunately, they only took conclusions by choosing one testimony that was considered the best, and some others concluded based on several testimonies that have the same version.

The fourth category contains cohorts that successfully passed the threshold portal and overcame the troublesome knowledge. They had recognised the inevitability of different versions in historical sources, assessed each source critically, and finally used all sources that had been criticised to construct their interpretations of the past. They became conscious of the importance of critiquing sources and did not necessarily and easily trust the contents and versions of those sources. At the end of the first intervention process, there were only two cohorts that can be categorised in this third category.

Their critical consciousness was manifested by their depth when critiquing sources and by their soundness of argumentation when establishing interpretation. All of this can be traced from the essays they wrote, especially from the arguments they raised during discussions and debates in the classroom, as well as proven from their answers during the focus group interview. Based on the essays written by the two cohorts in this category, they tried to compare sources and explore the perspectives of witnesses. When dealing with conflicting versions, they tried to judge and criticise each source, then openly describe the various versions in their 
essays. After that, they established their position of interpretations with sound reasonable argumentation based on the sources they had criticised.

Based on the process of discussion and debate in the classroom, the members of the two cohorts in this category were the most active in asking questions and often made students from other cohorts have difficulties during debates. The questions they raised were always about "why did you use that source?" or "what about other sources and versions?" and "why did you draw such a conclusion?" These debates indirectly made other cohorts aware of their weaknesses in treating sources and drawing conclusions. If the debate heated up, the teachers mediated the students, so they could resolve the dispute and the problem. This is for example reflected at the end of the following debate:

Teacher B: [Stop], wait a minute, you all answered based on Budi's [testimony], right? Including your cohort, you also use Budi's [testimony], right? What exactly is the weakness of Budi's [testimony]?

Bhernandae (SCH-B_EG01): [Budi did not see the incident first-hand], while Sudi witnessed the incident first-hand.

Bunikene (SCH-B_EG04): [No], Budi was directly involved, while Sudi only saw [the incident]. What someone saw is not necessarily true when compared with those who really did it themselves.

Bangelicae (SCH-B_EG01): [No, you are wrong]. Budi was indeed involved in designing the attack. But in Sudi Sujono's testimony, [he stated that Budi, after designing the attack], returned to his office. [Sudi's testimony] stated that "after he gave the order and instruction, comrade Budi asked for permission from his friend and went to BKR Kaliasin office and said he would be back soon". So, Budi was not there. Instead, Sudi was the direct witness.

From the example of the debate above, it was clear that one of the cohorts $\mathrm{SCH}-$ B_EG01) at School B had read the details of each source and compared the conflicting sources.

Other evidence that they had read and corroborated all the sources were also proven during the focus group interview. They were immediately able to assess the sources - which had versions that contradict their interpretations - that were asked during the interview, as illustrated in one of the following interview excerpt ( $\mathrm{SCH}$ C_EG01): 
Researcher: What about Soebowo's testimony? He delivered a different version, right? Soebowo has a different version compared to the testimonies of Budi, Sudi, and Hariono [that the perpetrators were Soenarjo instead of Hariono and Kusno].

Cakrahardiane: Budi, Sudi, and Hariono were at the scene [of the incident]. [They were] closer.

Researcher: But Soebowo was also there, right?

Cakrahardiane: Yes, but from a distance, so it's not convincing.

Their statements above indicate that they sought to understand the perspective of witnesses at the time of the incident and used it as a basis for assessing the quality of information from available sources.

Besides the aspect of eyewitness perspectives, the other evidence of students' historical thinking skills in critiquing sources was manifested in their ability to judge the chronological logic of the incident, which is also related with the aspect of cause and consequence. Their critical thinking skills were proven in one of the results of the focus group interview (SCH-B_EG01), as follows:

Aditya: Now I want to ask [something]. Based on Soebowo's testimony, the perpetrator of the flag tearing was Soenarjo, right? What do you think about Soebowo's testimony?

Bhernandae: [That testimony] does not make sense.

Aditya: Why does [it] not make sense?

Bhernandae: Because Soebowo stated that after the flag was lowered, the Dutch (Ploegman) came out [from the hotel], which means that [the incident of the flag tearing] has not happened yet.

Aditya: What is wrong with Soebowo's statement?

Bhernandae: He made it up

Buregise: it is not synchronous [with the chronology and the causeconsequence].

Aditya: What do you mean by not synchronous?

Buregise: Yes, as Bhernandae said, it does not make sense; that is my impression. [Because there should be negotiations and conflicts with the Dutch first, then the flag was torn]

Aditya: Are there other weaknesses from Soebowo's [testimony]?

Bhernandae: Soebowo saw [the incident] from the outside of the front fence, so from a distance.

Buregise: [His views] must be unclear.

Therefore, at the end of the first intervention stage, it can be seen that there are two most prominent themes obtained from the results of classroom observations and focus group interviews, as well as in their written essays. These two themes are related to how students dealt with sources that had different versions and about how 
they established their position of interpretations. These two themes seem to be a pattern that determined the development of students' historical thinking skills. It is important to note whether these two themes remain tracked in the same pattern or have changed during the implementation of the second learning intervention process. This can be found in the next sub-section.

\subsubsection{Students' historical thinking skills in the second intervention}

This sub-section presents the progression of students' historical thinking skills in the second stage of the intervention process. Based on the results of the WIE post-test 2, it was found that the control group students experienced a slight increase in their mean score and the experimental group students experienced a sharp increase in their mean score. Therefore, there were significant differences in the level of students' historical thinking skills between the two groups, and the differences became sharper in which the experimental group students were far better than the control group. In this sub-section, the quantitative findings from the WIE post-test 2 are correlated, compared, and integrated with qualitative findings obtained from the classroom observations and focus group interviews.

Based on the results of the interpretive essays written by the students on the WIE post-test 2, it was found that the variety of students' answers was also as complex as the variety of answers found in the WIE post-test 1 . In addition, both groups of students experienced higher difficulties because the available historical versions related to Mallaby's death were also more diverse and contradictory when compared to the topic of the flag incident. The control group students, who as before relied heavily on internet sources, were more easily exposed to sources that had conflicting versions on the internet. In the experimental group students, they were also faced with conflicting versions of the primary sources, with an even greater number of sources and of varying types.

If in the first learning intervention stage the www.berpikirsejarah.com website only had four menus, in the second intervention there were six different menus that were presented to the experimental group students when writing their interpretive essays. In this stage, students had to answer the central historical question by interpreting who killed Brigadier Mallaby in the battle of Surabaya. In the first menu, students could access short excerpts from the students' textbook that 
describe the chronology of the battle and mention about the process of Mallaby's death (http://berpikirsejarah.com/tm-buku-teks/). In this textbook, there is no mentioning of who killed Mallaby, and it only explained that Mallaby's car suddenly exploded in the Jembatan Merah area (Sardiman \& Lestariningsih, $2017 \mathrm{~b}$ ). The second menu is a short excerpt from the government official textbook, the national history of Indonesia (http://berpikirsejarah.com/tm-sni/). This book mentions that Mallaby was killed by Surabaya youths by stabbing him with sharpened bamboo spears and bayonets (Poesponegoro \& Notosusanto, 2010).

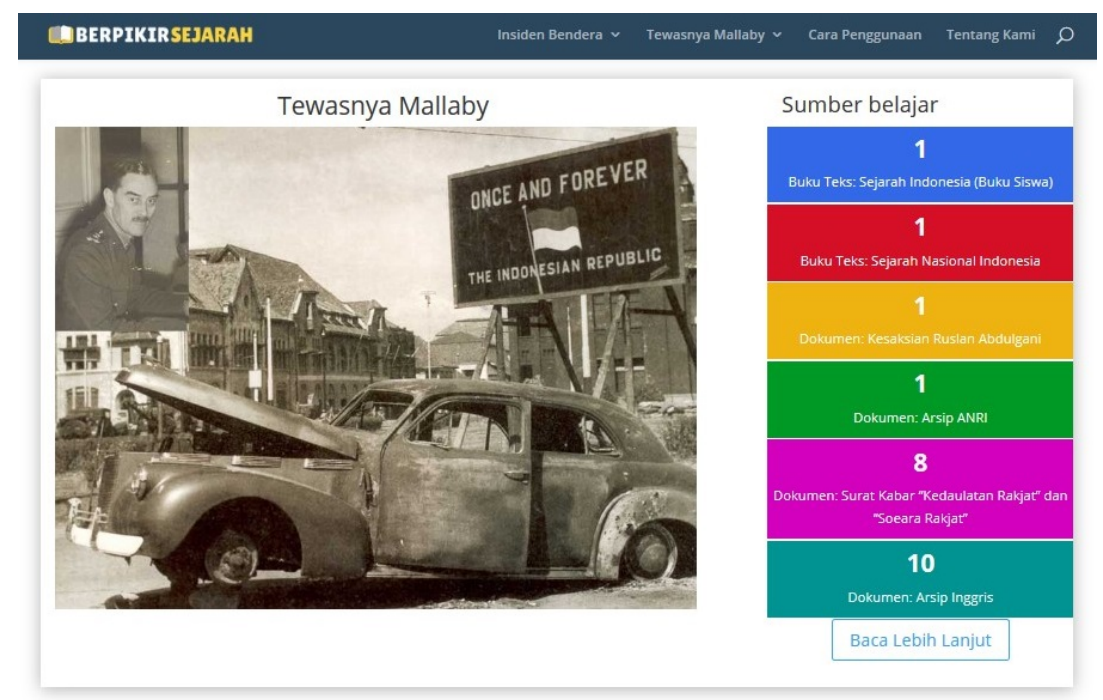

\section{Figure 6.4 Six menus of learning resources related to the incident of the death of Mallaby}

The third menu contained the testimony of Ruslan Abdulgani, a member of the Contact Bureau, who was at the scene when the incident happened (http://berpikirsejarah.com/tm-kesaksian/). In addition to reporting his testimony, he also quoted the testimonies of two other eyewitnesses who entered the Internatio building, namely Muhammad and Kundan. The essence of Ruslan' testimony is that Mallaby was killed by an unknown Indonesian youth's shot, according to another youth's report when Ruslan took refuge on the river's edge. That shot occurred after the British army violated the truce by firing from the inside of the Internatio building. Based on Kundan's testimony, he heard by himself that Mallaby whispered to Captain Shaw when giving an order that the D company could open fire on the crowd so that members of the D company could escape from the 
Internatio building which was surrounded by crowds of people who demanded the surrender of weapons belonging to British troops. While Muhammad's testimony stated that the D company in the building deliberately prepared to shoot the crowd so that they had time to escape and Mallaby's death could be due to mortar fire from inside the building.

The fourth menu is an archive containing vice-president Hatta's response to British accusation that the Indonesian government was incapable of handling various incidents in Indonesia (http://berpikirsejarah.com/tm-anri/). Regarding Surabaya, Hatta accused the British army who violated the agreement that they would only occupy the harbour area and the vicinity of the internment camp at Darmo, but in fact, intended to occupy all of Surabaya and disarm the Indonesians. The fifth menu contains eight articles from two newspapers published and reported the various incident during the Surabaya battle, certainly full of Indonesian perspectives (http://berpikirsejarah.com/tm-koran/). To gain perspectives from the British side, on the sixth menu there are 10 archives from the WO 203/2455 containing the interview statements of eyewitnesses and inquiry report into the circumstances leading to the death of Mallaby (http://berpikirsejarah.com/tminggris/), particularly, the testimonies of Captain Smith and Captain Laughland who sat in the same car with Mallaby.

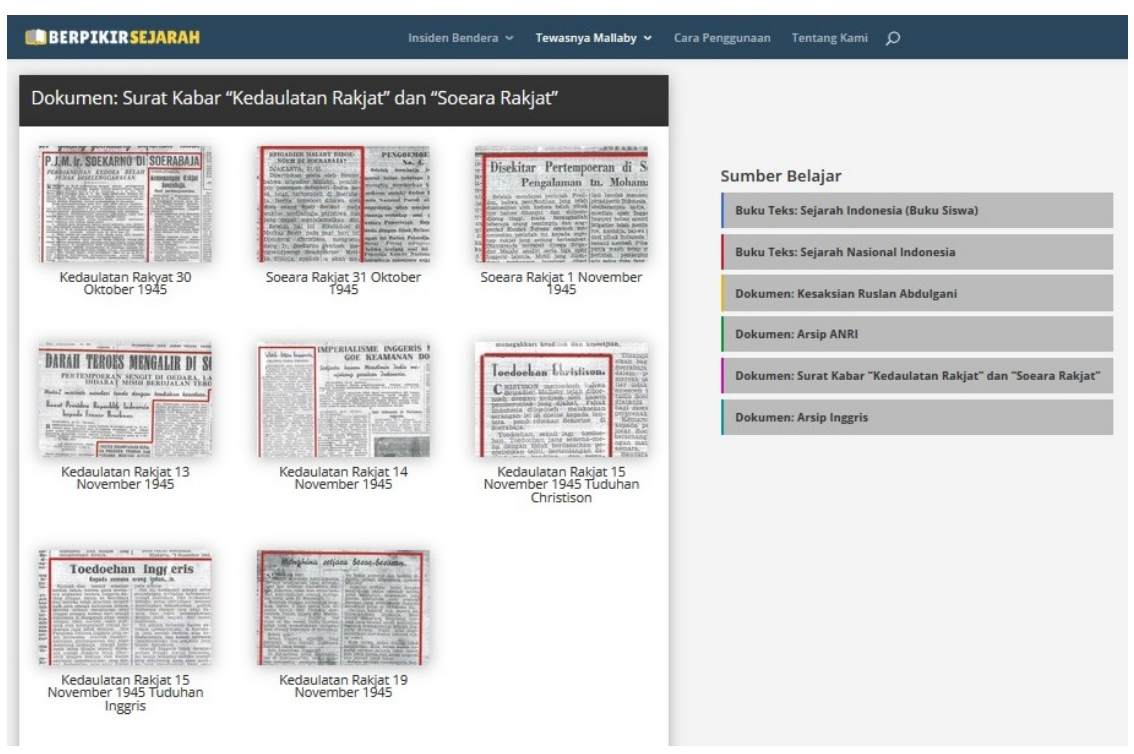

Figure 6.5 Eight articles from two newspapers in 1945 
As in the previous intervention process, both the control and the experimental group received the same learning process as designed in the lesson plan. The teacher participants were only allowed to teach history through problem-posing education by prioritising the dialogue process between teacher and students. At the third meeting, the teacher and students began to have a dialogue about general matters about the battle of Surabaya until the central historical question about who killed Mallaby was conveyed. The only difference from the previous stage was that students were given short footage of two movies before the central historical question was asked. The first movie is titled "The Battle of Surabaya", an animated movie depicting Mallaby being shot, looking still alive, and then being hit by a grenade explosion in his car. The second movie is titled "Sang Kiai" depicting Mallaby sitting alone in his car, shot by a young man named Harun, then two British officers from outside of the car threw a grenade to kill Harun, but at the same time destroyed Mallaby's car in an explosion. While watching the footage of the two movies, students looked so enthusiastic and even screamed hysterically when Harun - played by Adipati Dolken — was killed by a grenade. On the contrary, they were seen giving a flat response when they saw the scene that Mallaby was shot or his car exploded. When asked by the teacher, what caused Mallaby's death, the students' answers varied. Some said that he was shot, and some said he was hit by a grenade explosion. There was also a student named Aivano commented, "[no problem with different causes], the most important thing is that Mallaby was killed!" Based on their reaction, it seems that the movies could stimulate students' historical empathy, but their moral judgement was full of nationalist sentiments.

The purpose of showing these movies was to illustrate that the past could be interpreted differently, as presented in the two movies, including when students were watching the movies which also gave different perception regarding the cause of Mallaby's death. With expectations, they became more critical when reading sources with different versions. After the central historical question was asked, students were invited to look for historical sources, read and discuss the sources, and then write their interpretive essays. When getting the sources from the internet, the reaction of the control group students was no different from the previous intervention stage which was complaining about the various versions. For example, 
Buaninditao complained, "Ouch, so many versions, Ma'am." While the reaction of the experimental group students was not about the various versions, but on the amount of the sources that they had to read. For instance, Araihane commented "Oh Allah, there are so many [sources that must be read]" and Ahafifae suggested, "Let's download them first, [read later]."

At the third meeting, both the control and the experimental groups spent more time reading the sources. None of them had finished writing the essay so they had to continue writing their essays as homework. Only at the fourth meeting, when students had submitted their essays, presented and discussed the results of their interpretation in the classroom, could it be seen how the progress of students' historical thinking skills in both groups had changed.

In the control group students, there was a shift in the way they wrote essays. Based on the experience of the previous intervention, they realised that the past could be interpreted differently by various sources so that their essay also had to describe the various versions found. Moreover, regarding Mallaby's death, it was very easy to find various versions of narration regarding the incident on the internet. Often-times, one article on the internet also presented various versions. As happened previously, the control group students also still relied heavily on internet sources to write the WIE post-test 2. The internet sources were mainly from Wikipedia (5 cohorts), online magazines and newspapers (14 cohorts), and various unverified blogs ( 7 cohorts). Besides the internet, there were 5 cohorts that referred to their textbooks.

In answering the central historical question, students' answers could be grouped into three clusters of answers. The first cluster is students who answered that the Mallaby killer was Indonesian (6 cohorts). The second cluster is students who answered that the Mallaby killer was from the British army itself ( 3 cohorts). The third cluster is students who did not conclude to a single answer ( 9 cohorts). In writing their essays, they presented various versions they got from internet sources as if they were competing to present the various versions in their essays. However, although they all tried to explain the various versions obtained from various sources, apparently they were split into two categories in terms of how they established their position of interpretations. Some of them explained the various 
versions of sources without drawing any conclusions or did not dare to establish any interpretation. Some others presented various versions of the sources and then drew conclusions based on the version they considered best or whatever they wanted to believe.

In the first category, there were nine cohorts that did not establish their interpretation position. Whereas in the WIE post-test 1 , there was only one cohortthe outlier, who obtained leaked primary sources - that did not draw any conclusions. This indicates an increase in the number of cohorts who were unable to establish interpretations in the WIE post-test 2. This is the background of the low mean score of the control group students in the WIE post-test 2 because the teachers did not find conclusions or affirmation of interpretations in their essays, which meant the central historical question was not answered by the students.

As the first example in this category, the SCH-A_CG04 cohort was one of the cohorts that were unable to establish a position of interpretation. They wrote at the end of their essay, "It cannot be determined exactly who killed General Mallaby due to a lack of information and the many opinions of historians.....So, we draw the conclusion that until now it has not been known exactly who killed General Mallaby." When asked for clarification during the focus group interview, one student named Abrilliano answered, "Previously, it was not written [the position of interpretation in the essay] because there were too many [versions] that were different".

In the same way, the SCH-B_CG01 cohort also wrote in their essay, "It is still unclear how he was killed, what weapon was used to kill him (grenade or shot), and who did it." When questioned during the focus group interview session, they gave the following statement:

Researcher: Based on your essay regarding the death of Mallaby, why did you not confirm who the killer was? In your essay, you only explained many versions, without confirming by yourself who did it, why?

Budiaho: Because we were still in doubt. So, we only explained them (the versions).

Researcher: Any other opinions?

All students: The same, Sir.

Researcher: What about the cause of his death?

Buregino: Still confused. 
Bufannyo: Still in doubt. Because from several sources, some say he was stabbed by sharpened bamboo, being shot, and [hit by] a grenade [explosion]. So, it is still contradictory. So, we were still doubtful.

The same thing was done by the SCH-C_CG03 cohort as they were confused, and they could not confirm their interpretation position. In their essay, they compiled information from various sources on the internet, until they finally found nine different versions. Although they cited many sources, they were unable to confirm their position of interpretations. They wrote at the end of their essay, “Finally, after Mallaby's death has passed for many years, who Mallaby's killer was is still unclear. Not yet revealed. This case is the same as who ripped the flag at the Oranje Hotel on September 19, 1945." When asked for clarification during the focus group interview, one cohort member named Carrisao answered, "Because there were many versions, we were confused and could not decide."

The second category consists of cohorts who were able to draw conclusions after describing the various versions of the sources in their essays. There are nine cohorts included in this category. In dealing with conflicting sources, they simply chose one of the versions that were considered the best or interpreting whatever they wanted to believe. As if it was impossible to know the past with certainty, they interpreted freely whatever they wanted to interpret. They tend not to think critically by assessing the sources they got.

As the first example of this second category, the SCH-A_CG06 cohort presented three different versions of Mallaby's death in their essay. Without assessing the sources and without any argumentation, they concluded in their essay, "In our cohort opinion, the third version of Mallaby's death is the version that makes the most sense." The third version in that source explains that the killer of Mallaby was the British army itself as an excuse to occupy Indonesia. They used this version that they thought the best version when arguing with other cohorts as well, as stated by a cohort member named Atalithao during the debate, "If your [version] who killed [Mallaby] was an Indonesian but in my source [it states that] those who killed [Mallaby were] the British themselves who intentionally killed Mallaby so that later they could give a warning to Indonesia, so that Indonesia can be blamed." At the end of the discussion session, a member of this group named 
Airbaho drew a conclusion, "So, in my opinion, all the conclusions that exist [in each group] may only be various kinds of opinions from each student based on the news [articles] or sources obtained. The point is that history really depends on how we interpret the event." Even though their statements seemed convincing during the discussion session, but actually they still had doubts. This was proven during the focus group interview session, and they stated as follows:

Researcher: Based on your essay regarding Mallaby's death, you described three versions. Why did you conclude the event based on the third version?

Airbaho: Because, there were various versions, that we ourselves were still confused actually.

Afauzio: All the versions did not explain exactly who the killer was. It seems like the British themselves [killed Mallaby], in order to make the Indonesian people scapegoated. But yes, that is still uncertain.

Uncertainty in asserting interpretation was also experienced by the $\mathrm{SCH}$ B_CG03 cohort. In their essay, they presented several versions of Mallaby's death from three different internet sources, but suddenly they concluded that Mallaby's killer was Harun. In fact, Harun's name was even not mentioned in the sources they referenced. Harun is the name of the character who is described as Mallaby's killer in the Sang Kiai movie. In the classroom presentation, they explained the chronology of the event by reading the essay they had written. Then they closed it with a conclusion read by Bumardinatao, "We have read all [the contents of] the essay, and the central question: who actually killed Mallaby? In our opinion, the one who killed Mallaby was Harun." The uncertainty in establishing their position of interpretation was clearly captured during the debate process with other cohorts, as follows:

Bureinao (SCH-B_CG02): You said the death of General Mallaby was because he was shot, right? But in several other sources, he was killed by a grenade, because if he was indeed shot, he might still be alive.

Bumardinatao (SCH-B_CG03): Yes, I already told [you]

Bureinao (SCH-B_CG02): Yes, but you said earlier that [Mallaby] died because of a gunfire. If it was caused by a grenade, it was actually accidental. [The grenade] was thrown at Harun, not to Mallaby.

Bumardinatao (SCH-B_CG03): Yes, but it's still uncertain until now. Whether the death was caused by a grenade or was shot remains uncertain. 
Bureinao (SCH-B_CG02): But you said that [Mallaby] was shot, and then [he] was hit by a grenade!!! [tension increased].

Realising that the discussion process was turning into a heated debate, the teacher decided to get involved in the discussion:

Teacher B: [Stop, wait a minute]. What was your answer? Shot, and then hit by a grenade? Or hit by grenade only?

Bumardinatao (SCH-B_CG03): Shot first, then hit by a grenade explosion

Bureinao (SCH-B_CG02): No, you said [earlier] he was shot, and died. Then, he was hit by a grenade that Smith threw.

Teacher B: How do you explain that Bumardinatao?

Bumardinatao (SCH-B_CG03): I admit I slipped my tongue. Humans are not free from mistakes. At first, he was shot. [Now] I think, after being shot Mallaby was still breathing.

Bailhamo (SCH-B_CG03): When shot, bang! He was still alive (by demonstrating as being shot).

Bumardinatao (SCH-B_CG03): At that time, he was still in pain, dying. Then, the grenade came, exploded, and he died.

Attracted by students' effort to demonstrate the process of Mallaby's death, which depicted the chronology of the incident that seemed to have certainly happened, the teacher questioned how students could be so certain in interpreting the incident:

Teacher B: How do you know that when he was shot, he was still alive?

Bumardinatao (SCH-B_CG03): From the movie, Ma'am.

Teacher B: Oh, so this is the version from the Sang Kiai movie?

Bumardinatao (SCH-B_CG03): Yes.

Teacher B: So, your source is the movie?

Bumardinatao (SCH-B_CG03): I got an inspiration from the Sang Kiai movie, also from other sources that I got.

Based on the description of the discussion process above, students seemed that they were indecisive with their interpretation. The uncertainty of their interpretation position was reflected on how easily they changed their answers. They were also seen to be quite careless in making interpretations as if they could interpret whatever they wanted about the past.

In the same way, the SCH-C_CG04 cohort also easily concluded their work by simply selecting one of the versions described in their essay. They did not assess or criticise the source. Their conclusions were only by following the source version without establishing their own arguments. During the presentation, they finally conveyed their interpretation based on whatever they wanted to believe, as long as 
it made sense even without evidence or source. One of their members named Caksyarifo concluded at the end of the presentation as follows:

In our opinion, the killer was the Allies or the British themselves. Wherein, our opinion is corroborated by logic that if the Indonesian people did it, they must be proud. Definitely. They would have admitted it first because it would be a pride for them, to ignite the spirit of other arek-arek [youngsters of] Surabaya. But, if those who killed him were from the British army, they certainly would not confess it because they would be punished by the British.

Their statement implied that the fact no one claimed to be the perpetrators at that time means that the perpetrators were British and not Indonesian. At first glance, it made sense, but their argument had no evidential basis.

In the experimental group students, it seemed they had the valuable lesson learned which they gained from their first experience in the first learning intervention process. They have equilibrated their existing schemata (Beilin, 1992; Mascolo, 2015; Piaget, 1950, 1952, 1954; Stoltz, 2018). Prior to the intervention, they only assimilated one version of history. At this intervention processes, they had accommodated the fact that the past can be reported differently by the eyewitnesses, so they realised why historical sources can be interpreted differently by historians. They began to realise how historians' work, especially when reading their textbook and comparing it with primary sources. Moreover, students also learned from their mistakes during the first intervention, especially when conducting discussions and debates in front of the classroom. Their learning process was triggered by diverse opinions and by connecting different information in their learning community through continuous dialogue (Boitshwarelo, 2011; Goldie, 2016; Kop \& Hill, 2008; Siemens, 2004). So, in the second intervention stage, some students began to realise how to deal with conflicting sources and how to construct a reasonable interpretation from different sources.

In answering the central historical question, their answers can be grouped into three clusters of answers. The first cluster is students who answered that Mallaby's killer was Indonesian (10 cohorts). The second cluster is students who answered that Mallaby's killer was from the British army itself ( 5 cohorts). The third cluster is students who did not conclude any answer ( 3 cohorts). In writing their essays, they had utilised various primary sources available on the website 
www.berpikirsejarah.com, but there were also cohorts that added references obtained from other internet sources, including from Wikipedia ( 2 cohorts), online magazines and newspapers ( 5 cohorts), and unverified blogs ( 2 cohorts). In their essays, all cohorts presented the various versions they had obtained in various sources.

In terms of establishing the position of interpretations, student cohorts can be grouped into three categories. The first category is cohorts who did not draw conclusions or did not dare to establish their position of interpretation. The second category is cohorts that confirmed their interpretation position but only by referring to one source that they considered the best or referring to several sources that had the same version. The third category is cohorts that succeeded in constructing their interpretations by assessing, critiquing, and corroborating various sources. The first two categories basically did not construct their own interpretations because they did not assess and criticise the sources. They simply followed the version in the sources. Meanwhile, students who were in the third category could be said to have competent historical thinking skills already — certainly at student level.

In the first category, there were three cohorts who did not establish their position even though they did present various versions in their essays. For example, one of the cohorts in this category is the SCH-A_EG05 cohort. They wrote their conclusions in their essays as follows, "Therefore, our conclusions from the sources that we have read is that it is still not clear who killed/shot Mallaby at that time." During the focus group interview session, they explained their reasons why they did not establish any interpretation position. The following is their explanation given by a cohort member named Amalzae:

Well, actually, this is the same as my previous answer [in the WIE' post-test 1], right? The main point is basically because it was still not clear [who killed Mallaby], still in shades of grey. The student textbook must convey the truth; but in fact, the textbook also does not know (does not mention) who the killer of Mallaby was. The truth has not been found yet.

This cohort argued that it was impossible for them to draw any conclusion because too many versions were circulating about Mallaby's death. Even the student textbook did not clearly mention who killed Mallaby. 
Another example of a cohort included in this category is SCH-C_EG06 cohort. They presented four different versions in their essay, but did not draw any conclusion. During the presentation in front of the classroom, they also just explained the various versions without any conclusions. It was only when the teacher asked them to confirm their interpretation positions, finally, they did randomly draw conclusions. Based on these observation findings, I asked them for their confirmation during the focus group interview. The following is the excerpt from that interview:

Researcher: Based on your essay regarding Mallaby's death, the killer was......?

Ciputrie: The British army.

Researcher: Oh, really? Did you conclude that in your essay?

Ciputrie: No.

Researcher: When you presented the essay, did you confirm your conclusion?

Cayuninge: No.

Researcher: When the teacher asked you to conclude, what was your answer?

Ciputrie: The British army.

Researcher: Why? Is it not possible to draw conclusions?

Cakadame: In my opinion, at that time there was a shootout. Perhaps, if investigated, it could be that the gunfights from both sides were inaccurate. Maybe, they could hit their target or enemy. Maybe, they also missed [the target] and [friendly fire occurred] because of the chaotic situation. They panicked as well.

Researcher: Anyone wants to add answers?

Ciputrie: Because it occurred when it was dark, at night. So, it cannot be concluded clearly who [the killer was]. Although Indonesia had a hatred for the Allied forces, [they] could not be blamed for making deliberate fire at Mallaby [due to the crossfire]. But it could also be during the crossfire that the British soldier missed [the target] and hit Mallaby.

When they were asked for opinions on various versions of other sources, their answers were always consistent with being unsure of what happened in that incident, so they did not draw any conclusion. For example, when asked about the Kedaulatan Rakjat and Soeara Rakjat's versions stating that the British army themselves were Mallaby's killers, a student named Cayuninge replied, "In our opinion, that version is still unreliable. The problem is that we have to return to our cohort's conclusions that we still cannot conclude who did it." 
In the second category, there were six cohorts that were able to establish their position after describing several versions regarding Mallaby's death. However, they simply concluded their answer based on one source or several sources that had the same version. They were still unable to assess and compare conflicting sources to build a reasonable interpretation. As the first example, the case of SCH-A_EG01 cohort concluded that the killer of Mallaby was the British side by referring to the statements of three news articles in Kedaulatan Rakjat published on 13, 14, and 19 November 1945. This newspaper was definitely written with Indonesian perspective, but unfortunately, this cohort was not able to assess and criticise the sources. During the classroom discussion session, one member of the cohort named Athiae delivered their argument:

According to the Kedaulatan Rakjat newspaper, Gurkha soldiers killed [Mallaby], because every action of the Gurkha soldiers must be guaranteed by the British. Then, there was one member of the Contact Bureau (Muhammad) who entered the Internatio building [who witnessed] the Gurkha soldier firing at people [of Surabaya outside the building], shooting at the [Contact Bureau] members, and also shooting Mallaby [who were with members of the Contact Bureau].

The second example is the case of the SCH-B_EG02 cohort who concluded that Mallaby's killer was Indonesian. Their conclusion referred to Ruslan's testimony, even though they had previously described four different source versions in their essay. However, they only followed the version of Ruslan's testimony and ignored the other three in drawing their conclusions. During a focus group interview, when they were confronted with a different version, they rejected that version by showing another source that corresponded to their conclusions. The following is the excerpts from the interview.

Researcher: What about the Kedaulatan Rakjat newspaper version dated 15 November, 1945 which stated that the killer of Mallaby was the British army themselves? What do you think about that newspaper statement? Do you believe it or not?

Balfiane: I do not agree.

Researcher: Why?

Balfiane: There are many other explanations, SNI textbook [the national history of Indonesia] stated [the killer was an Indonesian] youth; Ruslan said [the killer was an Indonesian] youth. Many stated that an [Indonesian] youth was the killer. 
Their statement implies that two sources with the same version are enough to reject other, different versions.

In the third category, there were nine cohorts who were able to establish their position of interpretation by critically assessing conflicting sources. In their essay, they wrote the results of assessing and critiquing each source they used. They also compared those sources to construct reasonable interpretation. During classroom discussions, they often sparked a debate about the status of the sources and the reasons for determining their position of interpretation. In the focus group interview, they were also able to verbally assess conflicting sources that were asked about.

As the first example is the case of the SCH-A_EG04 cohort, who in their essay concluded that the killer of Mallaby was from the British side, they assessed the historical context around the scene, the Internatio building. They decided that the most potential shooter of Mallaby, who was with the members of the Contact Bureau outside the building, was from the British army side. During the focus group interview session, they reaffirmed the rational basis of their interpretation. The following is the excerpts from the interview:

Researcher: Based on your essay regarding Mallaby's death, why do you think that the killer was the British army themselves? Is that right?

Arifdahe: Yes.

Researcher: Why?

Arifdahe: Because at that time there were many Indonesian people in front of the Internatio building, while the British army [inside the building] was ready to aim their guns down, like that Sir. Automatically, the most likely to shoot Mallaby was the British.

When confronted with other versions that came from the official textbook, they were able to provide a critical interpretation of the textbook contents. They made the following statement:

Researcher: How about the national history of Indonesia, the SNI's version. There is a statement that "Mallaby was targeted by the youths", does that mean the perpetrators were Indonesian youths?

Arifdahe: The problem is, if the [Indonesian] youths stab him with sharpened bamboo, I think it was impossible. It does not make sense either.

Asalmae: The problem is that Mallaby was in a car.

Researcher: But this is the official version of the official textbook, right? 
Arifdahe: Yes, maybe, in the essence, the [Indonesian] government is trying to instil the idea that Indonesian youths could do it, even with any weapon, could kill the British-just maybe.

Researcher: OK, that makes sense.

Arifdahe: Yes, that is why I believe that the British [were the perpetrators].

Once again, when faced with another different version that came from primary sources, this cohort was also able to present their critical analysis as follows:

Researcher: How do you respond to the testimony of Captain Laughland, from the War Office archives, that the perpetrators were Indonesian youths? What do you think?

Arifdahe: Yes, the fact that the killer was from the Indonesian side was still possible. But in my opinion, it was impossible, Sir. The problem is why did Indonesia shoot Mallaby? The demand at that time was only to expel [the British soldiers from inside the Internatio building] and escort them to the port, without weapons, right? So, why kill Mallaby? Indonesia was also not looking for trouble.

As the second example, the SCH-B_EG01 cohort, who in their essay concluded that the killer of Mallaby was from the Indonesian side was able to weigh the strengths and weaknesses of each source, then used it to draw a reasonable interpretation. Since the first intervention phase, this cohort often made other cohorts experience difficulties during the debate. They always asked the reasons of the other cohorts in using certain sources in constructing their interpretations. This is as illustrated in one of the discussions at the fourth meeting as follows:

Buregise (SCH-B_EG01): What is your source, guys?

Bapriliae (SCH-B_EG06): Our sources are from [various] primary sources, namely from two newspapers, Soeara Rakjat 1945, Kedaulatan Rakjat 1945 as well as [some secondary sources] from the national history of Indonesia [textbook].

Bhernandae (SCH-B_EG01): Why don't you use testimonies from the British side?

Bangelicae (SCH-B_EG01): Yes, why? [For example,] the testimonies of Laughland and Smith.

Bapriliae (SCH-B_EG06): We did not use the testimonies from the British, because the leaders of the British occupation army did not want to look for or investigate the real cause of the dispute [as stated in the Kedaulatan Rakjat 15 November 1945]. 
Besides being reflected during classroom discussions, their skills in assessing and critiquing sources were also proven during the focus group interview session, as presented below:

Researcher: Based on your essay regarding Mallaby's death, why did you think that Mallaby's killer was from the Indonesian side? Is that so?

Bhernandae: Yes.

Researcher: Why did you think so?

Bhernandae: Because from various different sources, it was stated that the Indonesian was the perpetrator.

Researcher: What were the sources?

Bhernadae: Rulsan's [testimony], Captain Smith and Captain Laughland's [testimonies], from the British archives.

Researcher: Do you believe in those sources?

Bhernandae: Yes, because [their testimonies are] very strong.

Researcher: How strong?

Bhernadae: Because [their testimonies] corroborate each other; [their testimonies] supporting each other.

When confronted with another version that came from other different sources, they could also provide reasonable arguments, as follows:

Researcher: Now, how do you respond to the newspaper version, for example, the Kedaulatan Rakjat dated November 15, 1945, which described that the British themselves were Mallaby's killers. What do you think?

Bhernandae: Maybe, what is it, as encouragement?

Researcher: What kind of encouragement?

Bhernandae: Encouragement to the Indonesian youth.

Researcher: So, you do not believe the version in that newspaper?

Bhernandae: No.

Researcher: Why?

Buregise: We do not believe [because] the newspaper made it up. The newspaper headquarters was in Yogyakarta [so far from Surabaya]. They seemed to heat up the tension.

Bhernandae: Propaganda!

Researcher: What about the version of SNI (the national history of Indonesia)? You said that Mallaby's killer was Indonesian youth. What about the SNI's version that stated that Mallaby was killed by [Indonesian] youths by being stabbed by sharpened bamboo and bayonets? What do you think? Do you believe with that version?

Buregise: [No], in other testimonies, none said that he was stabbed by sharpened bamboo.

The third example in this category is the case of the SCH-C_EG01 cohort, who in their essay concluded that the killer of Mallaby was an Indonesian youth. 
Their conclusions were obtained after critiquing and analysing some sources, specifically from the War Office archives, Kedaulatan Rakjat and Soeara Rakjat newspapers, Ruslan' testimony, and the national history of Indonesia textbook. During the focus group interview session, they were able to explain their reasons for determining their position of interpretation as well as to assess other sources confronted with them during that session. The following is the excerpt from the interview:

Researcher: Based on your essay regarding Mallaby's death, why did you think that the killer was Indonesian?

Cakrahardiane: Because the Indonesian shot Mallaby. If there were no shots, Mallaby would not be killed.

Researcher: What were the sources?

Cakrahardiane: The sources were newspapers and others

Cakpurwantoe: Mainly, it was from the archives of Smith and Laughland's report.

Researcher: Do you believe in those sources?

Cakrahardiane: I do, because these are primary sources [in the form official archives]. There is no way the reporter was lying; it could be a disgrace to his country.

Cakpurwantoe: Because they were also in the car with Mallaby at that time. Thay also saw [the shooting] firsthand.

When confronted with other sources, this cohort was also able to provide their assessment as follows:

Researcher: You mentioned earlier that you also used the newspapers [as a reference], for example, based on Kedaulatan Rakjat, 15 November 1945, [that stated] that the killers of Mallaby were the British. What do you think about that version?

Cakpurwantoe: As I said earlier, most of these newspapers [articles] contained many appeals, kind of encouragement, the drive to ignite the spirit of the Surabaya people. Although it was reported in the article entitled "British accusations", which stated that the British army did not dare to conduct further investigations into the cause of Mallaby's death, basically they [the newspapers] also only accused [the British, without evidence]. However, according to British archives, there are testimonies of Captain Laughland and Captain Smith. Both sat in the same car with Mallaby and witnessed it [the death of Mallaby] first-hand. So, yes, the contents of the newspapers were only to encourage [the youngsters' spirits] at that time.

Researcher: What about the SNI's version, the official version of the government? It is stated that the cause of Mallaby's death was by being stabbed by sharpened bamboo? 
Cakpurwantoe: Well, we do not believe that, because after reading Captain Laughland's testimony, [it seemed] that the actual incident was not like that. Maybe what is written in the textbook is to encourage students, that in the past, the struggle of the people of Surabaya was great that they used sharpened bamboo, and [that is in order] to ignite students' enthusiasm.

Therefore, at the end of the second learning intervention, there were two themes that often appeared during the classroom observations and focus group interviews. The first theme was related to how students dealt with sources that had conflicting versions and the second theme was about how students establish their interpretative positions. These two themes became the main factors that determine the development of students' historical thinking skills. The two factors, as also found in the previous intervention stage, are related to how students dealt with sources that had different versions and about how they established their position of interpretations.

\subsection{The comparison of students' historical thinking skills in learning about the battle of Surabaya between the control group students and the experimental group students}

Based on the findings of the quantitative and qualitative data regarding students' historical thinking skills that have been described above, several comparisons between the control and experimental groups can be drawn. First, prior to the implementation of the learning intervention process, the level of historical thinking skills of students from both the control group and the experimental group was at an equal level. This was reflected in the mean score of the WIE's pre-test from both groups. In fact, the mean scores of the control group students were slightly better than the experimental group students. However, both groups were still unable to think critically when writing their essay. They did not develop their own interpretation and argumentation. Instead, they only followed the version of the source they got. In their pre-test essays, they only presented one version of history that came from one source that they considered having the "authority", such as textbooks or Wikipedia. If they found different versions, they would determine their interpretation based on "the majority" or counting the number of the most 
sources with the same version. Thus, before the learning intervention process, students' historical thinking skills from both groups were still equally low because they had not been able to construct their own interpretations and ignored sources that had different versions.

Second, in the first learning intervention stage, there were differences that began to appear between the control group and the experimental group students. Based on the quantitative data from the WIE's post-test 1, the mean score of the two groups increased, but the increase in the experimental group was higher. This means that the difference between the control group and the experimental group was statistically significant. Based on the qualitative data, the differences between the two groups can be explained. In the control group students, almost all the cohorts still wrote the WIE's post-test 1 essay in the same way when writing the WIE's pre-test. They tended to draw conclusions or establish interpretations by referring to secondary sources they deemed to have "the authority" or "the majority" versions. Only one cohort - the outlier, due to primary source leakagewas unable to draw any conclusions because they were dealing with conflicting primary sources.

Meanwhile, the cohorts in the experimental group could be grouped into four categories based on their strategies in dealing with sources for establishing their interpretations. First, there were eight cohorts that simply chose the sources that had the same version to construct their interpretation. They did not mention any other versions in their essays, even though they knew there were other sources that had versions that contradicted their conclusions. Second, there were three cohorts who described various versions in their essays, but they were unable to draw any conclusion. Third, there were five cohorts who described various versions in their essays, then they concluded their interpretations based on one source which they considered "the best" or several sources that had "the same" version. Fourth, there were two cohorts who succeeded in assessing and critiquing each source to establish interpretations or draw conclusions.

Third, in the second learning intervention stage, there were sharp differences between the control group and the experimental group students. Based on the quantitative data from the WIE's post-test 2 , the mean score of the control group 
had increased slightly, while the experimental group had increased sharply. This means that the difference between the control group and the experimental group was statistically significant. Based on the qualitative data, the differences between the two groups can be explained. In the control group students, there was a slight progression where they had realised that history had multi-perspectives. On one hand, they got this understanding from the previous intervention stage where it turned out there were differences in answers among the cohorts during classroom discussions. On the other, they very easily found different versions of Mallaby's death on the internet sources. In the end, there were two categories related to control group students' strategies in dealing with different sources for establishing interpretation. First, there were nine cohorts who were unable to establish their position of interpretations after presenting various versions obtained from different sources. Second, there were nine cohorts who were able to draw conclusions after describing the various versions of the sources in their essays. Their conclusions were established by simply choosing one of the versions that they considered the best, or interpreting whatever they wanted to believe.

In the experimental group, there was a vivid progression in which more cohorts were able to think historically. Based on their strategy in dealing with different sources for establishing their interpretation, there were three categories found. First, there were three cohorts that did not establish their interpretation even though they had presented various versions in their essays. Second, there were six cohorts that were able to establish their position of interpretations after describing various versions of the past. Third, there were nine cohorts that were able to establish their position of interpretations by critically assessing the conflicting sources.

Fourth, both in the control group and the experimental group, I found two themes that always appeared in two stages of the learning intervention. These two themes repeatedly emerged in students' utterances both during observation and interview. The first theme was related to how students dealt with sources that had different versions. The second theme was related to how students established their position of interpretations. These two themes formed the basis for the emergence 
of the strategic categories used by students both in the control and the experimental groups in writing their essays.

Therefore, based on the quantitative and qualitative data that described above, it can be seen clearly that teaching and learning history through analysing documents and interpreting textbooks contributed an improvement to students' historical thinking skills. In the next chapter, it is interesting to note whether the process of learning intervention through analysing documents and interpreting textbooks also contributes to students' epistemic beliefs about history. 
This page is intentionally left blank. 


\section{CHAPTER 7 \\ STUDENTS' EPISTEMIC BELIEFS ABOUT HISTORY}

The purpose of this chapter is to answer the second sub-question in this study, that is, whether the teaching and learning intervention process through analysing documents and interpreting textbooks has an impact on students' epistemic beliefs about history. The first section presents quantitative data regarding students' epistemic beliefs based on the historical beliefs questionnaire that was distributed three times during the intervention process. The second section presents qualitative findings regarding students' epistemic beliefs based on focus group interviews. The last section presents the general comparison of students' epistemic beliefs between the control group and the experimental group.

\subsection{Students' epistemic beliefs about history based on the historical beliefs questionnaire.}

The historical beliefs questionnaire (HBQ) was used to measure students' epistemic beliefs about history. This HBQ questionnaire adopted the statement items from the historical beliefs questionnaire that was developed by VanSledright (2014). There were 12 statements that students had to respond (see table 4.6 and appendix $\mathrm{H}$ ). The questionnaire was distributed three times, before the intervention (HBQ1), after the first intervention (HBQ2), and after the second intervention (HBQ3). When the questionnaire was distributed three times, all the experimental group students filled out the questionnaire ( $\mathrm{n}=96)$. Meanwhile, out of a total of 95 control group students, one student did not attend school when the second HBQ was distributed, and one other student did not attend school in the third distribution of HBQ. Thus, there were 93 control group students who filled out all three questionnaires ( $\mathrm{n}=93$ ) as valid cases, while there were 2 cases missing $(2.1 \%)$ which cannot be further processed.

From the results of the three-time HBQ distribution, I obtained consistency scores that reflect students' epistemic beliefs about history. HBQ consistency scores for control group students are presented in appendix O (page 299), while HBQ consistency scores for experimental group students are presented in appendix $\mathrm{P}$ 
(page 300). HBQ consistency score's data can be used to monitor the progress of students' epistemic beliefs before and after each intervention process. This study assumes that the process of intervening in teaching history through analysing documents and interpreting textbooks not only affects students' historical thinking skills but also their epistemic beliefs about history. Ideally, students' consistency scores could increase gradually from the HBQ1, HBQ2, to HBQ3. In reality, when examined individually, the HBQ consistency scores for each student presented in appendices $\mathrm{O}$ and $\mathrm{P}$ show mixed progression. In the control group, the consistency scores of students varied. There were some that had increased $(24.73 \%)$, some had decreased (30.11\%), the majority had fluctuated (40.86\%), and some had not progressed $(4.3 \%)$. In the experimental group, students' consistency scores also varied, the majority of students had increased (37.5\%), some had decreased (21.88\%), some had fluctuated (28.13\%), and some had not progressed $(12,5 \%)$.

HBQ consistency scores of students from both groups need further statistical analysis. The raw data of HBQ consistency scores presented in appendices $\mathrm{O}$ and $\mathrm{P}$ are firstly followed by descriptive statistical analysis. Some data findings from descriptive statistical analysis are presented in the following table:

Table 7.1 HBQ's mean score for each questionnaire distribution

\begin{tabular}{clll}
\hline HBQ & \multicolumn{1}{c}{ Group } & Median (minimum-maximum) & Mean \pm SD \\
\hline \multirow{2}{*}{ HBQ1 } & Control & $75.00(50-100)$ & $73.84 \pm 11.30$ \\
\cline { 2 - 4 } & Experimental & $75.00(50-100)$ & $75.26 \pm 12.36$ \\
\hline \multirow{2}{*}{ HBQ2 } & Control & $75.00(16.67-100)$ & $76.79 \pm 12.09$ \\
\cline { 2 - 4 } & Experimental & $75.00(33.33-100)$ & $77.69 \pm 12.88$ \\
\hline \multirow{2}{*}{ HBQ3 } & Control & $75.00(41.67-100)$ & $70.20 \pm 14.48$ \\
\cline { 2 - 4 } & Experimental & $83.33(50-100)$ & $79.77 \pm 11.89$ \\
\hline
\end{tabular}

Based on the table above, we can see the difference in the HBQ mean scores between the control group and the experimental group. In the HBQ1, the mean score of the control group was 73.84 and the experimental group was 75.26. It can be interpreted that the difference between the two groups was not too far, even the median, the minimum and maximum of the consistency score from both groups were roughly the same. In the HBQ2, the mean score of both groups was also similar, and both had increased compared to the HBQ 1. However, the minimum score of the two groups decreased. In the HBQ3, the mean score of the control group was 70.20 and the experimental group was 79.77 , so the difference between the two 
became even sharper, though (again) not too far. The progress of the mean scores of the two groups can be visualised in the following figure:

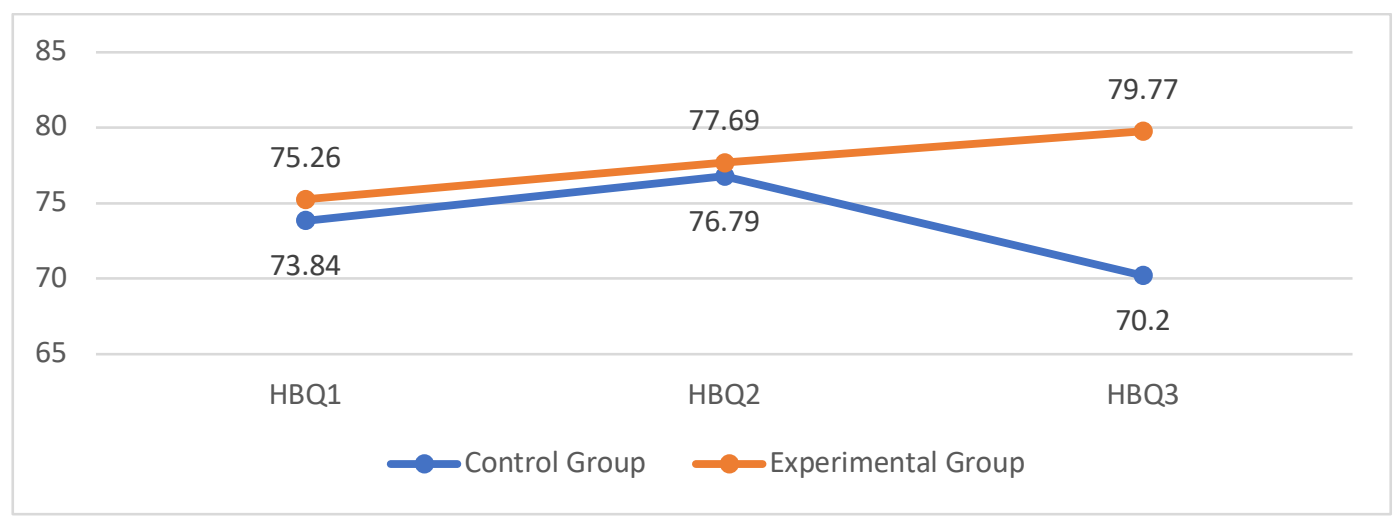

\section{Figure 7.1 Comparison of the HBQ mean scores between the control group} and the experimental group

Before proceeding to inferential statistical analysis, I had to check the normality of the data using a formal normality test. Since the valid sample size was 189 ( $\mathrm{n}>50)$, I used the Kolmogorov-Smirnov test because it was more appropriate for a large sample size (Mishra et al., 2019). If the p-value or the sig. value of the Kolmogorov-Smirnov test is greater than 0.05 , the data is normal. However, the Kolmogorov-Smirnov test showed that the p-value obtained was less than 0.05 $(p<0.05)$, which means that the distribution of the data was not normal. This suggested that further inferential statistic should be done through non-parametric methods. The results of the normality test can be seen in the following table:

Table 7.2 Test of normality of the HBQ consistency score

\begin{tabular}{clllll}
\hline \multirow{2}{*}{ HBQ } & \multicolumn{1}{c}{ Group } & \multirow{2}{*}{ Mean (SD); 95\% CI } & \multicolumn{2}{c}{ Kolmogorov-Smirnov } \\
\cline { 3 - 5 } & & & Statistic & Df & Sig. \\
\hline \multirow{2}{*}{ HBQ1 } & Control & $73.84(11.30) ;(71.50-76.16)$ & .156 & 93 & .000 \\
\cline { 2 - 6 } & Experimental & $75.26(12.36) ;(72.76-77.76)$ & .148 & 96 & .000 \\
\hline \multirow{2}{*}{ HBQ2 } & Control & $76.79(12.09) ;(74.30-79.28)$ & .162 & 93 & .000 \\
\cline { 2 - 6 } & Experimental & $77.69(12.88) ;(75.08-80.30)$ & .167 & 96 & .000 \\
\hline \multirow{2}{*}{ HBQ3 } & Control & $70.20(14.48) ;(70.23-76.19)$ & .126 & 93 & .001 \\
\cline { 2 - 6 } & Experimental & $79.77(11.89) ;(77.36-82.16)$ & .211 & 96 & .000 \\
\hline
\end{tabular}

${ }^{a}$ Lilliefors Significance Correction

The lack of normality of HBQ data distribution led me to use non-parametric tests to perform the inferential analysis. Therefore, I used the Friedman test because the HBQ consistency score data were obtained from measurements on three different occasions (Mackridge \& Rowe, 2018). The Friedman test results for the control group showed that the approximate significance level was 0.163 ( $>00.05)$ which means the differences between the medians were not statistically significant. 
While for the experimental group, the Friedman test results showed that the approximate significance level was $0.010(\mathrm{p}<0.05)$ which means the differences between the medians were statistically significant. The following table presents the results of the Friedman test in the control and experimental groups:

Table 7.3 Friedman test results for the HBQ

\begin{tabular}{|c|c|c|}
\hline \multirow{2}{*}{ Test statistics ${ }^{a}$} & \multicolumn{2}{|c|}{ Groups } \\
\hline & Control group & Experimental group \\
\hline $\mathrm{N}$ & 93 & 96 \\
\hline Chi-Square & 3.634 & 9.123 \\
\hline p-value & .163 & .010 \\
\hline
\end{tabular}

${ }^{a}$ Friedman Test

This Friedman test only produced one overall conclusion as to whether there were any differences among the time points of the questionnaire distribution or between HBQ1, HBQ2, HBQ3 within a group (Mackridge \& Rowe, 2018). The results showed that the difference between the three HBQ's in the control group was not significant, while in the experimental group it was significant. To determine which of the HBQ's medians in the experimental group were different, I proceeded through post hoc Wilcoxon analysis. Although the Friedman test results in the control group were not significant, I also continued with the Wilcoxon test to see differences between the HBQ's medians in this group. The results of Wilcoxon analysis for each of the pairs of HBQs in the both groups can be seen in the following table:

Table 7.4 The results of Wilcoxon test in the control and experimental group

\begin{tabular}{cccc}
\hline Group & HBQ & Z score & p-value \\
\hline Control group & HBQ2-HBQ1 & -1.925 & 0.054 \\
\cline { 2 - 4 }$n=93(\mathrm{p}=0.163)$ & HBQ3-HBQ1 & -0.376 & 0.707 \\
\cline { 2 - 4 } & HBQ3-HBQ2 & -2.472 & $0.013^{*}$ \\
\hline $\begin{array}{c}\text { Experimental group } \\
\mathrm{n}=96(\mathrm{p}=0.010)^{\mathrm{a}}\end{array}$ & HBQ2-HBQ1 & -1.675 & 0.094 \\
\cline { 2 - 4 } & HBQ3-HBQ1 & -2.508 & $0.012^{*}$ \\
\cline { 2 - 4 } & HBQ3-HBQ2 & -1.400 & 0.161 \\
\hline
\end{tabular}

${ }^{a}$ The data is significant statistically, Friedman test (significance level $\mathrm{p}<0.05$ )

*The data is significant statistically (multivariate analysis was used post hoc Wilcoxon analysis with significance level $\mathrm{p}<0.05$ )

To interpret the Wilcoxon test results in the table above, I referred to the pvalue obtained from the relation between the three HBQ's. If the p-value was less than or equal to the significant level $(\mathrm{p} \leq 0.05)$, it can be concluded that the difference between the population median and the hypothesized median was statistically different (Mackridge \& Rowe, 2018). For the experimental group, the results of 
interpretation to table 7.6 are as follows. First, the comparison between HBQ1 and HBQ2 showed that the relationship between the two had no significant differences. This refers to the $p$-value obtained was 0.094 ( $>0.05$ ). Second, the comparison between the HBQ3 and HBQ1 showed that statistically, the relationship between the two was significantly different. This refers to the p-value obtained was 0.012 $(\mathrm{p}<0.05)$. Third, the comparison between the HBQ3 and HBQ2 showed that statistically, the relationship between the two was not significantly different. This refers to the $\mathrm{p}$-value obtained was $0.161 \quad(\mathrm{p}>0.05)$. Therefore, statistically significant differences only occurred between the HBQ1 and HBQ3. This is presumably because the median has increased from 75 in HBQ1 to 83.33 in HBQ3.

Meanwhile, for the control group, although the overall Friedman test results showed that there was no significant difference between the three HBQ's, it was also necessary to study the differences between some of these HBQ relations separately. First, the comparison between HBQ1 and HBQ2 showed that the relations between the two had no significant differences because the p-value obtained was 0.054 ( $>0.05)$. Second, the comparison between the HBQ3 and HBQ1 showed that the relations between the two also had no significant differences because the $p$-value obtained was 0.707 ( $p>0.05)$. Meanwhile, the comparison between the HBQ3 and HBQ2 showed that the relations between the two were significantly different because the $p$-value was $0.013(p<0.05)$. This is presumably because the minimum score of HBQ2 is lower than HBQ3, despite having the same maximum score and median. In addition, the mean score also dropped sharply, from 76.79 in the HBQ2 to 70.20 in the HBQ3.

Next, to determine whether there were differences between the two separate groups or between the control group and the experimental group, I used the MannWhitney test (Mackridge \& Rowe, 2018). In this test, the results can be interpreted as statistically significant if the p-value is less than or equal to the significant level $(\mathrm{p} \leq 0.05)$. The results of the Mann-Whitney test are presented in the table below:

Table 7.5 The results of the Mann-Whitney test to determine the difference between the control and experimental group.

\begin{tabular}{lccc}
\hline & HBQ1 & HBQ2 & HBQ3 \\
\hline Z score & -.833 & -.812 & -3.280 \\
\hline p-value & .405 & .417 & $.001^{*}$ \\
\hline
\end{tabular}

*The data is statistically significant, Mann Whitney test (significance level $p<0.05$ ) 
Based on the table above, the data obtained can describe the extent of the difference between the two groups on the three HBQ's. First, in the HBQ1, there was no significant difference between the control and experimental groups (p-value $=0.405)$. This is because the median and the minimum-maximum scores in the two groups were the same, also because the mean scores were not far adrift, namely 73.84 for the control group and 75.69 for the experimental group. Second, in the HBQ2, there was also no significant difference between both groups ( $p$-value $=$ 0.417). The medians and the maximum score of the two groups were the same, as well as the minimum score, which equally decreased. As for the mean scores, the two groups equally increased theirs, but the difference was not so far, namely 76.79 for the control group and 77.69 for the experimental group. Third, in the HBQ3, there was a significant different between the control and experimental groups (pvalue $=0.001)$. This would be reasonable because the medians, the minimum scores, and the mean scores of the two groups were different.

Overall, it can be concluded that based on the quantitative data there were changes in students' epistemic beliefs about history after the intervention of teaching and learning history through analysing documents and interpreting textbooks. However, it seems that it takes a longer time for the historical thinking process intervention to have greater impact on students' epistemic beliefs. This was proven in the experimental group which showed significant changes only after the second intervention process. In addition, there was always a gradual increase in the mean score of the experimental group from HBQ1 to HBQ3. Meanwhile, in the control group, although there was a slight increase in the mean score from HBQ1 to HBQ2 - as was also the case in the experimental group - they turned out to have a sharp decrease in HBQ3. This seems to be influenced by the increasing complexity of the central historical question that students must interpret in the second intervention. These quantitative findings will be deepened with the qualitative findings presented in the next section. 


\subsection{Students' epistemic beliefs about history based on the teaching and learning process}

This section explains qualitatively the underlying rationale behind students' responses to statement items in the HBQ's. This qualitative response was mainly based on the results of the focus group interviews after students had responded to the questionnaire three times. During the interview, students could provide personal rationale which constituted individual epistemic beliefs and did not necessarily reflect the epistemic beliefs of the cohort. This section primarily explores the similarities and differences in reasons given from both the control and experimental groups in responding to questionnaire statements. The description of students' rationale is described based on the order of the statement items in the questionnaire as follows:

\subsubsection{First statement}

In response to the first statement that "there is no difference between the past and history," students' answers from both the control group and the experimental group were divided into two grounds; agree and disagree. Students who agreed stated that both history and the past were events that had occurred in the past. A control group student named Buumio, for instance, "Agreed because the past has happened, the same as history, so there is no difference," Students who disagreed argued that history was only for significant past events. For example, an experimental group student named Amalzae stated, "There is a past that can be history, and there is a past that cannot be history. For example, the past that can be history is like the battle of Surabaya. The past in general, which is not important, like I went to the toilet, did not become history."

\subsubsection{Second statement}

For the second statement that "historical facts speak for themselves," both groups of students expressed disagreement. For example, a control group student named Buregino stated her reason as follows:

Disagree. The problem is history, for example, like yesterdays, from various sources it was already bickering, there was this [version], this [version], this [version]. And, we have to prove it again, it depends on how we do it. We took [conclusions] from various sources, which [version] is the most. If the sources are not analysed first, it is not a fact. 
While an experimental group student named Ciputrie gave her reasons as follows: "I do not agree because it is still not certain that historical facts can be accepted directly by the community, right? So, surely historians also make different interpretations. So, [historical facts] must be compared, negotiated — something like that." Thus, both the control group and the experimental group students realised that historical facts had to be processed first. For the case of the control group students, this meant searching for the most similar versions from the sources, while for the case of experimental group students, it is comparing sources to produce interpretations.

\subsubsection{Third statement}

Similar to the first statement, students' responses to the third statement which states that "history is what happened in the past," both groups were also divided into two stances, agree and disagree. The reasons they gave also had the same tone as the first statement. For instance, a control group student named Buumio stated her agreement in that "the past and history are the same; both are events that have happened." Meanwhile, an experimental group student named Cahyaninge also stated, "I agree because, in my opinion, the past is part of a historical event. So, it's also like history was taken from the past. They're in a way interrelated".

There were also many students from both groups who expressed their disagreement. For example, a control group student named Adaffao stated as follows:

Yes, as I said earlier, every past does not have to be history, Sir. This is except for a memorable past, like the tearing of the Dutch flag, which was memorable so it became a part of [our] history. But, if it does not have any impression at all, then it does not [become history].

In the same vein, an experimental group student named Asalmae also stated, "[I] disagree because the past refers to a lot of things, whereas history is just like an important past event". Thus, students who disagreed had their assumptions surrounding the notion that history refers to a significant past only.

\subsubsection{Fourth statement}

In response to the fourth statement that "it is impossible to know anything about the past because none of us were there," there were differences between the control and experimental groups. In the control group students, there were 
differences in their opinions between those who agreed and disagreed, while in the experimental group, all interview participants expressed disagreement. One of the control group students who agreed with this fourth statement was Carissao, who referred to her experience when writing interpretive essays and was unable to draw conclusions in either the WIE post-test 1 or the WIE post-test 2. She stated, "Yes, [I] agree, just like [when we are writing about] the battle of Surabaya; we were not at the scene of the incident [so we cannot draw definite conclusions]."

However, most of the control group students and all experimental group students interviewed expressed their disagreement. For example, one of the control group students named Araihano stated, "I do not agree, Sir. In our case, we were not there at that time. But there are historians who can tell." Meanwhile, one of the experimental group students named Bhernandae stated, "[I do] not agree, because there are witnesses and documents. From there we can find out [what really happened in] the past." Of the two statements, they both indeed expressed disagreement, but the control group students relied on secondary sources written by historians, while the experimental group students relied on primary sources such as testimonies and documents that could provide access to the past.

\subsubsection{Fifth statement}

In responding to the fifth statement that "the past is simply what the investigator makes it to be," all students involved in the focus group interviewboth from the control and the experimental group - expressed their disagreement. The reasons also have similarities. For instance, one of the control group students named Busherlyo stated, "[I] disagree, because, in my opinion, historical researchers who want to write [history] need to analyse the evidence." The same thing was conveyed by Bangelicae, one of the students in the experimental group, who said, "In my opinion, I do not agree, because when historians process the past, he needs evidence and testimony. So, if it is written according to the will of the historical investigator, I disagree." Thus, both groups realised that writing history must be based on sources, which can be in the form of evidence, testimony, or documents. 


\subsubsection{Sixth statement}

In response to the sixth statement that "historical investigators know that history is just a matter of opinion", students' answers from both the control and the experimental group were divided into two stances, agree and disagree. One of the control group students named Cakpradikao agreed based on his experience when reading the dissent of historians in the internet sources he had read. He stated his opinion as follows:

Yes, in my opinion, I agree. For example, let's say if historian A knows [an event] from a different eyewitness, let's say eyewitness A, who witnessed the event, for example, that who tore [the flag] was Kusno. Then, historian B knows the event from eyewitness B who stated that the perpetrator was Juadi or anyone. Well, from this [point of view], I agree because history is in accordance with the opinion of each historian.

An experimental group student named Balfiane also agreed by stating, "If I prefer to agree because that's only the opinion, the [other available] opinions are different. They only argue, one like this, one like that, this, that."

Amongst the control group students who expressed their disagreement was, for instance, Afauzio who argued, "[I do] not agree, Sir, because not all of them are opinions; there are also facts that we found in history." In the same manner, an experimental group student named Cayuninge stated, "I disagree. The problem is that history must have historical evidence. So, it's not just an opinion but also [opinions] based on that evidence." Therefore, in both groups, each student had different views in responding to this sixth statement.

\subsubsection{Seventh statement}

There was a common answer between the control and the experimental groups in their response to the seventh statement that "since we cannot really know what happened in the past, we can believe whatever we want about it." All students involved in the focus group interview session expressed their disagreement with this statement. For example, a control group student named Balinggaro stated, "[I] disagree, because we can learn by using textbooks to study history, comparing it between one reference with another so that we can know which facts are true and which are not." By contrast, an experimental group student named Bangelicae 
stated, "[I do] not agree, because there are testimonies and documents, that we can compare each other with. So, we should not be arbitrary in giving opinions."

\subsubsection{Eighth statement}

In response to the eighth statement that "historical claims cannot be justified since they are simply a matter of interpretation," students' answers from both the control and the experimental groups were divided into two stances, agree and disagree. One of the control group students who agreed was Afauzio, who stated, "I agree, in my opinion, because everyone has different thoughts and they think according to the data. So, even though everyone has the [same] data they can have different thoughts." Ciputrie, one of the experimental group students, also stated her agreement as follows:

In my opinion, I agree because no one can be sure of the truth with certainty. Maybe there are people who witnessed or experienced it, but the person has died. Or it could also be that someone who experienced it does not necessarily want to tell the truth.

Meanwhile, there were also some students from both groups who stated their disagreement. For example, a control group student named Abriliano stated, "I disagree because there is historical evidence that can strengthen the historical claim." One of the students from the experimental group who stated disagreement was Buregise who said, "[I] disagree because those interpretations can be ascertained if we read and compare them. The interpretation was taken from several sources, right? Then, we can compare it and it can be trusted if there is a lot of evidence [supporting it]." Thus, both students realised that historical interpretation must refer to historical sources or evidence.

\subsubsection{Ninth statement}

In response to the ninth statement that "comparing sources and understanding author perspectives are crucial component of the process of investigating the past." students' answers from both the control and experimental groups during the focus group interview session all expressed an agreement. One of the control group students named Cigitao stated, "[I] agree because it is possible that between one source and another, there are differences in opinions. So, we compare [them], then we make conclusions, so we summarise it, Sir." Meanwhile, one of the experimental group students named Ciputrie stated her agreement as follows: 
For me, totally agree, because previously (before this learning intervention), we did not know [about this], [because] only one version was given, so we just follow or believe it. After we were given various sources which turned out to have different versions, even from the real testimonies written by eyewitnesses, it turned out that they had different testimonies. So, we should compare more sources.

Thus, students from both groups expressed their agreement with this ninth statement.

\subsubsection{Tenth statement}

Similar responses were given by the control group and the experimental group students when responding to the tenth statement that "history is a critical inquiry into the past." All students from both groups involved in the interview session agreed to this statement. For example, a control group student named Airbaho stated, "I agree because history is from the results of an investigation, through the evidence. So, a special investigation is needed." In line with that statement, an experimental group student named Arifdahe stated, "[I] agree because historical sources cannot be accepted outright. They must be processed. How do we process them? The sources must indeed be criticised and compared to find the historical facts." Therefore, students from both groups realised that history is a critical process for examining the past using historical sources and evidence.

\subsubsection{Eleventh statement}

In response to the eleventh statement that "reasonable interpretation of the past can be constructed even in the presence of conflicting evidence," students from both groups expressed their agreement during the interview session. For example, a control group student named Cakrizao stated, "Yes, because all sources are not necessarily the same; there must be conflicting sources. For example, there are [sources] from the British, and these sources are contrary to Indonesian sources. So, we have to process all of that." An experimental group student named Cakrahardiane also stated, "I agree because like the previous study, there was a lot of conflicting evidence, but it can be rearranged into a reasonable interpretation." Thus, all students involved in the focus group interview session expressed agreement with this eleventh statement. 


\subsubsection{Twelfth statement}

In response to the twelfth statement that "history is the reasonable construction of past occurrences based on the available evidence," students from both groups also expressed an agreement. A control group student named Araihano stated, "[I] agree, Sir. Yes, because the available evidence can support each other for the validity of history, Sir, because it cannot be made up in the opinion of some people, otherwise it may become invalid history." Meanwhile, Cinursalmae, an experimental group student said, "In my opinion, I totally agree because it must be based on the available evidence; there is evidence in the form of testimony, seeing first-hand, then being able to explain the event. That's really a reconstruction of the past." Thus, both groups of students believed that history must be reconstructed based on the available evidence.

From the twelve statement items above, a pattern of students' answers from both groups emerges. However, we must understand that the qualitative answers obtained from the interview did not reflect the historical beliefs of all student participants since only some students were involved; but at least it could be used to explore the reasons given by students. In fact, the differences in answers raised by students were natural because they certainly had different epistemic beliefs. What was interesting and important for further analysis, however, were the answers-incommon of the students. On one hand, I assumed that what students believed did not necessarily reflect what they practised in writing essays. On the other, I assumed that students had experienced epistemic belief changes at the end of the intervention process or after writing all three essays.

For the first to four statements which are in the naïve-objectivist category (VanSledright, 2014), students generally gave divergent answers, except for the second statement where the answers from both groups were all the same. All students involved in the interview expressed their disagreement with the second statement that "historical facts speak for themselves." Their historical beliefs in the interview session reflected their latest stance after writing interpretive essays three times. At that time, they seemed to have realised that historical facts could not speak for themselves and had to be processed first. However, when compared with the results of their WIE pre-test and WIE post-test 1, there were some cohorts who 
believed that some historical sources had the "authority" to contain historical facts that could automatically tell the past. For example, this was clearly reflected by their belief in Wikipedia which was considered to have the authority regarding the truth about the past-something the teacher participant called the "Wikipediaism"

The mismatch of students' epistemic beliefs between what was reflected in the essays and with what students stated in the focus group interviews showed the shifts in students' epistemic beliefs at the end of the intervention process. For examples, of the individual cases, a control group student named Buregino and an experimental group student named Ciputrie both stated their disagreement with the second statement item as described above. When triangulated with their questionnaire responses, Buregino agreed in HBQ1, strongly disagreed in HBQ2, and disagreed in HBQ3, while Ciputrie disagreed in HBQ then strongly disagreed in HBQ2 and HBQ3. Thus, they both experienced epistemic shifts towards increasing disagreement in their responses to the questionnaire, and it was confirmed in their statements during the interview.

In other case examples, an experimental group student named Amalzae responded to the first statement by "disagree" in HBQ1, then "agree" in HBQ2 and HBQ3. However, during the interview, Amalzae stated that he disagreed, giving some additional detailed arguments and examples. Ideally, this first statement must be responded by disagreeing. Thus, Amalzae experienced an epistemic shift in the right direction at the end of the intervention process. The opposite happened to a control group student named Carissao in her response to the fourth statement. When responding to the questionnaire, she stated "strongly agree" in HBQ1, "agree" in HBQ2, and "disagree" with HBQ3. However, during the interview, Carissaro stated that she agreed, adding an example and her rationale. Ideally, this fourth statement must be responded by disagreeing. Therefore, Carissao experienced an epistemic shift in the wrong direction. It should be noted, when giving that statements in the interview, both Amalzae and Carissao were not affected by the response of their cohort friends because they were the first to give statements in their cohort.

For statements five to eight which are in the naïve-subjectivist category (VanSledright, 2014), the answers of the two groups of students have differences for the sixth and eighth items but had similar answers for the fifth and seventh items. 
All students from both the control and the experimental groups disagreed with the fifth statement that "the past is simply what the investigator makes it to be" and the seventh statement that "since we cannot really know what happened in the past, we can believe whatever we want to about it." The best answer to respond to these two statements is indeed "disagree," but the same answer for all students during the interview needs to be further analysed. However, when compared to the results of the WIE post-test 1 and WIE post-test 2, there were several cohorts who interpreted history as they pleased based on what they considered as "the majority" or "the best" version of the past. As I assumed, what students believed was not automatically reflected in their essays, or it could be that they had just experienced an epistemic change after finishing writing the three essays.

The presence of this epistemic shift can be proven through a triangulation of the interview data of the students involved in the focus group interview with their questionnaire data. For the fifth and seventh statements, the majority of students from both groups expressed disagreement both in the questionnaire and during the interview. Also included are case examples of students described above, namely the statements of Busherlyo, Bangelicae, and Balinggaro who in the interviews were also consistent with what they filled during the three HBQ distributions. Meanwhile, students' responses to the sixth and eight statements indeed varied, both in the questionnaire and during the interview. An example of epistemic shifts at the end of the intervention phase was experienced by an experimental group student named Cahyaninge in her response to the sixth statement. As explained above, Cahyaninge stated that she did not agree at the time of interview as well as in the HBQ1 and HBQ3, but she gave the "agree" response in HBQ2. While Abriliano, a control group student, disagreed with the eighth statement during the interview, even though he always responded "agree" in the HBQ1, HBQ2, and HBQ3.

For the ninth to the twelfth statements which are in the criterialist category (VanSledright, 2014), all students' answers from both groups involved in the focus group interview expressed an agreement. The best answer for the last four statement items is indeed an agreement. Those who agreed with these four statements reflected their beliefs that history is a critical investigation into the past based on 
available sources and evidence, even if they conflicted with one another. However, when compared with the findings in the essays they had written, presented, and discussed-as described in the previous chapter-it turns out that what they stated in the interview did not fully reflect what they believed. Based on the results of all the three WIE essays as well as based on the results of all observation and interviews, there were only nine cohorts of the experimental group that could be categorised as having historical beliefs in the criterialist category at the end of learning intervention process, whereas in the control group students, there was not a single cohort that could be categorised as having criterialist beliefs. Surprisingly, it turns out that all the control group students involved in the interview expressed statements and responses that could be categorised as criterialist beliefs.

When triangulated between the focus group interview data and students' responses in the questionnaire, conformity was obtained. The majority of students, both in the control and experimental groups, responded with "agree" in the ninth to eleventh statements. Some students also experienced epistemic changes in the right direction. For example, in the eleventh statement, a control group student named Cakrizao responded "disagree" in HBQ1, "agree" in HBQ2, and "strongly agree" in HBQ3. During the interview, he confirmed his agreement with the eleventh statement. Meanwhile, Cakrahardiane, an experimental group student, consistently stated his agreement in both the questionnaire and in the focus group interview.

At the end of this section, a number of findings can be concluded. First, the students' verbal answers during the interview can be used as a basis for exploring students' reasons when responding to questionnaire statements. Second, in presenting their reasons when responding to the twelve statements, there were five items in which students from both groups gave different answers, while there were seven items that were responded by both groups with the same answers. Ideally, students' qualitative answers varied as reflected in their quantitative response. Those similar answers needed to be analysed in more depth. Third, when the same answers were compared with the results of their essays, a discrepancy was found between what was stated and what was practised. It showed that what students believed was not necessarily reflected in their essays or they experienced epistemic beliefs changes after the end of the intervention process. 


\subsection{The comparison of students' epistemic beliefs about history between the control group students and the experimental group students}

Based on the findings of the quantitative and qualitative data regarding students' epistemic beliefs that have been described above, several comparisons between the control and experimental groups can be drawn. First, based on the findings of quantitative data, it was found that the mean score of the control group students increased from the HBQ1 to HBQ2 but then experienced a sharp decrease in HBQ3. Meanwhile, the mean score of the experimental group students gradually increased from HBQ1, HBQ2, to HBQ3. This can be interpreted in a way that epistemic beliefs of control group students experienced confusion so that their HBQ mean scores decreased, while the experimental group experienced epistemic belief changes that improved gradually. These epistemic beliefs shifts occurred because students were confronted with troublesome knowledge when they were stimulated to think historically (Meyer \& Land, 2003; Walker, 2013). The difference in the direction of the epistemic change of these two groups was most likely influenced by the increasingly complex central historical questions they had to interpret and the more conflicting historical sources they had to deal with. The experimental group experienced better epistemic changes because the historical sources provided for them had been specifically and systematically designed for learning purposes, while the control group students got sources from the internet that were not intended specifically for learning purposes.

Second, based on the qualitative data findings, several reasons were obtained from students' answers regarding their basis for responding to the questionnaire. Ideally, their answers differed from one another as found in the questionnaire data. Apparently, it turned out that there were seven statement items that received similar answers from all student participants involved in the interview, both from the control and the experimental groups. When those answers were compared with the results of the essay they had written, presented and discussed, apparently there was a discrepancy between what they conveyed in the interview and what they delivered while writing the essays. On one side, it can be interpreted that what students believed was not automatically reflected in their essays. On the other, it can also be 
interpreted that they finally experienced epistemic changes after the end of the intervention process. The shift in students' epistemic beliefs can also be traced from the comparison between students' responses in the questionnaire to their statements in the interview. Therefore, to develop students' historical thinking skills, it is necessary to examine how students become aware of the nature of history (Maggioni, 2010) because in the critical pedagogy perspective students must appreciate various perspectives on how knowledge is produced and deployed (Kincheloe, 2008).

Therefore, based on the quantitative data, it can be concluded that the process of teaching and learning intervention through analysing documents and interpreting textbooks contributes to the change in students' epistemic beliefs about history. However, the qualitative data suggest that epistemic change did not necessarily manifest in the results of interpretive essays written by students. It showed how difficult it was for students to write interpretive essays using conflicting sources. The next chapter presents qualitative data about the difficulties and opportunities in teaching history through analysing documents and interpreting textbooks to foster students' historical thinking skills. 


\section{CHAPTER 8 \\ TEACHING HISTORY THROUGH ANALYSING \\ DOCUMENTS AND INTERPRETING TEXTBOOKS TO \\ FOSTER STUDENTS' HISTORICAL THINKING SKILLS}

The purpose of this chapter is to answer the third sub-question regarding the challenges and opportunities of conducting teaching history through analysing documents and interpreting textbooks to foster students' historical thinking skills. This chapter presents qualitative data containing the perspectives of teacher participants and the experimental group students regarding the implementation of teaching and learning history through analysing documents and interpreting textbooks to foster students' historical thinking skills. By referring to the experiences of teacher and student participants during the intervention process, various challenges and difficulties of this approach are presented in the first section. The second section presents the opportunities and advantages of teaching history through analysing documents and interpreting textbooks to foster students' historical thinking skills. The findings in this chapter will be useful for refining this approach so that it can be applied in a broader context in Indonesia in particular, and other developing countries in general.

\subsection{The challenges of conducting teaching history through analysing documents and interpreting textbooks to foster students' historical thinking skills}

Learning history with a new approach is not an easy thing for students because they are faced with situations that are different from what they are used to. The essential novelty of the situation caused students to no longer be able to apply the familiar schemata to the new situation by simply repeating old means of learning (Piaget, 1952). Students had to accommodate new means of learning to equilibrate their existing schemata so that they could establish new schemata based on the current situation. This equilibration process confronted them with troublesome knowledge that required extra effort so that they could cross the threshold portal in 
studying history through analysing documents and interpreting textbooks (Beilin, 1992; Meyer \& Land, 2003; Stoltz, 2018; Walker, 2013).

This section presents the challenges and difficulties that students faced in learning history through analysing documents and interpreting textbooks. This section also presents the challenges and difficulties in teaching history with this approach based on the experiences and perspectives of the three teacher participants who implemented this approach. Based on the perspective of student participants, there were two learning challenges that they conveyed during the interview session, which were also found during the classroom observations.

The first difficulty felt by students when involved in the learning intervention process was in comparing various versions of historical sources. This is because they were habituated to receiving information from textbooks that have a single version of information. This was the most dominant difficulty expressed by students during the interview session. For example, a student named Cakpurwantoe stated as follows:

The difficulty was in comparing historical sources, since there were lots of testimonies, lots of archives, lots of documents. Therefore, we must read them one by one first. [Then, we ask] what is the content and information in each of these documents? And start linking between one source with another. Then, we are looking for the most balanced and the most reasonable outcome of the decisions.

In the same manner, a student named Cinursalmae also stated, "In my opinion, the difficulty was comparing one evidence with another; the problem is that people's opinions differ. Then, we also had trouble deciding which one was right." Despite the difficulties, students admitted that it challenged them to read even more sources. This was stated by them as follows:

Bhernandae: [This is difficult] because of the many conflicting sources. Buregise: Yes, but that challenged me. That was the challenge; we must read and read again.

Bhernandae: Yes, it was challenging for us to draw the most reasonable conclusions.

The second difficulty, which is closely related to the first difficulty, was about making interpretations or conclusions by themselves, particularly because students were not used to making their own interpretation when learning history and only received information delivered by the teachers based on the textbooks. When they 
were given the opportunity to make their own conclusions, they found it difficult. This difficulty as expressed by a student named Amalzae was as follows:

Yes, one of the difficulties was that we have to be able to conclude in our way of thinking. We must be able to analyse from many conflicting sources, in that there may be several sources in the same [version]; and some are conflicting. So, we must be able to conclude according to our own critical analysis.

Establishing an interpretation was increasingly difficult if each student in one cohort had differences in their opinions. This is stated by Ciputrie as follows:

Like our previous study, in our essay, we also have not concluded yet the cause of Mallaby's death, right? So, it is hard to conclude with our own opinions. Moreover, we also work as a cohort. Surely each of us has our own opinions.

The statements above, made by students during the interview session regarding these two main difficulties, were also found during the classroom observations. As described in the sixth chapter, students often complained to the teacher during the learning process when dealing with sources with various conflicting versions and found it difficult to establish their own interpretations. These two difficulties became the "threshold" or "portal" that determined whether students were able to think historically or not (Land et al., 2005; Meyer \& Land, 2003, 2005). Students who were unable to cross the threshold would experience obstacles in developing their historical thinking skills, while students who could cross the portal would experience success in developing their historical thinking skills. These two difficulties also determined the pattern of students' historical thinking skills which will be discussed in the tenth chapter.

Based on the perspective of the teacher participants, there were three difficulties that they felt could complicate the process of teaching history through analysing documents and interpreting textbooks. The first two difficulties were related to students who had never learned with this new approach, while the third difficulty was related to the position of the teacher who had to organise the learning process based on problem-posing education.

First, based on the viewpoints of the teacher participants, the main challenge in teaching history through analysing documents and interpreting textbooks was because students were not accustomed to learning history with this new approach. 
Students were previously more accustomed to learning history by receiving historical material from the teacher through lectures based on the textbook version. These teachers' perspectives were in accordance with students' confession above, that they had difficulty when dealing with diverse versions of the sources and they also had difficulty in establishing their own interpretations. These teachers' perspectives, for example, were clearly represented in Teacher A's statement, saying that "I think the difficulty was because it requires habituation students were still not used. The challenge was that students were not used to it."

This difficulty became even more complicated because students were not accustomed to writing history because they were only consumers of history. The effect was sometimes what students had in mind did not match with what they had written in their essays. This was stated by Teacher $\mathrm{C}$ as follows:

Sometimes if we look at their presentation, [they were good]. When they were asked, [they were good], their analysis was good, their thinking was good. However, maybe they were still not accustomed to writing their own thoughts. So, what they thought was different from what they wrote.

Therefore, it takes time to make students accustomed to thinking historically by confronting them with various conflicting sources and habituating them to become producers of history through writing interpretive essays. This can be proven from the intervention process - as described in the sixth chapter-that there was an increase in historical thinking skills of the experimental group students in the second intervention stage compared to the results of the first intervention stage.

Second, the teacher participants also considered that students were still not confident in constructing their own interpretations. This happened because previously they were taught only to accept a single version of history. This was revealed by Teacher A who stated, "The problem was that students still lacked confidence-confident in the sense that they were still afraid when they want to make a decision because they were too accustomed to being taught what is right and what is wrong." If history learning had been "oppressing" students to accept a single truth, when they were in the "praxis of liberation" and "conscientisation" process (Freire, 2005b, 2005a) through analysing documents and interpreting textbooks, apparently they still did not have confidence in themselves to establish conclusions in their essays. This lack of confidence was triggered by a "culture of 
silence" (Freire, 2005b): Oppressed students have a single version of history since they were in primary school. Therefore, it seems that it takes time for students to have self-confidence in being able to build their own interpretations. This was also proven in the intervention process - in the sixth chapter - that in the first intervention many cohorts did not dare to draw conclusions, while in the second intervention many cohorts were able to make their own conclusions.

Third, in the implementation of problem-posing education (Freire, 2005b), the teacher participants found it difficult given their new position as the mediator in the learning process. This was due to the teachers being more accustomed to teacher-centred learning through lecturing. This was expressed by Teacher B as follows:

When we were in the middle of the students, it was like being the moderator, a mediator. If, for example, we were not able to manage the class, well, that would not make the class run well. We really should be the mediators like that. Then, we also have to be able to motivate the students, which is important to make them discuss.

Apparently, the new approach not only made it difficult for students but also for teachers who were still unfamiliar with this model. Specifically, previously they merely expose the historical contents through lectures, but now they must manage the class so that the students were able to think by themselves and discuss what they had learned in the classroom. Although it was difficult for both parties, the opportunities offered by this learning model had many benefits, as explained in the next section.

\subsection{The opportunities for conducting teaching history through analysing documents and interpreting textbooks to foster students' historical thinking skills}

At the beginning of this section, it can be deduced that teaching history through analysing documents and interpreting textbooks offer opportunities to foster students' historical thinking skills in Indonesia. This conclusion is based on the results of the intervention processes that have been presented in the previous chapters as well as referring to the statements of the teacher and student participants at the interview session at the end of the intervention process. From their 
perspectives, there were at least three aspects that support the implementation of teaching history through analysing documents and interpreting textbooks which enable the development of students' historical thinking skills.

First, students got their first experience of using primary sources for learning history, which is necessary to develop historical thinking skills. Primary source evidence is one of the most important aspects to foster students' historical thinking skills (Hover et al., 2016; P. J. Lee, 2005; Wineburg, 1991a, 1991b). This was confirmed by Teacher $\mathrm{C}$ who considered that her students had "gained new experience" in using primary sources for learning history. Teacher B also stated the same thing that the use of primary sources was a new experience for both herself and her students. She stated, "I have never used primary sources for my students before. I have never given it [to my students] before. So, that provides new knowledge and new experiences for me and my students." Therefore, teacher participants' first experience of teaching history using primary sources became the first step for them to be able to develop students' historical thinking skills.

The students also felt that they had gained a new experience in learning history that they had never felt before. Students who previously only learned from secondary sources in the form of textbooks, finally realised that there are primary sources that can be used to study history. For example, this was expressed by a student named Balfiane who stated as follows:

After participating in this activity (learning intervention), I know more about primary sources and secondary sources. Before this, I was just like, if there were historical questions, I only sought the answer from secondary sources. I did not know yet if there are primary sources.

Many other students also expressed the same statement that this was their first experience using primary sources. Many of them shared their impressions. Asabrinae said, "I became aware of more accurate sources". Afredoe stated, "Information in primary sources is more complete than what the textbooks summarise." Cakpurwantoe conveyed his impression as follows:

The advantage is that, first, we can know the evidence or the primary sources of the real event and this also adds new insight to students, to us, that the actual historical events were formed from testimonies, then including from the archives, from abroad as well. So, with this method we can look for our own decision, "oh, this person said he killed [Mallaby], but then other person said it was not him who killed 
[Mallaby]." So, it's like we can deduce by ourselves which one is true or not, and then [interpret] what actually happened in that incident. When using a textbook, it is usually not possible to do so, because the information is limited and only covers the general, one version.

By dealing with primary sources, students are imaginatively engaged as if they felt the events themselves. A student named Asalmae expressed her feelings that "it's cool, like wow, as if I know right away; the documents are directly from there, for example, from November 10. The event was straightforward. Really, I feel it". The historical empathy felt by Asalmae was also expressed by Ciputrie who stated as follows:

Yes, [using the primary sources] is more exciting, because [those] who write [the testimonies] really see what happened, then they described it in detail, so real, like if they move like this, it's also described, written, described as so. So, we can also indirectly feel what they feel, like that.

Therefore, the use of primary sources for learning history not only gives students new experiences in learning history but also gives them new experiences "to feel" the past.

Second, the process of teaching history through analysing documents and interpreting textbooks turned out to make students interested in learning history, while previously many of them were not interested in the history subjects. Students' interest in learning history subsequently caused them to be more curious and challenged to explore the topic being studied in more depth. The escalation of students' interest and motivation to learn history was felt by Teacher A who explained as follows:

The advantage, firstly, was that students became more interested [in learning history]. In general, what became my impression was that the students turned out to be interested. [They are] interested in learning resources in the form of primary sources, because they have never used it before, both from anthropology, sociology, especially history. So, the students were very interested. That's what I saw when there were historical sources offered to students in the form of primary sources.

The impression felt by the teacher corresponds with what students felt, in that they recognised that they became more interested in learning history. This was revealed by Amalzae who stated, "I think it's a new thing, and also since then, I became more interested in learning history and I can understand more than before." The interest in learning history was also felt by Arifdahe who stated as follows: 
[I was interested] because I knew straight away from the people who experienced it. Previously, it was only explained in the textbook that General Mallaby died because his car exploded, right? But from the primary sources it is explained that prior to the explosion there were still [other events, such as] shootings. So, it is explained in more detail. Maybe that's what makes me more interested.

The interest felt by students made them curious about the topic being studied making them feel challenged to learn more deeply. This curiosity was expressed by Teacher B who stated, "Because mostly I just refer to the textbook, I have never implemented [a learning model] like this before. So, when given [a task like] this, it's different, Sir. It turns out that when the students were given this model, they were enthusiastic, more curious." The same impression was expressed by Teacher A who stated the following:

In addition to students' interest was the presence of students' curiosity. Especially when they got many sources, they began to be curious. [They were] between curious and confused, to be exact, in my impression. Then, in addition, I also saw the students start to think "oh, apparently, there's something new" in regarding the information that they did not encounter before. Something like that, Sir.

This curiosity indeed appeared in many students during the learning intervention process, as also recognised by a student named Bangelicae who stated, "I became interested at reading. I mean like, I was curious, so I want to keep reading. Then, I gained additional insight. I know more." What these students have felt was also observed by the teachers while teaching them. As Teacher $\mathrm{C}$ said as follows:

This model built and invited students to enjoy reading, because, like it or not, with the documents provided, the students had to read. And if they had read one testimony, for example, they would be curious to read the next testimony. So, it was a kind of an inducement to be able to analyse the documents. From there, they were more creative to write, draw conclusions, and interpret from much of the data they have obtained. Then, it can open up insights.

The students' insights were opened because they not only got historical information from their textbooks but also from the primary sources. This was recognised by a student named Cakhendrye in his statement as follows:

In my opinion, [learning] like this is more interesting. It is because by using primary sources we become more insightful; we know better what actually happened in the past when the incident occurred. In contrast, if we only use textbooks, we don't know in this textbook what has been changed, which is not in accordance with what happened at that time. 
If we use primary sources, we can be more certain, even though these primary sources sometimes differ in their perspectives.

The teacher participants also admitted that they gained insights on how to use new teaching models, not just through lectures. Teacher B stated, "For me, it added insight to me because finally, I was able to apply another teaching model." In the same vein, Teacher $\mathrm{C}$ also stated the following:

I am very happy with this [teaching approach] because this opens a new method for me to teach history, especially in terms of utilising primary sources. All this time, our difficulties, particularly as educators, are that we know that the use of primary sources is important, but for us to access them is difficult.

Third, the main opportunity offered from the implementation of teaching history through analysing documents and interpreting textbooks was able to make students think critically. The practice of critical thinking is a fundamental aspect in the historical thinking process which involves high-level cognition (McLaughlin \& McGill, 2017; Philpot, 2017). Students' critical thinking skills were triggered because they were confronted with primary sources which had various versions. The difference in students' way of thinking was felt by Teacher A who stated the following:

They became able to think, in the sense of thinking that, well, indeed learning must be assumed by thinking, but this way of thinking of students is not like before, which if there is a question from the teacher, they immediately search on Google. No. But they tried to think that, "oh, apparently there are steps A, B, C, and so on." They think critically, Sir. They could be more open, in the sense that they did not immediately believe in one source. They tried to open, "oh, apparently someone said something else," like that.

The students' critical thinking skills were not only observed by the teacher participants but also felt by students themselves. A student named Asalmae claimed, "It seems, I can think more critically." Another student named Arifdahe also claimed, "I can think more critically, more broadly. That's the point, Sir. The point is that I can cultivate more sources than just reading the textbook." The emergence of students' critical thinking skills which was triggered by a variety of sources was also recognised by many other students. Cakbaguse said, "We can think critically because of the various sources and various information that we get. We put it together, that maybe it can be the proof of what really happened." Annisae 
said, "So, my brain is like being trained to analyse primary sources one by one, that there is a connection between one primary source and the other." Amalzae stated, "In general, we can learn and analyse history directly from its primary sources and we can develop our minds with our own way and in our own language." Cinursalmae explained in more details as follows:

We are more broad-minded now, while previously, we used to learn only through textbooks. Now, we can explore more through primary sources. So, we are more broad-minded as in, "oh, the scope of history is not only from textbooks." So, we can think better by using those primary sources.

Besides being triggered by primary sources, the emergence of students' critical thinking skills was also due to the fact that they were given the opportunity to interpret independently what happened in the past. Previously, the learning process that only received a single historical version obtained from history teachers and textbooks caused students to not think critically because they simply memorised information. Although it was troublesome, learning history by analysing documents and interpreting textbooks caused students to develop their critical thinking skills. The improvement in students' historical thinking skills was thoroughly observed by Teacher B who stated as follows:

In my opinion, this [learning model] can increase students' thinking power, [they] can think critically; because they have to analyse first, interpret, also learn to write better; because writing is not easy. If for example, we never made students write interpretive essays, later, they will have difficulties at the university level. Generally, it is like that. In fact, many alumni are still contacting their teachers until now [due to writing difficulties in tertiary institutions]. That becomes their obstacle, Sir. Then, another advantage was the argument. They were finally able to present [their own] argument. If for example they are not confronted with a learning model like this, usually to convey their own arguments, they are timid, afraid of being wrong. But when they had to learn [with this model], they had to read first. If, for example, they did not read, did not analyse first, then, did not know how to establish the argument. Well, from there, finally they, indirectly, got lesson learned for them to be able to argue.

Because they were asked to construct their own interpretations and arguments, the emergence of students' critical thinking skills, was also recognised by students. A student named Annisae explained why they could improve their critical thinking skills as she stated, "Because we have to read [sources] one by one, 
then we have to understand, and after that, we also have to practice developing an argument with our critical analysis.”. Similarly, Cakadame stated as follows:

In my opinion, if we use those primary sources, we can analyse by ourselves, from the beginning [we tried] to find facts, so we are more critical. Now, if we criticise it first, then [written as] an essay, it can make us more critical. [We are] no longer dependent on other sources that are not necessarily true.

There were also students who admitted that they were more challenged because they had to think how they would confirm their own interpretations. For example, a student named Cayuninge stated, "That makes me challenged because between one testimony with another are different opinions, so we must be able to think about it by ourselves." Another student, named Ciputrie, liked this way of learning because it allowed her to think by herself. She explained about it as follows:

So, we can have our own opinions. All this time, we have only been told that if there was an event, it was only explained that this was the perpetrator. That's all, because there was only one version. Now, being provided by various sources, we can have our own perspective. So, we have our own opinions. I like something like this.

Since students think critically and produce their own knowledge, they feel that they can better understand history. This is in accordance with Cakpurwantoe's statement as follows:

Our experience during this activity... Well, previously, we only learn through the textbooks; the point is we were only directed or told to understand the material in the textbook. Then, in this activity, we are given primary sources, the historical evidence. There, we can compile [the sources] by ourselves, design [the interpretation] by ourselves, and find out exactly the history of the incident or event. So, activities like this add to our horizons, which previously only came from textbooks or the internet. Now, there are primary sources. So, we increasingly understand that the actual events are like this, like this, like this. Like that, Sir.

At the end of this chapter, referring to the statements of the research participants above, it is clear that teaching and learning history through analysing documents and interpreting textbooks awakens students to think historically. Through the process of problem-posing education (Freire, 2005b), students are required to interpret the past by themselves through writing interpretive essays. In the beginning, they experienced troublesome knowledge (Meyer \& Land, 2003; D. Perkins, 2006) when faced with various versions of historical sources as well as 
having difficulties when making their own interpretations. In the next process, after they experienced conscientisation (Freire, 2005a), students became aware that the single version that they had received from the textbook did not entirely contain the truth. After accommodating the new schemata (Mascolo, 2015; Piaget, 1954), students realised that the past was reported in different versions by primary sources. In the wake of gaining experience dealing with primary sources that have various versions, students were even more curious and challenged to find the truth of what happened in the past. This is what caused them to be motivated to think critically. Finally, the practice of critical thinking encouraged the growth of students' historical thinking skills.

Therefore, teaching history through analysing documents and interpreting textbooks did provide challenges and difficulties for both students and teachers. However, this approach offered many opportunities to foster students' historical thinking skills. In the next chapter, I describe the challenges and opportunities of teaching history by using web-based historical sources as learning resources to foster students' historical thinking skills. 


\section{CHAPTER 9}

\section{TEACHING HISTORY BY USING WEB-BASED HISTORICAL SOURCES AS LEARNING RESOURCES TO FOSTER STUDENTS' HISTORICAL THINKING SKILLS}

The purpose of this chapter is to answer the fourth sub-question regarding the utilisation of the web-based historical sources which was used as the learning resources in this study. To foster students' historical thinking skills in Indonesia, teachers need to utilise primary sources in teaching history rather than using textbooks as the only learning resource. However, it is not easy for teachers to access primary sources in Indonesia. For that reason, this study also offered alternative learning resources in the form of digital primary sources that are presented on a website. As a prototype, this website currently presents only historical sources related to the battle of Surabaya. In the future, this website will be developed with other learning resources related to the history of Indonesia. Therefore, this research needs to identify in advance the strengths and weakness of this website. The first section presents the challenges and difficulties of teaching history by using web-based historical sources as learning resources to foster students' historical thinking skills. In addition, the opportunities and advantages of using the digitised primary sources as web-based learning resources to foster students' historical thinking are presented in the second section.

\subsection{The challenges for conducting teaching history by using web-based historical sources as learning resources to foster students' historical thinking skills}

In this digital age, a learning process that utilises information and communication technology should be accessible for both teachers and students. In its practice, however, the application of digital technology in Indonesia still has many challenges and difficulties. Likewise, in this study, the application of digitised primary sources presented on the website that was deliberately developed as learning resources to foster students' historical thinking skills also contain 
challenges and difficulties for its users, both teachers and students. This section describes those challenges and difficulties based on the perspectives of the teacher and student participants.

First, there were some students who had no difficulty with the website used in this study (www.berpikirsejarah.com). For example, a student named Amalzae gave a detailed explanation of his claim that the presence of web-based historical sources made it easier for him to learn history. He stated it as follows:

There were no difficulties. It made things easier, because all the sources were available, and the arrangement could also make it easier for us to choose. So, we were not confused. It's already sorted there. Moreover, it also had transcripts, which were the most important. So, we can find things out more clearly. So, there's no need to be confused if we have trouble reading from the original sources. If there is something unclear, a clearer explanation is available (the transcription). So, from the website www.berpikirsejarah.com, we were able to more easily analyse from the primary sources available.

Similar to the statements of the students above, Teacher A considered that the webbased historical sources used in the intervention process actually did not contain any weaknesses. The problem was only that the students were not accustomed to using digitised primary sources. He stated his view as follows:

Regarding the difficulties, first, it was not a matter of the digital primary sources on the website anyway, but students still needed to get used to it. They were not used to reading a lot of primary sources. The second thing was, as I said [about the difficulties of the new learning approach], students were still not confident because there were many digitised primary sources and their transcripts. They felt hesitant [to establish interpretation]. That's the main problem, self-confidence.

The statement of Teacher A above is the same as the perspective of a student named Besane who stated, "I can read and use it [the website]. The confusion is in choosing the sources; there are many sources there." Thus, there were some students who had the perspective that the website had no problems and instead made it easier for them to study. This perspective was also supported by the result of classroom observation, that not a single student was found who to have problems operating the website. However, students' difficulties - as described in the sixth chapterwere related to difficulties in developing their historical thinking skills, specifically when using conflicting versions of historical sources to construct their interpretations. 
Second, there were some students who claimed to have difficulty reading the digitised primary sources because they accessed the website using their smartphone. Only a small portion of students accessed the website using their laptops. This, for example, was revealed by Bangelicae who said, "For me, I had difficulty reading it because I read it using my smartphone. So, if it is not clear, I have to read it again, and read it again." The same difficulty was expressed by Ciputrie who explained as follows:

Then, for example, if I read it for a long time, I became dizzy because I looked at the screen continuously, due to the screen radiation. So, when we wrote an essay about the flag incident, we print it too, so that I can read more clearly, without needing to zoom in and zoom out.

Thus, one of challenges in reading digitised primary sources was it could cause eyestrain because most students read the sources on a small smartphone screen, as well as due to the exposure of screen radiation. This challenge was overcome by some students by printing some of the documents needed. Sometimes, teacher participants also had difficulty reading the sources using their smartphones. For instance, on November 1, 2018, Teacher $\mathrm{C}$ was observed having difficulty reading the sources using her smartphone because her laptop was borrowed by the students for their presentations in front of the class. So, Teacher $\mathrm{C}$ borrowed the documents that had been printed by one of the students.

Third, there were some students who confessed that sometimes they could not concentrate on reading the sources because they were distracted by the notification received on their smartphone. For example, this was expressed by a student named Cakrahardiane who stated, "The difficulty was, while I was studying and there was a notification above [the smartphone screen], I immediately left the source [on the website] that I was reading." The loss of concentration of these students was also captured by Teacher A who explained one of the challenges of the web-based historical sources in his statement:

The next was, what is it, if I want to say that the smartphone is a problem, but it's not the real problem. However, sometimes students became less focused. We gave them the opportunity to use their smartphones, to access the digital sources. But they still, well, because there was a chance, open WhatsApp and the other [applications]. That was what actually made their focus split. 
Fourth, most of the students stated that the biggest difficulty in using the webbased historical sources was when the internet connection was unstable or when they did not have any data plan. During classroom observations, I captured some moments when students shook their phones or pointed it towards the classroom windows or door to get a better internet connection. For example, on October 25, 2018, a student named Cakrahardiane shook his phone towards the classroom door to get an internet connection. During the focus group interview session, some students also said that the main challenge was the poor internet connection. For example, a student named Balfiane revealed, "The difficulty was the internet access. The connection was unstable, depending on the internet." Meanwhile, Buregise stressed the problem of a data plan. She said, "The problem was the internet data as well because sometimes there are times when I do not have data plan." This situation was also realised by the teacher participants. Teacher B stated, "[The challenge was] if the [internet] connection was difficult, and the $\mathrm{Wi}-\mathrm{Fi}$ was unstable. That's it, inaccessible." The instability of internet connections in developing countries such as Indonesia has indeed become a challenge for teaching history by using web-based historical sources as the learning resources. However, this should not be an excuse not to instil students' historical thinking skills in Indonesia by using web-based historical sources.

Fifth, based on the perspectives of the two teacher participants, they considered the contents of the website to be very good though needed to be developed further for other materials. Teacher $\mathrm{C}$ stated that "for the material presented on the website for this study, there are already enough [of it] to teach [the battle of Surabaya]. Maybe, I hope. My hope is that [the website is] not only about the battle of Surabaya." In a different interview session, Teacher A also stated the same thing. He said, "My difficulty now is [after the intervention process was over], my students start asking 'where are the primary sources, Sir?'. So, I hope it contains more [not only about the battle of Surabaya]." Thus, from the teacher participants' perspectives, one of the deficiencies contained in the website www.berpikirsejarah.com is the limited content of the learning resources that are still only related to the battle of Surabaya. 
Therefore, from the various challenges in the use of web-based historical sources as mentioned by research participants, it was discovered that the main difficulty was related to the unstable internet connection in Indonesia. However, this difficulty should not be an obstacle to teaching students' historical thinking skills by using digitised primary sources. The teacher must be able to facilitate the internet connections in the classroom and help students critically examine sources (Barnett et al., 2013; Siemens, 2004). An alternative solution for students who do not have internet data is that they can download the sources while at school and read those sources offline anywhere. As for students who claim to be tired with screen radiation due to reading sources from their smartphone screens, they can print the sources at school so they can read the printed version. Regarding the weakness of the website which is still limited to historical sources related to the battle of Surabaya, it can still be refined at a later stage after this thesis is finished. Uniquely, many students evaluated that the website did not have any weaknesses and instead made it easier for them to learn. The opportunities and advantages of this website are presented in the next section.

\subsection{The opportunities for conducting teaching history by using web- based historical sources as learning resources to foster students' historical thinking skills}

To develop students' historical thinking skills, primary sources that are easily accessible to both the teachers and the students are essentially needed. For that reason, this research also developed a website that provides historical sources that can be accessed for the benefit of teaching and learning history in Indonesia. This section presents research findings related to the strength of web-based historical sources as learning sources to foster students' historical thinking skills. The data presented came from the results of classroom observations, students' focus group interviews, and teachers' semi-structured interviews.

The first advantage of using digitised primary sources presented in the webbased learning resources was that both teachers and students had easier access to the primary sources. From the students' perspectives, the availability of learning resources presented on a website made it easy for them to gain access to primary 
sources. Students only had to access and read the sources without having to look one up by themselves. For example, this was stated by Bhernandae who said, "[The website makes it] easier to access primary sources." That statement was also supported by Besane who stated, "We do not need to look for the sources, since from the beginning, they are already provided. We only need to read."

According to the teachers' perspectives, the availability of learning resources in the form of digitised primary sources on a website made it easy for them to teach history. For example, Teacher A felt helped by the availability of learning resources from the website that was deliberately developed for educational purposes. He felt that the availability of primary sources was far better than his students using unverified internet sources which were not intended for educational purposes.

Teacher A states the following:

It really made me easy to teach, Sir. Instead of the students taking secondary sources from the internet sources that are still unclear [unverified], those sources are still confusing [for students]. It is very necessary that historical primary sources are digitised for education purposes. Above all, it can make things easier; make it easier to access it.

The same response was expressed by Teacher B. She claimed to have tried to find primary sources related to the battle of Surabaya, but was unable to access them. She explained is in more detail as follows:

It made it easier for them [students] when searching for [learning resources], because, all this time, especially when faced with the material [related the flag incident]. Well, before this model was applied, in the past, I had taught students to find out who tore the flag [in the flag incident]. I once asked that. But because we only relied on sources obtained from the internet, well, they were finally confused, which one is correct. And I was also confused because I did not have the primary sources. When I tried to search for it, I also did not find [its primary sources] at that time. Therefore, if there are now digitised primary sources [available], it makes it easier for me as a teacher, as well as making it easier for my students.

Thus, the existence of the www.berpikirsejarah.com website has made it easier for both teachers and students to access learning resources, specifically to access the primary sources.

Second, another advantage of using digitised primary sources from the webbased historical sources was made accessing the learning resources easier for 
students at any time and from anywhere. Students claimed that they could access the website whenever and wherever they want to study, not necessarily at school nor at home. For instance, Asalmae stated the web-based historical sources were "comfortable, [because] it can be read at any time, so it becomes easier [to read]." Besides being accessible at any time, another advantage was that students could access it from anywhere. For example, this was expressed by Buregise who stated, "More efficient and effective. It can be taken anywhere, can be read anywhere; it's practical." This advantage was also recognised by Teacher B who stated as follows:

By using digitised sources, it's easy for them to be able to access learning resources from anywhere. So, when students are given assignments for homework, like yesterday, it actually makes it easier for them. This means that their ability to think historically actually does not have to be practised while in the classroom only but also out the classroom as well.

Third, the availability of digitised historical sources in the web-based learning resources made it easy for students to learn because, in their daily life, the majority of their activities cannot be separated from their smartphones. For example, a student named Balfiane stated that "I like to study like this because I rarely open books. I open my smartphone more often. So, I can learn by using my smartphone. I am too lazy to read books". This was also revealed by students named Arifdahe and Asalmae as follows:

Arifdahe: [Learning by using sources] from the website is easier.

Aditya: Can you explain more why it is easier?

Arifdahe: The reason is that most of us, at this time, when [learning] using books were bored. Most of my friends are like that, including me too. So, most of us prefer learning by using a smartphone.

Asalmae: Yes, in our daily life we cannot be separated from the internet either.

Arifdahe: Yes, we use the internet more often with our smartphone. Back then, when I studied history using the website from www.berpikirsejarah.com, I became willing to read, even though normally when using a textbook, I was lazy to read it.

From their statement above, it can be seen that in today's digital era, students cannot be separated from the internet and their gadgets. So, those two things must be used positively for the benefit of teaching history. This was recognised by Teacher $\mathrm{C}$ during the teaching intervention process, as she stated the following: 
I used students' enthusiasm in using digital facilities. For example, during the intervention, when they used the internet or gadgets, they were more enthusiastic than they were told to open books. This is because they preferred to access teaching materials from the internet.

Fourth, the opportunity to foster students' historical thinking skills by using digitised primary sources was due to the availability of primary sources as well as its transcription on the website. For example, teacher A stated that "one of the advantages of using primary sources that were digitised is that students could directly get the information from the primary sources. They could easily understand because they are in digital formats, including the transcripts." Based on the results of classroom observations, most students indeed preferred to read primary sources in the transcript version because it was easier and more practical. For example, the statement of a student named Balfiane could represent this category, he said, "I prefer to read the transcript version because it is clearer. As for the original document version, it is a bit blurry." However, there were also some students who preferred to read the digitised primary sources than the transcription. For example, Cayuninge stated that "I prefer to read the original source because it is more challenging as we can really see the physical form. It feels more like [the reality]. We must also carefully read it. As for reading it from the transcript, it's like reading ordinary text." Thus, the digitised version made students more challenged to read historical documents while the transcript version made it easier for them to understand the contents of the documents.

Fifth, another advantage in using web-based historical sources was that it made it easier for students to learn because the learning resources could be downloaded. For example, Cakpurwantoe shared his experience in using the website as follows:

It was interesting to use because the sources on the website could be downloaded. So, if for example there is no internet in my house, I can still read [the sources] if I have downloaded them first [at school]. So, yeah, it's like I read the book, I can open it every day. Then, the sources also provide more complete information than the textbooks or other printed books, which are secondary sources.

Thus, students who did not have internet facilities at home or did not have any data on their smartphones could still read the sources, as long as they have downloaded the learning resources available on the website. 
Sixth, the availability of digital learning resources provides an opportunity to foster students' critical thinking, which is essential in historical thinking skills. For example, a student named Cakpurwantoe felt he had new information that he had never gotten before. His statement is as follows:

This website is very helpful. It provides a lot of information, primary sources, original evidence of historical events and it's like opening our minds. It's like, "oh, so the flag incident in Surabaya was like this, who tore the flag was actually two people." Then, about the death of Mallaby, "oh, apparently those who killed Mallaby were from the Indonesian side as well." With that, with sources on the website, we get a lot of information, which we get for the first time. We become aware that seeing at the lessons from elementary school until now, it turns out there is information that is true, and sometimes is wrong. So, it's like giving us real evidence.

The teacher also realised there was a change in students' critical thinking skills. As Teacher A said, "My students are more able to think critically, Sir. So, they are not—no longer-like previously, only giving short answers. Now, they are trying to find the answers coherently." Students' critical thinking skills grew because they got more diverse information presented on the website.

Seventh, from the perspective of the teacher participants, the existence of web-based historical sources as learning resources can facilitate them in teaching history. This is because all this time, history teachers in Indonesia have had difficulty accessing learning resources other than the official history textbook from the government, especially if they want to obtain additional learning resources in the form of primary sources for teaching purposes. The advantage of digitised historical sources was expressed by Teacher A who stated:

Since the learning resources are available in digital form, it can greatly facilitate history teachers, especially for teachers who teach outside of Java. They-well, although I have not met with many teachers, sometimes - there are teachers from Medan [in Sumatera Island], from Kalimantan [Island], who contact me, asking, "Sir, do you have these sources? These books?" This means that they have difficulty obtaining historical source. So, when there are historical sources in digital form, they can certainly be used [to teach history].

The same thing was expressed by Teacher B, who considered that the existence of digital primary sources presented on a learning website was very important. Without this facility, the teaching model through analysing documents and interpreting textbooks would not be optimal. She stated the following: 
The advantage is that the website makes it easier for us as educators when we want to find additional learning resources. My point is that if this teaching model is going to be implemented, then the digital sources from the website, the primary sources, are the solution. In my opinion, it is like that. So, it must be combined, as complementary. So, for example, if the teacher only applies the teaching model, without using primary sources, it will be useless. When those two things exist and used, then I am sure it can make it easier for the history teachers, because it is easy to implement, easy to access.

Thus, the existence of web-based historical sources as learning resources facility is essential to support the efforts to foster students' historical thinking skills because it is not easy for either teachers or students to access primary sources in Indonesia.

Therefore, from various opportunities offered by web-based historical sources to foster students' historical thinking skills, it is apparent that the main advantage of this website is that it makes it easier for the teachers to teach and the students to learn history. Digitised historical sources are "easier to access" (J. K. Lee, 2002) because it can be accessed anytime and anywhere. Besides, digitised primary sources also encourage students to learn history because it stimulates their reading interest. Digitised primary sources presented on www.berpikirsejarah.com are also "flexible" to use (J. K. Lee, 2002) because the students can download the learning resources and choose to read the original digitised documents or the transcripts. The data shows that most students read the transcript version, but many of them also preferred and felt more challenged to read the original digitised document version. Although Wineburg and Martin (2009) suggest that students do not need to be given the original primary sources and sufficiently given a simplified and adapted primary sources transcript, the results of this study indicate that students should be given the opportunity to read the original digitised primary sources because it can challenge them to read the sources and obtain some historical sense. Finally, the web-based learning resources which contain digitised primary sources made it easy for teachers to teach and encourage students to develop their critical thinking skills which are needed to foster their historical thinking skills (Federspiel, 2004; Fránquiz \& Salinas, 2011; J. K. Lee, 2002; Tally \& Goldenberg, 2005).

The next chapter is dedicated to the discussion of the key finding points from the Chapters Five, Six, Seven, Eight and Nine. The main focus of the discussion 
chapter is whether teaching history through analysing documents and interpreting textbooks contribute to students' historical thinking skills. 
This page is intentionally left blank. 


\section{CHAPTER 10 DISCUSSION}

In the previous five chapters, I have explored the development of students' historical thinking skills triggered by the teaching and learning intervention of analysing documents and interpreting textbooks. These findings revealed that the experimental group students who were exposed to this learning model seemed to develop more advanced historical thinking skills compared to the control group students. In this chapter, I analyse the factors that can influence the value of teaching history through analysing documents and interpreting textbooks so that this learning model can be applied, in particular to the Indonesian context and to developing countries in general. In the first section, I discuss the patterns of students' historical thinking skills after interacting with a variety of conflicting primary sources, while previously they were accustomed to passively consuming one version of history from their textbook. In the second section, I discuss the indirect effects of fostering students' historical thinking on the pattern of students' epistemic beliefs about history. In the third section, I discuss the potential of the learning model through analysing documents and interpreting textbooks in fostering students' historical thinking skills. In the last section, I discuss the potential of webbased historical sources as the learning resources to support teachers in Indonesia on instilling historical thinking skills to their students by utilising www.berpikirsejarah.com as an instructional tool.

\subsection{The pattern of students' historical thinking skills}

Historical primary sources offer positive benefits in fostering students' historical thinking skills. Many researchers have proven that the utilisation of primary sources to teach history in the classroom has a positive impact on fostering students' historical thinking skills (Ashby, 2011; Barton, 1997; Cercadillo, 2006; Culminas-Colis et al., 2016; P. Lee \& Shemilt, 2003; Malkmus, 2010; Pierce, 2008; Reisman, 2012a, 2012b; Sheehan, 2013; Sheehan \& Davison, 2017; VanSledright \& Afflerbach, 2005; Wineburg, 1991b, 1991a; Wineburg \& Martin, 2009; Wineburg et al., 2011). These studies are mostly carried out in developed countries 
where the education system is well established, and students are trained to have the freedom to think about what they want to learn and have been supported by adequate educational facilities. However, there are only a few studies examining how students respond in developing countries, such as Indonesia, when they are given the opportunity to learn history using primary sources that contain various versions of the past as well as interpret these sources independently, whereas previously, students were passive consumers of a single version of history from their textbooks.

This study aims to bridge this gap. From the quantitative analysis, it was found that the historical thinking skills of the experimental group students were better than the control group students (see Chapter 6, specifically section 6.1). Previously, the two groups of students had a similar level of the initial understanding of the battle of Surabaya and tended not to think critically (see Chapter 5 and section 6.2.1). Indeed, these results are aligned with similar studies that show the same results that the use of primary sources has a positive contribution in triggering students' historical thinking skills (Reisman, 2012b, 2012a; Wineburg, 1991a, 1991b). This study is not revolutionary in the field of historical thinking in the global context, but it has a potential in the Indonesian context. Thus, what is different is that this study tries to balance the curriculum demands in Indonesia where teachers have to embed the official version of history from the state (presented in the official textbooks) with the demands of $21^{\text {st }}$ century that aims to equip students with historical thinking skills (Hasan, 2019; Lévesque, 2008; Widja, 2018). For this reason, students were trained to analyse historical documents and at the same time still had to use their textbooks but in a critical manner by "interpreting interpretations" of their textbook version (Harada, 2012).

The uncritical approaches of the students were reflected in the preintervention stage by referring to the results of the open-ended questionnaire. In Chapter 5, I described that most of the students from both groups could answer correctly what events in the two images presented in the open-ended questionnaire. This finding reflects that historical images are a useful point of entry for many students to instantly recognise historical features and information (Tally \& Goldenberg, 2005), especially if the pictures were continuously presented in the 
textbooks and always taught by history teachers since elementary schools. This results in an almost certainty that both images have been embedded in students' existing schemata (Bormanaki \& Khoshhal, 2017; Piaget, 1950, 1954; Piaget \& Inhelder, 1997). So, it was not surprising that most students claimed that the sources of their information for answering the two images in the questionnaire were from the textbooks and the teachers' explanation. However, while senior secondary school students typically rely on authoritative sources such as textbooks and teachers $(\mathrm{Paz}, 2005)$, they tend to remember the concrete facts from the pictures and lack analytical thinking of the events (Breakstone \& Smith, 2013; Cowgill \& Waring, 2017). Therefore, when they were asked to describe the causes and consequences of both events in the open-ended questionnaire, students from both groups only mentioned one possible answer for each event. These findings support Lee (2005) and Ong's (2018) conclusions that students tend to have simplistic notions about the cause and consequence of historical events. The lack of critical thinking was also seen when students were asked to determine whether both events had historical significance; almost all students saw the flag incident and the death of Mallaby as significant events for Indonesia by only referring to their sense of nationalism and without reference to any historical evidence. This finding has parallels with Sheehan \& Davison's (2017, p. 260) conclusion that students in New Zealand saw Gallipoli/ANZAC as significant but "did not draw on historical evidence to justify why this was so."

After being involved in the learning intervention process through analysing documents and interpreting textbooks, students' analytical and critical thinking skills developed gradually. From the quantitative analysis in Chapter 6, it was found that the historical thinking skills of the experimental group students were better than the control group students. Whereas, before the intervention, the two groups had relatively the same level of narrative understanding and had never been involved in evidential work, which indicated that the development of historical thinking skills did not depend too much on understanding a narrative. These findings appear to affirm Wineburg (1991a) study' which showed that historians with different specialisations had the same heuristic in analysing sources, which indicated that students' historical thinking skills could be developed regardless of their narrative 
understanding. In general, the quantitative findings of my study resonate with the findings of many other studies (Reisman, 2012a, 2012b; Sheehan, 2013; Wineburg, 1991b, 1991a; Wineburg \& Martin, 2009), that primary sources positively contribute to students' historical thinking skills. However, there are still not many studies that explain how students develop their historical thinking skills if previously habituated to being fed with a single version of history as in Indonesia. That being said, some studies gave some hints that cultivating historical thinking is complex (Cowgill \& Waring, 2017; VanSledright, 2004) and often full of struggles and difficulties (Culminas-Colis et al., 2016; McAleavy, 1998; McGrew et al., 2018). Therefore, the qualitative findings of this study are expected to fill in this gap.

From the analysis of the qualitative data (Chapter 6, section 6.2), two themes emerged both in the control group and the experimental group where they struggled to think historically. The first theme was related to how students deal with historical sources that contain different versions, while the second theme was related to how students established their position of interpretation after obtaining different versions in historical sources. These two themes emerged repeatedly during the intervention process as captured in students' utterances when observed and in their statements when interviewed. They became, in effect, a form of "troublesome knowledge" for students during the intervention process (Meyer \& Land, 2003; D. Perkins, 2006) because they were more habituated to using sources that had a single version of Indonesian history from their textbooks and teacher lectures assimilated from primary school to senior secondary school. Thus, when they realised that apparently historical sources could contain different versions of the past, students had to accommodate this new knowledge to equilibrate their existing schemata (Beilin, 1992; Mascolo, 2015; Piaget, 1950, 1952, 1954; Stoltz, 2018). Moreover, because students were accustomed to only being consumers of history and historical knowledge that was considered as "a gift bestowed by those who consider themselves knowledgeable upon those whom they consider to know nothing" (Freire, 2005b, p. 72), their inability to think critically was ultimately impacted. Therefore, when students were given the opportunity to interpret the past 
independently based on conflicting sources, they also experienced another level of troublesome knowledge (Meyer \& Land, 2003; D. Perkins, 2006).

Interestingly, it seemed that these two emerging themes of troublesome knowledge experienced by students formed the patterns of how they would develop their historical thinking skills. These findings highlight the importance of sources and interpretation to foster students' historical thinking skills and resonate strongly with Johnston \& Sheehan's (2016, p. 81) notion that "the historical thinking concepts of evidence and interpretation are core elements of how historians' analyse and construct historical explanations." Therefore, I argued that the troublesome knowledge became a kind of threshold "portal" or "conceptual gateway" that determines whether students were able to develop their historical thinking skills or not (Baillie et al., 2013; Land et al., 2005; Meyer \& Land, 2003, 2006). The first portal was related to how students dealt with sources that had diverse and conflicting versions. Students who had not successfully crossed this threshold tended to write essays by referring to sources with the same version and ignoring others with different versions, even though they already knew that there were conflicting sources available. In contrast, students who had successfully passed this threshold tended to write essays that included sources that had various versions as their references. Meanwhile, the second portal was related to how students interpreted these sources. Students who had not successfully passed the threshold tended to establish weak interpretations because they did not critically assess the sources they used or simply followed the version of the sources they referred to. In contrast, students who had successfully crossed this threshold tended to establish strong interpretations by assessing all the sources they referenced and build their own argumentations. The intersection of the two portals formed clusters that depicted the level of students' historical thinking skills. The intersection of these two thresholds can be illustrated in the following figure: 


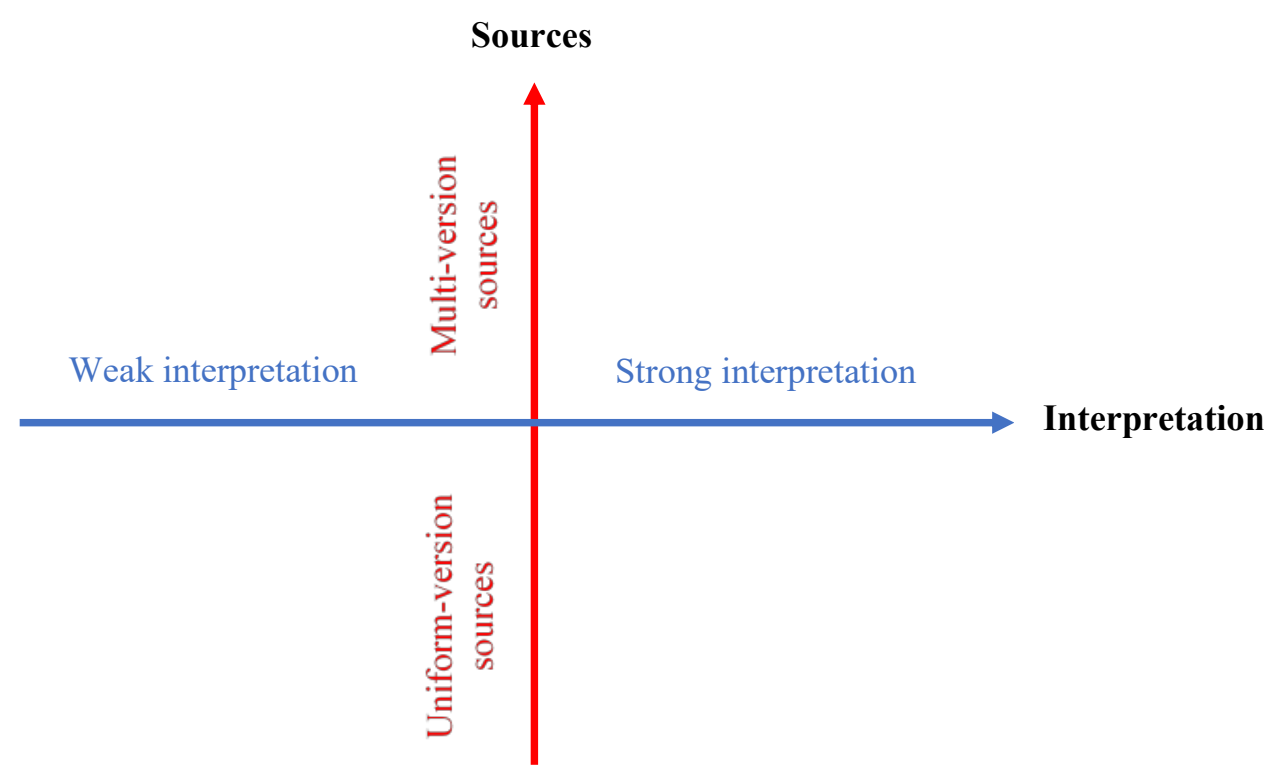

Figure 10.1 The intersection between the two thresholds

Based on the intersection of the two thresholds that emerged from the results of this study, the patterns of students' historical thinking skills were revealed. I argue that these patterns were shaped by how students coped with troublesome knowledge when dealing with sources that had conflicting versions and when they had to establish their own interpretations. However, the findings in my study did not fall into a neat and tidy pattern. From the four clusters formed from the intersection of two troublesome knowledge, only three clusters were supported by the data. Thus, based on students' response in overcoming the troublesome knowledge, I only obtained three clusters of students' historical thinking skills. The three clusters of students' historical thinking skills levels emerging from the results of the intervention process in this study can be illustrated in the following figure: 


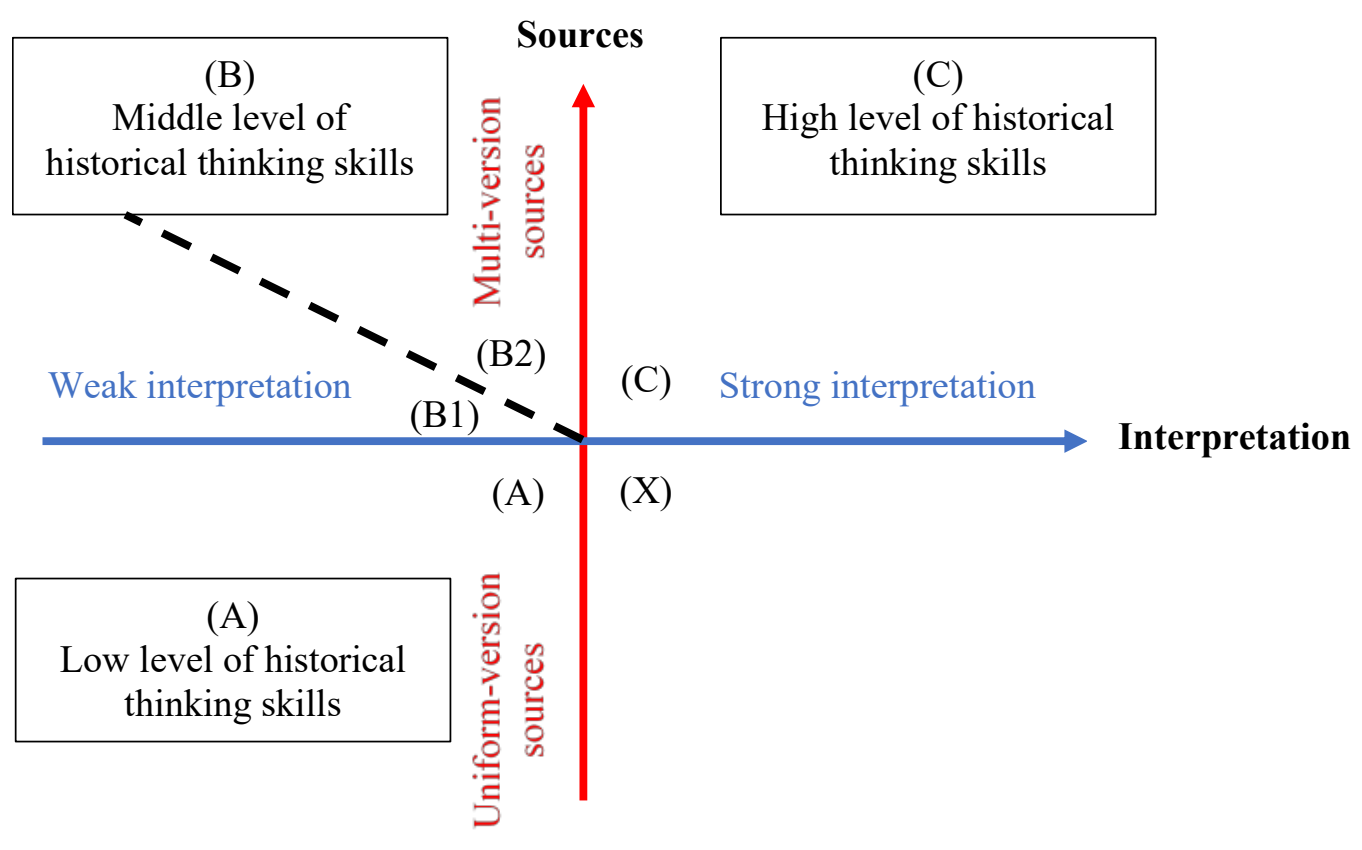

Figure 10.2 The clusters of students' historical thinking skills level

The first cluster (A) was the domain of students who I considered still had low-level historical thinking skills. They tended to only use sources that had the same version and establish their interpretations by only following the version of the sources without critically assessing them. Even if they found sources that had different versions, they would determine the trustworthiness by counting the number of sources that had the same version and negate the rest. For this reason, they felt no need to mention or refer to sources that had different versions in their essay.

The second cluster (B) was the domain of students who I assumed had intermediate level historical thinking skills. They realised that the past can be interpreted differently by various sources, so they refer to and describe the various sources in their essay. However, they still had trouble establishing a strong interpretation by critically assessing the sources. Some of them could not or decided not to establish their position of interpretation (B1) and some of them established their position of interpretation by simply following the version of the sources which they considered the best or the majority of sources with the same version (B2). 
The third cluster (C) was the domain of students who had high-level historical thinking skills. In their essay, they used and referred multiple sources with different versions. Finally, they were able to establish their position of interpretation with strong argumentation by assessing the sources critically. While the findings from my research did not obtain any data to categorise students in the lower-right quarter, at first, I doubted that the historical thinking patterns I proposed in this thesis could be academically justified. However, after I reviewed the themes by checking and re-checking the data findings, I still did not find a single cohort or student that could be categorised to enter this cluster. Therefore, I named this cluster as " $\mathrm{X}$ " or "terra incognita". It is possible to surmise that this cluster will remain empty because it is unlikely students to be able to build strong and critical interpretations if they only use a single source in learning history. In that regard, this cluster seems to suggest that to enhance the level of students' historical thinking skills, they must be confronted with multiple historical sources since it is not sufficient to simply use a single source, such as a history textbook.

This research also found that the progression of historical thinking skills level of each cohort of students was diverse. There were some cohorts whose progression of historical thinking skills developed gradually, from low, middle, and then advanced to high levels, but there were some cohorts whose progression was not gradual - which jumped from low to high. These findings appear to affirm Lee \& Shemilt' (2003) suggestion that the progression of students' historical thinking skills when dealing with historical evidence is not in any rigid sequence of ladderlike. This was evidenced in the progression of the level of students' historical thinking skills within their cohorts from WIE pre-test, WIE post-test 1, to WIE posttest 2 . These progressions are discussed chronologically as follows: 


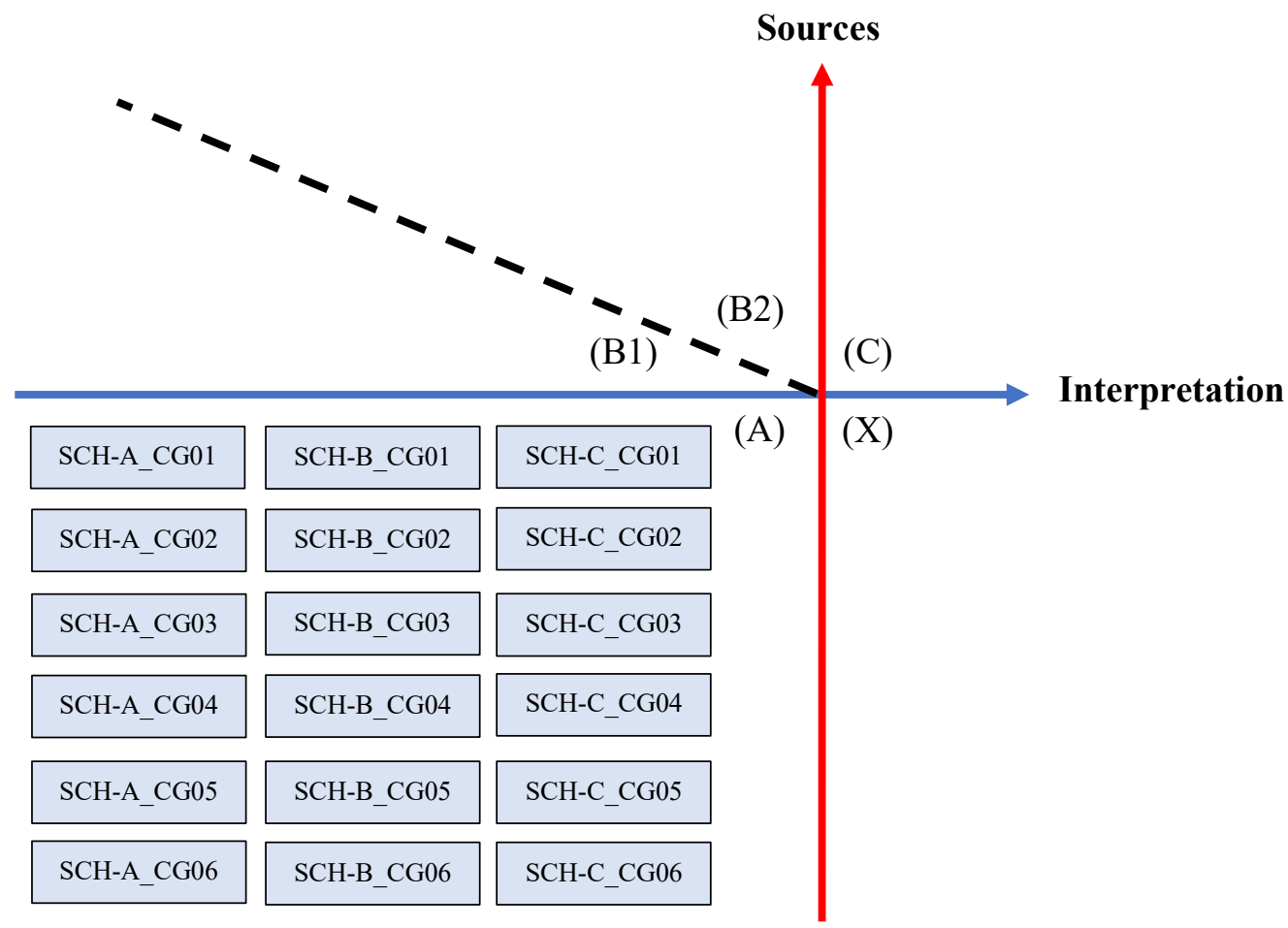

Figure 10.3 The level of the control group students' historical thinking skills based on the WIE pre-test results.

Based on the figure above, in the control group students, all cohorts had historical thinking skills that can be categorised as still at a low level when writing the WIE pre-test. The same thing happened in the experimental group students, where all the cohorts were still categorised as having low historical thinking skills prior to the intervention process - which can be seen in Figure 10.4 below. Thus, before the intervention process, the two groups were at the same level. Their lack of historical thinking skills was reflected in treating sources as evidence for writing history. They only chose sources that were primarily from textbooks or the internet, which had uniform version. Even though they found different versions on the internet, they tended to ignore and not discuss them in their essays. Some of the students in this study, Afredoe in particular, illustrated how they treat sources. Afredoe's statement that "the textbook said that Indonesian won, so that the Indonesian won" reflects that the textbook is a trustworthy source. This finding seems to resonate with both Wineburg's (1991a, 1991b) and Lee's (2005) studies that most students - unlike historians - view the textbooks as constituents of the 
"primary" source as repositories for facts and bearers of information. They tended to consider textbooks as more trustworthy than primary sources because of years of exposure to a transmission model of learning (Stahl et al., 1996).

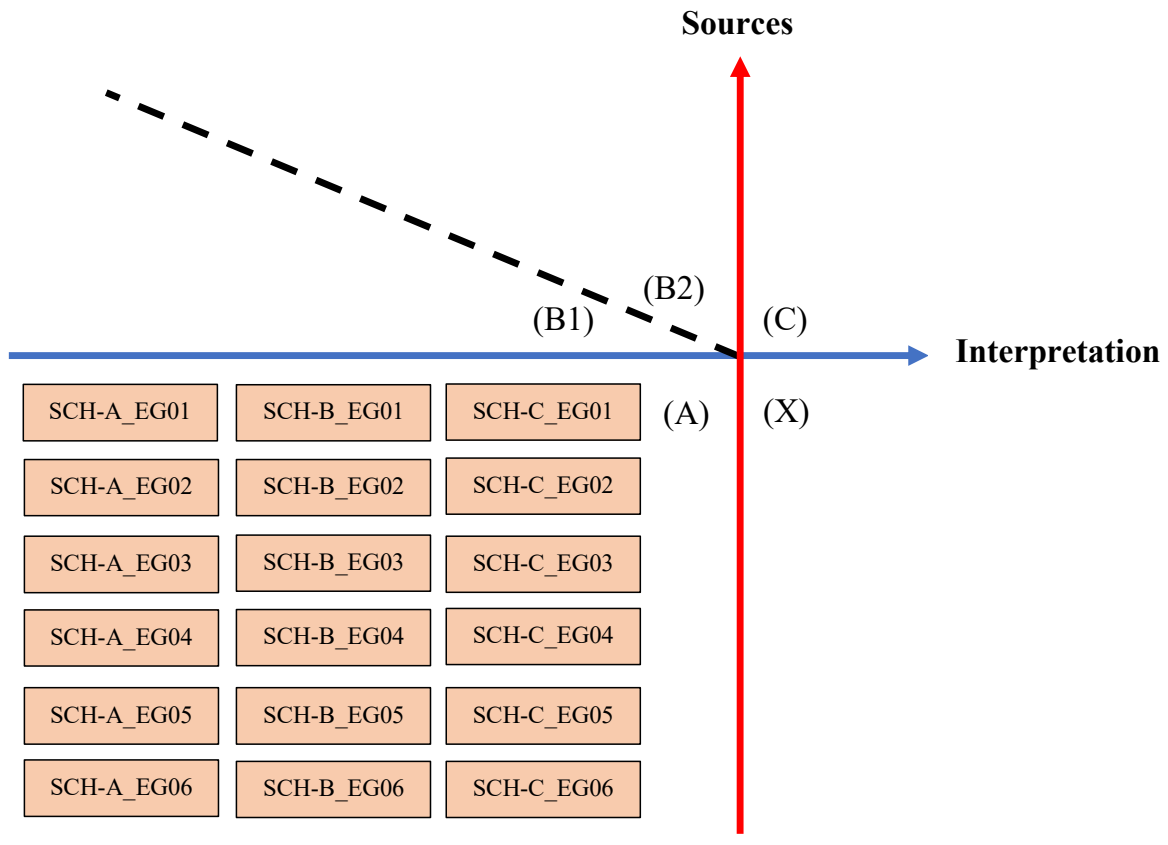

Figure 10.4 The level of the experimental group students' historical skills based on the WIE pre-test results

In establishing the position of interpretation, both the control group and the experimental group students only followed the version of the sources they obtained. Their way of thinking when they found various information was determining the trustworthiness of the sources by counting the number of similar versions to construct their interpretation. Ciputrie's acknowledgement that "because the other web content was the same" corresponds with Stahl et al.'s (1996) arguments that students are inclined to choose the same ideas from the sources, while other contradictory information would have to be ignored. Furthermore, the information that students got from the internet would be considered trustworthy if it turned out to have the same information as contained in Wikipedia. Some students assessed the sources as Buregino did by a way of considering that "the majority of other sources were the same as Wikipedia". So, it was not surprising that the teacher participant considered her students to embrace "Wikipediaism" because "it is more 
verified than other free blogs" as Cakrahadyano said. This was perhaps the effect of search results that frequently put Wikipedia in the top position when students type "the flag incidents in Surabaya" or "the death of Mallaby" in Google's search box. Hence, this finding resonates with McGrew et al.'s (2018, p. 167) argument that "young people interpret the order of search results as a signal of websites' trustworthiness." Interestingly, although most cohorts could correctly answer that Indonesia lost in the battle of Surabaya, many of them just realised this fact after writing their pre-test essay since they previously thought Indonesia won in the battle because it was always commemorated as Indonesia Hero's Day annually.

Then, the differences in patterns of students' historical thinking skills between the two groups began to appear at the first intervention stage when they studied the flag incident. They were stimulated to think critically by being asked to interpret who the perpetrators of tearing the Dutch flag were in the flag incident. For the control group students, their way of thinking on the WIE post-test 1 was basically the same as the previous stage when they wrote the WIE pre-test. In choosing sources to write their essays, they tended to use sources with uniform versions. Likewise, in determining their position of interpretation, they tended to be uncritical and immediately accept the version of the sources. This happened to 17 cohorts of control group students who selected sources by determining to what extent the sources were considered to have authority (such as textbook and Wikipedia) and how many of the sources had similar versions. They were hampered in developing their critical thinking because they viewed these sources as "authoritative" and "treated in the same way as a textbook or a lecture" (Hover et al., 2016, p. 215). Therefore, they were still "bounded" by the frontiers of their existing schemata that history must have one version (Meyer \& Land, 2003; Piaget \& Inhelder, 1997; Walker, 2013). Even when they found sources with different versions, they did not want to accommodate the new situation, preserved the old schemata, and negated the different versions by counting the number of sources that had the same version in order to determine the truth of the past (Mascolo, 2015; Piaget, 1952; Valsiner, 2005). This means that their historical thinking skills did not develop and remained at a low level. The position of control group students' 
historical thinking skills level based on their cohorts can be seen in the following figure:

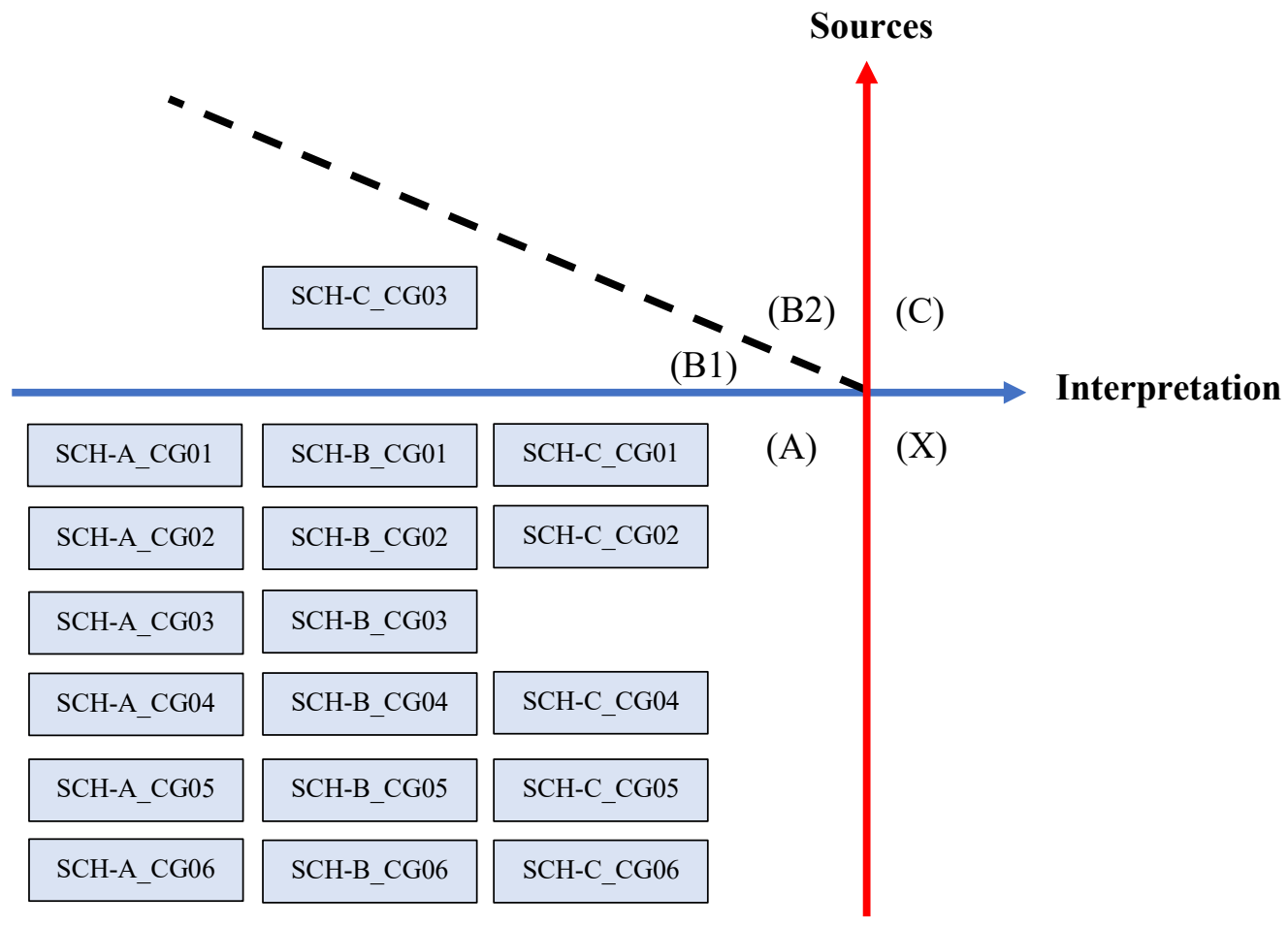

\section{Figure 10.5 The level of the control group students' historical thinking skills based on the WIE post-test 1 results.}

Based on the figure above, there is only one cohort that became an outlier (B1). This situation happened because they accidentally got access to several digitised primary sources in the form of testimony from the perpetrators of the flag incident. In contrast to other cohorts who only used secondary sources, the outlier group who got the leaked primary sources began to realise that historical actors who witnessed the flag incident turned out to give different testimonies. Apparently, students tend to find it difficult to see that sources could have a different status and nature in providing information about the past (McAleavy, 1998), which even witnesses who were present at the time of the incident turned out to provide different reports. Hence, they experienced "troublesome knowledge" in determining a position of interpretation in their essay (Meyer \& Land, 2003; D. Perkins, 2006). The impact was that they were doubtful and could not make come 
to a conclusion, so they only explained various versions of the past in their essays. On one hand, they had accommodated a new learning environment, recognising that the past can be reported differently (Piaget, 1952), but on the other, they were not able to think critically enough when given the freedom to think in order to establish historical interpretations (Biesta, 2016b; Freire, 2005b).

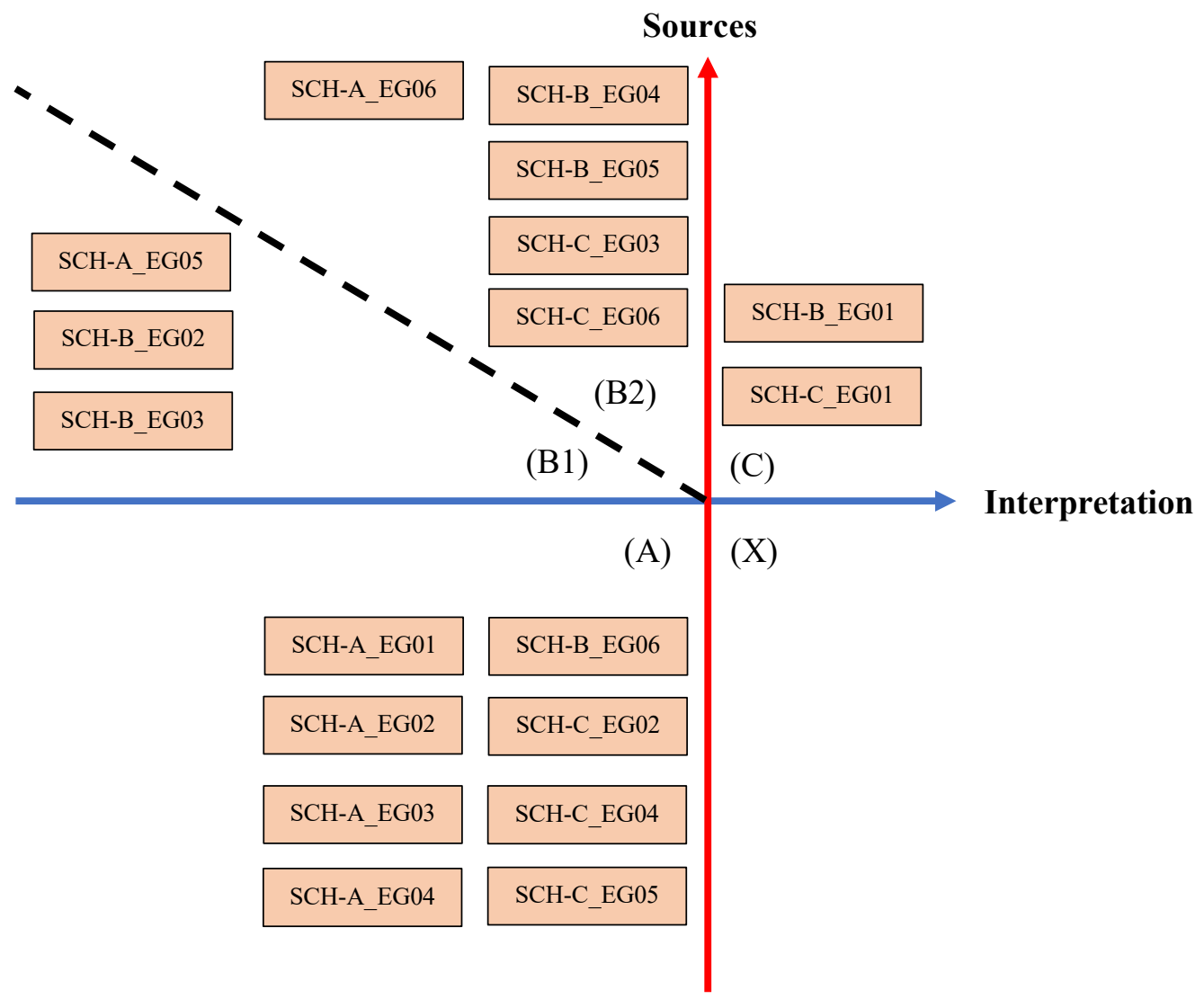

Figure 10.6 The level of the experimental group students' historical thinking skills based on the WIE post-test 1 results.

For the experimental group students, the levels of students' historical thinking skills in the first intervention stage were spread into three different clusters as seen in Figure 10.6 above. There were eight cohorts whose way of thinking still followed the strategy they used in writing the WIE's pre-test. They tended to use sources that have a uniform version only, although they already knew that there were some sources that had different versions available on www.berpikirsejarah.com. This finding corresponds with Cohen's $(2004$, p. 294) reminder that the web is a mixed blessing, "open to all but taken seriously by few". It also looks like they were still "bounded" by the frontiers of their existing schemata that history must have one 
version only (Meyer \& Land, 2003; Piaget \& Inhelder, 1997; Walker, 2013). When faced with various versions in the primary sources, the strategy they used in dealing with troublesome knowledge was to choose some sources that had the same version and completely ignored other sources that had different versions. Students like Bupramuditae gave the reason "because it was the most voted"; Abdullahe reasoned "almost the same"; and Arifdahe, who claimed not to read different testimonies, came to a basis that they selected sources based on the uniform version. Once again, these findings support Stahl et al.'s (1996) argument that students have the tendency to choose sources that have the same version and ignore other sources that have different versions. Therefore, they could still be categorised as having a low level of historical thinking skills (A).

There were also eight cohorts that could be categorised as having a middle level of historical thinking skills. They were cohorts that had experienced a transformative way of thinking by crossing the threshold portal in the form of troublesome knowledge when dealing with sources that had various, conflicting versions (Baillie et al., 2013; Meyer \& Land, 2003). They had accommodated the new cognitive structure in their schemata and understand that the past can be reported differently by historical sources (Barrouillet, 2015; de Ribaupierre, 2015; Piaget, 1950; Wineburg, 2001). For this reason, in their essays, they described different versions obtained from different sources. Unfortunately, they failed to cross the second portal of troublesome knowledge in establishing their position of interpretation critically based on the sources available. Out of the eight cohorts, three did not confirm their position of interpretation (B1) because they had difficulty with their source of information and then tended to not even set their ideas (Stahl et al., 1996) as evidenced by Amalzae who did not draw conclusions because “....there were many answers." At the same time, five other cohorts confirmed their position of interpretation just based on several sources that had the same version or some sources that were considered to have the best version (B2). For example, the SCH-C_EG06 cohort established a conclusion only based on two testimonies after presenting various versions from ten testimonies. One of the cohort members, Cinursalmae, gave the reasons for selecting the two testimonies as "the most complete and truest of these testimonies." This example seems to suggest that 
students still place a bias in the sources as binary (Wineburg, 1991a) and therefore compiling information in the sources as "finding blemishes on apples in a supermarket in order to reject them" (P. Lee, 2011). They were still unable to think critically due to the lack of effort in investigating and assessing sources, making them only produce "fragility of arguments" when constructing interpretations due to over-simplifying the different versions (Freire, 2005a).

Out of the eighteen cohorts, there were two cohorts that could be categorised as having high levels of historical thinking skills (C). They were able to successfully cross both troublesome knowledge portals (Meyer \& Land, 2003; D. Perkins, 2006). Firstly, they accommodated a new cognitive structure that history can have different versions, so they referred to several sources that had different versions and described those versions in their essays. Secondly, they were able to establish their position of interpretation with sound arguments through assessing and critiquing the historical sources referenced (Freire, 2005a). For example, what the SCHB_EG01 cohort did, when Bhangelicae comparing Budi' and Sudi' testimonies, she stated that "Budi was indeed involved in designing the attack" but "Budi was not there" showed that they were not just using sources for compiling information only. They recognised that "a source is an account constructed by an author" (VanSledright \& Afflerbach, 2005, p. 2) in that they can be identified as having critically assessed testimonies through the "sourcing" process (Wineburg, 1991b, 1991a). Thus, they modified their schemata by accommodating a new cognitive structure: the past can be interpreted differently by historical sources, that these sources must be used critically (Piaget, 1950, 1952).

In the second intervention stage, both groups experienced a progress in their levels of historical thinking skills. However, the progress achieved by the experimental group was far better than the control group. I argued (in Chapter 6) that the increase in the level of historical thinking skills in these two groups occurred because they were both dealing with more diverse and conflicting sources to interpret who killed Mallaby. For the control group students, this variety of conflicting sources could easily be obtained by students from the internet. As for the experimental groups, this variety of conflicting sources were deliberately designed and presented in a learning website that was aimed to stimulate students' 
historical thinking skills. The levels of students' historical thinking skills in the control group are presented in the figure below:

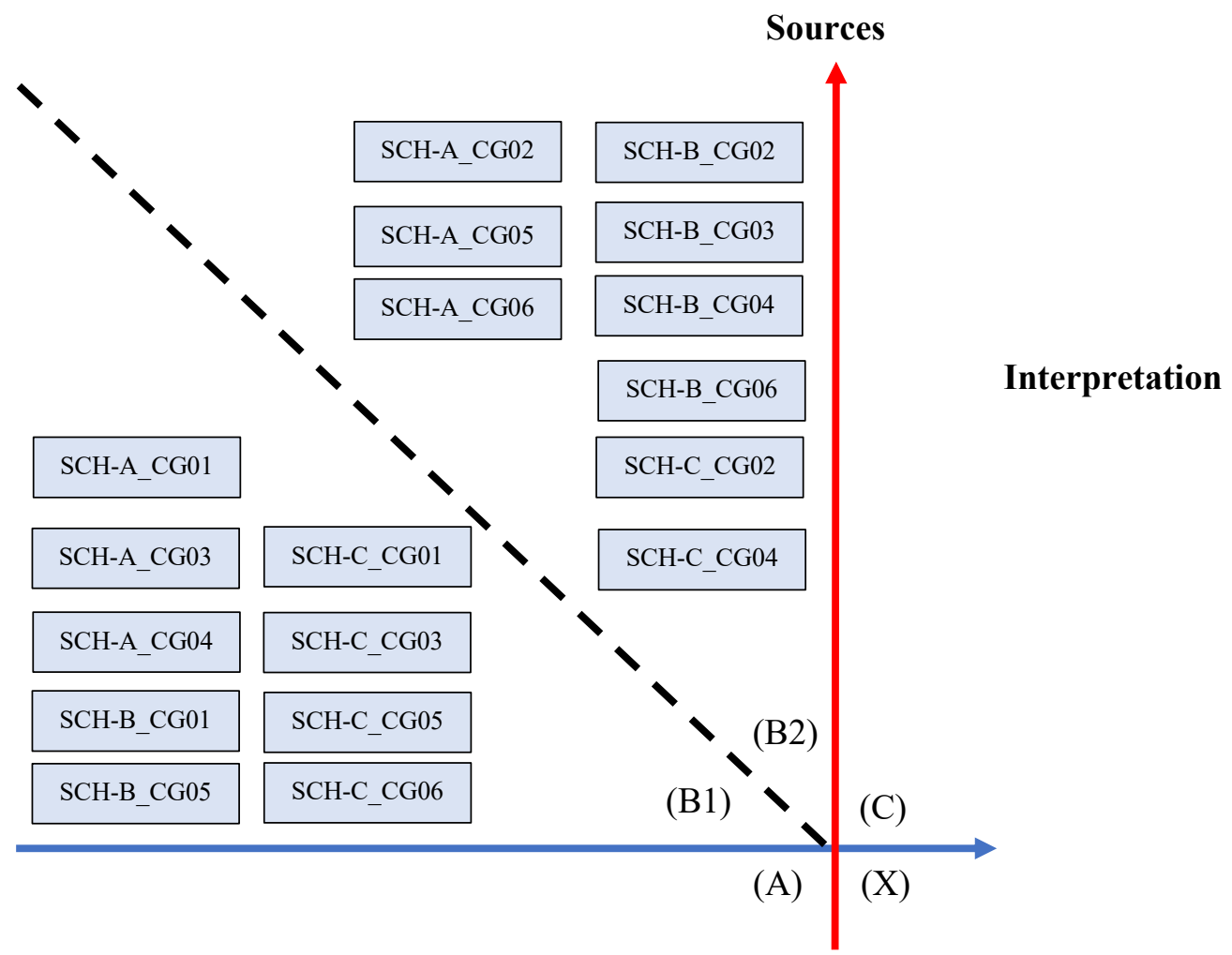

\section{Figure 10.7 The level of the control group students' historical thinking skills based on the WIE post-test 2 results.}

As presented in Figure 10.7 above, we can see the progress of students' historical thinking skills in the control group. At the second stage of intervention, all cohorts in the control group students had their historical thinking skills increase to the middle level, while at the previous stage there was only one cohort at this level and the rest still at the low level. They had crossed one of the threshold portals (Meyer \& Land, 2003) related to the matters of sources which contained various versions of the past. Previously, their schemata assumed that historical sources should only contain one version of the past. But in this second phase of the intervention process, they had accommodated new knowledge that historical sources could have different versions of the past (Boom, 2009; Piaget, 1950, 1952). For this reason, in their essays, they presented all versions of Mallaby's death from the sources they had obtained. Unfortunately, they were not able to establish their 
own position of interpretation with strong arguments by assessing these sources critically. Nine cohorts did not establish their position of interpretation or any conclusions (B1). For example, they wrote the conclusion in their essay as "it cannot be determined exactly who killed General Mallaby" or "Mallaby's killer is still unclear" as well as admitted during the interview that "we were confused and could not decide." It seemed as if they were having trouble consolidating their ideas when establishing conclusions (Stahl et al., 1996). Meanwhile, nine other cohorts only drew their conclusions by following a version of one of the sources or following sources that had the same version-whatever they wanted to believe (B2). Their way of thinking in assessing sources was demonstrated by them only using common sense without evidence basis or critical thinking. For example, they said, "The third version....makes most sense" as if they could interpret the past as they pleased. This example parallels with Stahl et al.'s (1996, p. 448) argument that "simply presenting them with multiple texts did not encourage them to think like historians." Thus, they were still experiencing troublesome knowledge in developing critical interpretations based on conflicting sources (Meyer \& Land, 2003; D. Perkins, 2006).

For the experimental group students, most cohorts also made progress in their level of historical thinking skills. In the second stage of intervention, there were nine cohorts that could be categorised as having high levels of historical thinking skills (C), while the other nine cohorts could be categorised as having middle levels of historical thinking skills (B). As can be seen in Figure 10.8 below, the nine cohorts at the middle level could be divided into two sub-categories, namely between cohorts who did not confirm the interpretation position (B1) and those who confirmed the interpretation position but were still weak (B2). There were three cohorts that did not confirm their position of interpretation nor conclusion on their essays even though they had presented various versions of Mallaby's death based on the sources they referenced. This indicated that they had crossed one of the threshold portals in the form of multiple sources (Meyer \& Land, 2003, 2005). They had accommodated this new knowledge and modified their schemata that historical sources can have various versions in reporting the past (Bormanaki \& Khoshhal, 2017; Mascolo, 2015; Piaget, 1950). However, they were still unable to overcome 
one aspect of troublesome knowledge in terms of establishing their interpretations based on conflicting sources (Meyer \& Land, 2003, 2006; D. Perkins, 2006). Therefore, they only explained the various versions of the past in their essays, but did not establish strong interpretations and only made a weak conclusion, as the SCH-A_EG05 cohort wrote, "it is still not clear who killed/shot Mallaby at that time" just because they did not find a definite answer in the textbook.

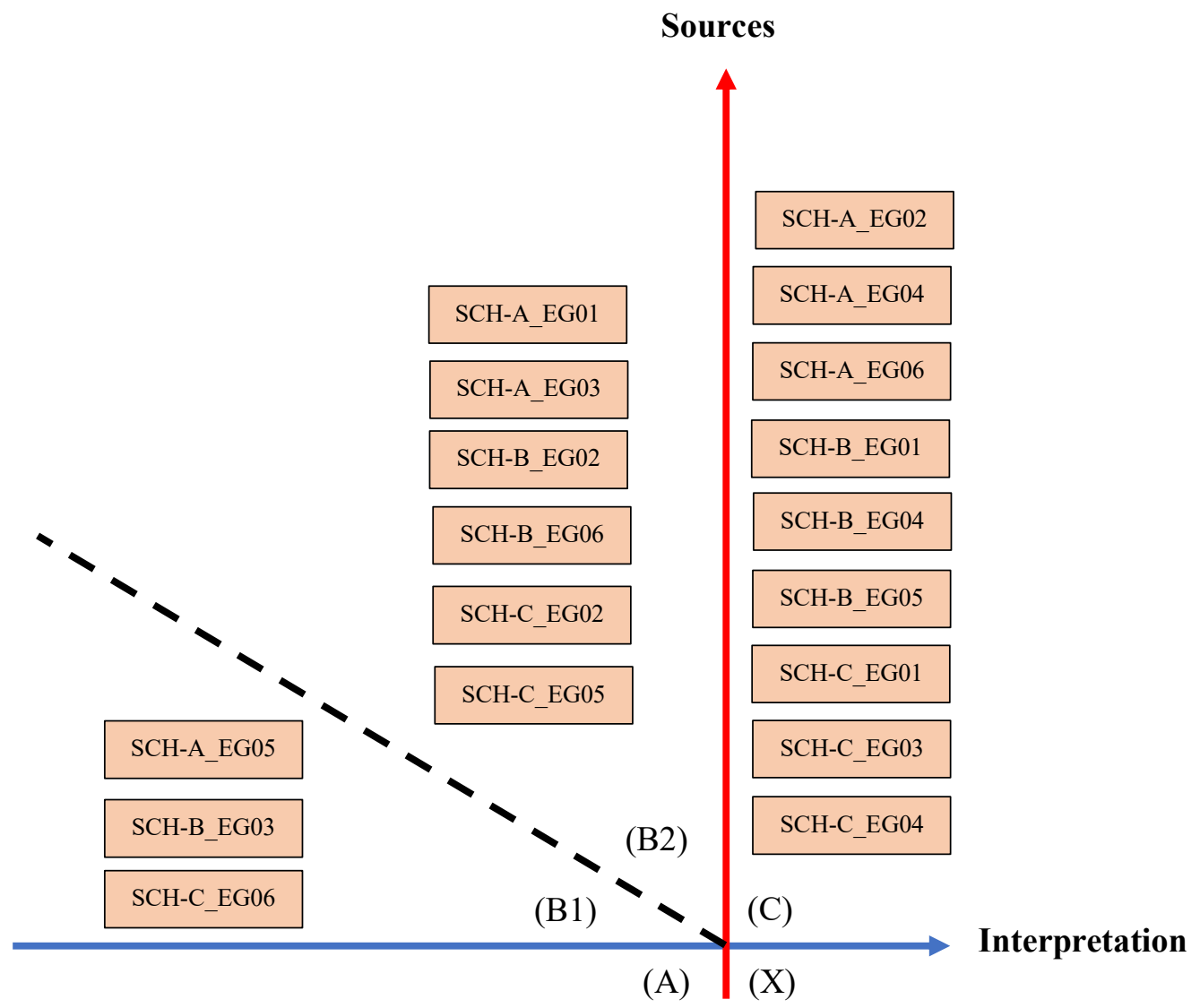

Figure 10.8 The level of the experimental group students' historical thinking skills based on the WIE post-test 2 results.

Meanwhile, there were six cohorts from the experimental group students who were able to draw conclusions after describing various versions of Mallaby's death (B2). Although they were no longer bound by their old schemata, thinking that historical sources could only have a single version, they still experienced troublesome knowledge in producing interpretations of the past by critically assessing sources (Baillie et al., 2013; Meyer \& Land, 2003; Walker, 2013). In determining their position of interpretation, they simply followed one version of the 
source that was considered the 'best' version or only followed one version from several sources that had the same version in reporting the past. Thus, when confronted with conflicting versions, they gave the same response as cohorts in the A and B1 clusters. They simply determined the trustworthiness of the sources based on the number of the same version, as Balfiane stated, "Many stated that an [Indonesian] youth was the killer" in order to reject a different version (Hover et al., 2016; P. Lee, 2011). Their failure to produce a critical interpretation was because they over-simplified other different versions and lacked the interest to carry out deeper investigations into different sources (Freire, 1998, 2005a; Monchinski, 2008). Hence, their historical thinking skills were not well-honed because they did not critically assess the historical sources.

In the third cluster, there were nine cohorts that could be categorised as having high levels of historical thinking skills (C). They had been able to overcome two troublesome knowledge as well as crossed the two threshold portals so that they were able to think more critically than the cohorts in the other two clusters (Meyer \& Land, 2003; D. Perkins, 2006). They accommodated new knowledge and modified their schemata (Bormanaki \& Khoshhal, 2017; Mascolo, 2015; Piaget, 1950) which historians usually activate when reading documents (Wineburg, 1991a), that historical sources can report what happened in the past in different versions. They were also able to assess historical sources critically in establishing their position of interpretation. Different from other cohorts, they had an interest in investigating the sources more deeply, interpreting the problems contained in the sources in-depth, and establishing sound arguments in their interpretations (Elias, 1974; Freire, 1998, 2005a; Monchinski, 2008). For example, in analysing the documents of Captain Smith and Captain Laughland, the SCH-C_EG01 cohort assessed the contents of the reports to be reliable because "they were also in the car with Mallaby" and "there is no way the reporter was lying, it could be a disgrace to his country." These findings indicate that they have analysed the documents by assessing "the authors and the circumstances of document generation" (Wineburg, 1991a, p. 84), including being able to assess the contents of the Kedaulatan Rakjat and Soeara Rakjat newspapers as "propaganda" (Bhernandae). They were also able to "interpreting interpretations" of the National History of Indonesia textbook 
(Harada, 2012) that Mallaby died from being stabbed by bamboo spears, by assessing that "the [Indonesian] government is trying to instil the idea that Indonesian youth could do it, even with any weapon, could kill the British" (Arifdahe). This finding reflects that they recognised that the textbook "is an account constructed by an author" and has a "political position" perspective (VanSledright \& Afflerbach, 2005, pp. 2-3).

Therefore, until the end of the second intervention session, the number of cohorts in the experimental group that could be categorised as having a high level of historical thinking skills was higher than the control group. One of the determining factors was that the experimental group could focus more on developing historical thinking in assessing historical sources that were available on the www.berpikirsejarah.com website, without being preoccupied with searching for sources. In contrast, the control group had to look for historical sources for themselves that they could access, mainly from the internet. Nevertheless, the learning process in both groups was equally influenced by "non-human appliances" in the internet format (Goldie, 2016; Kop \& Hill, 2008; Siemens, 2004). The primary sources on the website that was deliberately provided for the experimental group in this had study affected their historical thinking skills.

Moreover, the availability of primary sources made it easier for the experimental group students to overcome the troublesome knowledge related to multi-version historical sources and in asserting their interpretation position. This happened because the experimental group students realised more immediately that the past could be interpreted differently as what they found in the testimonies of historical actors and witnesses. On the other hand, the control group was more hampered in realising that the past could be interpreted differently because they relied more on secondary sources. So, they thought that if there were different versions of the sources in interpreting the past, they would simply think in binary terms that there was a right version and a wrong version. However, once the two groups realised the nature of historical sources which could have different versions, this concept could not be reversed and remained integrated into their new schemata (Mascolo, 2015; Meyer \& Land, 2003; Piaget, 1950; Walker, 2013). At least that is the hope, as evidenced in the data findings from the two intervention processes, 
where no cohorts of students who have been at a higher level of historical thinking then degraded to a lower level of historical thinking. Meanwhile, the patterns of students' historical thinking skills were also related to the patterns of students' epistemic beliefs about history, as discussed in the next section.

\subsection{The pattern of students' epistemic beliefs about history}

In investigating the past, the act of historical inquiry by historians is framed by their beliefs about history (Wineburg, 1991a). Likewise, students asked to interpret the past in their essay after learning history through analysing documents and interpreting textbooks also involved their beliefs about history. The findings of the quantitative data in this study revealed that both the control and experimental groups experienced an increase in the mean score of epistemic beliefs in the first intervention stage. But, in the second intervention stage, the mean score of the control group decreased while the experimental group continued to increase. This was perhaps the indirect effects of learning history through analysing documents and interpreting textbooks that were intervened in the experimental group. However, the findings of the qualitative data in this study demonstrated the greater complexity of students' epistemic beliefs about history.

By referring to the quantitative data obtained from the writing interpretive essay score and the results of historical beliefs questionnaire, my study suggests that the patterns of students' epistemic beliefs about history can be mapped through the same diagram as the patterns of students' historical thinking skills. It is likely that the three clusters of students' historical thinking levels as have been discussed in the previous section (Figure 10.2) also reflected the students' epistemic belief stance as can be seen in Figure 10.9 below. For the first cluster (A), students who still had low levels of historical thinking skills tended to directly trust the contents of the sources, such as textbooks or Wikipedia. These findings indicate that they treat sources as "direct access to the past" (P. Lee \& Shemilt, 2003, p. 21) and "historical sources can speak for themselves" (VanSledright, 2014, p. 98), so they can be categorised as having naïve-objectivist stance. For the second cluster (B), students who still had middle levels of historical thinking skills tended to have realised the nature of historical sources that can have many versions of the past. 
However, in setting their interpretations they tended to be uncritical and only "by deciding which report is best" (P. Lee \& Shemilt, 2003, p. 21) or believe "the past is simply what the investigator makes it to be" (VanSledright, 2014, p. 98). Thus, they can be categorised as having naïve-subjectivist stance. For the third cluster (C), where students already had a high level of historical thinking skills, they tended to treat sources in their historical context and were able to construct reasonable interpretations of the past critically even in the presence of conflicting evidence (P. Lee \& Shemilt, 2003; VanSledright, 2014). So, they can be categorised as having criterialist stance because they had "the ability of historical thinkers to use disciplinary tools and criteria for historical inquiry" (Maggioni et al., 2009, p. 195). Meanwhile, for the lower right corner, since there is no data found about students' historical thinking skills in that position, there is also no category of students' epistemic beliefs about history in that corner (X). I named this cluster as "naïve" since it is too simple-minded to expect students to understand the critical nature of history if they are only exposed to a single source when learning history. The patterns of students' epistemic beliefs about history described above is illustrated in the following figure:

\section{Sources}

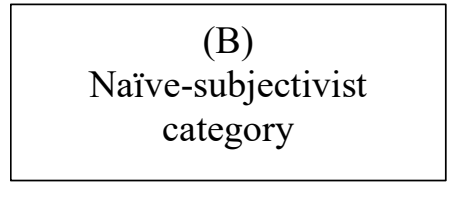

Weak interpretation

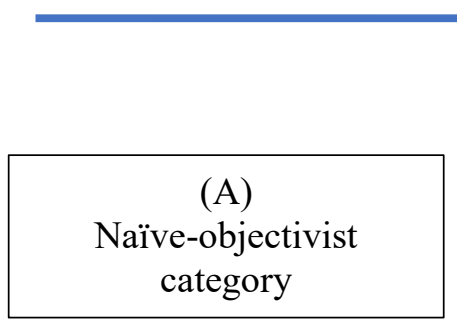

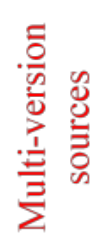

(B)
(C)

Criterialist category

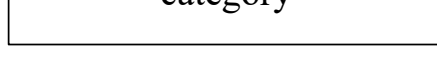

(C) Strong interpretation

Interpretation

(A)

(X)

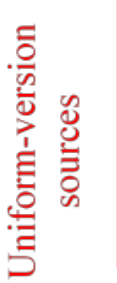

Figure 10.9 The categories of students' epistemic beliefs about history 
Since I argued that the level of students' historical thinking skills also reflected their epistemic beliefs about history, the progression of students' epistemic beliefs stance also followed the development of their historical thinking skills as I have described in the previous section. To some extent, my argument resonates with Nokes's (2014, p. 396) rationale that "most students' understanding of the nature of history as an academic discipline became more sophisticated" if they are given the opportunities to work with documents to solve historical controversies. However, the results of the focus group interviews indicate that students' epistemic beliefs about history were not as simple as the patterns described above.

My findings show that students' statements in the interviews were not always in line with their responses to the questionnaire or always reflected the results of their written essays. In that regard, I would argue that what students believed was not automatically reflected in their essays or questionnaire and it can also be interpreted that students finally experienced epistemic changes immediately after the intervention process had ended or when the interview was conducted. Apparently, my study also reflects similarities with Maggioni's (2010) findings regarding "epistemic inconsistency" and with what VanSledright and Reddy (2014) call "epistemic wobbling". This was evidenced in the verbal answers of some students during the interview, which differed from their responses when filling out the questionnaire. As in the historical thinking skills of students who progressed through the stages of intervention, it seemed that the development of students' epistemic beliefs also needed time to develop. Apart from the phenomenon of epistemic inconsistency experienced by some students, learning history through analysing documents and interpreting textbooks has the potential to foster their historical thinking skills. The potential of this learning model will be discussed in the following section.

\subsection{The potential of analysing documents and interpreting textbooks as a learning model to foster students' historical thinking skills}

In Chapter 8, I described how learning history through analysing documents and interpreting textbooks has several challenges as well as opportunities to foster 
students' historical thinking skills. All the potential offered by this learning model in fostering students' historical thinking skills needs to be discussed in this section so that this approach can be optimally utilised by history teachers in developing countries, especially Indonesia. Instilling historical thinking skills for students in Indonesia which have a curriculum that mandates specific substantive content knowledge which is determined by the state, certainly requires a different approach from other countries, such as New Zealand (Sheehan, 2020) whose curriculum is framed by the procedural concepts of historical thinking but does not mandate substantive content knowledge. Specifically, when teaching content that is considered to have historical significance for the country, like the battle of Surabaya, it definitely it also has its own challenges that are different from other countries, such as United Kingdom (Pennell \& Sheehan, 2020) which have the challenges of conceptualising how students remembrance the First World War.

The learning model offered by this study is indeed not revolutionary because teachers must keep on using the textbooks required by the curriculum. This model only follows Singleton \& Giese's (1999, p. 149) suggestion “to challenge students with an alternative perspective or explanation to that offered in the textbook." The findings of this study indicate that learning history through analysing documents and interpreting textbooks contributes to students' historical thinking skills, as evidenced in the experimental group students. However, there were some difficulties and opportunities emerging from this model which needs to be considered so that its potential can be maximised.

This study has revealed that many students experienced troublesome knowledge when dealing with conflicting sources and establishing their position of interpretations. As recognised by Cakpurwantoe that "the difficulty was in comparing historical sources" or by Bhernandae that "it was challenging... to draw the most reasonable conclusions." The complaints they made were reasonable because previously they only consumed narrative types of textbooks and were not given any space to develop argumentative critical thinking (Henríquez \& Ruiz, 2014). Especially if the single version of the narrative presented in the textbook is continuously assimilated by students and embedded strongly in their schemata, they would find it troublesome to accommodate new knowledge that the past can be 
reported differently in historical sources (Beilin, 1992; Mascolo, 2015; Piaget, 1952; Stoltz, 2018). This is reflected in the perspectives of the teacher participants, that students' difficulties were caused by not being accustomed to this learning model and still requires an extended habituation process. Likewise, teacher participants also felt that they needed time to shift from teacher-centred to studentcentred approach. The key success of teaching history through analysing documents and interpreting textbooks needs to be supported by a learning environment that positions the teacher as a facilitator, while students are given space to construct their own knowledge (J. K. Lee, 2002).

The findings of this study also revealed that students gained many benefits from learning history through analysing documents and interpreting textbooks, such as getting first-hand experience utilising primary sources, becoming increasingly curious and challenged, and also feeling able to think more critically. Students' first experience using primary sources contributed to the improvement of their historical thinking skills compared to control group students who did not use primary sources. This study supports Reisman's (2012a, 2012b) findings that students' historical thinking who were part of the intervention $(n=236)$ with historical documents outperformed their counterparts who did not receive the document-based lesson. Related to the findings of this study which showed that students were increasingly curious and challenged to learn history when dealing with primary sources, it seems to resonate both with Tally \& Goldenberg's (2005) studies that primary sources can raise and renew students' interest in learning history and with Culminas-Colis et al.'s (2016) study that students enjoy the activity of doing history. In addition, student participants who claimed to be more able to think critically after engaging in the intervention process in this study, seems to run in parallel with many other studies related to the benefits of using primary sources in the doing of history (Ashby, 2011; Barton, 1997; Culminas-Colis et al., 2016; Endacott \& Sturtz, 2015; Hover et al., 2016; Leur et al., 2017).

I believe that the improvement of historical thinking skills in the experimental group students was an effect of learning history through analysing documents and interpreting textbooks. I also believe that the improvement was triggered by various other factors related to the application of this learning model. These factors were 
identified from the findings of my study. First, students had the opportunity to learn history from multiple sources other than the textbook, whereas previously students were habituated to learn history primarily from the textbook only. This finding was not surprising since the positive impacts of multiple sources have been conveyed by various studies for a long time, that exposing students to multiple documents changes how they reason and understand history (Barton, 1997; Rouet et al., 1996; Wiley \& Voss, 1999). Consequently, students who were given the opportunity to analyse primary sources can open their horizons of historical and critical thinking (Staysniak \& Staysniak, 2016). Not only primary sources, but students who were given alternative secondary sources other than textbooks could also improve their historical thinking skills (Purnaman, 2015; Tricahyono, 2017). This is why the control group students in this study also experienced an increased in their historical thinking skills because they also tried to find other sources besides their textbooks.

The second factor, which led to an increase in students' historical thinking skills, was because they were given the opportunity to interpret the past independently as learning history should be centred on the process of historical interpretation (Barton \& Levstik, 2003). In the context of this study, students constructed their interpretations guided by central questions and then presented in the form of interpretive essays. By doing that, students basically transformed the act of reading sources into a process of active inquiry (Reisman \& Wineburg, 2012) as well as create their own interpretations (Cercadillo, 2006). These processes reflected students' true historical thinking skills. Thinking historically actually requires deep thinking and cannot simply be measured by think-aloud protocol (Wineburg, 1991a, 1991b), ranking test (Wineburg, 1991a), constructed response task (Maggioni, 2010), or even multiple-choice test (Reisman, 2012a), as evidenced by student participants statements who needed to read sources repeatedly and carefully before they could write their interpretations. In addition, they must first overcome the troublesome knowledge related to multiple conflicting sources to construct their own interpretations. This also caused the control group students to experience an increase in their historical thinking skills. However, their increase was only small because they were preoccupied with the activity of finding sources and most of them only found secondary sources from the internet. 
The third factor, which helped trigger the increase in students' historical thinking skills was the process of debate and discussion in the classroom. The findings of this study indicated that many students were aware of the nature of history after they discussed each other's various interpretations. These findings parallel with Harada's $(2012$, p. 8) suggestion that it is beneficial for teachers to "provide opportunities for students to share their interpretations with each other in class so that students will realise there are various interpretations of history." Debates in class helped students not only to understand other people's interpretations but also construct their own interpretations since they had to take grounds on historical debates (Martell, 2013). As Barton \& Levstik (2003, p. 358) state, "History can be understood only by considering perspectives that differ from our own." It turns out that the students in this study also tried to understand the perspectives of their friends, not only other cohorts but also their own cohortsalthough it was troublesome - as Ciputrie said, "So, it is hard to conclude our own opinions. Moreover, we also work as a cohort. Surely each of us has our own opinions." It cannot be denied that the discussion factor has also caused the control group students to experience an increase in their historical thinking skills.

Although both groups experienced an increase in their historical thinking skills, the increase in the experimental group students exceeded the control group students. On one hand, the experimental group obtained a more systematic learning model in processing historical sources from the study's intervention design. On the other, the experimental group also obtained more systematic learning resources presented on the learning website, as discussed in the next section.

\subsection{The potential of teaching history by using web-based historical sources as learning resources to foster students' historical thinking skills}

In the digital age, there are many materials available — whether born-digital or digitised materials - in various digital media that can be utilised as tools for thinking (Shep, 2014, 2016). Likewise, in teaching history, teachers believe that digitised primary sources available on websites can be used to enhance students' historical thinking skills (Salinas et al., 2011). The findings of this study have also 
revealed that the www.berpikirsejarah.com website contributes to students' historical thinking skills. However, some of the strengths and weakness that have been expressed by research participants regarding the potential use of historical sources available on learning website to develop students' historical thinking skills need to be discussed in this section so that the website can be further optimised.

The findings of this study indicate that there were some students who claimed that learning history using web-based historical sources to access learning resources had no weaknesses at all and even made it easier for them to access historical sources. For example, Amalzae convinced that "there were no difficulties. It made things easier, because all the sources were available." However, his perspective does not prove that learning history by utilising this learning website was without challenges. The main challenge of the learning process that relies on internet access was the availability of a strong and stable internet network. This was evidenced from Balfiane' statement that the difficulty was "when the connection was unstable, depending on the internet" or Buregise' difficulty "when I do not have data plan." Including observational data that found the struggles of some students, for example, Cakrahardiane, had to shake his phone to get a better internet connection. Findings like this that I have never read from the results of other studies, which are usually conducted in developed countries and expose more on positive potential (J. K. Lee, 2002; Martin et al., 2008; Salinas et al., 2011).

Another challenge felt by students when accessing primary sources available on the web-based learning resources was that they were sometimes distracted by notifications received on their smartphones. This was because most students access the website using their smartphones, only a few students own and use laptops to access sources. For example, this was revealed by Cakrahardiane who stated, “...if there was a notification above [the smartphone screen]. I immediately left the source [on the website] that I was reading." This finding might still not have been thought of by Cohen (2004) more than a decade ago, who was still concerned about the availability of an internet-connected computer, but Lee (2002, p. 512) was already worried about the time spent by students who were distracted by "viewing websites unrelated to the research". The next difficulty, since most students used their smartphones to access the website, some of them complained of being dizzy 
from screen radiation. For example, Ciputrie who expressed “....if I read it for a long time, I became dizzy, because I looked at the screen continuously, due to the screen radiation." However, some students deal with this obstacle by printing the sources.

Meanwhile, based on the teacher participants' perspectives, the challenges emerging from the web-based historical sources as learning resources were only felt after the intervention process had ended. This was stated by Teacher A who claimed, "My difficulty now [after the intervention process was over], is my students start asking, 'where are the primary sources, Sir?'.” This statement seems to resonate with the findings of Salinas et al. (2011, p. 191) where teachers tend to think that "more is better" because they see the website "as opportunities to gather primary sources for their teaching". This is supported by Teacher C's expectations who states, "my hope is that [the website is] not only about the Surabaya battle". Thus, based on teachers' perspective, the use of www.berpikirsejarah.com website did not have significant difficulties. They only hoped that the content would be further developed.

Despite the challenges, the existence of the website also offers many opportunities to foster Indonesian students' historical thinking skills. Based on the research participants' perspective, the main advantage of this website is the ease of access to learning resources in the form of primary sources. The ease of access was mainly because the website was developed intentionally for educational purposes; all historical sources presented on the website were deliberately chosen according to mandated specific content knowledge and those which could stimulate students' historical thinking skills. This is for example expressed by a student named Bhernanda who stated, "[It's] easier to access primary sources," and the teacher felt "it really made me easy to teach" (Teacher A). This ease of access has been predicted by Lee (2002, p. 504) who stated, "Through the World Wide Web, learners have a level of direct access to the raw materials of history that educators could never have imagined." Since the primary sources were available on the website, students can access them anytime and anywhere. Like a student named Asalmae who was excited because "it can be read at any time" or Buregise who felt facilitated because the sources "can be read anywhere." The advantage of the 
website which contains primary sources has been acknowledged by Cohen (2004, p. 295) because it is "enabling the storage and transmission of huge amounts of information" that can be accessed by students "regardless of physical location." This ease of access made it easy for students to learn history.

To support students' learning of history in a better way, the learning process should follow the learning styles preferred by students of the "digital age". I do not want to be trapped in hyperbole terms like "digital native" vis-à-vis "digital immigrant" or "Gen Z" and this study also does not intend to respond to the polemics arising from these terms (Gentina et al., 2018; McGrew et al., 2017; Noonan, 2013). However, my findings show that many students claimed to have a tendency of excessive dependence on the smartphone (Ahn \& Jung, 2016) and felt they could learn history better and benefited from the existence of the www.berpikirsejarah.com website. This was proven, for example, from Balfiane confession that "I rarely open books. I open my smartphone more often. So, I can learn by using my smartphone" or from Asalmae statement, "In our daily life we cannot be separated from the internet either." Thus, regardless of the polemic, student participants who could be categorised as digital natives claimed to be able to learn history better by being provided with web-based historical sources that they accessed with their mobile devices.

The findings of this study indicate that the contents of the website, which contain the original version of primary sources as well as the transcript version, are considered by students able to facilitate them in understanding history from its sources. Of the two versions, there were some students who liked to read the transcript version and not a few of them preferred to read the original version. For example, Cayuninge stated, "I prefer the original source because it is more challenging." In that regard, I would argue that some studies from Wineburg and his colleagues (Reisman \& Wineburg, 2012; Wineburg \& Martin, 2009) which suggest modifying the content of the documents are not relevant to be applied in Indonesia. Their reasons for making it easier for students to read the historical text are unacceptable because it would result in students losing the opportunity to study the past by themselves and from the original version of the primary sources. How is it possible to awaken students' historical thinking skills if previously they only 
obtained an "unoriginal" version of the past from their textbooks and then given also the "unoriginal" version of the documents? Students would miss many opportunities to think critically.

The biggest benefit of having web-based historical sources as learning resources is the opportunity to foster students' critical and historical thinking skills. Students must be given the experience to deal with historical sources in its original version; and if they have difficulty, they can read the transcript version but without any content modification. Lee (2002, p. 504) has suggested creating a "learnercentred experience" because "web-based digital historical resources empower students to construct a more personal understanding of history" which is needed to foster students' historical thinking skills. So that many students can gain conscientization (Freire, 2000, 2005a; Monchinski, 2008), as Cakpurwantoe has gained, indicated from his statement: “....that seeing at the lessons from elementary school until now, it turns out there is information that is true, and sometimes is wrong. So, it's like giving us real evidence." The findings of this study highlight that students are not born with historical thinking skills so they must be taught (Noonan, 2013) by giving them the opportunity to think independently and by providing them the access to historical sources available on the learning website. 
This page is intentionally left blank. 


\section{CHAPTER 11 CONCLUSION}

In this final chapter, I highlight the key findings in this study. This chapter also presents the pedagogical implications and recommendations based on the analysis of the key findings. I also suggest several opportunities for further research in this field. I end the chapter with the concluding reflections of the thesis.

\subsection{Review of findings}

The major finding of this study has revealed that teaching history through analysing documents and interpreting textbooks contribute to students' developing historical thinking skills. This was the focus of the main research question which explored alternative efforts to overcome the difficulties faced by history teachers in Indonesia to instil students' historical thinking skills. These difficulties were triggered by the ambivalent position of history education in Indonesia which on one hand is still used as a subject to foster nationalism and patriotism, whereas on the other must be used to educate young people to become democratic, critical and responsible citizens. To achieve both, teachers should no longer teach history by mainly relying on lectures or only using the official textbooks as the main learning resources which tend to offer only one official version of the past. To achieve this, the study examined the effectiveness of a learning model through analysing documents and interpreting textbooks in which students were given the opportunity to analyse historical documents presented on a learning website and at the same time being asked to interpret their textbooks critically.

The process of learning intervention through this learning model revealed that the historical thinking skills of the experimental group students progressed better than those of the control group students. Prior to the intervention process, the two groups proved to have the same level of the initial understanding of the battle of Surabaya (Chapter 5). In addition, it was revealed that both groups of students tended to see history in the one version they obtained from their textbooks. This was the focus of the first sub-question. Then, after going through two interventions (Chapter 6), the quantitative data clearly showed that the experimental group 
experienced better progression in their historical thinking skills, while the complexity of the qualitative data revealed that there were two themes that frequently emerged, namely sources and interpretations. These two themes appeared to be "troublesome knowledge" for students who were accustomed to learning history from school textbooks that presented only one version of interpretation (Meyer \& Land, 2003; D. Perkins, 2006). Students who were able to overcome these two "troublesome knowledge" phases could successfully cross "the threshold" that determined the level of their historical thinking skills (Meyer \& Land, 2003; Walker, 2013). This thesis also demonstrates that students who were able to cross the threshold were those who had accommodated new knowledge in their cognitive schemata that historical sources can report the past divergently, and a reasonable interpretation of the past could be constructed if historical sources are critically assessed (Bormanaki \& Khoshhal, 2017; Freire, 2005b, 2005a; Mascolo, 2015; Piaget, 1950). The main conclusion that can be drawn from this major finding is that teaching history through analysing documents and interpreting textbooks has a positive effect on students' historical thinking skills.

The intervention process of teaching history through analysing documents and interpreting textbooks also appeared to have indirect effects on students' epistemic beliefs about history. This was the focus of the second sub-question in this study and has been addressed in Chapter 7. The quantitative data obtained from the questionnaire revealed that the mean score of the experimental group increased gradually throughout the two intervention stages while the control group decreased on the second intervention; that is, on HBQ3 there was a statistically significant difference between the two groups. Although the quantitative data revealed that individual student's consistency scores experienced mixed progressions and the essay they wrote reflected their type of epistemic beliefs about history, the complexity of the qualitative data seems to indicate that students' changing epistemic beliefs took a long time, and apparently some students experienced epistemic inconsistencies. The qualitative data obtained from the focused group interview showed that students had experienced epistemic changes after the intervention process had ended as reflected during the interview. 
Furthermore, this study, to some extent, has demonstrated the potential of teaching history through analysing documents and interpreting textbooks to foster students' historical thinking skills. This was the focus of the third sub-question and has been addressed in Chapter 8. Student and teacher participants revealed various positive potentials of this learning model in stimulating students' historical thinking skills. Although it can make students experience difficulties in the process of learning history, but after they have become accustomed to this learning model, it could stimulate students to think critically; something that is needed to foster their historical thinking skills.

This study has revealed that www.berpikirsejarah.com holds the potential to be used as a web-based learning resource that can be utilised by history teachers to foster students' historical thinking skills in Indonesia. This was the focus of the fourth sub-question of this study and has been addressed in Chapter 9. As a digital learning resource that requires the availability of gadgets and internet facilities, its use could indeed pose certain challenges and difficulties in Indonesia. However, the research participants' statements obviously revealed that the advantages outweighed its challenges.

\subsection{Implications and recommendation}

This study has generated many significant implications and recommendations on issues related to the efforts to teach students to have historical thinking skills, in the context of Indonesia in particular, and developing countries in general. Firstly, history teachers need to become familiar with utilising primary sources in teaching history in their classrooms. The findings of the present study confirm the importance of using primary sources in stimulating students' historical thinking skills (Ashby, 2011; P. Lee \& Shemilt, 2003; Sheehan, 2013; Wineburg, 1991a, 1991b; Wineburg \& Martin, 2009; Wineburg et al., 2011). The position of history education in Indonesia which is still focused on constructing national identity by instilling nationalism and patriotism in students must be balanced with critical pedagogy which aims to educate them to become democratic and responsible citizens who are able to think critically. To educate students to have historical thinking skills that require critical thinking skills, the teacher must be aware that it 
is not sufficient to merely use textbooks as a learning resource that is presented through lectures to the students. The study findings inform our understating on the way to foster students' historical thinking skills through analysing documents and interpreting textbooks. I suggest that history teachers in Indonesia use this learning model to develop their students' historical thinking skills.

Secondly, to support the success of the efforts to foster students' historical thinking skills, I suggest history teachers must pay attention to students' epistemic beliefs about history. To cultivate students' historical thinking skills, it is necessary to consider students' epistemic beliefs about history, about how their understanding of the nature of history and how history is constructed. The findings of this study indicate that students had difficulty in thinking historically because they have been accustomed to accepting history in one version as presented in the textbooks and have never been involved in the process of producing history through analysing historical sources to construct their own interpretations. For this reason, I suggest that history teachers must first examine their students' epistemic beliefs about history before attempting to foster their historical thinking skills.

Thirdly, related to the importance of digitised primary sources presented on the learning resources website to stimulate students' historical thinking skills, this study suggests the National Archive of the Republic Indonesia and the regional archive office to digitise their historical documents and collections so that they can be used by teachers and students to learn history. I realise that this is difficult to fulfil in the near future, so I suggest that history teachers in Indonesia use the digitised learning resources available on the website www.berpikirsejarah.com. At least, for the time being, it can be used to teach the battle of Surabaya as well as an initial training for students using primary sources.

Finally, since teaching historical thinking is relatively new in Indonesia, its success needs to be supported by training for history teachers on how to teach it. For in-service teachers, they need to receive training in their ongoing professional development. Especially in the 2013 Curriculum training program, they need to be given materials on how to teach their students to have historical thinking skills. Meanwhile, pre-service history teachers, also need to receive special training on how to teach historical thinking skills in one of their courses. 


\subsection{Suggestion for future research}

I believe that some aspects discussed in this study can be explored further in future research. I realise that there are several limitations of the study which lead to some avenues that would advance the findings presented in this thesis. Since this study only examined the intervention process to foster students' historical thinking skills when studying the battle of Surabaya, future studies could focus on the use of historical learning model through analysing documents and interpreting textbooks for other historical content knowledge that are required to be taught in Indonesia. However, due to limitations and difficulties in accessing primary sources in Indonesia, future researchers must also provide the necessary historical documents to make it easier for teachers and students to learn the historical topics to be studied. Although it can be given in the form of printed historical documents, this study shows that digitised primary sources presented on a learning website could make it easier for both teachers and students to access the learning resources.

Further studies could focus specifically on developing other learning models that could be used to foster students' historical thinking skills. This should be apparent since each country has its own challenge, has different curriculum characteristics, and has different historical educational goals. I believe that there are some other ways that can be used to foster students' historical thinking skills. However, it should be noted, in the context of Indonesia, where the aim of history education is still used to instil the spirit of nationalism and patriotism but at the same time is required to train students to think critically, future studies must also equilibrate these two curriculum demands.

\subsection{Concluding reflections}

This study has highlighted the importance of teaching history aimed at fostering students' historical thinking skills. Despite the complexity of the data findings, this study presents the potential for teaching history through analysing documents and interpreting textbooks that are proven to improve students' historical thinking skills. Given the enthusiasm of the student and teacher participants with this new approach, I am confident that this teaching and learning 
model can be disseminated more broadly in Indonesia. At the time of completing this thesis, I am aware that I have the responsibility to disseminate this approach to other history teachers in Indonesia. I am also aware that I have the responsibility to further develop the www.berpikirsejarah.com website so that it can be utilised for the benefit of teaching and learning history in Indonesia. 


\section{REFERENCES}

Act of The Republic of Indonesia Number 20 Year 2003. (2003). UndangUndang Nomor 20 Tahun 2003 tentang Sistem Pendidikan Nasional. Jakarta: State Secretary of the Republic of Indonesia.

Afflerbach, P., \& VanSledright, B. A. (2001). Hath! Doth! What? Middle graders reading innovative history text. Journal of Adolescent \& Adult Literacy, 44(8), 696-707. Retrieved from https://www.jstor.org/stable/40018742

Agustinova, D. E. (2018). Penerapan Kurikulum 2013 pada mata pelajaran sejarah pada Sekolah Menengah Atas. Istoria: Jurnal Pendidikan Dan Ilmu Sejarah, 14(1), 1-9. Retrieved from https://www.jstor.org/stable/40018742

Ahn, J., \& Jung, Y. (2016). The common sense of dependence on smarthphone: A comparison between digital natives and digital immigrants. New Media \& Society, 18(7), 1236-1256. https://doi.org/10.1177/1461444814554902

Alexander, H. A. (2018). What is critical about critical pedagogy? Conflicting conceptions of criticism in the curriculum. Educational Philosophy and Theory, 50(10), 903-916. https://doi.org/10.1080/00131857.2016.1228519

Alfian, S. Y. (2017). Multiperspektif dalam mata pelajaran sejarah: Langkah nyata dalam menghargai kebhinekaan di ruang kelas. Jurnal Sejarah Dan Budaya, 11(2), 199-205. https://doi.org/10.1797/um020v11i22017p199

Alfian, S. Y. (2018). Kesinambungan dan perubahan: Pemanfaatannya sebagai kerangka pembelajaran sejarah. Jurnal Sejarah Dan Budaya, 12(2), 173-179. https://doi.org/10.17977/um020v12i22017p173

Alfian, S. Y. (2019). Pararaton sebagai sumber sejarah: Pemanfaatannya dalam pembelajaran di era digital. Jurnal Pendidikan Sejarah Indonesia, 2(1), 3848. Retrieved from http://www.jurnalpsi.com/index.php/jpsi/article/view/33/24

Alfian, S. Y., Andarwati, M., \& Hidayah, T. (2017). Strategi argumentasi dalam pembelajaran sejarah. Jurnal Sejarah Dan Budaya, 11(1), 112-122. https://doi.org/10.17977/sb.v11i1.9127

Aman. (2019). The competence of history teacher in implementing the authentic assessment: A case study at SMA Negeri 2 Yogyakarta. Istoria: Jurnal Pendidikan Dan Ilmu Sejarah, 15(1), 101-139. https://doi.org/10.21831/istoria.v15i1.24382

Anas, Z. (2010). Reformulation of learning and teaching history at elementary and secondary level of education. Historia: Jurnal Pendidik Dan Peneliti Sejarah, 11(2), 119-134. https://doi.org/10.17509/historia.v11i2.12334

Andarwati, M. (2019). Pembelajaran sejarah kontekstual, kreatif, menyenangkan di kelas dengan "power director" bagi generasi Z. Jurnal Pendidikan Sejarah Indonesia, 2(1), 64-81.

Anderson, L. W., \& Krathwohl, D. R. (Eds.). (2001). A taxonomy for learning, teaching, and assessing: A revision of Bloom's taxonomy of educational objectives: Abridged edition. New York: Longman.

Anderson, R. C. (1977). The notion of schemata and the educational enterprise: General discussion of the conference. In R. C. Anderson, R. J. Spiro, \& W. E. Montague (Eds.), Schooling and the acquisition of knowledge (pp. 415431). New Jersey: Lawrence Erlbaum Associates. 
Anfara, V. A. (2008). Theoretical frameworks. In L. M. Given (Ed.), The SAGE encyclopedia of qualitative research methods (pp. 870-873). Thousand Oaks: Sage Publications.

Ary, D., Jacobs, L. C., Sorensen, C., \& Razavieh, A. (2010). Introduction to research in education. Belmont: Wadsworth.

Ashby, R. (2011). Understanding historical evidence: Teaching and learning challenges. In I. Davies (Ed.), Debates in history teaching (pp. 137-147). London: Routledge.

Awang, M. M., Ahmad, A. R., Yakub, N. M., \& Seman, A. A. (2016). Historical thinking skills among pre-service teachers in Indonesia and Malaysia. Creative Education, 7, 62-76. https://doi.org/10.4236/ce.2016.71007

Baillie, C., Bowden, J. A., \& Meyer, J. H. F. (2013). Threshold capabilities: Threshold concepts and knowledge capability linked through variation theory. Higher Education, 65(2), 227-246. https://doi.org/10.1007/s10734012-9540-5

Barnett, J., McPherson, V., \& Sandieson, R. M. (2013). Connected teaching and learning: The uses and implications of connectivism in an online class. Australasian Journal of Educational Technology, 29(4), 685-698. https://doi.org/10.14742/ajet.243

Barradell, S. (2013). The identification of threshold concepts: a review of theoretical complexities and methodological challenges. Higher Education, 65(2), 265-276. https://doi.org/10.1007/s10734-012-9542-3

Barrouillet, P. (2015). Theories of cognitive development: From Piaget to today. Developmental Review, 38, 1-12. https://doi.org/10.1016/j.dr.2015.07.004

Barton, K. C. (1997). "I just kinda know": Elementary students' ideas about historical evidence. Theory and Research in Social Education, 25(4), 407430. https://doi.org/10.1080/00933104.1997.10505821

Barton, K. C. (2005). Primary sources in history: Breaking through the myths. The Phy Delta Kappan, 86(10), 745-753. https://doi.org/10.1177/003172170508601006

Barton, K. C., \& Levstik, L. S. (2003). Why don't more history teachers engage students in interpretation? Social Education, 67(6), 358-361. Retrieved from https://www.socialstudies.org/publications/socialeducation/october2003/why -dont-more-history-teachers-engage-students-in-interpretation

Barton, K. C., \& Levstik, L. S. (2008). "It wasn't a good part of history": National identity and students' explanation of historical significance. In L. S. Levstik \& K. C. Barton (Eds.), Researching history education (pp. 240-272). New York: Routledge.

Beilin, H. (1992). Piaget's enduring contribution to developmental psychology. Developmental Psychology, 28(2), 191-204. https://doi.org/10.1037/00121649.28.2.191

Biesta, G. (2009). Good education in an age of measurement: on the need to reconnect with the question of purpose in education. Educational Assessment, Evaluation and Accountability, 21(1), 33-46. https://doi.org/10.1007/s11092-008-9064-9

Biesta, G. (2015). What is education for? On good education, teacher judgement, and educational professionalism. European Journal of Education, 50(1), 7587. https://doi.org/10.1111/ejed.12109 
Biesta, G. (2016a). Good education in an age of measurement: Ethics, politics, democracy. London: Routledge.

Biesta, G. (2016b). The beautiful risk of education. London: Routledge.

Bloomberg, L. D., \& Volpe, M. (2008). Completing your qualitative dissertation: A roadmap from beginning to end. London: Sage Publications.

Blow, F. (2011). "Everything flows and nothing stays": How students make sense of the historical concepts of change, continuity and development. Teaching History, 145, 47-55. Retrieved from https://www.jstor.org/stable/43260465

Boitshwarelo, B. (2011). Proposing an integrated research framework for connectivism: Utilising theoretical synergies. The International Review of Research in Open and Distributed Learning, 12(3), 161-179. https://doi.org/10.19173/irrodl.v12i3.881

Boom, J. (2009). Piaget on equilibration. In U. Müller, J. I. M. Carpendale, \& L. Smith (Eds.), The Cambridge Companion to Piaget (pp. 132-149). Cambridge: Cambridge University Press.

Bormanaki, H. B., \& Khoshhal, Y. (2017). The role of equilibration in Piaget's theory of cognitive development and its implication for receptive skills: A theoretical study. Journal of Language Teaching and Research, 8(5), 9961005. https://doi.org/10.17507/jltr.0805.22

Braun, V., \& Clarke, V. (2006). Using thematic analysis in psychology. Qualitative Research in Psychology, 3(2), 77-101. https://doi.org/10.1191/1478088706qp063oa

Braun, V., \& Clarke, V. (2012). Thematic analysis. In H. Cooper, P. M. Camic, D. L. Long, A. T. Painter, \& D. Rindskopf (Eds.), APA handbook of research methods in psychology, Vol 2: Research designs: Quantitative, qualitative, and biological (pp. 57-71). Washington, DC: American Psychologycal Association.

Breakstone, J., \& Smith, M. (2013). Using Library of Congress primary sources for assessment. The TPS Journal, 6(1), 2-4. Retrieved from https://www.loc.gov/teachers/tps/journal/assessing_historical_thinking/pdf/as sessing_historical_thinking.pdf

Britt, M. A., \& Aglinskas, C. (2002). Improving students' ability to identify and use source information. Cognition and Instruction, 20(4), 485-522. https://doi.org/10.1207/S1532690XCI2004_2

Brooks, S. (2011). Historical empathy as perspective recognition and care in one secondary social studies classroom. Theory and Research in Social Education, 39(2), 166-202. https://doi.org/10.1080/00933104.2011.10473452

Bruton, B. (2003). LJ Infotech Webwatch. Library Journal, 128(16), 28-30. Retrieved from http://web.a.ebscohost.com/ehost/pdfviewer/pdfviewer?vid=0\&sid=fc3a06fe -cd76-4c3c-85e0-89a3954ea7e4\%40sdc-v-sessmgr01

Budiarti, \& Fahmi, G. R. (2013). Content of women history in the curriculum of history for senior high school comparison study of 1994, 2004, and 2006. Historia: International Journal of History Education, 14(1), 69-76. https://doi.org/10.17509/historia.v14i1.1921

Burhanudin, M., \& Sodiq, I. (2018). Kendala guru sejarah dalam Kurikulum 2013 menggunakan pendekatan saintifik di SMK Negeri 7 Semarang. Indonesian 
Journal of History Education, 6(1), 89-102.

Carr, E. H. (2001). What is history? Basingstoke: Palgrave.

Carr, P. R. (2008). "But what can I do?" Fifteen things education students can do to transform themselves in/through/with education. International Journal of Critical Pedagogy, 1(2), 81-97.

Carretero, M., Rodriguez-Moneo, M., \& Asensio, M. (2012). History education and the construction of a national identity. In M. Carretero, M. Asensio, \& M. Rodriguez-Moneo (Eds.), History education and the construction of national identities (pp. 1-14). Charlotte: Information Age Publishing.

Cercadillo, L. (2006). "Maybe they haven't decided yet what is right:" English and Spanish perspectives on teaching historical significance. Teaching History, 125, 6-9. Retrieved from https://www.jstor.org/stable/43260148

Chan, E. K. H. (2014). Standards and guidelines for validation practices: Development and evaluation of measurement instruments. In B. D. Zumbo \& E. K. H. Chan (Eds.), Validity and validation in social, behavioral, health sciences (pp. 9-24). London: Springer.

Chapman, A. (2011). Historical interpretations. In I. Davies (Ed.), Debates in history teaching (pp. 96-108). London: Routledge.

Clarà, M., \& Barberà, E. (2014). Three problems with the connectivist conception of learning. Journal of Computer Assisted Learning, 30(3), 197-206. https://doi.org/10.1111/jcal.12040

Cochran, M. M. (2010). Teaching historical thinking: The challenge of implementing reform-minded practices for three first year teachers (Doctoral Dissertation, University of Maryland, Maryland, USA). Retrieved from https://drum.lib.umd.edu/handle/1903/11141

Cohen, D. J. (2004). History and the second decade of the Web. Rethinking History, 8(2), 293-301. https://doi.org/10.1080/13642520410001683950

Counsell, C. (2011). What do we want students to do with historical change and continuity. In I. Davies (Ed.), Debates in history teaching (pp. 109-123). London: Routledge.

Couttenier, M. (2010). "No documents, no history." Museum History Journal, 3(2), 132-148. https://doi.org/10.1179/10.1179/mhj.2010.3.2.123

Cowgill, D. A., \& Waring, S. M. (2017). Historical thinking: An evaluation of student and teacher ability to analyze sources. Journal of Social Studies Education Research, 8(1), 115-145. Retrieved from https://eric.ed.gov/?id=EJ1141860

Creswell, J. W. (2012). Educational research: Planning, conducting and evaluating quantitative and qualitative research (4th ed.). Boston: Pearson.

Creswell, J. W. (2015). A concise introduction to mixed methods research. Los Angeles: Sage Publications.

Creswell, J. W., \& Clark, V. L. P. (2018). Designing and conducting mixed methods research (3rd ed.). Los Angeles: Sage Publications.

Cruz, A. L. (2015). From practice to theory \& from theory to praxis: A journey with Paulo Freire. In B. J. Porfilio \& D. R. Ford (Eds.), Leaders in Critical Pedagogy: Narratives for Understanding and Solidarity (pp. 169-183). Rotterdam: Sense Publishers.

Culminas-Colis, M. V., Reyes, W. M., \& Garcia, E. B. (2016). Teaching historical thinking skills through "reading like a historian" method. The Normal Lights, 
10(1), 56-77. Retrieved from

http://po.pnuresearchportal.org/ejournal/index.php/normallights/article/view/ 174

Darmawan, W. (2010). Historiography analysis of history textbook from neerlandocentric to scientific. Historia: International Journal of History Education, 11(2), 99-118. https://doi.org/10.17509/historia.v11i2.12333

Darmawan, W., Sjamsuddin, H., \& Mulyana, A. (2018). The past ghost: The experience of narrative ideology in history textbooks during the New Order and Reformasi in Indonesia. Paramita: Historical Studies Journal, 28(2), 224-233. https://doi.org/10.15294/paramita.v28i2.15043

Daryanti, F., Hasan, \& Nuraedah. (2017). Pengaruh sumber sejarah dan kemampuan berpikir historis terhadap hasil belajar siswa pada mata pelajaran sejarah di SMA Negeri 6 Sigi. Katalogis, 5(6), 28-36. https://doi.org/10.22487/j23022019.2017.v5.i6.9602

Davies, I., \& Marshall, M. (1991). Preparing to teach about causation. Teaching History, 63, 18-22. Retrieved from https://www.jstor.org/stable/43259805

Davison, M. (2014a). Evidence: Making warranted assertions about the past. In M. Davison, P. Enright, \& M. Sheehan (Eds.), History Matters 2: A handbook for teaching and learning how to think historically (pp. 7-23). Wellington: NZCER Press.

Davison, M. (2014b). Historical empathy: Walking in the shoes of a historical character. In M. Davison, P. Enright, \& M. Sheehan (Eds.), History Matters 2: A handbook for teaching and learning how to think historically (pp. 2441). Wellington: NZCER Press.

Davison, M. (2017). Teaching about the First World War today: Historical empathy and participatory citizenship. Citizenship Social \& Economics Education, 16(3), 148-156. https://doi.org/10.1177/2047173417736906

Davison, M., Enright, P., \& Sheehan, M. (2014). History matters 2: A handbook for teaching and learning how to think historically. Wellington: NZCER Press.

de Castro, L. S. V. (2016). Critical pedagogy and Marx, Vygotsky and Freire. London: Palgrave Macmillan UK.

de Ribaupierre, A. (2015). Piaget's Theory of Cognitive Development. In International Encyclopedia of the Social \& Behavioral Sciences (pp. 120124). Amsterdam: Elsevier.

Dewantara, K. H. (1967). Some aspects of national education and the Taman Siswa Institute of Jogjakarta. Indonesia, 4, 150-168. https://doi.org/10.2307/3350909

Dewantara, K. H. (1977). Bagian I Pendidikan. Yogyakarta: Majelis Luhur Persatuan Tamansiswa.

Dewi, S. S. K., \& Aman. (2019). The implementation of authentic assessment in history learning at senior high school. International Journal of Social Studies, 15(1), 34-46. Retrieved from https://journal.uny.ac.id/index.php/international/article/view/25229/12184

Dexter, M. (1996). History repeats itself: Primary documents go online at the library of congress. School Library Journal, 42(9), 129-131. Retrieved from https://search.proquest.com/docview/57390989?accountid=14782

Dunaway, M. K. (2011). Connectivism: Learning theory and pedagogical practice 
for networked information landscapes. Reference Services Review, 39(4), 675-685. https://doi.org/10.1108/00907321111186686

Elias, J. L. (1974). Social learning and Paulo Freire. The Journal of Educational Thought, 8(1), 5-14.

Emerson, C. D. (2013). Historical concepts and national examinations: Have Olevel structured-essay questions encouraged the teaching of historical concepts. HSSE Online, 2(2), 40-61. Retrieved from https://www.hsseonline.edu.sg/sites/default/files/uploaded/journal_articles/co lin.pdf

Endacott, J. L. (2010). Reconsidering affective engagement in historical empathy. Theory and Research in Social Education, 38(1), 6-47. https://doi.org/10.1080/00933104.2010.10473415

Endacott, J. L., \& Brooks, S. (2018). Historical empathy: Perspectives and responding to the past. In S. A. Metzger \& L. M. Harris (Eds.), The Wiley International Handbook of History Teaching and Learning (pp. 203-226). New York: Wiley-Blackwell.

Endacott, J. L., \& Sturtz, J. (2015). Historical empathy and pedagogical reasoning. The Journal of Social Studies Research, 39(1), 1-16. https://doi.org/10.1016/j.jssr.2014.05.003

Enright, P. (2014a). Historical significance: Shaping the past to explain and analyse. In M. Davison, P. Enright, \& M. Sheehan (Eds.), History Matters 2: A handbook for teaching and learning how to think historically (pp. 76-98). Wellington: NZCER Press.

Enright, P. (2014b). Perspective: Exploring historical viewpoints to develop a broader view. In M. Davison, P. Enright, \& M. Sheehan (Eds.), History Matters 2: A handbook for teaching and learning how to think historically (pp. 42-75). Wellington: NZCER Press.

Ercikan, K., \& Seixas, P. (2015). Issues in designing assessments of historical thinking. Theory into Practice, 54(3), 255-262. https://doi.org/10.1080/00405841.2015.1044375

Farawita, F. (2018). Degradasi ekologi dan kapitalisme revolusi hijau dalam buku teks sejarah SMA. Historia: Jurnal Pendidik Dan Peneliti Sejarah, 1(2), 7782. https://doi.org/10.17509/historia.v1i2.10705

Farrow, R. (2017). Open education and critical pedagogy. Learning, Media and Technology, 42(2), 130-146. https://doi.org/10.1080/17439884.2016.1113991

Federspiel, M. (2004). Focus on the questions in high school. In S. H. Veccia (Ed.), Uncovering our history: Teaching with primary sources (pp. 101112). Chicago: American Library Association.

Ferguson, L. E., Bråten, I., \& Strømsø, H. I. (2012). Epistemic cognition when students read multiple documents containing conflicting scientific evidence: A think-aloud study. Learning and Instruction, 22(2), 103-120. https://doi.org/10.1016/j.learninstruc.2011.08.002

Ford, D. R. (2014). A critical pedagogy of ineffability: Identity, education and the secret life of whatever. Educational Philosophy and Theory, 46(4), 380-392. https://doi.org/10.1080/00131857.2013.779218

Foster, R. (2013). The more things change, the more they stay the same: Developing students' thinking about change and continuity. Teaching 
History, 151, 8-17. Retrieved from https://www.jstor.org/stable/43260898

Foster, S. J. (2001). Historical empathy in theory and practice: Some final thoughts. In O. L. Davies, E. A. Yeager, \& S. J. Foster (Eds.), Historical empathy and perspective taking in the social studies (pp. 167-181). Lanham: Rowman \& Littlefield Publishers.

Foster, S. J., Morris, J. W., \& Davis, O. L. (1996). Prospects for teaching historical analysis and interpretation: National curriculum standards for history meet current history textbooks. Journal of Curriculum and Supervision, 11(4), 367-385. Retrieved from https://eric.ed.gov/?id=EJ529277

Fránquiz, M. E., \& Salinas, C. (2011). Newcomers developing English literacy through historical thinking and digitized primary sources. Journal of Second Language Writing, 20(3), 196-210. https://doi.org/10.1016/j.jslw.2011.05.004

Freebersyser, W. L. (2015). A narrative of a teacher's awakening of consciousness: Learning to become an effective witness (Doctoral dissertation, University of Missoury, St. Louis, USA). Retrieved from https://irl.umsl.edu/dissertation/184/

Freire, P. (1998). Cultural action and conscientization. Harvard Educational Review, 68(4), 499-521.

Freire, P. (2000). Pedagogy of the heart. New York: Continuum.

Freire, P. (2001). Pedagogy of freedom: Ethics, democracy, and civic courage. Lanham: Rowman \& Littlefield Publishers.

Freire, P. (2005a). Education for critical consciousness. London: Continuum.

Freire, P. (2005b). Pedagogy of the oppressed. New York: Continuum.

Freire, P., \& Macedo, D. (2005). Literacy: Reading the word and the world. London: Taylor \& Francis Group.

Friedman, D. A. (2012). How to collect and analyse qualitative data. In A. Mackey \& S. M. Gass (Eds.), Research methods in second language acquisition: A practical guide (pp. 180-200). West Sussex: WileyBlackwell.

Gentina, E., Tang, T. L.-P., \& Dancoine, P.-F. (2018). Does Gen Z's emotional intelligence promote iCheating (cheating with iPhone) yet curb iCheating through reduced nomophobia? Computer \& Education, 126, 231-247. https://doi.org/10.1016/j.compedu.2018.07.011

Gil-Glazer, Y. (2015). Photography, critical pedagogy and 'difficult knowledge.' International Journal of Education Through Art, 11(2), 261-276. https://doi.org/10.1386/eta.11.2.261_1

Goldie, J. G. S. (2016). Connectivism: A knowledge learning theory for the digital age? Medical Teacher, 38(10), 1064-1069. https://doi.org/10.3109/0142159X.2016.1173661

Gonggong, A. (2008). Revitalisasi pendidikan yang berbasis nasionalisme: Posisi khas sejarah membangsa Indonesia. Khasanah Pendidikan: Jurnal Ilmiah Kependidikan, 1(1), 1-15. https://doi.org/10.30595/jkp.v1i1.633

Grant, C., \& Osanloo, A. (2014). Understanding, selecting, and integrating a theoretical framework in dissertation research: Creating the blueprint for your "house." Administrative Issues Journal: Connecting Education, Practice, and Research, 4(2), 12-26. https://doi.org/10.5929/2014.4.2.9 
Guba, E. (1981). Criteria for assessing the trustworthiness of naturalistic inquiries. ERIC/ECTJ Annual Review Paper, 29(2), 75-91.

Hammond, M., \& Wellington, J. (2013). Research methods: The key concepts. London: Routledge Taylor \& Francis Group.

Handayani, S., Basri, M., \& Ekwandari, Y. S. (2018). Implementasi Kurikulum 2013 Perubahan pada mata pelajaran sejarah di SMA Negeri 1 Seputih Raman. Pesagih: Jurnal Pendidikan Dan Penelitian Sejarah, 6(4), 1-12.

Haniah, A. R., \& Rokhman, M. N. (2017). Pelaksanaan pembelajaran sejarah dengan Kurikulum 2013 di SMA Negeri 2 Wates DIY. Risalah, 4(4), 625644.

Harada, T. (2012). New directions for reconstructing history education: History curriculum which does not teach history. The Journal of Social Studies Education, 1(1), 1-9. Retrieved from https://journal.unesa.ac.id/index.php/jsse/article/view/2645/1745

Harcourt, M., Fountain, G., \& Sheehan, M. (2011). Historical significance and sites of memory. Set: Research Information for Teachers, 2, 26-31. Retrieved from https://www.nzcer.org.nz/system/files/set2011_2_026.pdf

Hasan, S. H. (2010). The development of historical thinking and skills in the teaching history in the senior secondary curriculum in Indonesia. Historia: International Journal of History Education, 11(2), 1-23. https://doi.org/10.17509/historia.v11i2.12324

Hasan, S. H. (2011). History education as an educational medium to embody the spirit of nationality. Historia: International Journal of History Education, 12(1), 55-66. https://doi.org/10.17509/historia.v12i1.12117

Hasan, S. H. (2013). History education in Curricuulum 2013: A new approach to teaching history. Historia: International Journal of History Education, 14(1), 163-178. https://doi.org/10.17509/historia.v14i1.2023

Hasan, S. H. (2019). Pendidikan sejarah untuk kehidupan abad ke 21. Historia: Jurnal Pendidik Dan Peneliti Sejarah, 2(2), 61-72. https://doi.org/10.17509/historia.v2i2.16630

Henríquez, R., \& Ruiz, M. (2014). Chilean students learn to think historically: Construction of historical causation through the use of evidence in writing. Linguistics and Education, 25, 145-157. https://doi.org/10.1016/j.linged.2013.10.003

Hofer, B. K., \& Pintrich, P. R. (1997). The development of epistemological theories: Beliefs about knowledge and knowing and their relation to learning. Review of Educational Research, 67(1), 88-140. https://doi.org/10.2307/1170620

Horton, M., \& Freire, P. (1990). We make the road by walking: Conversations on education and social change. Philadelphia: Temple University Press.

Hover, S. van, Hicks, D., \& Dack, H. (2016). From source to evidence? Teachers' use of historical sources in their classroms. The Social Studies, 107(6), 209217. https://doi.org/10.1080/00377996.2016.1214903

Hussey, M. (2011). Teaching with online primary sources: Documents from the national archives: DocsTeach.gov from the national archives. Teaching History: A Journal of Methods, 36(1), 34-38. Retrieved from https://go.gale.com/ps/i.do?\&id=GALE\%7CA253626011\&v=2.1\&u=vuw\&i $\mathrm{t}=\mathrm{r} \& \mathrm{p}=\mathrm{ITOF} \& \mathrm{sw}=\mathrm{w}$ 
Imenda, S. (2014). Is there a conceptual difference between theoretical and conceptual frameworks? Journal of Social Sciences, 38(2), 185-195. https://doi.org/10.1080/09718923.2014.11893249

Irani, P. R., Habibah, W. N., Gladys, I., Eldiansyah, I., Soepeno, B., \& Puji, R. P. N. (2018). Problematik kompetensi guru mata pelajaran sejarah Indonesia di SMKN 1 Jember. Jurnal Pendidikan Sejarah Indonesia, 1(2), 202-213.

Jay, L., \& Reisman, A. (2019). Teaching change and continuity with historical analogies. Social Studies Research and Practice, 14(1), 98-104. https://doi.org/10.1108/SSRP-03-2019-0020

Jensen, J. (2008). Developing historical empathy through debate: An action research study. Social Studies Research and Practice, 3(1), 55-67. Retrieved from http://www.socstrpr.org/files/Vol 3/Issue 1 - Spring, 2008/Action Research/3.1.4.pdf

Johnson, R. B., \& Christensen, L. (2014). Educational research: Quantitative, qualitative, and mixed approaches (5th ed.). Los Angeles: Sage Publications.

Johnston, M., Hipkins, R., \& Sheehan, M. (2017). Building epistemic thinking through disciplinary inquiry: Contrasting lessons from history and biology. Curriculum Matters, 13, 80-101. https://doi.org/10.18296/cm.0020

Johnston, M., \& Sheehan, M. (2016). Historical thinking and the "boy friendly" curriculum. Assessment Matters, 10, 74-99. https://doi.org/http://dx.doi.org/10.18296/am.0018

Jones, K. M. L., \& Farrington, P.-A. (2013). Learning from libraries that use WordPress: Content-management system best practices and case studies. Chicago: American Library Association.

Karaj, D. (2017). The relationship between the teaching of history and critical thinking. European Journal of Economics, Law, and Social Sciences, 1(1), 106-110.

Karchmer, R. A. (2004). Issues in technology. Reading \& Writing Quarterly, 20(3), 331-335. https://doi.org/10.1080/10573560490446330

Kartodirdjo, S. (2011). Metode penggunaan bahan dokumen. Jurnal Sejarah Indonesia, 3(1), 1-8.

Kaufmann, J. J. (2010). The practice of dialogue in critical pedagogy. Adult Education Quarterly, 60(5), 456-476. https://doi.org/10.1177/0741713610363021

Keating, J., \& Sheldon, N. (2011). History in education: Trends and themes in history teaching. In I. Davies (Ed.), Debates in history teaching (pp. 5-17). London: Routledge.

Kincheloe, J. L. (2008). Knowledge and critical pedagogy: an Introduction. Dordrecht: Springer Netherlands.

Kincheloe, J. L., \& Steinberg, S. R. (1997). Changing multiculturalism. Philadelphia: Open University Press.

Kitson, A., Husbands, C., \& Stewards, S. (2011). Teaching and learning history 11-18: Understanding the past. Berkshire: Open University Press.

Kop, R., \& Hill, A. (2008). Connectivism: Learning theory of the future or vestige of the past? The International Review of Research in Open and Distributed Learning, 9(3), 1-13. https://doi.org/10.19173/irrodl.v9i3.523

Körber, A., \& Meyer-Hamme, J. (2015). Historical thinking, competencies, and their measurement: Challenges and approches. In K. Ercikan \& P. Seixas 
(Eds.), New directions in assessing historical thinking (pp. 89-101). New York: Routledge.

Krathwohl, D. R. (2002). A revision of Bloom's taxonomy: An overview. Theory Into Practice, 41(4), 212-218. https://doi.org/10.1207/s15430421tip4104_2

Kuhn, D., \& Weinstock, M. (2002). What is epistemological thinking and why does it matter? In B. K. Hofer \& P. R. Pintrich (Eds.), Personal epistemology: The psychology of beliefs about knowledge and knowing (pp. 121-144). New York: Routledge.

Land, R., Cousin, G., Meyer, J. H. F., \& Davies, P. (2005). Threshold concepts and troublesome knowledge (3): Implications for course design and evaluation. In C. Rust (Ed.), Improving students learning - diversity and inclusivity (pp. 53-64). Oxford: OCSLD.

Lang, J. (2016). Grounded application of connectivism in the classroom. NACTA Journal, 60(3), 347-348.

Larson, K. L. (2014). Critical pedagogy(ies) for ELT in Indonesia. TEFLIN Journal, 25(1), 122-138.

Lazer, S. (2015). A large-scale assessment of historical knowledge and reasoning. In K. Ercikan \& P. Seixas (Eds.), New directions in assessing historical thinking (pp. 145-158). New York: Routledge.

Lederman, N. G., \& Lederman, J. S. (2015). What is a theoretical framework? A practical answer. Journal of Science Teacher Education, 26(7), 593-597. https://doi.org/10.1007/s10972-015-9443-2

Lee, J. K. (2002). Digital history in the history/social studies classroom. The History Teacher, 35(4), 503-517. https://doi.org/10.2307/1512472

Lee, P. (2011). History education and historical literacy. In I. Davies (Ed.), Debates in history teaching (pp. 63-72). London: Routledge.

Lee, P. J. (2005). Putting principles into practice: Understanding history. In M. S. Donovan \& J. D. Bransford (Eds.), How students learn: History in the classroom (pp. 31-78). Washington, DC: The National Academies Press.

Lee, P., \& Shemilt, D. (2003). A scaffold, not a cage: progression and progression models in history. Teaching History, 113, 13-23. Retrieved from https://www.jstor.org/stable/43259908

Leppink, J. (2019). Statistical Methods for Experimental Research in Education and Psychology. Cham: Springer International Publishing.

Lesh, B. (2011). Making historical thinking a natural act. Historically Speaking, 12(3), 17-19. https://doi.org/10.1353/hsp.2011.0045

Leur, T. De, Boxtel, C. van, \& Wilschut, A. (2017). "I saw angry people and broken statues": Historical empathy in secondary history education. British Journal of Educational Studies, 65(3), 331-352. https://doi.org/10.1080/00071005.2017.1291902

Lévesque, S. (2008). Thinking historically: Educating students for the twenty-first century. Toronto: University of Toronto Press.

Lorenc, J., Mrozowski, K., Oniszczuk, A., Staniszewski, J., \& Starczynowska, K. (2012). How is chronological thinking tested? Edukacja: Studia, Badania, Innowacje, 125(5), 89-47.

Lourenço, O. M. (2016). Developmental stages, Piagetian stages in particular: A critical review. New Ideas in Psychology, 40, 123-137.

https://doi.org/10.1016/j.newideapsych.2015.08.002 
Mackridge, A., \& Rowe, P. (2018). A practical approach to using statistics in health research: From planning to reporting. Hoboken: John Wiley \& Sons.

Maggioni, L. (2010). Studying epistemic cognition in the history classroom: Cases of teaching and learning to think historically (Doctoral dissertation, University of Maryland, Maryland, USA). Retrieved from https://drum.lib.umd.edu/handle/1903/10797

Maggioni, L., VanSledright, B. A., \& Alexander, P. A. (2009). Walking on the borders: A measure of epistemic cognition in history. The Journal of Experimental Education, 77(3), 187-214. https://doi.org/10.3200/JEXE.77.3.187--214

Malkmus, D. (2010). "Old stuff” for new teaching method: Outreach to history faculty teaching with primary sources. Portal: Libraries and the Academy, 10(4), 413-435. https://doi.org/10.1353/pla.2010.0008

Malott, C. S. (2011). Critical pedagogy and cognition: An introduction to a postformal educational psychology. Dordrecht: Springer Netherlands.

Marchand, H. (2012). Contributions of Piagetian and post-Piagetian theories to education. Educational Research Review, 7(3), 165-176. https://doi.org/10.1016/j.edurev.2012.04.002

Mardiana, S., \& Sumiyatun. (2017). Implementasi Kurikulum 2013 dalam pembelajaran sejarah di SMA Negeri 1 Metro. Historia: Jurnal Program Studi Pendidikan Sejarah, 5(1), 45-54. https://doi.org/10.24127/hj.v5i1.732

Martell, C. C. (2013). Learning to teach history as interpretation: A longitudinal study of beginning teachers. The Journal of Social Studies Research, 37(1), 17-31. https://doi.org/10.1016/j.jssr.2012.12.001

Martin, D., \& Wineburg, S. (2008). Seeing thinking on the web. The History Teacher, 41(3), 305-319. https://doi.org/10.2307/30036914

Martin, D., Wineburg, S., Rosenzweig, R., \& Leon, S. (2008). Historicalthinkingmatters.org: Using the web to teach historical thinking. Social Education, 72(3), 140-143. Retrieved from https://eric.ed.gov/?id=EJ790351

Mascolo, M. F. (2015). Neo-Piagetian theories of cognitive development. In International Encyclopedia of the Social \& Behavioral Sciences (pp. 501510). Amsterdam: Elsevier.

Mayer, R. E. (2012). Information processing. In K. R. Harris, S. Graham, T. Urdan, C. McCormick, \& G. M. Sinatra (Eds.), APA Educational Psychology Handbook, Vol.1, Theories, Construct, and Critical Issues (pp. 85-99). Washington: American Psychologycal Association.

McAleavy, T. (1998). The use of sources in school history 1910-1998: a critical perspective. Teaching History, 91, 10-16. Retrieved from https://www.jstor.org/stable/26236917

McCullagh, D. (2017). "No documents, no history." Retrieved from RTE website: https://www.rte.ie/news/analysis-and-comment/2017/0119/846262-nodocuments-no-history/

McGowan, S. (2016). The career of threshold concepts in a large-lecture history course: An examination of uptake of disciplinary actions. In R. Land, J. H. F. Meyer, \& M. T. Flanagan (Eds.), Threshold concepts in practice (pp. 39-52). Rotterdam: Sense Publishers.

McGregor, K. E. (2008). Ketika sejarah berseragam: Membongkar ideologi 
militer dalam menyusun sejarah Indonesia. Yogyakarta.

McGrew, S., Breakstone, J., Ortega, T., Smith, M., \& Wineburg, S. (2018). Can students evaluate online sources? Learning from assessments of civic online reasoning. Theory and Research in Social Education, 46(2), 165-193. https://doi.org/10.1080/00933104.2017.1416320

McGrew, S., Ortega, T., Breakstone, J., \& Wineburg, S. (2017). The challenge that's bigger than fake news: Civic reasoning in a social media environment. American Educator, 41(3), 4-9. Retrieved from https://eric.ed.gov/?id=EJ1156387

McLaughlin, A. C., \& McGill, A. E. (2017). Explicitly teaching critical thinking skills in a history course. Science \& Education, 26(1-2), 93-105. https://doi.org/10.1007/s11191-017-9878-2

Meyer, J. H. F., \& Land, R. (2003). Threshold concepts and troublesome knowledge 1 - Linkages to ways of thinking and practising within the disciplines. In C. Rust (Ed.), Improving students learning - Theories and practice ten years on (pp. 414-424). Oxford: OCSLD.

Meyer, J. H. F., \& Land, R. (2005). Threshold concepts and troublesome knowledge (2): Epistemological considerations and a conceptual framework for teaching and learning. Higher Education, 49(3), 373-388. https://doi.org/10.1007/s10734-004-6779-5

Meyer, J. H. F., \& Land, R. (2006). Threshold concepts and troublesome knowledge: Issues of liminality. In J. H. F. Meyer \& R. Land (Eds.), Overcoming barriers to students understanding: Threshold concepts and troublesome knowledge (pp. 19-32). London: Routledge.

Miles, M. B., Huberman, A. M., \& Saldaña, J. (2014). Qualitative data analysis: A methods sourcebook (3rd ed.). Los Angeles: Sage.

Ministry of Education and Culture. (2013a). Peraturan Menteri Pendidikan dan Kebudayaan Nomor 67 Tahun 2013. Jakarta: Kementerian Pendidikan dan Kebudayaan.

Ministry of Education and Culture. (2013b). Peraturan Menteri Pendidikan dan Kebudayaan Nomor 68 Tahun 2013. Jakarta: Kementerian Pendidikan dan Kebudayaan.

Ministry of Education and Culture. (2013c). Peraturan Menteri Pendidikan dan Kebudayaan Nomor 69 Tahun 2013. Jakarta: Kementerian Pendidikan dan Kebudayaan.

Ministry of Education and Culture. (2016a). Peraturan Menteri Pendidikan dan Kebudayaan Nomor 21 Tahun 2016. Jakarta: Kementerian Pendidikan dan Kebudayaan.

Ministry of Education and Culture. (2016b). Peraturan Menteri Pendidikan dan Kebudayaan Nomor 22 Tahun 2016. Jakarta: Kementerian Pendidikan dan Kebudayaan.

Ministry of Education and Culture. (2016c). Peraturan Menteri Pendidikan dan Kebudayaan Nomor 23 Tahun 2016. Jakarta: Kementerian Pendidikan dan Kebudayaan.

Ministry of Education and Culture. (2016d). Peraturan Menteri Pendidikan dan Kebudayaan Nomor 24 Tahun 2016. Jakarta: Kementerian Pendidikan dan Kebudayaan.

Ministry of Education and Culture. (2016e). Peraturan Menteri Pendidikan dan 
Kebudayaan Nomor 8 Tahun 2016. Jakarta: Kementerian Pendidikan dan Kebudayaan.

Ministry of Education and Culture. (2016f, June). Empat perbaikan Kurikulum 2013. Jendela Pendidikan Dan Kebudayaan, 1(3), 7-6. Retrieved from https://www.kemdikbud.go.id/main/uploads/default/documents/DIKBUD_M AJALAH_edisi3.pdf

Mishra, P., Pandey, C., Singh, U., Gupta, A., Sahu, C., \& Keshri, A. (2019). Descriptive statistics and normality tests for statistical data. Annals of Cardiac Anaesthesia, 22(1), 67-72. https://doi.org/10.4103/aca.ACA_157_18

Monchinski, T. (2008). Critical pedagogy and the everyday classroom. Dordrecht: Springer Netherlands.

Montangero, J. (2015). Piaget, Jean (1896-1980). In International Encyclopedia of the Social \& Behavioral Sciences (pp. 114-119). Amsterdam: Elsevier.

Müeller, U., Carpendale, J. I. M., \& Smith, L. (2009). Introduction: Overview. In U. Müller, J. I. M. Carpendale, \& L. Smith (Eds.), The Cambridge Companion to Piaget (pp. 1-44). Cambridge: Cambridge University Press.

Mulyana, A. (2013). Nasionalisme dan militerisme: Ideologisasi historiografi buku teks pelajaran sejarah SMA. Paramita: Historical Studies Journal, 23(1), 78-87. https://doi.org/10.15294/paramita.v23i1.2498

Nichterlein, S. (1974). Historicism and historiography in Indonesia. History and Theory, 13(3), 253-272. https://doi.org/10.2307/2504778

Nokes, J. D. (2010). Observing literacy practices in history classrooms. Theory and Research in Social Education, 38(4), 515-544. https://doi.org/10.1080/00933104.2010.10473438

Nokes, J. D. (2014). Elementary students' roles and epistemic stances during document-based history lessons. Theory and Research in Social Education, 42(3), 375-413. https://doi.org/10.1080/00933104.2014.937546

Nokes, J. D., Dole, J. A., \& Hacker, D. J. (2007). Teaching high school students to use heuristics while reading historical texts. Journal of Educational Psychology, 99(3), 492-504. https://doi.org/10.1037/0022-0663.99.3.492

Noonan, E. (2013). The history textbook, born digital. Radical History Review, (117), 131-138. https://doi.org/10.1215/01636545-2210658

Norhidayat. (2018). Pemahaman sejarah lokal, kemampuan berpikir kritis, dan kemampuan berpikir kreatif dalam membina sikap patriotisme siswa. Historia: Jurnal Pendidik Dan Peneliti Sejarah, 2(1), 29-34. https://doi.org/10.17509/historia.v2i1.12569

Ong, N. T. P. (2018). Rethinking the approach to teaching causation in the history classroom. HSSE Online, 7(2), 50-58. Retrieved from https://www.hsseonline.edu.sg/journal/volume-7-issue-2-2018/rethinkingapproach-teaching-causation-history-classroom

Onwuegbuzie, A. J., \& Combs, J. P. (2010). Emergent data analysis techniques in mixed methods research: A synthesis. In A. Tashakkori \& C. Teddlie (Eds.), Handbook of mixed methods in social \& behavioral research (pp. 397-430). Thousand Oaks: Sage.

Onwuegbuzie, A. J., \& Johnson, R. B. (2006). The validity issue in mixed research. Research in the Schools, 13(1), 48-63.

Onwuegbuzie, A. J., \& Teddlie, C. (2003). A framework for analyzing data in 
mixed methods research. In A. Tashakkori \& C. Teddlie (Eds.), Handbook of mixed methods in social \& behavioral research (pp. 351-383). Thousand Oaks: Sage.

Paciotti, K. D. (2013). Cognitivism: Ways of knowing. In B. J. Irby, G. Brown, R. Lara-Alecio, \& S. Jackson (Eds.), The Handbook of Educational Theories (pp. 105-113). North Carolina: Information Age Publishing.

Palmos, F. (2011). Surabaya 1945: Sacred teritory: Revolutionary Surabaya as the birthplace of Indonesian independence (Doctoral thesis, The University of Western Australia, Perth, Australia). Retrieved from https://researchrepository.uwa.edu.au/en/publications/surabaya-1945-sacred-territoryrevolutionary-surabaya-as-the-birt

Pattiz, A. E. (2004). The idea of history teaching: Using Collingwood's idea of history to promote critical thinking in the high school history classroom. The History Teacher, 37(2), 239-249. https://doi.org/10.2307/1555655

Paz, S. D. La. (2005). Effects of historical reasoning instruction and writing strategy mastery in culturally and academically diverse middle school classrooms. Journal of Educational Psychology, 97(2), 139-156. https://doi.org/10.1037/0022-0663.97.2.139

Pennell, C., \& Sheehan, M. (2020). But what do they really think? Methodological challenges of investigating young people's perspectives of war remembrance. History Education Research Journal, 17(1), 21-36. https://doi.org/10.18546/HERJ.17.1.03

Perkins, D. (1999). The many faces of constructivism. Educational Leadership, $57(3), 6-11$.

Perkins, D. (2006). Constructivism and troublesome knowledge. In J. H. F. Meyer \& R. Land (Eds.), Overcoming barriers to students understanding:

Threshold concepts and troublesome knowledge (pp. 33-47). London: Routledge.

Perkins, D. N., \& Simmons, R. (1988). Patterns of misunderstanding: An integrative model for science, math, and programming. Review of Educational Research, 58(3), 303-326. https://doi.org/10.3102/00346543058003303

Petri, G. (2004). It's elementary! In S. H. Veccia (Ed.), Uncovering our history: Teaching with primary sources (pp. 73-87). Chicago: American Library Association.

Philpot, R. (2017). What critical pedagogy is possibly becoming and why this is not the preferred outcome. New Zealand Physical Educator, 50(1), 12-13.

Piaget, J. (1928). Judgement and reasoning in the child. New York: Harcourt, Brace and Company.

Piaget, J. (1930). The child's conception of physical causality. London: Kegan Paul, Trench, Trubnet \& Co. Ltd.

Piaget, J. (1950). The psychology of intelligence. London: Routledge \& Kegan Paul Ltd.

Piaget, J. (1952). The origins of intelligence in children. New York: International Universities Press, Inc.

Piaget, J. (1954). The construction of reality in the child. New York: Basic Books. Piaget, J. (1965). The moral judgment of the child. Glencoe: The Free Press.

Piaget, J. (1971a). Genetic epistemology. New York: The Norton Library. 
Piaget, J. (1971b). The child's conception of the world. London: Routledge \& Kegan Paul Ltd.

Piaget, J. (2001). The language and thought of the child. London: Routledge.

Piaget, J., \& Inhelder, B. (1997). The child's conception of space. New York: Routledge.

Pierce, A. (2008). Learning to think, care, and know: Primary sources in the classroom: how can we teach history students to care? Agora, 43(3), 4-8.

Pii. (2016). Mengembangkan pembelajaran dan penilaian berpikir tingkat tinggi pada mata pelajaran sejarah SMA. Sejarah Dan Budaya, 10(2), 197-208. https://doi.org/10.17977/um020v10i22016p197

Poesponegoro, M. D., \& Notosusanto, N. (2010). Sejarah Nasional Indonesia VI. Jakarta: Balai Pustaka.

Porter, B. (2006). My country. Right or wrong? History Today, 32-33. Retrieved from

http://web.a.ebscohost.com/ehost/pdfviewer/pdfviewer?vid=0\&sid=9d0c137 3-8f66-402e-8d7c-80a105e173cb\%40sdc-v-sessmgr01

Purnaman, P. N. (2015). Mengembangkan keterampilan berpikir kesejarahan siswa dalam pembelajaran sejarah melalui penggunaan biografi tokoh R.A. Lasminingrat sebagai sumber pembelajaran sejarah. Jurnal Pendidikan Ilmu Sosial, 24(1), 1-13. https://doi.org/10.17509/jpis.v24i1.1613

Purwanto, B. (2006). Gagalnya historiografi Indonesiasentris?!. Yogyakarta: Penerbit Ombak.

Rantala, J., Manninen, M., \& Berg, M. van den. (2016). Stepping into other people' shoes proves to be a difficult task for high school students: Assessing historical empathy through simulation exercise. Journal of Curriculum Studies, 48(3), 323-345. https://doi.org/10.1080/00220272.2015.1122092

Reisman, A. (2012a). Reading like a historian: A document-based history curriculum intervention in urban high schools. Cognition and Instruction, 30(1), 86-112. https://doi.org/10.1080/07370008.2011.634081

Reisman, A. (2012b). The "document-based lesson": Bringing disciplinary inquiry into high school history classrooms with adolescent struggling readers. Journal of Curriculum Studies, 44(2), 233-264. https://doi.org/10.1080/00220272.2011.591436

Reisman, A., \& Wineburg, S. (2012). "Text complexity" in the history classroom: Teaching to and beyond the common core. Social Studies Review, 51, 24-29. Retrieved from http://web.a.ebscohost.com/ehost/pdfviewer/pdfviewer?vid=0\&sid=d7eadda 2-c277-4547-ab49-205f94e41d33\%40sdc-v-sessmgr02

Rhem, J. (2013). Critical pedagogy. The National Teaching \& Learning Forum, 22(6), 1-12. https://doi.org/10.1002/ntlf.20011

Ridgway, E. (2009). Teaching with primary sources: Professional development from the Library of Congress at your fingertips. Knowledge Quest, 38(2), 60-61. Retrieved from https://go.gale.com/ps/anonymous?id=GALE\%7CA215720529\&sid=google Scholar \&v $=2.1 \& \mathrm{it}=\mathrm{r} \&$ linkaccess $=\mathrm{abs} \& \mathrm{issn}=10949046 \& \mathrm{p}=\mathrm{AONE} \& \mathrm{sw}=\mathrm{w}$

Robertson, S., Scanfeld, V., Cunningham, C., \& Dotoli, V. (2017). Throw out your histoy textbook: A case for primary source analysis. AMLE Magazine, $5,25-27$. Retrieved from 
http://www.amle.org/TabId/270/ArtMID/888/ArticleID/775/Throw-OutYour-History-Textbook.aspx

Romadhoni, A. A., \& Witir, D. W. (2019). Internalisasi nilai kearifan lokal Indonesia melalui pembelajaran sejarah untuk membangun karakter generasi muda Jaman Now. Jurnal Pendidikan Sejarah Indonesia, 2(1), 24-37.

Roni, S. M., Merga, M. K., \& Morris, J. E. (2020). Conducting quantitative research in education. Singapore: Springer.

Rose, A. (2004). Teaching concepts: Historical significance. Teaching History, 48(3), 50-53. Retrieved from

https://search.informit.com.au/documentSummary; $\mathrm{dn}=695485468818180 ;$ res $=$ IELHSS

Rouet, J.-F., Britt, M. A., Mason, R. A., \& Perfetti, C. A. (1996). Using multiple sources of evidence to reason about history. Journal of Educational Psychology, 88(3), 478-493. https://doi.org/10.1037/0022-0663.88.3.478

Ruja, I. N., \& Sukamto. (2015). Survey permasalahan implementasi Kurikulum Nasional 2013 mata pelajaran Ilmu Pengetahuan Sosial Sekolah Menengah Pertama di Jawa Timur. Sejarah Dan Budaya, 9(2), 193-199. https://doi.org/10.17977/sb.v912.5001

Sahai, H., \& Ageel, M. I. (2000). The analysis of variance: Fixed, random and mixed models. Boston, MA: Birkhäuser Boston.

Salinas, C., Bellows, M. E., \& Liaw, H. L. (2011). Preservice social studies teachers' historical thinking and digitized primary sources: What they use and why. Contemporary Issues in Technology and Teacher Education, 11(2), 184-204. Retrieved from https://eric.ed.gov/?id=EJ939037

Sardiman, A., \& Lestariningsih, A. D. (2017a). Sejarah Indonesia: Buku Guru. Jakarta: Kementerian Pendidikan dan Kebudayaan.

Sardiman, A., \& Lestariningsih, A. D. (2017b). Sejarah Indonesia: Buku Siswa Kelas XI Semester II. Jakarta: Kementerian Pendidikan dan Kebudayaan.

Sayono, J. (2013). Pembelajaran sejarah di sekolah: Dari pragmatis ke idealis. Jurnal Sejarah Dan Budaya, 7(1), 9-17. https://doi.org/10.17977/sb.v7i1.4733

Seixas, P. (1997). Mapping the terrain of historical significance. Social Education, 61(1), 22-27. Retrieved from https://eric.ed.gov/?id=EJ540240

Seixas, P. (2017). A model of historical thinking. Educational Philosophy and Theory, 49(6), 593-605. https://doi.org/10.1080/00131857.2015.1101363

Seixas, P., \& Ercikan, K. (2015). Introduction: The new shape of history assessments. In K. Ercikan \& P. Seixas (Eds.), New directions in assessing historical thinking (pp. 1-13). New York: Routledge.

Seixas, P., \& Morton, T. (2013). The big six: Historical thinking concepts. Toronto: Nelson Education.

Seng, L. K., Baildon, M., Lim, I. M., İnanç, G., \& Jaffar, J. (2014). Introduction: Controversy, history and history education in Asia. In M. Baildon, K. S. Loh, I. M. Lim, G. İnanç, \& J. Jaffar (Eds.), Controversial history education in Asian contexts (pp. 3-18). London: Routledge.

Sheehan, M. (2008). "Defending the high ground" the transformation of the discipline of history into a senior secondary school subject in the late 20th century: A New Zealand curriculum debate (Doctoral thesis, Massey University, Palmerston North, New Zealand). Retrieved from 
https://mro.massey.ac.nz/bitstream/handle/10179/728/01 front.pdf

Sheehan, M. (2013). "History as something to do not just something to learn":

Historical thinking, internal assessment and critical citizenship. New Zealand Journal of Educational Studies, 48(2), 69-83.

Sheehan, M. (2014). "A degree of latitude": Thinking historically and making holistic judgements about internally assessed NCEA course work. Set: Research Information for Teachers, 2, 18-23.

Sheehan, M. (2016). "A historically conscious future"-Indigenous perspectives on war remembrance. Public History Weekly, 15. Retrieved from https://publichistory-weekly.degruyter.com/4-201615/indigenous war_remembrance new zealand/

Sheehan, M. (2020). Historical thinking, 'difficult histories,' and Māori perspectives of the past. In C. Berg \& T. Christoe (Eds.), The Palgrave Handbook of History and Social Studies Education (pp. 497-510). Cham: Springer Nature.

Sheehan, M., \& Davison, M. (2017). "We need to remember they died for us": How young people in New Zealand make meaning of war remembrance and commemoration of the First World War. London Review of Education, 15(2), 259-271. https://doi.org/10.18546/LRE.15.2.09

Sheehan, M., \& Howson, J. (2012). Learning to think historically: Developing historical thinking through internally assessed research projects. In M. Harcourt \& M. Sheehan (Eds.), History Matters: Teaching and learning history in New Zealand secondary schools in the 21st century (pp. 105-115). Wellington: NZCER Press.

Shep, S. J. (2014). The printers' web: New tools to crack old chestnuts. In P. L. Arthur \& K. Bode (Eds.), Advancing digital humanities: Research, methods, theories (pp. 68-82). New York: Palgrave Macmillan.

Shep, S. J. (2016). Digital materiality. In S. Schreibman, R. Siemens, \& J. Unsworth (Eds.), A new companion to digital humanities (pp. 322-330). West Sussex: Wiley-Blackwell.

Shep, S. J., Lenihan, R., McKinley, D., Plummer, M., \& Dudding, M. (2017). Moving beyond the threshold: Investigating digital literacies and historical thinking in New Zealand universities. Practice and Evidence of Scholarship of Teaching and Learning in Higher Education, 12(2), 312-332.

Shor, I., \& Freire, P. (1987). A pedagogy for liberation: Dialogues on transforming education. Massachusetts: Bergin \& Garvey Publishers.

Siemens, G. (2004). Connectivism: A learning theory for the digital age. Retrieved October 15, 2019, from https://www.learningnetwork.ac.nz/shared/professionalReading/TRCONN20 11.pdf

Singleton, L. R., \& Giese, J. R. (1999). Using online primary sources with students. The Social Studies, 90(4), 148-151. https://doi.org/10.1080/00377999909602406

Slameto. (2015). Rasional dan elemen perubahan Kurikulum 2013. Scholaria: Jurnal Pendidikan Dan Kebudayaan, 5(1), 1-9. https://doi.org/10.24246/j.scholaria.2015.v5.i1.p1-9

Solehan, S. (2010). Konsepsi Panca Dharma Ki Hadjar Dewantara ditinjau dari sudut pandang pendidikan Islam. Ta'dib, 15(1), 1-30. 
Stahl, S. A., Hynd, C. R., Britton, B. K., McNish, M. M., \& Bosquet, D. (1996). What happen when students read multiple source documents in history? Reading Research Quarterly, 31(4), 430-456. https://doi.org/10.1598/RRQ.31.4.5

Staysniak, C., \& Staysniak, J. (2016). Teaching with the archives. The Catholic Library World, 87(2), 94-98. Retrieved from https://search.proquest.com/docview/1852963710/fulltextPDF/9550CE5A94 E743B9PQ/1?accountid $=14782$

Stoltz, T. (2018). Consciousness in Piaget: possibilities of understanding. Psicologia: Reflexão e Crítica, 31(1), 30. https://doi.org/10.1186/s41155018-0110-3

Suwignyo, A. (2012). The breach in the dike: Regime change and the standardization of public-primary school teacher training in Indonesia, 1893-1969 (Doctoral dissertation, Universiteit Leiden, Leiden, Netherlands). Retrieved from https://openaccess.leidenuniv.nl/handle/1887/18911

Syaikhudin, A. (2012). Konsep pemikiran pendidikan menurut Paulo Freire dan Ki Hajar Dewantoro. Cendekia: Jurnal Kependidikan Dan Kemasyarakatan, 10(1), 79-92. https://doi.org/10.21154/cendekia.v10i1.403

Tally, B., \& Goldenberg, L. B. (2005). Fostering historical thinking with digitized primary sources. Journal of Reasearch on Technology in Education, 38(1), 1-21. https://doi.org/10.1080/15391523.2005.10782447

Timmermans, J. A., \& Meyer, J. H. F. (2019). A framework for working with university teachers to create and embed 'Integrated Threshold Concept Knowledge' (ITCK) in their practice. International Journal for Academic Development, 24(4), 354-368. https://doi.org/10.1080/1360144X.2017.1388241

Towaf, S. M. (2016). The national heritage of Ki Hadjar Dewantara in Tamansiswa about culture-based education and learning. Journal of Education and Practice, 7(23), 167-176.

Tricahyono, D. (2017). Penerapan model pembelajaran resource based learning (RBL) untuk meningkatkan kemampuan berpikir historis siswa kelas XI IPA 1 SMA Negeri 1 Durenan Trenggalek (Undergraduate Thesis, Universitas Negeri Malang, Malang, Indonesia). Retrieved from http://karyailmiah.um.ac.id/index.php/sejarah/article/view/58125

Tschofen, C., \& Mackness, J. (2012). Connectivism and dimensions of individual experience. The International Review of Research in Open and Distributed Learning, 13(1), 124-143. https://doi.org/10.19173/irrodl.v13i1.1143

Tucker, V. M., Weedman, J., Bruce, C. S., \& Edwards, S. L. (2014). Learning portals: Analyzing threshold concept theory for LIS education. Journal of Education for Library and Information Science, 55(2), 150-165.

UCLA History. (2019). Historical thinking standards. Retrieved from Public History Initiative website: https://phi.history.ucla.edu/nchs/historicalthinking-standards/

Umasih. (2010). History learning in Indonesia during the New Order. Historia: International Journal of History Education, 11(2), 89-98. https://doi.org/10.17509/historia.v11i2.12332

Utami, I. W. P. (2019). Teaching historical empathy through reflective learning. Paramita: Historical Studies Journal, 29(1), 1-9. 
https://doi.org/10.15294/paramita.v29i1.11479

Valsiner, J. (2005). Participating in Piaget. Society, 42(2), 57-61. https://doi.org/10.1007/BF02687400

VanSledright, B. A. (2002a). Confronting history's interpretive paradox while teaching fifth graders to investigate the past. American Educational Research Journal, 39(4), 1089-1115. https://doi.org/10.3102/000283120390041089

VanSledright, B. A. (2002b). Fifth graders investigating history in the classroom: Results from a researcher-practitioner design experiment. The Elementary School Journal, 103(2), 131-160. https://doi.org/10.1086/499720

VanSledright, B. A. (2004). What does it mean to think historically...and how do you teach it? Social Education, 68(3), 230-233. Retrieved from https://www.socialstudies.org/publications/socialeducation/april2004/whatdoes-it-mean-to-think-historically-and-how-do-you-teach-it

VanSledright, B. A. (2011). The challenge of rethinking history education: On practices, theories, and policy. New York: Routledge.

VanSledright, B. A. (2014). Assessing historical thinking and understanding: Innovative designs for new standards. New York: Routledge.

VanSledright, B. A., \& Afflerbach, P. (2005). Assessing the status of historical sources: An exploratory study of eight US elementary students reading documents. In R. Ashby, P. Gordon, \& P. Lee (Eds.), International Review of History Education, Vol 4: Understanding History: Recent Research in History Education (pp. 1-19). London: RoutledgeFalmer.

VanSledright, B. A., \& Grant, S. G. (1994). Citizenship education and the persistent nature of classroom teaching dilemmas. Theory and Research in Social Education, 22(3), 305-339. https://doi.org/10.1080/00933104.1994.10505727

VanSledright, B. A., \& Reddy, K. (2014). Changing epistemic beliefs? An exploratory study of cognition among prospective history teacher. Revista Tempo e Argumento, 6(11), 28-68. https://doi.org/10.5965/2175180306112014028

Veccia, S. H. (2004). Uncovering our history: Teaching with primary sources. Chicago: American Library Association.

Voss-Hubbard, A. (1995). "No document-No history": Mary Ritter Beard and the early history of women's archives. The American Archivist, 58(1), 16-30. Retrieved from https://www.jstor.org/stable/40293886

Voss, J. F., \& Wiley, J. (1997). Developing understanding while writing essays in history. International Journal of Educational Research, 27(3), 255-265. https://doi.org/10.1016/S0883-0355(97)89733-9

Walker, G. (2013). A cognitive approach to threshold concepts. Higher Education, 65(2), 247-263. https://doi.org/10.1007/s10734-012-9541-4

Walsh, W. H. (1963). Historical causation. Proceeding of the Aristotelian Society, 63, 217-236. Retrieved from https://www.jstor.org/stable/pdf/4544679.pdf

Wansink, B., Akkerman, S., Zuiker, I., \& Wubbels, T. (2018). Where does teaching multiperspectivity in history education begin and end? An analysis of the uses of temporality. Theory and Research in Social Education, 46(4), 495-527. https://doi.org/10.1080/00933104.2018.1480439

Waring, S. M., \& Torrez, C. A. F. (2010). Using digital primary sources to teach historical perspective to preservice teachers. Contemporary Issues in 
Technology and Teacher Education, 10(3), 294-308. Retrieved from https://eric.ed.gov/?id=EJ912426

Wertsch, J. V. (2008). Blank spots in collective memory: A case study of Rusia. The Annals of the American Academy of Political and Social Science, 617, 68-71. https://doi.org/10.1177/0002716207312870

Widiadi, A. N. (2009). Problematika dan tantangan PESEK (pembelajaran sejarah emofif dan kontroversial). Sejarah Dan Budaya, 2(2), 81-92.

Widiadi, A. N. (2013). Pembelajaran sejarah berbasis ADITS sebagai solusi PESEK (pembelajaran sejarah emotif dan kontroversial). In A. N. Widiadi, Wahyudi, T. A. Ahmad, Aman, Y. Maryuni, D. Kumalasari, ... Zulkarnain (Eds.), Pendidikan sejarah, suatu keharusan: Reformulasi pendidikan sejarah (pp. 5-23). Yogyakarta: Universitas Negeri Yogyakarta.

Widiadi, A. N. (2019). Historical significance in Indonesian history: The position of the battle of Surabaya 1945 in Indonesian curriculum and history textbooks. In Warsono, Hartono, S. Bachri, \& A. Purnomo (Eds.), Proceedings of the 1st International Conference on Social Knowledge Sciences and Education (ICSKSE 2018) (pp. 74-81). Retrieved from https://download.atlantis-press.com/proceedings/icskse-18/125909568

Widja, I. G. (2018). Pembelajaran sejarah yang mencerdaskan: Suatu alternatif menghadapi ancaman kehidupan berbangsa berlandaskan ke-Indonesiaan. Jakarta: Krishna Abadi Publishing.

Wijayanti, D. (2018). Character education designed by Ki Hadjar Dewantara. EduHumaniora: Jurnal Pendidikan Dasar, 10(2), 85-91. https://doi.org/10.17509/eh.v10i2.10865

Wijayanti, Y. (2017). Peranan penting sejarah lokal dalam kurikulum di Sekolah Menengah Atas. Jurnal Artefak, 4(1), 53-60.

Wiley, J., \& Voss, J. F. (1996). The effects of "playing historian" on learning in history. Applied Cognitive Psychology, 10(7), 63-72. https://doi.org/10.1002/(SICI)1099-0720(199611)10:7<63::AIDACP438>3.0.CO;2-5

Wiley, J., \& Voss, J. F. (1999). Constructing arguments from multiple sources: Tasks that promote understanding and not just memory for text. Journal of Educational Psychology, 91(2), 301-311. https://doi.org/10.1037/00220663.91.2.301

Wilson, T. (1998). Conscientization. In F. C. Power, R. J. Nuzzi, D. Narvaes, D. K. Lapsley, \& T. C. Hunt (Eds.), Moral Education: A handbook, Volume 1: $A$-L. Wesport: Praeger.

Wineburg, S. (1991a). Historical problem solving: A study of the cognitive processes used in the evaluation of documentary and pictorial evidence. Journal of Educational Psychology, 83(1), 73-87. https://doi.org/10.1037/0022-0663.83.1.73

Wineburg, S. (1991b). On the reading of historical texts: Notes on the breach between school and academy. American Educational Research Journal, 28(3), 495-519. https://doi.org/10.3102/00028312028003495

Wineburg, S. (1998). An essay review of teaching and learning history in elementary schools. Teaching and Teacher Education, 14(2), 233-243. https://doi.org/10.1016/S0742-051X(98)00006-7

Wineburg, S. (2001). Historical thinking and other unnatural acts: Charting the 
future of teaching the past. Philadelphia: Temple University Press.

Wineburg, S. (2007). Unnatural and essential: The nature of historical thinking. Teaching History, 129, 6-11. Retrieved from https://www.jstor.org/stable/43259304

Wineburg, S., \& Martin, D. (2009). Tampering with history: Adapting primary sources for struggling readers. Social Education, 73(5), 212-216. Retrieved from https://eric.ed.gov/?id=EJ864071

Wineburg, S., Martin, D., \& Monte-Sano, C. (2011). Reading like a historian: Teaching literacy in middle and high school history classroom. New York: Teachers College Press.

Wineburg, S., \& Reisman, A. (2015). Disciplinary literacy in history: A toolkit for digital citizenship. Journal of Adolescent \& Adult Literacy, 58(8), 636-639. https://doi.org/10.1002/jaal.410

Wohl, J., \& Braiker, B. (2018). The ABC's of Gen Z. Advertising Age, 89(2), 20. Retrieved from https://adage.com/article/digital/abcs-gen-z/311999

Yilmaz, K. (2007). Historical empathy and its implications for classroom practices in schools. The History Teacher, 40(3), 331-337. https://doi.org/10.2307/30036827

Yogev, E. (2013). On the need to strengthen political-critical thinking in history education. International Review of Education, 59(5), 627-645. https://doi.org/10.1007/s11159-013-9360-6

Yusuf, M., Taylor, P. C., \& Damanhuri, M. I. M. (2017). Designing critical pedagogy to counteract the hegemonic culture of the traditional chemistry classroom. Issues in Educational Research, 27(1), 168-184. 
This page is intentionally left blank. 


\section{APPENDICES}

\section{Appendix A: Victoria University of Wellington, Human Ethics Committee, Ethics Approval}

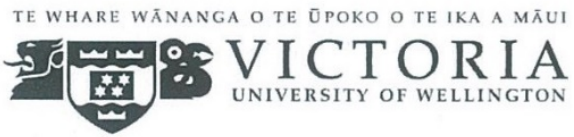

MEMORANDUM

$$
\text { Phone } \quad 0-4-4636028
$$

Email

@vuw.ac.nz

\begin{tabular}{|c|c|}
\hline TO & Aditya Widiadi \\
\hline FROM & Dr Judith Loveridge, Convenor, Human Ethics Committee \\
\hline DATE & 31 July 2018 \\
\hline PAGES & 1 \\
\hline SUBJECT & $\begin{array}{l}\text { Ethics Approval: } 26218 \\
\text { Analysing Documents and Interpreting Textbooks: Students } \\
\text { Historical Thinking Skills in Learning the Battle of Surabaya }\end{array}$ \\
\hline
\end{tabular}

Thank you for your application for ethical approval, which has now been considered by the Human Ethics Committee.

Your application has been approved from the above date and this approval is valid for three years. If your data collection is not completed by this date you should apply to the Human Ethics Committee for an extension to this approval.

Best wishes with the research.

Kind regards

Judith Loveridge

Convenor, Victoria University Human Ethics Committee 


\section{Appendix B: Information sheet for school headmasters}

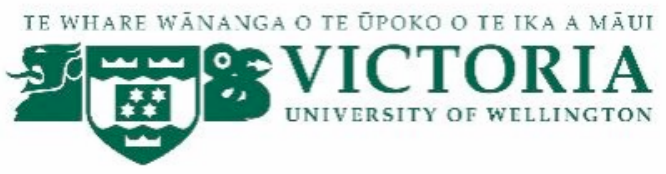

\section{Analysing Documents and Interpreting Textbooks: Students Historical Thinking Skills in Learning the Battle of Surabaya INFORMATION SHEET FOR SCHOOL HEADMASTERS}

Your school is invited to take part in this research. Please read this information before deciding whether or not to take part. If you decide to participate, thank you. If you decide not to participate, thank you for considering this request.

\section{Who am I?}

My name is Aditya Nugroho Widiadi and I am a doctoral student in Education at Victoria University of Wellington, New Zealand. This research project is work towards my dissertation.

\section{What is the aim of the project?}

This research project intends to shed light on how does teaching history through analysing historical documents and interpreting textbooks contribute to students' historical thinking skills in learning the battle of Surabaya. This research also will try to find out what are the challenges and opportunities for conducting teaching history through analysing documents and interpreting textbooks by using digital history to foster students' historical thinking skills in Indonesia when learning the battle of Surabaya in 1945.

This research has been approved by the Victoria University of Wellington Human Ethics Committee (no. 26218).

\section{How can you help?}

Your school has been invited to participate because the availability of internet and computer facilities in your school to support the use of website to access the learning resources. Your school also has history teachers who have digital literacy and a passion to implement learning innovation in their classroom. 
If you are happy for me to process with this research in your school, a history teacher and students from Grade XI in two classroom (approximately 60 students) will be invited to be involved into this research. One classroom will be the experimental group and one classroom as control group. Teacher or students do not have to be part of my research and their participation will be voluntary.

For the experimental group, the teacher will be invited to conduct teaching history using learning resources in the form of documents (archives, official letters, testimonies, and newspapers) and history textbooks. Meanwhile, for the control group will only use history textbooks as the main learning resources. The teachinglearning activities will be held for four meetings and will be observed for each meeting. At the next stage, the teacher will be invited to participate in an individual interview and see how their response to the challenges and opportunities in their teaching activities. These interviews would take place at school and will be conducted during normal school hours and will last approximately one hour.

The students learning activities will be observed during the teaching-learning process in the classroom. At the next stage, I will also invite some students to participate in a focus group interview and see how their responses to the learning process that has taken place. I will make sure that students are comfortable during these focus group to talk about their historical thinking and will last approximately forty-five minutes.

\section{What will happen to the information that your teacher and students give?}

This research is confidential. This means that the researcher named below will be aware of school identity but the research data will be combined and your school identity will not be revealed in any reports, presentations, or public documentation. The names of teacher and all students will remain confidential to the researcher, and they will be given pseudonyms in any publications or public dissemination of data.

All data collected will be stored in a locked filing cabinet and all electronic information will be password protected. All data will be destroyed five years after completion of the research.

\section{What will the project produce?}

The information from my research will be used in my $\mathrm{PhD}$ dissertation that will be available through Victoria University of Wellington library and will be submitted for publication in academic journals and conferences. 


\section{If you accept this invitation, what are your rights as a school headmaster?}

You do not have to accept this invitation if you don't want to. If you do decide that your school is willing to participate, you have the right to:

- ask any questions about the study at any time;

- be able to read any reports of this research by emailing the researcher to request a copy.

If you have any questions or problems, who can you contact?

If you have any questions, either now or in the future, please feel free to contact me or my supervisors:

\section{Student:}

Name: Aditya Nugroho Widiadi

$\mathrm{PhD}$ student of School of Education

Faculty of Education

Victoria University of Wellington

email address: aditya.widiadi@vuw.ac.nz

\section{Supervisor:}

Name: Dr Mark Sheehan

Role: Primary Supervisor

Email:

@vuw.ac.nz
Supervisor:

Name: Dr Sydney J. Shep

Role: Secondary Supervisor

Email:

\section{Human Ethics Committee information}

If you have any concerns about the ethical conduct of the research you may contact the Victoria University HEC Convenor: Dr Judith Loveridge. Email hec@vuw.ac.nz or telephone +64-4-463 6028. 


\section{Appendix C: Consent form for school headmasters}

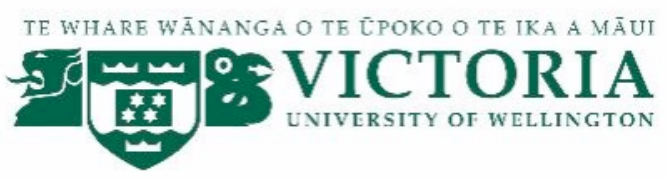

\section{Analysing Documents and Interpreting Textbooks: Students Historical Thinking Skills in Learning the Battle of Surabaya \\ CONSENT TO PARTICIPATION IN RESEARCH: SCHOOL HEADMASTERS}

This consent form will be held for five years.

Researcher: Aditya Nugroho Widiadi, School of Education, Faculty of Education, Victoria University of Wellington.

- I have read the Information Sheet and the project has been explained to me. My questions have been answered to my satisfaction. I understand that I can ask further questions at any time.

- I agree that my school takes part in this research.

understand that:

- $\quad$ [Name of school] will not be named in research publications.

- Any information will be kept confidential to the researcher and the supervisors.

- Names of teacher and students will be altered so they are not identifiable and that teacher will have a chance to give input on this process.

- I give consent for Aditya Nugroho Widiadi to invite a teacher and students in one classroom to participate in his research project.

- I understand that the results will be used for a $\mathrm{PhD}$ dissertation, academic publication, and conferences.

- I would like to receive feedback on the findings of this research.

Signature of headmaster:

Name of headmaster:

Date:

School:

Contact details: 


\title{
Appendix D: Information sheet for teacher participants
}

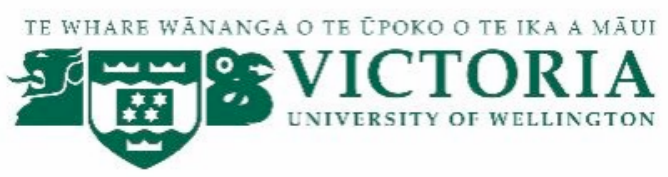

\author{
Analysing Documents and Interpreting Textbooks: \\ Students Historical Thinking Skills in Learning the Battle of Surabaya
}

\section{INFORMATION SHEET FOR TEACHERS}

You are invited to take part in this research. Please read this information before deciding whether or not to take part. If you decide to participate, thank you. If you decide not to participate, thank you for considering this request.

\section{Who am I?}

My name is Aditya Nugroho Widiadi and I am a doctoral student in Education at Victoria University of Wellington, New Zealand. This research project is work towards my dissertation.

\section{What is the aim of the project?}

This research project intends to shed light on how does teaching history through analysing historical documents and interpreting textbooks contribute to students' historical thinking skills in learning the battle of Surabaya. This research also will try to find out what are the challenges and opportunities for conducting teaching history through analysing documents and interpreting textbooks by using digital history to foster students' historical thinking skills in Indonesia when learning the battle of Surabaya in 1945.

This research has been approved by the Victoria University of Wellington Human Ethics Committee (no. 26218).

\section{How can you help?}

You have been invited to participate because you have digital literacy and a passion to implement learning innovation in your classroom. 
If you agree to take part in my research, I will ask you to teach history through analysing documents and interpreting textbooks in one of your history classroom. I will ask you to conduct teaching history using learning resources in the form of documents (archives, official letters, testimonies, and newspapers) and history textbooks. I have prepared all the necessary lesson plans and learning materials, and you just need to follow the instructions given for you to use in teaching history of Indonesia in your classroom. I also will ask you to teach another one of your history classroom using history textbooks as the main learning resources, without analysing historical documents. The teaching-learning process for each group will take four meeting and will take time about ninety minutes for each meeting. Your students in both classrooms will be asked to do the same task in the form of writing interpretive essay.

During the teaching-learning process, I will observe your classroom. I will audio and video record the teaching-learning process with your permission. The observation process will focus on students' historical thinking skills when learning the battle of Surabaya.

After the four teaching-learning stage, I will interview you about the challenges and opportunities in teaching history through analysing documents and interpreting textbooks. You can choose to not answer any question or stop the interview at any time, without giving a reason. These interviews would take place at school and will be conducted during normal school hours and will last approximately one hour.

You can withdraw from the study by contacting me at any time before data analysis commences without providing any explanation. The information gathered from you and your classroom will be destroyed after your withdrawal, including all photograph, audio and video recordings will be deleted.

\section{What will happen to the information gathered from the observation and interview?}

This research is confidential. This means that the researcher named below will be aware of your identity but the research data will be combined and your identity will not be revealed in any reports, presentations, or public documentation.

Your name will remain confidential to the researcher, and you will be given pseudonyms in any publications or public dissemination of data. Only my supervisors and I will read the observation notes and transcript of the interview.

All data collected will be stored in a locked filing cabinet and all electronic information will be password protected. All data will be destroyed five years after completion of the research. 


\section{What will the project produce?}

The information from my research will be used in my $\mathrm{PhD}$ dissertation that will be available through Victoria University of Wellington library and will be submitted for publication in academic journals and conferences.

\section{If you accept this invitation, what are your rights as a research participant?}

You do not have to accept this invitation if you don't want to. If you do decide to participate, you have the right to:

- ask for the recorder to be turned off at any time during the classroom observation;

- choose not to answer any question in the interview;

- ask for the recorder to be turned off at any time during the interview;

- withdraw from the study before 1 December 2018

- ask any question at any time;

- receive a copy of your classroom observation notes;

- receive a copy of your interview transcript;

- be able to read any reports of this research by emailing the researcher to request a copy.

\section{If you have any questions or problems, who can you contact?}

If you have any questions, either now or in the future, please feel free to contact me or my supervisors:

\section{Student:}

Name: Aditya Nugroho Widiadi

$\mathrm{PhD}$ student of School of Education

Faculty of Education

Victoria University of Wellington

email address: aditya.widiadi@vuw.ac.nz

\section{Supervisor:}

Name: Dr Mark Sheehan

Role: Primary Supervisor

Email:

@vuw.ac.nz

\author{
Supervisor: \\ Name: Dr Sydney J. Shep \\ Role: Secondary Supervisor \\ Email:
}

\section{Human Ethics Committee information}

If you have any concerns about the ethical conduct of the research you may contact the Victoria University HEC Convenor: Dr Judith Loveridge. Email hec@vuw.ac.nz or telephone +64-4-463 6028. 


\section{Appendix E: Consent form for teacher participants}

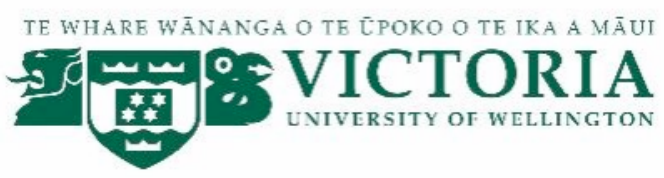

\section{Analysing Documents and Interpreting Textbooks: \\ Students Historical Thinking Skills in Learning the Battle of Surabaya \\ CONSENT TO PARTICIPATION IN RESEARCH: TEACHERS}

This consent form will be held for five years.

Researcher: Aditya Nugroho Widiadi, School of Education, Faculty of Education, Victoria University of Wellington.

- I have read the Information Sheet and the project has been explained to me. My questions have been answered to my satisfaction. I understand that I can ask further questions at any time.

- I agree to take part in this research.

understand that:

- My name will not be used in reports, nor will any information that would identify me.

- Any information I provide will be kept confidential to the researcher and the supervisors.

- I can withdraw from the project before the data analysis is commenced, which is 1 December 2018.

- All research notes and data will be destroyed five years after the conclusion of the research.

- The information I have provided will be used only by Aditya Nugroho Widiadi for a $\mathrm{PhD}$ dissertation, academic publications, and presented to conferences.

- I would like to receive a copy of the transcript of my interview.

Signature of teacher participant:

Name of teacher participant:

Date:

Contact details: 


\section{Appendix F: Information sheet for student participants}

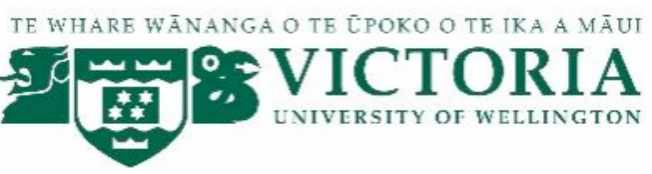

\section{Analysing Documents and Interpreting Textbooks: Students Historical Thinking Skills in Learning the Battle of Surabaya}

INFORMATION SHEET FOR STUDENTS

Hi there,

\section{Who am I?}

My name is Aditya Nugroho Widiadi and I am a doctoral student in Education at Victoria University of Wellington, New Zealand. This research project is work towards my dissertation.

\section{What is the aim of the project?}

This research project intends to shed light on how does teaching history through analysing historical documents and interpreting textbooks contribute to students' historical thinking skills in learning the battle of Surabaya. This research also will try to find out what are the challenges and opportunities for conducting teaching history through analysing documents and interpreting textbooks by using digital history to foster students' historical thinking skills in Indonesia when learning the battle of Surabaya in 1945.

This research has been approved by the Victoria University of Wellington Human Ethics Committee (no. 26218).

\section{How can you help?}

You have been invited to participate in this project because your class has been chosen as a place of research. However, you have the right not to take part in the research. If you decide to participate, thank you. If you decide not to participate, thank you for considering this request.

[For experimental group:] If you agree to take part, I will observe the teachinglearning process in your classroom. Your history teacher will teach the history of Indonesia subject matter through analysing documents and interpreting textbooks, and you have to use historical documents (archives, official letters, testimonies, and newspapers) and textbooks as your learning resources to learning the battle of Surabaya. The teaching-learning process will take four meeting and will take time about ninety minutes for each meeting. 
[For control group:] If you agree to take part, I will observe the teaching-learning process in your classroom. Your history teacher will teach the history of Indonesia subject matter by using history textbooks to learning the battle of Surabaya.

I will ask you to fill out a questionnaire containing your beliefs about history. You will be asked to complete this questionnaire three times, before the first meeting, after the second meeting, and then after the fourth meeting.

During the learning process, your teacher will give you assignment in the form of writing interpretive essay.

After the last teaching-learning process, I will invite some of the students in focus group interview (which consist of 5-10 students). I will talk to you (probably) and some of your friends about the learning process that has taken place in your classroom. This focus group interview will last approximately forty-five minutes.

\section{What will happen to the information you give?}

I won't share your real name with anyone else. Instead, if you choose to be involved, I will give you a 'code' name to disguise your identity and I will not name your school. Also since this will be a focus group interview, you will need to keep the responses of your friends confidential. You will get a chance to check what I have collected and analysed and have an opportunity to give me some more ideas about the research at this stage. You can choose to pull out of the research at any time before the data analysis is commenced, which is 1 December 2018. If you withdraw from the study, all your personal information and all research data related to your name will be destroyed. However, all photographs, audio, and video recordings from classroom observation and focus group interview that related to you cannot be removed and will still be used for my research, but your name and role in that activities will not be included in my research analysis and will not be published in any form.

All data collected will be stored in a locked filing cabinet and all electronic information will be password protected so other people can't get their hands on it who we didn't intend to see it.

\section{What will the project produce?}

The information from this research will be used to write up my $\mathrm{PhD}$ dissertation, academic publications, and conferences.

\section{If you have any questions or problems, who can you contact?}

Please feel free to contact me with any question that you may have regarding the research by email below:

\section{Student:}

Name: Aditya Nugroho Widiadi

PhD student of School of Education

Faculty of Education

Victoria University of Wellington

email address: aditya.widiadi@vuw.ac.nz 


\section{Supervisor:}

Name: Dr Mark Sheehan

Role: Primary Supervisor

Email:

@@vuw.ac.nz

\section{Supervisor:}

Name: Dr Sydney J. Shep

Role: Secondary Supervisor

Email:

\section{Human Ethics Committee information}

If you have any concerns about the ethical conduct of the research you may contact the Victoria University HEC Convenor: Dr Judith Loveridge. Email hec@vuw.ac.nz or telephone +64-4-463 6028. 


\section{Appendix G: Consent form for student participants}

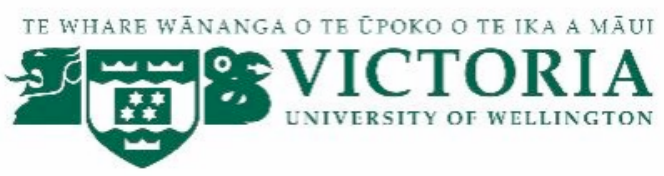

Analysing Documents and Interpreting Textbooks:

Students Historical Thinking Skills in Learning the Battle of Surabaya

\section{CONSENT TO PARTICIPATION IN RESEARCH: STUDENTS}

This consent form will be held for five years.

Researcher: Aditya Nugroho Widiadi, School of Education, Faculty of Education, Victoria University of Wellington.

- I have read the Information Sheet and the project has been explained to me. My questions have been answered to my satisfaction. I understand that I can ask further questions at any time.

- I agree to take part in this research.

understand that:

- My name will not be used in reports, nor will any information that would identify me. I will have an opportunity to choose a 'code name' or have one allocated to me by the researcher.

- Any information I provide will be kept confidential to the researcher and his supervisors.

- Any information that my friends have provided during the focus group interview I will need to keep confidential.

- I may withdraw myself (or any information I have provided) from this project (before the data analysis is commenced, which is 1 December 2018) without having to give reasons or without penalty of any sort.

- $\quad$ Name of school] will not be named in research publications;

- All research notes and data will be destroyed five years after the conclusion of the research.

- I am happy for Aditya to observe my classroom when learning history.

- I am happy for Aditya to record me talking about my experience in learning history. 
- I understand that the results will be used for a $\mathrm{PhD}$ dissertation, academic publication, and conferences.

- I would like to receive feedback on the findings of this research.

\begin{tabular}{|l|}
\hline Name: \\
\hline Signature of the student: \\
\hline $\begin{array}{l}\text { I agree that } \\
\text { son/daughter/under my guardianship, may take part in this research (If student } \\
\text { is under } 16 \text { years). } \\
\text { Signature of the parent/guardian: }\end{array}$ \\
Name of the parent/guardian:
\end{tabular}




\title{
Appendix H: Historical belief questionnaire (Indonesian version)
}

\author{
Angket Keyakinan mengenai Sejarah \\ (VanSledright, 2014)
}

Nama :

Sekolah :

Angket ini menanyakan keyakinanmu tentang sejarah. Silahkan memberikan respon berdasarkan apa yang kamu yakini mengenai sejarah, sebab tidak ada jawaban yang benar dan salah. Namamu akan dirahasiakan. Angket ini bukan bagian penilaian pembelajaran dan hanya digunakan untuk kepentingan penelitian.

Petunjuk: Silahkan membaca pernyataan dengan cermat dan berikan tanda centang $(\sqrt{ })$ pada kolom yang mencerminkan tingkat persetujuan/tidak persetujuanmu terhadap pernyataan yang diberikan.

\begin{tabular}{|c|c|c|c|c|c|}
\hline No & Pernyataan & $\begin{array}{l}\text { Sangat } \\
\text { Setuju }\end{array}$ & Setuju & $\begin{array}{l}\text { Tidak } \\
\text { Setuju }\end{array}$ & $\begin{array}{l}\text { Sangat } \\
\text { Tidak } \\
\text { Setuju }\end{array}$ \\
\hline 1 & Tidak terdapat perbedaan antara masa lalu dan sejarah & & & & \\
\hline 2 & $\begin{array}{l}\text { Fakta sejarah dapat langsung menceritakan peristiwa di masa } \\
\text { lalu, tanpa perlu diproses terlebih dahulu oleh sejarawan }\end{array}$ & & & & \\
\hline 3 & $\begin{array}{l}\text { Semua hal yang pernah terjadi di masa lalu dapat menjadi } \\
\text { bagian dari peristiwa sejarah }\end{array}$ & & & & \\
\hline 4 & $\begin{array}{l}\text { Tidak mungkin untuk mengetahui segala sesuatu tentang masa } \\
\text { lalu karena kita tidak berada pada masa itu }\end{array}$ & & & & \\
\hline 5 & $\begin{array}{l}\text { Masa lalu hanyalah apa yang ditulis menurut kehendak peneliti } \\
\text { sejarah. }\end{array}$ & & & & \\
\hline 6 & $\begin{array}{l}\text { Para peneliti sejarah memahami bahwa sejarah hanyalah } \\
\text { masalah pendapat/opini mengenai masa lalu. }\end{array}$ & & & & \\
\hline 7 & $\begin{array}{l}\text { Karena kita tidak dapat memahami dengan pasti apa yang } \\
\text { terjadi di masa lalu, maka kita boleh meyakini apapun tentang } \\
\text { masa lalu semau kita. }\end{array}$ & & & & \\
\hline 8 & $\begin{array}{l}\text { Klaim sejarah mengenai peristiwa di masa lalu tidak dapat } \\
\text { dipastikan kebenarannya, karena hal itu hanyalah masalah } \\
\text { penafsiran terhadap masa lalu. }\end{array}$ & & & & \\
\hline 9 & $\begin{array}{l}\text { Membandingkan sumber sejarah dan memahami perspektif } \\
\text { penulis sumber sejarah adalah komponen penting dalam proses } \\
\text { meneliti masa lalu }\end{array}$ & & & & \\
\hline 10 & Sejarah adalah penyelidikan kritis terhadap masa lalu & & & & \\
\hline 11 & $\begin{array}{l}\text { Interpretasi yang masuk akal mengenai masa lalu dapat } \\
\text { dibangun meskipun dihadapkan pada bukti yang saling } \\
\text { bertentangan }\end{array}$ & & & & \\
\hline 12 & $\begin{array}{l}\text { Sejarah adalah rekonstruksi peristiwa di masa lalu secara masuk } \\
\text { akal berdasarkan bukti yang tersedia }\end{array}$ & & & & \\
\hline
\end{tabular}




\title{
Appendix I: Writing interpretive essay tasks
}

\author{
TUGAS MENULIS ESAI INTERPRETATIF \\ Pre Test
}

\section{Petunjuk:}

Tulislah sebuah esai interpretatif yang tersusun dengan baik, yang mencakup bagian pendahuluan, beberapa paragraf dan kesimpulan. Kamu harus menegaskan posisi penafsiranmu dalam menjawab pertanyaan-pertanyaan historis yang utama (central historical questions). Kamu harus menggunakan dan merujuk secara langsung kepada sumber-sumber sejarah yang spesifik (lebih dari satu) dalam membangun argumen dalam interpretasimu. Dukunglah penafsiranmu dengan fakta, contoh, dan detail yang relevan dari sumber-sumber yang kamu gunakan. Kamu boleh menggunakan informasi tambahan diluar buku teks dengan cara mengutip dan merujuk sumber tersebut dengan benar.

\section{Konteks Sejarah:}

Setelah proklamasi kemerdekaan Indonesia, muncul ancaman akan kembalinya penjajah Belanda yang datang bersama tentara Sekutu. Sehingga terjadilah pertempuran di berbagai daerah di Indonesia, seperti Pertempuran Surabaya, Pertempuran Lima Hari di Semarang, Pertempuran Ambarawa, Peristiwa Bandung Lautan Api, Pertempuran Medan Area dan lain sebagainya. Dari berbagai pertempuran yang terjadi pada periode 1945-1949, pertempuran Surabaya diperingati sebagai hari pahlawan di Indonesia setiap tanggal 10 November.

\section{Pertanyaan-pertanyaan Sejarah yang Utama (Central Historical Questions):}

Gunakanlah informasi dari dokumen sejarah dan buku teksmu, lalu tulislah sebuah esai yang mana kamu harus menafsirkan jawaban dari pertanyaan berikut ini:

\section{Central questions:}

- Apakah bangsa Indonesia memenangkan pertempuran Surabaya?

Sub-questions:

- Bagaimana pertempuran tersebut terjadi (kronologinya)?

- Mengapa tanggal 10 November diperingati sebagai Hari Pahlawan di Indonesia?

- Dengan terjadinya peristiwa pertempuran Surabaya, apakah terdapat perubahan dan/atau kesinambungan dalam strategi dan bentuk perjuangan bangsa Indonesia dalam upaya mempertahankan kemerdekaan dari ancaman Sekutu dan Belanda?

\section{Petunjuk:}

Dalam menulis esai interpretatif, pastikan kamu memperhatikan aspek berikut:

- Kembangkan semua aspek dalam tugas untuk menjawab pertanyaan utama

- Tegaskan dengan jelas posisi interpretasimu.

- Kembangkan berbagai argumen untuk mendukung interpretasimu

- Rujuklah secara langsung kepada sumber yang spesifik (lebih dari satu)

- Bandingkan dan kontraskan berbagai perspektif dalam sumber untuk membangun interpretasimu

- Kamu harus mengevaluasi berbagai sumber yang kamu gunakan untuk membangun interpretasimu.

- Kamu harus memahami dan menyadari konteks sejarah saat peristiwa terjadi

- Batas kata: 1000 kata (maksimal) 


\section{TUGAS MENULIS ESAI INTERPRETATIF \\ Tugas Kelompok \#1}

\section{Petunjuk:}

Tulislah sebuah esai interpretatif yang tersusun dengan baik, yang mencakup bagian pendahuluan, beberapa paragraf dan kesimpulan. Kamu harus menegaskan posisi penafsiranmu dalam menjawab pertanyaan-pertanyaan historis yang utama (central historical questions). Kamu harus menggunakan dan merujuk secara langsung kepada sumber-sumber sejarah yang spesifik (lebih dari satu) dalam membangun argumen dalam interpretasimu. Dukunglah penafsiranmu dengan fakta, contoh, dan detail yang relevan dari sumber-sumber yang kamu gunakan. Kamu boleh menggunakan informasi tambahan diluar buku teks tersedia dengan cara mengutip dan merujuk sumber tersebut dengan benar.

\section{Konteks Sejarah:}

Pada tanggal 19 September 1945, sekelompok orang Belanda bekas interniran perang yang didukung oleh anggota RAPWI (Recovery of Allied Prisoners of Wars and Internees) mengibarkan bendera tiga warna di luar Hotel Yamato (sebelumnya bernama Hotel Oranje, sekarang bernama Hotel Majapahit) di Jalan Tunjungan, Surabaya, Jawa Timur. Hal itu memprovokasi kelompok pemuda, kerumunan rakyat dan milisi nasionalis bangsa Indonesia untuk menyerbu orang-orang Belanda, dan kemudian merobek warna biru dari bendera tiga warna, lantas mengubahnya menjadi bendera Indonesia yang berwarna merah dan putih.

Pertanyaan-pertanyaan Sejarah yang Utama (Central Historical Questions):

Gunakanlah informasi dari dokumen sejarah dan buku teksmu, lalu tulislah sebuah esai yang mana kamu harus menafsirkan jawaban dari pertanyaan berikut ini:

Central questions:

- Siapa sebenarnya yang merobek bendera Belanda dalam peristiwa Insiden Bendera di Hotel Yamato?

\section{Sub-questions:}

- Bagaimana peristiwa itu terjadi (kronologi Insiden Bendera)?

- Apa penyebab tewasnya Mr. Ploegman?

- Dengan terjadinya peristiwa Insiden Bendera, apakah terdapat perubahan dan/atau kesinambungan dalam strategi dan bentuk perjuangan bangsa Indonesia dalam upaya mempertahankan kemerdekaan dari ancaman Sekutu dan Belanda?

\section{Petunjuk:}

Dalam menulis esai interpretatif, pastikan kamu memperhatikan aspek berikut:

- Kembangkan semua aspek dalam tugas untuk menjawab pertanyaan utama

- Tegaskan dengan jelas posisi interpretasimu.

- Kembangkan berbagai argumen untuk mendukung interpretasimu

- Rujuklah secara langsung kepada sumber yang spesifik (lebih dari satu)

- Bandingkan dan kontraskan berbagai perspektif dalam sumber untuk membangun interpretasimu

- Kamu harus mengevaluasi berbagai sumber yang kamu gunakan untuk membangun interpretasimu.

- Kamu harus memahami dan menyadari konteks sejarah saat peristiwa terjadi

- Batas kata: 1000 kata (maksimal) 


\section{TUGAS MENULIS ESAI INTERPRETATIF \\ Tugas Kelompok \#2}

\section{Petunjuk:}

Tulislah sebuah esai interpretatif yang tersusun dengan baik, yang mencakup bagian pendahuluan, beberapa paragraf dan kesimpulan. Kamu harus menegaskan posisi penafsiranmu dalam menjawab pertanyaan-pertanyaan historis yang utama (central historical questions). Kamu harus menggunakan dan merujuk secara langsung kepada sumber-sumber sejarah yang spesifik (lebih dari satu) dalam membangun argumen dalam interpretasimu. Dukunglah penafsiranmu dengan fakta, contoh, dan detail yang relevan dari sumber-sumber yang kamu gunakan. Kamu boleh menggunakan informasi tambahan diluar buku teks dengan cara mengutip dan merujuk sumber tersebut dengan benar.

\section{Konteks Sejarah:}

Pada tanggal 26 Oktober 1945, Brigadier Mallaby membuat kesepakatan dengan Pak Suryo, Gubernur Jawa Timur Republik Indonesia, bahwa pasukan Inggris tidak akan meminta pasukan dan milisi Indonesia untuk menyerahkan senjata mereka, dan hanya akan bertugas mengamankan tawanan tentara Jepang dan mengurus Bangsa Eropa bekas tawanan Jepang. Akan tetapi pada tanggal 27 Oktober 1945, sebuah pesawat Inggris dari Jakarta menjatuhkan selebaran di wilayah Surabaya mendesak semua pasukan dan milisi Indonesia untuk menyerahkan senjata yang mereka miliki. Pemimpin pasukan dan milisi bangsa Indonesia marah, melihat hal ini sebagai pelanggaran perjanjian yang telah disepakati sehari sebelumnya. Kemudian, terjadilah pertempuran tiga hari, yang menyebabkan pasukan Inggris hampir mengalami kekalahan. Pada tanggal 30 Oktober 1945, pihak Inggris menerbangkan Sukarno, Hatta, dan Amir Syarifudin ke Surabaya untuk menegosiasikan gencatan senjata dengan Major General Hawthorn. Pada sore hari tanggal 30 Oktober 1945, Mallaby dan anggota Kontak Biro berkeliling Surabaya untuk mengumumkan kesepakatan gencatan senjata. Mallaby ternyata tewas di depan gedung Internatio dekat Jembatan Merah Surabaya.

\section{Central Historical Question:}

Gunakanlah informasi dari dokumen sejarah dan buku teksmu, lalu tulislah sebuah esai yang mana kamu harus menafsirkan jawaban dari pertanyaan berikut ini:

\section{Central questions:}

- Siapa yang sebenarnya membunuh Mallaby?

\section{Sub-questions:}

- Bagaimana hal itu terjadi (kronologi peristiwa tewasnya Mallaby)?

- Apa penyebab tewasnya Mallaby?

- Dengan terjadinya peristiwa tewasnya Mallaby, apakah terdapat perubahan dan/atau kesinambungan dalam strategi dan bentuk perjuangan bangsa Indonesia dalam upaya mempertahankan kemerdekaan dari ancaman Sekutu dan Belanda?

\section{Petunjuk:}

Dalam menulis esai interpretatif, pastikan kamu memperhatikan aspek berikut:

- Kembangkan semua aspek dalam tugas untuk menjawab pertanyaan utama

- Tegaskan dengan jelas posisi interpretasimu.

- Kembangkan berbagai argumen untuk mendukung interpretasimu

- Rujuklah secara langsung kepada sumber yang spesifik (lebih dari satu)

- Bandingkan dan kontraskan berbagai perspektif dalam sumber untuk membangun interpretasimu

- Kamu harus mengevaluasi berbagai sumber yang kamu gunakan untuk membangun interpretasimu.

- Kamu harus memahami dan menyadari konteks sejarah saat peristiwa terjadi

- Batas kata: 1000 kata (maksimal) 


\section{Rubrik Penskoran Penilaian untuk Tugas Writing Interpretive Essay}

\begin{tabular}{|c|c|}
\hline Skor & Keterangan Pemberian Skor \\
\hline \multicolumn{2}{|r|}{$\begin{array}{l}\text { Menetapkan atau Memberi Argumentasi atas Posisi Interpretasi } \\
\text { (Establish/Argues Position of Interpretation) }\end{array}$} \\
\hline 4 & $\begin{array}{l}\text { Dengan jelas menegaskan posisi interpretasi mengenai apa yang terjadi (atau dipikirkan telah } \\
\text { terjadi), memberi argumentasi yang meyakinkan, memberi sangkalan terhadap interpretasi } \\
\text { lain yang mungkin timbul. }\end{array}$ \\
\hline 3 & $\begin{array}{l}\text { Menegaskan posisi interpretasi-akan tetapi argumentasi tidak terlalu jelas, tidak langsung, } \\
\text { ringkas, dan tidak sekuat skor } 4 \text {, memberi penolakan yang lebih lemah atas interpretasi } \\
\text { lainnya. }\end{array}$ \\
\hline 2 & $\begin{array}{l}\text { Menegaskan posisi interpretasi, didukung argumen, akan tetapi argumennya masih } \\
\text { meragukan, tidak memberi sangkalan terhadap posisi interpretasi lain meskipun } \\
\text { menggunakan kalimat kondisional (pengandaian). }\end{array}$ \\
\hline 1 & $\begin{array}{l}\text { Menegaskan posisi interpretasi, akan tetapi sedikit sekali memberi argumentasi terhadap } \\
\text { posisinya, mungkin menggunakan kalimat kondisional (pengandaian). }\end{array}$ \\
\hline 0 & Tidak menegaskan posisi interpretasi, menghindari interpretasi. \\
\hline \multicolumn{2}{|r|}{ Mengutip Bukti/Sumber (Citing Evidence) } \\
\hline 4 & $\begin{array}{l}\text { Merujuk secara langsung ke sumber yang spesifik (lebih dari satu); menyebut nama sumber } \\
\text { (misal: judul, nomor dokumen, penulis) }\end{array}$ \\
\hline 3 & $\begin{array}{l}\text { Merujuk ke sumber; tapi tidak mengutip secara konsisten dengan menyebut nama sumber } \\
\text { sebagaimana pada skor } 4\end{array}$ \\
\hline 2 & $\begin{array}{l}\text { Umumnya menyinggung sumber, tapi hanya mengambil dari satu sumber; mengabaikan } \\
\text { sumber lain yang tidak selaras dengan interpretasinya. }\end{array}$ \\
\hline 1 & Tidak menyebut sumber, meski telah menyajikan posisi interpretasi \\
\hline 0 & Tidak menyebut sumber, seolah tidak pernah baca sumber atau tanpa sumber \\
\hline \multicolumn{2}{|r|}{ Bukti yang Menguatkan (Corroboration) } \\
\hline 4 & $\begin{array}{l}\text { Membandingkan/mengkontraskan banyak sumber/perspektif yang secara langsung digunakan } \\
\text { untuk membentuk interpretasi }\end{array}$ \\
\hline 3 & $\begin{array}{l}\text { Membandingkan/mengkontraskan sumber untuk membentuk sumber, tapi tidak sekonsisten, } \\
\text { tidak sejelas, dan tidak selangsung dibanding skor } 4 \text {. }\end{array}$ \\
\hline 2 & $\begin{array}{l}\text { Memberi kiasan (tidak langsung) dalam membandingkan/mengkontraskan perspekftif, akan } \\
\text { tetapi mengabaikan beberapa sumber dan perspektif yang lain. }\end{array}$ \\
\hline 1 & $\begin{array}{l}\text { Tidak ada bukti yang menguatkan (koroborasi) karena interpretasinya yang sederhana dan } \\
\text { tidak langsung. }\end{array}$ \\
\hline 0 & $\begin{array}{l}\text { Tidak ada bukti yang menguatkan (koroborasi) seolah perspektif yang beragam dalam sumber } \\
\text { tidak pernah ada/tidak mungkin }\end{array}$ \\
\hline \multicolumn{2}{|r|}{ Menilai Status Sumber (Assessing Accoun Status) } \\
\hline 4 & $\begin{array}{l}\text { Terdapat evaluasi yang spesifik terhadap kualitas/keterpercayaan sumber dalam membangun } \\
\text { interpretasi. }\end{array}$ \\
\hline 3 & $\begin{array}{l}\text { Sesekali mengevaluasi kualitas/keterpercayaan sumber, tapi tidak secara langsung atau } \\
\text { sekonsisten skor } 4\end{array}$ \\
\hline 2 & Hanya mengevaluasi sumber yang digunakan dalam interpretasi tunggal \\
\hline 1 & Tidak ada evaluasi sumber, interpretasi yang tunggal dan searah \\
\hline 0 & $\begin{array}{l}\text { Tidak ada evaluasi sumber, seolah tidak perlu dilakukan dalam membangun kesimpulan dan } \\
\text { menghasilkan interpretasi dianggap sebagai sesuatu yang mustahil atau terlalu sulit. }\end{array}$ \\
\hline \multicolumn{2}{|r|}{ Kontekstualisasi (Contextualisation) } \\
\hline 4 & $\begin{array}{l}\text { Tetap dalam konteks sejarah, dan membuat komentar yang merefleksikan kesadaran diri } \\
\text { untuk melakukannya, tidak ada presentisme. }\end{array}$ \\
\hline 3 & Tetap dalam konteks sejarah, tidak ada presentisme \\
\hline 2 & $\begin{array}{l}\text { Menghasilkan analisis argumen yang mencampurkan perspektif masa lalu dan masa kini } \\
\text { (presentisme) }\end{array}$ \\
\hline 1 & $\begin{array}{l}\text { Hanya menggunakan perspektif kekinian (presentisme) seolah peristiwa yang dibahas baru } \\
\text { terjadi kemarin dan menggunakan standar norma kontemporer. }\end{array}$ \\
\hline 0 & Tidak ada batasan konteks sejarah karena menegakkan konteks sejarah dianggap tidak perlu. \\
\hline
\end{tabular}




\section{Writing Interpretive Essay \\ Pre-Test}

\section{Directions:}

Write a well-organized interpretive essay that includes an introduction, several paragraphs, and a conclusion. You have to assert your interpretive position to answer the central historical questions. You have to use and refer directly to specific sources (more than one) to build your argument in your interpretation. Support your interpretation with relevant facts, examples, and details from the sources that you are using. You may include additional outside information by citing and referring the sources correctly.

\section{Historical Context:}

After the proclamation of Indonesian independence, there were threats of the return of the Dutch colonialist who came with the Allied troops. So that there were battles in various regions in Indonesia, such as the Battle of Surabaya, the Five-Day Battle in Semarang, the Battle of Ambarawa, the Battle of Medan Area, and so on. Of the various battles that took place in 19451949 period, the Battle of Surabaya is commemorated as Heroes' Day in Indonesia every November 10.

\section{Central Historical Questions:}

Using information from the documents and your textbooks, write an essay in which you interpret:

\section{Central questions:}

- Did the Indonesian win the battle of Surabaya?

\section{Sub-questions:}

- How did the chronology of the battle take place?

- Why is November 10 always commemorated as Heroes' Day in Indonesia?

- With the occurrence of the battle of Surabaya, were there any changes and/or continuity in the efforts to defend independence from the threat of the Allies and the Netherlands?

\section{Guidelines:}

In your interpretive essay, be sure to:

- Develop all aspects of the tasks

- Clearly assert your interpretive position

- Provide arguments to support your interpretation

- Refer directly to specific sources (more than one)

- Compare and contrast multiple accounts/perspectives to form your interpretation

- You have to evaluate your specific sources that you are using in forming interpretation

- You have to aware of the historical context when the event occurred.

- Word limit: 1000 words maximum 


\section{Writing Interpretive Essay \\ Group Task \#1}

\section{Directions:}

Write a well-organized interpretive essay that includes an introduction, several paragraphs, and a conclusion. You have to assert your interpretive position to answer the central historical questions. You have to use and refer directly to specific sources (more than one) to build your argument in your interpretation. Support your interpretation with relevant facts, examples, and details from the sources that you are using. You may include additional outside information by citing and referring the sources correctly.

\section{Historical Context:}

On 19 September 1945, a group of Dutch ex-internees and supported by a RAPWI team raised the Dutch tricolour flag outside the Yamato Hotel (formerly Oranje Hotel, now become Majapahit hotel) in Tunjungan Street, Surabaya, East Java. This provoked nationalist Indonesian militias, youngsters, and crowds who overran the Dutch and then tore off the blue stripe from the tricolour, changing it into the red and white Indonesian flag.

\section{Central Historical Questions:}

Using information from the documents and your textbooks, write an essay in which you interpret:

\section{Central questions:}

- Who actually tore the flag in the flag incident at Yamato Hotel on 19 September 1945? How did it happen (the chronology)?

\section{Sub-questions:}

- How did the incident happen (the chronology of the flag incident)?

- How was Mr.Ploegman killed?

- With the occurrence of the flag incident, were there any changes and/or continuity in the efforts to defend independence from the threat of the Allies and the Netherlands?

\section{Guidelines:}

In your interpretive essay, be sure to:

- Develop all aspects of the tasks

- Clearly assert your interpretive position

- Provide arguments to support your interpretation

- Refer directly to specific sources (more than one)

- Compare and contrast multiple accounts/perspectives to form your interpretation

- You have to evaluate your specific sources that you are using in forming interpretation

- You have to aware of the historical context when the event occurred.

- Word limit: 1000 words maximum 


\section{WRITING INTERPRETIVE ESSAY \\ Group Task \#2}

\section{Directions:}

Write a well-organized interpretive essay that includes an introduction, several paragraphs, and a conclusion. You have to assert your interpretive position to answer the central historical questions. You have to use and refer directly to specific sources (more than one) to build your argument in your interpretation. Support your interpretation with relevant facts, examples, and details from the sources that you are using. You may include additional outside information by citing and referring the sources correctly.

\section{Historical Context:}

On 26 October 1945, Brigadier Mallaby reached an agreement with Mr. Suryo, the Republic of Indonesia's governor of East Java, that the British would not ask Indonesian troops/militia to hand over their weapons, would only secure the surrendered Japanese soldiers and would take care of European internees. But on 27 October 1945, a British plane from Jakarta dropped leaflets over Surabaya urging all Indonesian troops and militia to surrender their weapons. The leaders of the Indonesian troops and militia were angered, seeing it as breaking of the agreement reached the previous day. Then, there was a three-day battle, which led to the British army almost seeing defeated. On 30 October 1945, the British flew Sukarno, Hatta, and Amir Syarifudin into Surabaya to negotiate a ceasefire with Major General Hawthorn. On the afternoon of 30 October 1945, Mallaby and the Contact Bureau members travelled Surabaya to spread the news about the ceasefire. Mallaby was killed in the front of Internatio Building near the Jembatan Merah (Red Bridge) Surabaya.

\section{Central Historical Question:}

Using information from the documents and your textbooks, write an essay in which you interpret:

\section{Central questions:}

- Who killed Brigadier Mallaby?

Sub-questions:

- How did the incident happen (the chronology of the death of Mallaby)?

- How was Mallaby killed?

- With the occurrence of the death of Mallaby, were there any changes and/or continuity in the efforts to defend independence from the threat of the Allies and the Netherlands?

\section{Guidelines:}

In your interpretive essay, be sure to:

- Develop all aspects of the tasks

- Clearly assert your interpretive position

- Provide arguments to support your interpretation

- Refer directly to specific sources (more than one)

- Compare and contrast multiple accounts/perspectives to form your interpretation

- You have to evaluate your specific sources that you are using in forming interpretation

- You have to aware of the historical context when the event occurred.

- Word limit: 1000 words maximum 


\section{Assessment Scoring Rubrics \\ Writing Interpretive Essay}

\begin{tabular}{|c|c|}
\hline Score & Scoring notes \\
\hline \multicolumn{2}{|r|}{ Establish/Argues Position of Interpretation } \\
\hline 4 & $\begin{array}{l}\text { Clearly stakes out a position on what was occurred (or thought), argues } \\
\text { convincingly, refutes other possible interpretations }\end{array}$ \\
\hline 3 & $\begin{array}{l}\text { Stakes out position-argument not as clear, concise, direct, or as strong as } 4 \text {, } \\
\text { weaker refutation of other interpretations. }\end{array}$ \\
\hline 2 & $\begin{array}{l}\text { Takes a position, supported, but questionable argument, no refutation of other } \\
\text { positions despite use of conditional language }\end{array}$ \\
\hline 1 & $\begin{array}{l}\text { Takes a position but does little to effectively argue that position, may use some } \\
\text { conditional language }\end{array}$ \\
\hline 0 & Takes no position, avoids interpretation. \\
\hline \multicolumn{2}{|r|}{ Citing Evidence } \\
\hline 4 & $\begin{array}{l}\text { Refers directly to specific accounts (more than one); mentions by name (e.g., } \\
\text { title, document number, author) }\end{array}$ \\
\hline 3 & Refers to accounts; does not cite consistently by name of frequency (as in a 4) \\
\hline 2 & $\begin{array}{l}\text { Generally alludes to evidence, but draws from only one account; ignores } \\
\text { accounts not aligned to interpretation }\end{array}$ \\
\hline 1 & No mention of evidence despite offering an interpretation \\
\hline 0 & No mention of evidence as thought accounts were not read/did not exist \\
\hline \multicolumn{2}{|r|}{ Corroboration } \\
\hline 4 & Compares/contrast multiple accounts/perspectives directly to form interpretation \\
\hline 3 & $\begin{array}{l}\text { Compares/contrast account to form interpretation but not as consistently, clearly, } \\
\text { or directly as a } 4\end{array}$ \\
\hline 2 & $\begin{array}{l}\text { Allusions (indirect) to comparing/contrasting perspectives, but ignores some } \\
\text { accounts or perspectives }\end{array}$ \\
\hline 1 & No evidence of corroboration because of unidirectional, simplistic interpretation \\
\hline 0 & $\begin{array}{l}\text { No evidence of corroboration as though multiple perspectives in accounts did not } \\
\text { exist/not possible }\end{array}$ \\
\hline \multicolumn{2}{|r|}{ Assessing Account Status } \\
\hline 4 & $\begin{array}{l}\text { Direct presence of evaluations of specific sources' quality/reliability in forming } \\
\text { interpretation }\end{array}$ \\
\hline 3 & $\begin{array}{l}\text { Occasional evaluations of sources' quality/reliability, but not as direct or } \\
\text { consistent as a } 4\end{array}$ \\
\hline 2 & Evaluates only that those source/used in singular interpretation \\
\hline 1 & Non existent evaluation; singular, unidirectional interpretation \\
\hline 0 & $\begin{array}{l}\text { No evaluation, as though none were necessary because establishing a thesis and } \\
\text { conducting an interpretation is considered impossible or too difficult }\end{array}$ \\
\hline \multicolumn{2}{|r|}{ Contextualisation } \\
\hline 4 & $\begin{array}{l}\text { Stays within historical context and makes comments that reflect self-awareness } \\
\text { of doing so; no presentism }\end{array}$ \\
\hline 3 & Stays within historical context, no presentism \\
\hline 2 & Argument analyses/mixes both past and presentist perspectives \\
\hline 1 & $\begin{array}{l}\text { Solely presentist as though decision event happened yesterday and } \\
\text { contemporaneous normative standards apply }\end{array}$ \\
\hline 0 & $\begin{array}{l}\text { No bounding within historical context because establishing context was not seen } \\
\text { as necessary }\end{array}$ \\
\hline
\end{tabular}




\section{Appendix J: Open-ended questionnaire}

\section{Kuesioner Terbuka \#1}

Nama :

Sekolah:

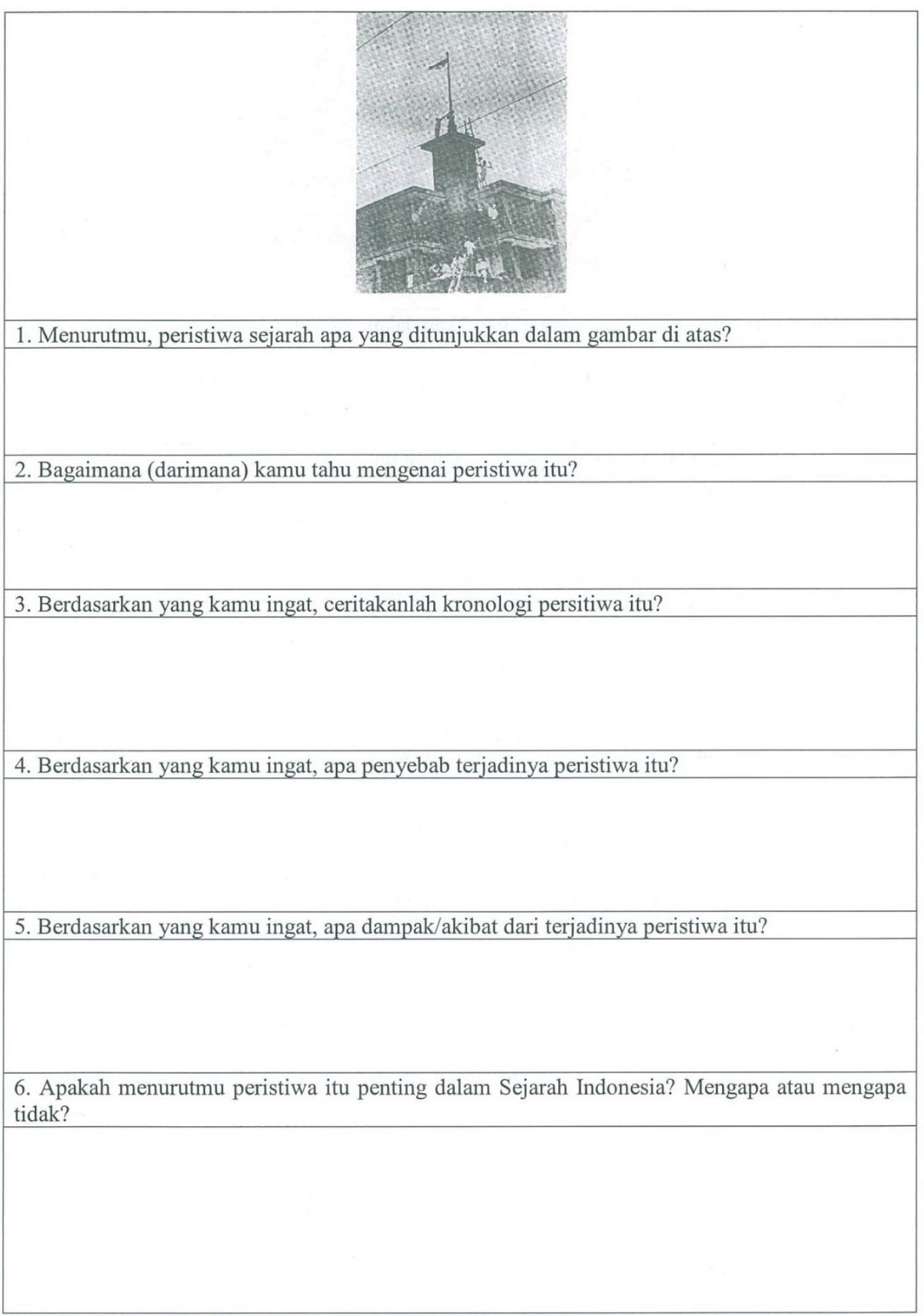


Kuesioner Terbuka \#2

Nama :

Sekolah:

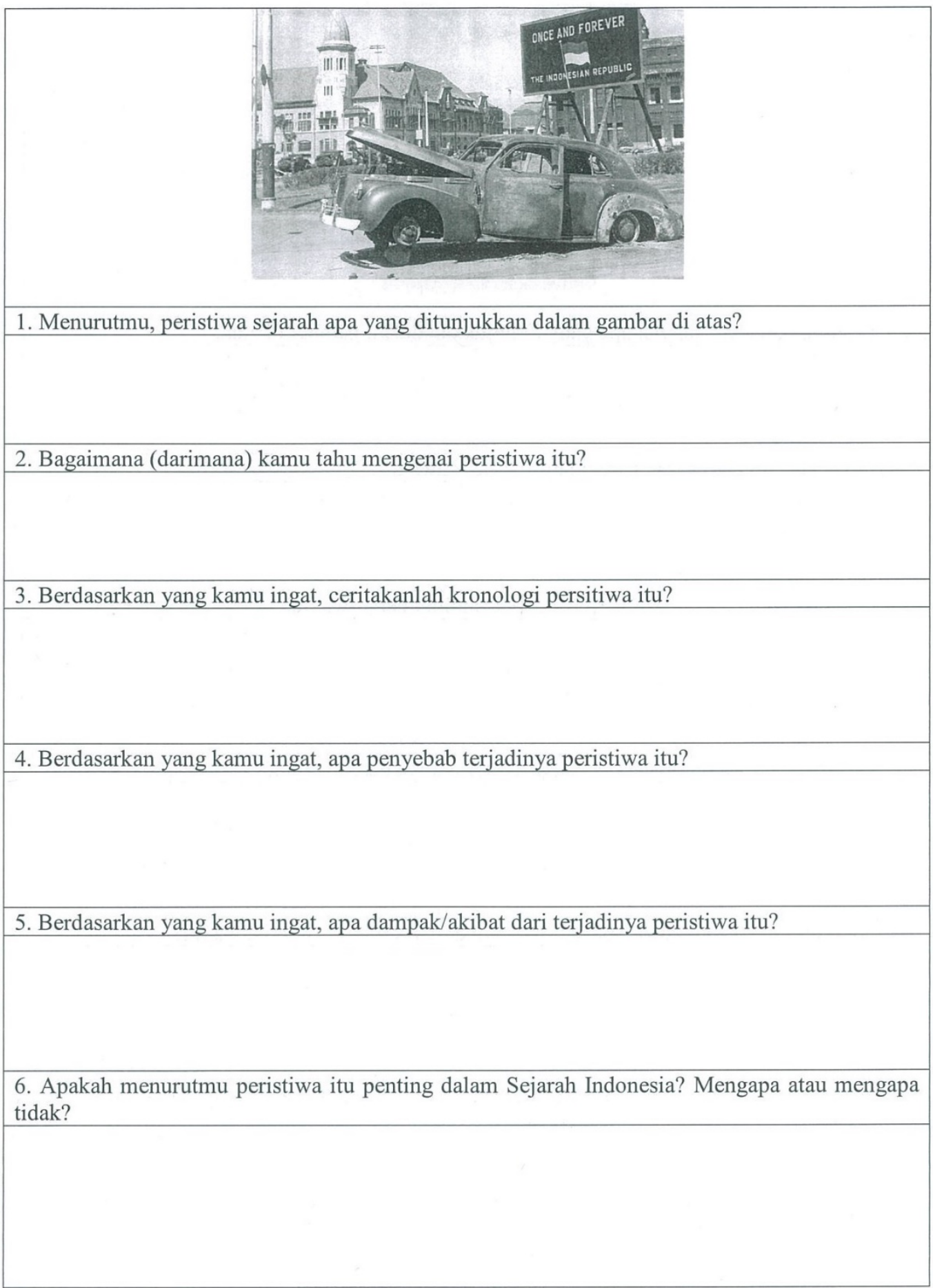




\section{Appendix K: Protocol for classroom observation}

\section{Observation Protocol}

- Observer's role: Non-participant. Although the lesson plan and all learning materials are prepared by the researcher. When the teaching-learning process takes place, my role is as just as a non-participant observer. That is, the observer does not take any active part in the classroom that is being observed. The observer's activities are limited to observing the teacher and students' teaching and learning activities as well as taking notes and making audio-visual recordings of these practices. Nonetheless, due to the focus of this study, a closer attention will be given to students' activities rather than teacher activities.

- What to observe: During classroom observations, observed are the students' learning activities in analysing historical documents and interpreting textbooks. A particular attention will be given to the students' historical thinking in writing interpretive essay, and how they discuss different interpretations in classroom discussion.

- What to collect: The data to be collected comprise evidence of students historical thinking skills, which is manifested in how students reading historical sources, how they interpret the sources, how they discuss the sources, and how they present their own interpretation in an essay. These may include evidence of teacher teaching activities despite less attention being paid.

- What to record: In these classroom observations, the teaching-learning practices are audio-visually recorded. These include teacher delivery of the lessons and managing class activities. The focus will be on students' historical thinking, particularly the ways students deal with contesting claim of the past from various type of primary and secondary sources related to the battle of Surabaya.

- How to record: Recording of the classroom observations will be in the form of audio-visual or video recordings and fieldnotes. Video recordings and note takings will be conducted in silence and in a manner that is as unobtrusive as possible. These recording will also be used in teacher interviews and student focus group interview. 
Classroom Observation Fieldnotes

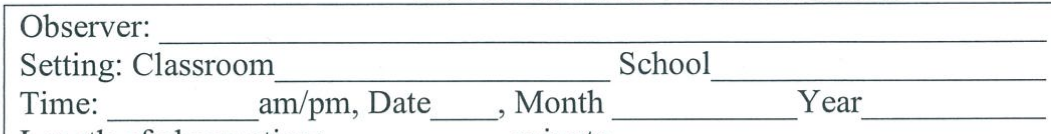

Length of observation: minute

Focus of observation:

1. History teaching and learning process through analysing document and interpreting textbook (experimental group only).

2. History teaching and learning process using digital history through learning website (experimental group only)

3. Students' historical thinking skills in learning process.

\begin{tabular}{|l|l|}
\hline 3. Students' & \\
\hline Descriptive Notes & \\
\hline & \\
\hline Observation findings: (temporary conclusion) \\
\hline
\end{tabular}




\section{Appendix L: Focus group interview protocol and rules (English translation)}

\section{Focus group interview guide for students}

\section{Focus group protocol and rules:}

1. Welcome: Thank you for participating, moderator introduction, participants“ introduction

2. Introduction: Voluntary participation, confidentiality, initials/pseudonym will be used, purpose of study, purpose of the group discussion, possible topic, audio-recorded, 45-60 minutes, rules of discussion.

3. Ground rules: Invited to do the talking, everyone is expected, every persons experiences and opinions are equally important, every person speaks at a time, no right or wrong answer, speak up whether agree or disagree, open discussion, free to comment on each other's answer.

\section{Opening questions}

[For Experimental Group]

1. Recently you took part in a study to learn history through analysing document and interpreting textbook by using digital history in your classroom. What are your overall impressions of that study?

2. Do you think learning history using primary sources is challenging? Do you enjoy it or not? Tell me why?

3. Do you think learning history using digitised primary sources through webbased historical sources is challenging? Do you enjoy it or not? Tell me why?

\section{[For Control Group]}

1. Recently you took part in a study to learn the history of the battle of Surabaya using your textbooks. What are your overall impressions of that study?

2. Do you think learning history by using textbooks only is interesting or not? Do you like it or not? Tell me why?

\section{Questions on students' historical beliefs}

1. What do you think about the statement that there is no difference between the past and history"? Tell me why?

2. What do you think about the statement that historical facts speak for themselves"? Tell me why?

3. What do you think about the statement that History is what happened in the past"? Tell me why?

4. What do you think about the statement that it is impossible to know anything about the past because none of us were there"? Tell me why?

5. What do you think about the statement that the past is simply what the investigators makes it to be"? Tell me why?

6. What do you think about the statement that historical investigators know that history is just a matter of opinion"? Tell me why?

7. What do you think about the statement that since we cannot really know what happened in the past, we can believe whatever we want to about it"? Tell me why?

8. What do you think about the statement that historical claims cannot be justified since they are simply a matter of interpretation"? Tell me why? 
1. What do you think about the statement that "comparing sources and understanding authors' perspectives are crucial components of the process of investigating into the past"? Tell me why?

2. What do you think about the statement that "history is a critical inquiry into the past"? Tell me why?

3. What do you think about the statement that "reasonable interpretations of the past can be constructed even in the presence of conflicting evidence"? Tell me why?

4. What do you think about the statement that "history is the reasonable reconstruction of past occurrences based on the available evidence"? Tell me why?

\section{Questions on students' historical thinking skills through analysing document and interpreting textbook by using digital history \\ The winner of the battle of Surabaya}

1. Based on tour essay about the battle of Surabaya, why did you think that was the winner of the battle of Surabaya? On what evidence?

\section{The flag incident}

2. Based on your essay about the flag incident, why did you think that was the perpetrator of the flag tear? What is the evidence? How about the other testimony from that the perpetrator was ?

3. Why did you think that Mr. Ploegman was killed because of On what evidence? How about other testimony from cause of Mr. Ploegman killed was because

?
that the

4. What was the cause of the flag incident? On what evidence?

5. What was the consequence of the flag incident? On what evidence?

6. Can you tell me the cause and the consequence of the flag incident chronologically?

7. With the occurrence of the flag incident, what has changed and/or continues in the strategies and forms of the Indonesian struggle in defending the independence from the Allies and Dutch threats?

\section{The death of Mallaby:}

8. Based on your essay about the death of Mallaby, why did you think that was the killer of Mallaby? What is the evidence? How about the other sources from that the possibility killer was ?

9. Why did you think that Mallaby was killed because of ? On what evidence? How about other sources from that the cause of Mallaby killed was because ?

10. What was the cause of the incident of the death of Mallaby? On what evidence?

11. What was the consequence of the incident of the death of Mallaby? On what evidence?

12. Can you tell me the cause and the consequence of incident of the death of Mallaby chronologically?

13. With the occurrence of the incident of the death of Mallaby, what has changed and/or continues in the strategies and forms of the Indonesian struggle in defending the independence from the Allies and Dutch threats? 
Questions on the challenges and opportunity of learning history through analysing document and interpreting textbook (for students in experimental group only)

1. What are the challenges of learning history through analysing document and interpreting textbook?

2. What are the opportunities of learning history through analysing document and interpreting textbook?

Questions on the challenges and opportunity of learning history by using webbased historical sources as learning resources (for students in experimental group only)

1. What are the challenges of learning history by using digitised primary sources as presented in learning website?

2. What are the opportunities of learning history by using digitised primary sources as presented in learning website?

\section{Ending questions}

1. What are your expectations for learning history in Indonesia? Especially related the way to learn history?

2. Before we finish, what questions or comments do you have for me? 


\section{Appendix M: Semi-structured interview protocol (English translation)} Semi-structured interview guide for teachers

\section{Demographic Information:}

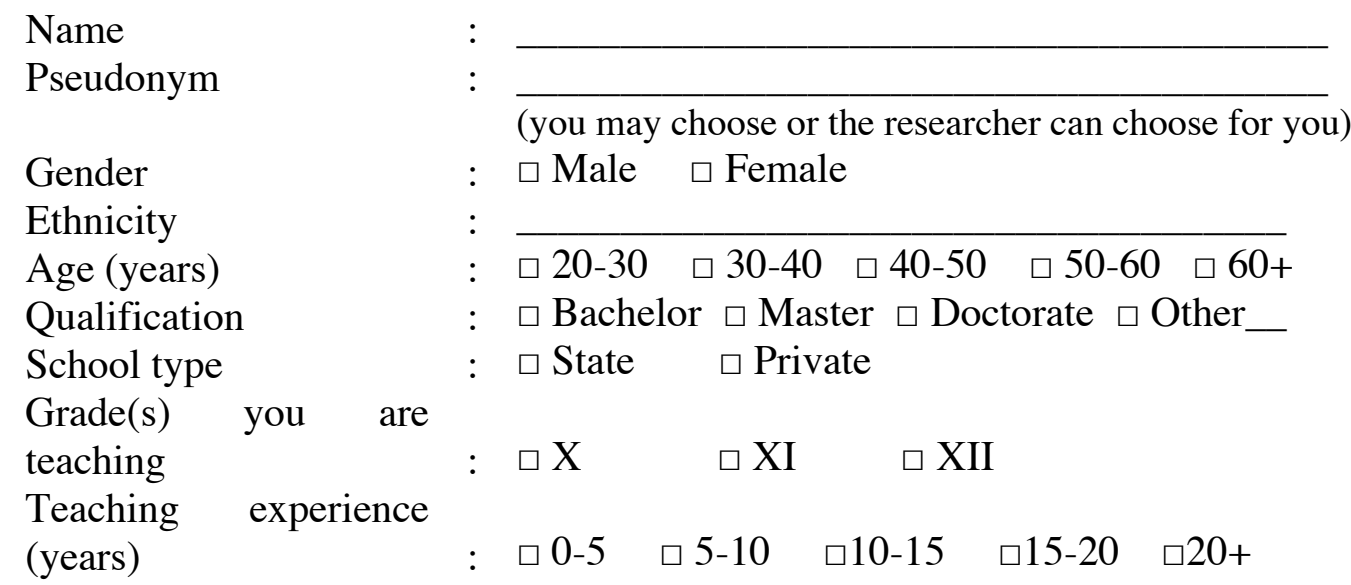

\section{Opening questions:}

1. Recently you took part in a study to teaching history through analysing document and interpreting textbook by using digitised primary sources presented through web-based historical sources in your classroom. What are your overall impressions of that study?

2. What influenced you in your decision to be involved in this study?

3. Do you feel you are benefiting from your involvement in this study? Can you explain more?

\section{Questions on the challenges and opportunity of teaching history through} analysing document and interpreting textbook

1. Reflecting from your teaching experience, what are the challenges and difficulties of teaching history in Indonesia related to the availability of learning resources?

2. Reflecting from your teaching experience, what are the advantages and opportunities of teaching history in Indonesia related to the availability of learning resources?

3. In your opinion, is it necessary to teach history by using primary sources or other historical sources beside the textbooks?

4. In your opinion, is it necessary to teach history through analysing document?

5. Reflecting on the intervention process in the classroom, what are the advantages and opportunities of teaching history through analysing document?

6. Reflecting on the intervention process in the classroom, what are the challenges and difficulties of teaching history through analysing document?

7. In your opinion, is it sufficient to teach history only by using textbook?

8. In your opinion, is it necessary to teach history through interpreting textbook?

9. Reflecting on the intervention process in the classroom, what are the opportunities of teaching history through interpreting textbook? 
1. Reflecting on the intervention process in the classroom, what are the challenges of teaching history through interpreting textbook?

\section{Questions on the challenges and opportunity of teaching history by using} digital history

1. Reflecting from your teaching experience, have you ever used primary sources for teaching history? If yes, in what form? If not, why not?

2. In your opinion, do you think is it necessary to have access to digitised historical sources in Indonesia, so it can be used for teaching history?

3. Reflecting on the intervention process on the classroom, what are the opportunities and advantages of teaching history using digitised primary sources as presented in the learning website?

4. Reflecting on the intervention process on the classroom, what are the challenges and difficulties of teaching history using digitised primary sources as presented in the learning website?

Questions on the challenges and opportunity of teaching history to fostering students $^{6}$ historical thinking skills through analysing document and interpreting textbook by using digital history

1. In your opinion, is it necessary to teach history in order to foster student historical thinking skills in Indonesia?

2. Reflecting on the intervention process on the classroom, what are the opportunities and advantages of teaching history to foster student historical thinking skills through analysing document and interpreting textbook by using digital history?

3. Reflecting on the intervention process on the classroom, what are the challenges and difficulties of teaching history to fostering student historical thinking skills through analysing document and interpreting textbook by using digital history?

\section{Ending questions}

1. Do you think history teachers in Indonesia are willing to teaching history through analysing document and interpreting textbook by using digitised primary sources?

2. Do you think history teachers in Indonesia are able to teaching history through analysing document and interpreting textbook by using digitised primary sources?

3. Do you think history teachers in Indonesia willing to teaching history to foster their student historical thinking skills?

4. Before we finish, what questions or comments do you have for me? 


\section{Appendix N: Permission to use instruments}

Bruce Vansledright <bvansled@uncc.edus

to me -

Hi Aditya. These instruments are out in the public domain via the books I published. Therefore you can use them for the purposes you describe as long as you cite them in full (author, title, date, publisher, page numbers). This is called "fair use." under U.S. copyright law. You cannot use them to generate income (as in, for example, to sell them to others) since that goes beyond "fair use."

I appreciate your interest in my work. Best wishes on yours.

Bruce

Bruce VanSledright, Professor

History/Social Studies Education Research

Department of Reading and Elementary Education

Cato College of Education

University of North Carolina at Charlotte

9201 University City Blvd.

Charlotte, NC 28223
Mon, Aug 27, 2018, 8:28 AM 
Appendix O: HBQ consistency scores of the control group

\begin{tabular}{|c|c|c|c|c|c|c|c|c|c|}
\hline \multirow{2}{*}{ No } & \multirow{2}{*}{$\begin{array}{l}\text { Code } \\
\text { name }\end{array}$} & \multicolumn{3}{|c|}{ Consistency Score } & \multirow{2}{*}{ No } & \multirow{2}{*}{ Code name } & \multicolumn{3}{|c|}{ Consistency Score } \\
\hline & & HBQ1 & HBQ2 & HBQ3 & & & HBQ1 & HBQ2 & HBQ3 \\
\hline 1 & CGA01 & 66.7 & 83.3 & 66.7 & 49 & CGB24 & 66.7 & 83.3 & 75.0 \\
\hline 2 & CGA02 & 83.3 & 83.3 & 91.7 & 50 & CGB25 & 66.7 & 66.7 & 66.7 \\
\hline 3 & CGA03 & 75.0 & 83.3 & 100.0 & 51 & CGB26 & 91.7 & 75.0 & 58.3 \\
\hline 4 & CGA04 & 75.0 & 58.3 & 50.0 & 52 & CGB27 & 75.0 & 100.0 & 83.3 \\
\hline 5 & CGA05 & 83.3 & 83.3 & 91.7 & 53 & CGB28 & 75.0 & 91.7 & 91.7 \\
\hline 6 & CGA06 & 83.3 & 75.0 & 75.0 & 54 & CGB29 & 75.0 & 75.0 & 83.3 \\
\hline 7 & CGA07 & 75.0 & 66.7 & 58.3 & 55 & CGB30 & 50.0 & 66.7 & 50.0 \\
\hline 8 & CGA08 & 75.0 & 75.0 & 66.7 & 56 & CGB31 & 75.0 & 75.0 & 91.7 \\
\hline 9 & CGA09 & 66.7 & 75.0 & 66.7 & 57 & CGB32 & 75.0 & 75.0 & 75.0 \\
\hline 10 & CGA10 & 66.7 & 58.3 & 58.3 & 58 & CGB33 & 91.7 & 83.3 & 83.3 \\
\hline 11 & CGA11 & 66.7 & 91.7 & 75.0 & 59 & CGB34 & 91.7 & 83.3 & 91.7 \\
\hline 12 & CGA12 & 83.3 & 66.7 & 75.0 & 60 & CGC01 & 66.7 & 75.0 & 58.3 \\
\hline 13 & CGA13 & 83.3 & 91.7 & 83.3 & 61 & CGC02 & 58.3 & 75.0 & 75.0 \\
\hline 14 & CGA14 & 66.7 & 75.0 & 41.7 & 62 & CGCO3 & 91.7 & 75.0 & 66.7 \\
\hline 15 & CGA15 & 50.0 & 83.3 & 75.0 & 63 & CGC04 & 66.7 & 75.0 & 50.0 \\
\hline 16 & CGA16 & 58.3 & 75.0 & 66.7 & 64 & CGC05 & 66.7 & 75.0 & 58.3 \\
\hline 17 & CGA17 & 83.3 & 91.7 & 91.7 & 65 & CGC06 & 83.3 & 66.7 & 58.3 \\
\hline 18 & CGA18 & 66.7 & 91.7 & 75.0 & 66 & CGC07 & 75.0 & 91.7 & 100.0 \\
\hline 19 & CGA19 & 66.7 & 75.0 & 83.3 & 67 & CGC08 & 83.3 & 66.7 & 66.7 \\
\hline 20 & CGA20 & 83.3 & 66.7 & 75.0 & 68 & CGC09 & 66.7 & 83.3 & 50.0 \\
\hline 21 & CGA21 & 75.0 & 66.7 & 66.7 & 69 & CGC10 & 66.7 & 66.7 & 66.7 \\
\hline 22 & CGA22 & 83.3 & 91.7 & 91.7 & 70 & CGC11 & 83.3 & 0.0 & 66.7 \\
\hline 23 & CGA23 & 66.7 & 16.7 & 50.0 & 71 & CGC12 & 66.7 & 66.7 & 58.3 \\
\hline 24 & CGA24 & 66.7 & 58.3 & 58.3 & 72 & CGC13 & 91.7 & 91.7 & 66.7 \\
\hline 25 & CGA25 & 58.3 & 83.3 & 75.0 & 73 & CGC14 & 75.0 & 66.7 & 66.7 \\
\hline 26 & CGB01 & 83.3 & 75.0 & 83.3 & 74 & CGC15 & 75.0 & 75.0 & 100.0 \\
\hline 27 & CGB02 & 66.7 & 83.3 & 91.7 & 75 & CGC16 & 83.3 & 100.0 & 66.7 \\
\hline 28 & CGB03 & 91.7 & 83.3 & 100.0 & 76 & CGC17 & 100.0 & 75.0 & 58.3 \\
\hline 29 & CGB04 & 75.0 & 50.0 & 50.0 & 77 & CGC18 & 91.7 & 75.0 & 50.0 \\
\hline 30 & CGB05 & 83.3 & 83.3 & 75.0 & 78 & CGC19 & 66.7 & 66.7 & 83.3 \\
\hline 31 & CGB06 & 75.0 & 66.7 & 75.0 & 79 & CGC20 & 75.0 & 75.0 & 75.0 \\
\hline 32 & CGB07 & 58.3 & 83.3 & 83.3 & 80 & CGC21 & 66.7 & 83.3 & 58.3 \\
\hline 33 & CGB08 & 91.7 & 83.3 & 91.7 & 81 & CGC22 & 58.3 & 75.0 & 91.7 \\
\hline 34 & CGB09 & 66.7 & 91.7 & 83.3 & 82 & CGC23 & 50.0 & 75.0 & 66.7 \\
\hline 35 & CGB10 & 83.3 & 83.3 & 75.0 & 83 & CGC24 & 91.7 & 75.0 & 0.0 \\
\hline 36 & CGB11 & 83.3 & 83.3 & 91.7 & 84 & CGC25 & 66.7 & 91.7 & 66.7 \\
\hline 37 & CGB12 & 66.7 & 83.3 & 75.0 & 85 & CGC26 & 83.3 & 66.7 & 66.7 \\
\hline 38 & CGB13 & 58.3 & 75.0 & 75.0 & 86 & CGC27 & 91.7 & 91.7 & 100.0 \\
\hline 39 & CGB14 & 58.3 & 91.7 & 91.7 & 87 & CGC28 & 75.0 & 66.7 & 66.7 \\
\hline 40 & CGB15 & 83.3 & 66.7 & 83.3 & 88 & CGC29 & 75.0 & 66.7 & 66.7 \\
\hline 41 & CGB16 & 66.7 & 91.7 & 83.3 & 89 & CGC30 & 75.0 & 75.0 & 83.3 \\
\hline 42 & CGB17 & 66.7 & 58.3 & 58.3 & 90 & CGC31 & 91.7 & 75.0 & 66.7 \\
\hline 43 & CGB18 & 83.3 & 83.3 & 75.0 & 91 & CGC32 & 75.0 & 75.0 & 66.7 \\
\hline 44 & CGB19 & 91.7 & 75.0 & 83.3 & 92 & CGC33 & 66.7 & 66.7 & 50.0 \\
\hline 45 & CGB20 & 66.7 & 100.0 & 75.0 & 93 & CGC34 & 50.0 & 75.0 & 50.0 \\
\hline 46 & CGB21 & 75.0 & 66.7 & 83.3 & 94 & CGC35 & 50.0 & 66.7 & 50.0 \\
\hline 47 & CGB22 & 75.0 & 83.3 & 66.7 & 95 & CGC36 & 75.0 & 75.0 & 83.3 \\
\hline 48 & CGB23 & 75.0 & 91.7 & 91.7 & & & & & \\
\hline
\end{tabular}


Appendix P: HBQ consistency scores of the experimental group

\begin{tabular}{|c|c|c|c|c|c|c|c|c|c|}
\hline \multirow{2}{*}{ No } & \multirow{2}{*}{$\begin{array}{l}\text { Code } \\
\text { name }\end{array}$} & \multicolumn{3}{|c|}{ Consistency Score } & \multirow{2}{*}{ No } & \multirow{2}{*}{ Code name } & \multicolumn{3}{|c|}{$\begin{array}{c}\text { Consistency Score } \\
\end{array}$} \\
\hline & & HBQ1 & HBQ2 & HBQ3 & & & HBQ1 & HBQ2 & HBQ3 \\
\hline 1 & EGA01 & 83.3 & 75.0 & 66.7 & 49 & EGB22 & 75.0 & 91.7 & 91.7 \\
\hline 2 & EGA02 & 83.3 & 83.3 & 91.7 & 50 & EGB23 & 100.0 & 83.3 & 83.3 \\
\hline 3 & EGA03 & 58.3 & 91.7 & 91.7 & 51 & EGB24 & 66.7 & 91.7 & 91.7 \\
\hline 4 & EGA04 & 75.0 & 75.0 & 91.7 & 52 & EGB25 & 83.3 & 83.3 & 83.3 \\
\hline 5 & EGA05 & 66.7 & 83.3 & 83.3 & 53 & EGB26 & 75.0 & 91.7 & 83.3 \\
\hline 6 & EGA06 & 75.0 & 100.0 & 91.7 & 54 & EGB27 & 91.7 & 66.7 & 83.3 \\
\hline 7 & EGA07 & 75.0 & 75.0 & 75.0 & 55 & EGB28 & 75.0 & 83.3 & 83.3 \\
\hline 8 & EGA08 & 83.3 & 91.7 & 100.0 & 56 & EGB29 & 75.0 & 83.3 & 91.7 \\
\hline 9 & EGA09 & 75.0 & 75.0 & 83.3 & 57 & EGB30 & 83.3 & 91.7 & 83.3 \\
\hline 10 & EGA10 & 50.0 & 66.7 & 50.0 & 58 & EGB31 & 75.0 & 100.0 & 91.7 \\
\hline 11 & EGA11 & 50.0 & 66.7 & 75.0 & 59 & EGB32 & 75.0 & 83.3 & 75.0 \\
\hline 12 & EGA12 & 66.7 & 66.7 & 83.3 & 60 & EGB33 & 58.3 & 75.0 & 66.7 \\
\hline 13 & EGA13 & 66.7 & 75.0 & 83.3 & 61 & EGB34 & 75.0 & 75.0 & 58.3 \\
\hline 14 & EGA14 & 75.0 & 83.3 & 83.3 & 62 & EGC01 & 50.0 & 75.0 & 100.0 \\
\hline 15 & EGA15 & 75.0 & 83.3 & 75.0 & 63 & EGC02 & 91.7 & 91.7 & 91.7 \\
\hline 16 & EGA16 & 83.3 & 75.0 & 100.0 & 64 & EGC03 & 75.0 & 91.7 & 91.7 \\
\hline 17 & EGA17 & 66.7 & 83.3 & 75.0 & 65 & EGC04 & 50.0 & 41.7 & 58.3 \\
\hline 18 & EGA18 & 66.7 & 75.0 & 83.3 & 66 & EGC05 & 75.0 & 58.3 & 83.3 \\
\hline 19 & EGA19 & 58.3 & 33.3 & 66.7 & 67 & EGC06 & 66.7 & 58.3 & 58.3 \\
\hline 20 & EGA20 & 91.7 & 91.7 & 91.7 & 68 & EGC07 & 83.3 & 83.3 & 83.3 \\
\hline 21 & EGA21 & 91.7 & 75.0 & 75.0 & 69 & EGC08 & 75.0 & 83.3 & 75.0 \\
\hline 22 & EGA22 & 66.7 & 66.7 & 83.3 & 70 & EGC09 & 66.7 & 75.0 & 91.7 \\
\hline 23 & EGA23 & 75.0 & 91.7 & 58.3 & 71 & EGC10 & 66.7 & 58.3 & 58.3 \\
\hline 24 & EGA24 & 75.0 & 66.7 & 66.7 & 72 & EGC11 & 91.7 & 83.3 & 75.0 \\
\hline 25 & EGA25 & 91.7 & 75.0 & 66.7 & 73 & EGC12 & 58.3 & 75.0 & 83.3 \\
\hline 26 & EGA26 & 75.0 & 75.0 & 66.7 & 74 & EGC13 & 91.7 & 91.7 & 83.3 \\
\hline 27 & EGA27 & 91.7 & 83.3 & 83.3 & 75 & EGC14 & 91.7 & 83.3 & 83.3 \\
\hline 28 & EGB01 & 83.3 & 83.3 & 91.7 & 76 & EGC15 & 66.7 & 66.7 & 58.3 \\
\hline 29 & EGB02 & 83.3 & 91.7 & 91.7 & 77 & EGC16 & 66.7 & 75.0 & 75.0 \\
\hline 30 & EGB03 & 91.7 & 75.0 & 75.0 & 78 & EGC17 & 83.3 & 83.3 & 83.3 \\
\hline 31 & EGB04 & 91.7 & 91.7 & 91.7 & 79 & EGC18 & 83.3 & 66.7 & 66.7 \\
\hline 32 & EGB05 & 50.0 & 75.0 & 66.7 & 80 & EGC19 & 75.0 & 75.0 & 83.3 \\
\hline 33 & EGB06 & 75.0 & 66.7 & 75.0 & 81 & EGC20 & 91.7 & 91.7 & 100.0 \\
\hline 34 & EGB07 & 91.7 & 83.3 & 75.0 & 82 & EGC21 & 58.3 & 75.0 & 83.3 \\
\hline 35 & EGB08 & 75.0 & 83.3 & 91.7 & 83 & EGC22 & 66.7 & 66.7 & 66.7 \\
\hline 36 & EGB09 & 66.7 & 83.3 & 83.3 & 84 & EGC23 & 83.3 & 83.3 & 83.3 \\
\hline 37 & EGB10 & 83.3 & 50.0 & 91.7 & 85 & EGC24 & 75.0 & 66.7 & 66.7 \\
\hline 38 & EGB11 & 83.3 & 75.0 & 75.0 & 86 & EGC25 & 91.7 & 91.7 & 75.0 \\
\hline 39 & EGB12 & 83.3 & 100.0 & 83.3 & 87 & EGC26 & 66.7 & 75.0 & 66.7 \\
\hline 40 & EGB13 & 91.7 & 91.7 & 91.7 & 88 & EGC27 & 50.0 & 58.3 & 58.3 \\
\hline 41 & EGB14 & 75.0 & 66.7 & 58.3 & 89 & EGC28 & 58.3 & 50.0 & 58.3 \\
\hline 42 & EGB15 & 75.0 & 75.0 & 75.0 & 90 & EGC29 & 50.0 & 58.3 & 83.3 \\
\hline 43 & EGB16 & 66.7 & 66.7 & 83.3 & 91 & EGC30 & 75.0 & 91.7 & 83.3 \\
\hline 44 & EGB17 & 91.7 & 83.3 & 100.0 & 92 & EGC31 & 66.7 & 50.0 & 83.3 \\
\hline 45 & EGB18 & 66.7 & 75.0 & 75.0 & 93 & EGC32 & 83.3 & 91.7 & 91.7 \\
\hline 46 & EGB19 & 83.3 & 83.3 & 83.3 & 94 & EGC33 & 66.7 & 66.7 & 58.3 \\
\hline 47 & EGB20 & 83.3 & 91.7 & 91.7 & 95 & EGC34 & 58.3 & 75.0 & 75.0 \\
\hline 48 & EGB21 & 91.7 & 100.0 & 100.0 & 96 & EGC35 & 91.7 & 75.0 & 83.3 \\
\hline
\end{tabular}

